\title{
Classificação do Risco de Infestação de Regiões por Plantas Daninhas Utilizando Lógica Fuzzy e Redes Bayesianas
}

\author{
Glaucia Maria Bressan
}

Tese apresentada à Escola de Engenharia de São Carlos da Universidade de São Paulo, como parte dos requisitos para obtenção do título de Doutora em Engenharia Elétrica

Orientadora: Profa. Dra. Vilma Alves de Oliveira 
Aos meus pais

Por acreditarem nos meus sonhos 
Agradeço todas as pessoas que, direta ou indiretamente, contribuíram para o desenvolvimento deste trabalho, em especial:

- a Deus, por estar presente em todos os momentos da minha vida, por guiar meus caminhos e me conceder sabedoria e saúde;

- a minha família, por me proporcionar a base necessária para me tornar quem sou;

- a Universidade de São Paulo (USP), por oferecer toda a estrutura necessária para o desenvolvimento deste trabalho;

- a Capes, pelo apoio financeiro e pela bolsa concedida;

- o ICMC - USP, pelo título de Mestre que obtive em 2003, o qual me preparou para um trabalho muito maior no doutoramento;

- a professora Vilma, pela oportunidade, pela orientação e amizade, pelo crescimento que me proporcionou, pelos ensinamentos, conversas, reuniões e pelos conselhos profissionais e até mesmo pessoais!

- os professores Estevam e Maria do Carmo (UFSCar), pela excelente contribuição que proporcionou a conclusão deste trabalho e algumas publicações;

- a Embrapa Milho Sorgo, especialmente Décio Karam, por permitir a realização dos experimentos em campo e esclarecer muitas dúvidas "agronômicas";

- os amigos do LAC, que são verdadeiros irmãos para mim, por compartilhar as dificuldades e as alegrias e por conviverem comigo como uma família;

- o Fábio e o Luciano, que, além de serem amigos muito queridos, me proporcionaram um auxílio técnico e computacional de altíssimo nível!

- os meus amigos pessoais, cujos nomes nem são necessários citar, pois sabem que levam com eles um pouco de mim e deixam comigo um pouco deles;

- o Fabiano, pela oportunidade de amar, compartilhar, conviver, aprender e ensinar, por "querer estar preso por vontade". 


\section{Lista de Figuras}

Figura 3.1 Foto aérea da área experimental - Sete Lagoas, MG. . . . . . . . 16

Figura 3.2 Representação de uma parcela experimental. . . . . . . . . . . . 17

Figura 3.3 Quadro utilizado em campo para coletar amostras de plantas daninhas. . . . . . . . . . . . . . . . . . . . . 19

Figura 3.4 Plantas daninhas: mentrasto (esquerda) e capim colchão (direita). 21

Figura 3.5 Contagem de espécies de plantas daninhas nas parcelas. . . . . . 22

Figura 3.6 Número de plantas daninhas por parcela. . . . . . . . . . . . . . 22

Figura 4.1 Modelo variográfico exponencial. . . . . . . . . . . . . . . . . 30

Figura 4.2 Dinâmica simulada a partir de $(4.11) \ldots \ldots$. . . . . . . . . . . 44

Figura 4.3 Dinâmica simulada a partir de $(4.12) \ldots \ldots$. . . . . . . . . . 44

Figura 4.4 Densidade de sementes em função da taxa de germinação. . . . . 45

Figura 5.1 Procedimento pra inferência fuzzy. . . . . . . . . . . . . . . . 56

Figura 6.1 Arquitetura do sistema de classificação fuzzy com $D P$ a densidade de plantas, $F L$ a densidade de plantas folha larga, $F E$ a densidade de plantas folha estreita, $v_{1}$ o atributo da cobertura foliar de plantas daninhas por região, $v_{2}$ o atributo da densidade de sementes por região, $v_{3}$ o atributo da extensão média dos agrupamentos de sementes e $v_{4} \mathrm{o}$ atributo da competitividade entre plantas e cultura por região. . . . . . 69 
Figura 6.2 Funções de pertinência das entradas (atributos da densidade de semente, da cobertura foliar, da extensão dos agrupamentos de semente e da competitividade) e da saída (risco de infestação) do sistema de classificação fuzzy simulado. . . . . . . . . . . . . . . . . . . . . . . . .

Figura 6.3 Funções de pertinência das entradas (atributos da densidade de sementes, da cobertura foliar, da extensão dos agrupamentos de sementes e da competitividade) e da saída (risco de ifestação) do sistema de classificação fuzzy com dados coletados em campo. . . . . . . . . . . . . .

Figura 7.1 Densidade de sementes em função da geração da planta para os parâmetros $X_{0}=1$ semente $m^{-2}, g=0,10, s=248, a=4,0 \times 10^{-3} \mathrm{e}$ $b=2,77$ usando $(4.12)$

Figura 7.2 (a) Distribuição dos dados simulados de cobertura foliar; (b) Distribuição dos dados simulados de densidade de sementes.

Figura 7.3 (a) Histograma para os dados simulados de cobertura foliar. Estatísticas descritivas: Média $=67,512$, Desvio padrão $=66,900$, Máximo $=364,310$ e Mínimo =0,0114; (b) Histograma para os dados da geração de sementes $t=6$. Estatísticas descritivas: Média $=424,437$, Desvio padrão $=681,980$, Máximo $=2042,100$ e Mínimo $=0,0037 \ldots \ldots$. . .

Figura 7.4 Ajuste dos variogramas teóricos obtido com o modelo exponencial (linha contínua) para os dados de (a) cobertura foliar na geração $t=5$ com $C_{0}=3,75 \times 10^{3}, C_{0}+C_{1}=4,8 \times 10^{3}$ e (b) densidade de sementes na geração $t=6 \operatorname{com} C_{0}=3,8 \times 10^{5}, C_{0}+C_{1}=5,0 \times 10^{5}$ e os correspondentes variogramas experimentais (pontos) . . . . . . . . .

Figura 7.5 (a) Mapa de cobertura foliar de plantas daninhas estimado por Krigagem na geração $t=5$; (b) Mapa da densidade de sementes de plantas daninhas estimado por Krigagem na geração $t=6 \ldots \ldots \ldots$

Figura 7.6 Histograma para média do resíduo da estimativa com $95 \%$ de confiança: (a) cobertura foliar $(t=5)$; (b) densidade de sementes $(t=6) . \quad 89$

Figura 7.7 (a) Variância dos valores dos resíduos para a cobertura foliar $(t=5)$ e (b) para a densidade de sementes $(t=6) \ldots \ldots \ldots \ldots$ 
Figura 7.8 Teste da probabilidade normal dos resíduos: (a) cobertura foliar; (b) densidade de sementes para a geração $t=6$. Na margem inferior à esquerda são fornecidos a média dos resíduos, o desvio padrão e o número de dados. Na margem inferior à direita é dado o p-valor. . . . . . . . . .

Figura 7.9 Mapa dos objetos conectados identificados no mapa de cobertura foliar simulado.

Figura 7.10 Mapa de regiões de valor médio ponderado de cobertura foliar de acordo com a matriz $\Upsilon_{1}$.

Figura 7.11 Mapa dos objetos conectados identificados no mapa de densidade de sementes simulado.

Figura 7.12 Mapa de regiões de valor médio ponderado de densidade de sementes de acordo com a matriz $\Upsilon_{2}$.

Figura 7.13 Mapa de regiões de valor médio de extensão dos agrupamentos de densidade de sementes de acordo com a matriz $\Upsilon_{3}$.

Figura 7.14 Mapa de regiões de ocupação de gramíneas em porcentagem referentes à $\Upsilon_{4}$.

Figura 7.15 (a) Distribuição dos dados de cobertura foliar; (b) Distribuição dos dados de densidade de sementes.

Figura 7.16 (a) Histograma para os dados coletados de cobertura foliar, com estatísticas descritivas: Média $=0,4585$, Desvio padrão $=0,2239$, Máximo $=0,97$ e Mínimo $=0,15$; (b) Histograma para os dados coletados de densidade de sementes, com estatísticas descritivas: Média $=2549,60$, Desvio padrão $=2543,8$, Máximo $=8540$ e Mínimo $=105 \ldots \ldots$. . . .

Figura 7.17 Ajuste dos variogramas teóricos obtido com o modelo exponencial (linha contínua) para os dados de (a) cobertura foliar com $C_{0}=$ 0, 038, $C_{0}+C_{1}=0,05$ e (b) densidade de sementes com $C_{0}=5,09 \times$ $10^{6}, C_{0}+C_{1}=6,50 \times 10^{6}$ e os correspondentes variogramas experimentais

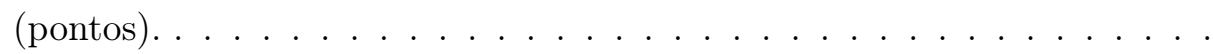

Figura 7.18 Imagens estimadas por Krigagem associadas aos mapas de (a) cobertura foliar na geração $t-1$ e (b) densidade de sementes na geração $t .101$ 
Figura 7.19 Mapa dos objetos conectados identificados no mapa de cobertura foliar dos dados coletados em campo da geração $t-1 . \quad$. . . . . . . . . 102

Figura 7.20 Mapa de regiões de valor médio ponderado de cobertura foliar, de acordo com a matriz $\Upsilon_{1}^{\prime} \ldots \ldots \ldots$. . . . . . . . . . . . 103

Figura 7.21 Mapa dos objetos conectados identificados no mapa de densidade de sementes dos dados coletados em campo da geração t . . . . . . . . . . 104

Figura 7.22 Mapa de regiões de valor médio ponderado de densidade de sementes de acordo com a matriz $\Upsilon_{2}^{\prime} \ldots$. . . . . . . . . . . . . . . . . . 104

Figura 7.23 Mapa de regiões de valor médio ponderado referente à matriz $\Upsilon_{3}^{\prime} .105$

Figura 7.24 Estrutura da rede neurofuzzy com DP a densidade total de plantas daninhas, FL a densidade de plantas do tipo folha larga, FE a densidade de plantas do tipo folha estreita. . . . . . . . . . . . . . 106

Figura 7.25 Funções de pertinência ajustadas pelo sistema neurofuzzy. .. . 107

Figura 7.26 Mapa de regiões de competitividade das plantas daninhas por regiões referente à $\Upsilon_{4}^{\prime} \ldots \ldots \ldots$. . . . . . . . . . . . . . . . . . . . . 108

Figura 7.27 Mapa de intensidades de riscos de infestação por plantas daninhas por regiões referente à matriz Risco. . . . . . . . . . . . . . . . . . . . . 109

Figura 7.28 Mapa dos agrupamentos de riscos de infestação de acordo com as intensidades da matriz RGrupos. . . . . . . . . . . . . . . . . . . 112

Figura 7.29 (a) Distribuição dos dados de cobertura foliar; (b) Distribuição dos dados de densidade de sementes.

Figura 7.30 (a) Histograma para os dados coletados de cobertura foliar, com estatísticas descritivas: Média $=0,273$, Desvio padrão $=0,25$, Máximo $=1$ e Mínimo $=0$; (b) Histograma para os dados coletados de densidade de sementes, com estatísticas descritivas: Média $=1905$, Desvio padrão $=1588$, Máximo $=6500$ e Mínimo $=0 \ldots \ldots \ldots \ldots \ldots$. . . . . . 114 
Figura 7.31 Ajuste dos variogramas teóricos obtido com o modelo exponencial (linha contínua) para os dados de (a) cobertura foliar com $C_{0}=$ 0,048, $C_{0}+C_{1}=0,063$. e (b) densidade de sementes com $C_{0}=2,0 \times$ $10^{6}, C_{0}+C_{1}=2,60 \times 10^{6}$ e os correspondentes variogramas experimentais

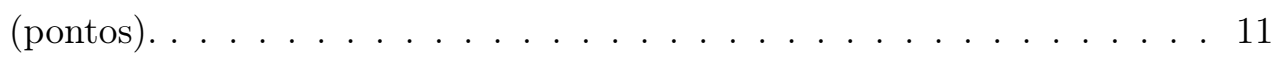

Figura 7.32 Imagens associadas aos mapas estimados por Krigagem de (a) cobertura foliar na geração $t+1$ e (b) densidade de sementes na geração

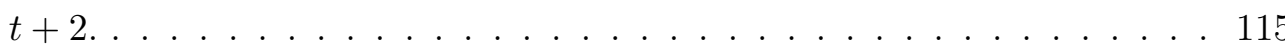

Figura 7.33 Mapa dos objetos conectados identificados no mapa de cobertura foliar dos dados coletados em campo da geração $t+1 \ldots$. . . . . . 117

Figura 7.34 Mapa de regiões de valor médio ponderado de cobertura foliar, de acordo com a matriz $\Upsilon_{1}^{\prime \prime} \ldots \ldots \ldots \ldots \ldots$

Figura 7.35 Mapa dos objetos conectados identificados no mapa de densidade de sementes dos dados coletados em campo da geração $t+2 . \quad \ldots$. . . 119

Figura 7.36 Mapa de regiões de valor médio ponderado de densidade de sementes de acordo com a matriz $\Upsilon_{2}^{\prime \prime} \ldots \ldots$. . . . . . . . . . . . . 119

Figura 7.37 Mapa de regiões de valor médio ponderado referente à matriz $\Upsilon_{3}^{\prime \prime} .120$

Figura 7.38 Funções de pertinência ajustadas pelo sistema neurofuzzy com os dados coletados na geração $t+1 \ldots \ldots \cdots \cdots \cdot \cdots \cdot \cdots$

Figura 7.39 Mapa de intensidades de competitividade das plantas daninhas por regiões referente à $\Upsilon_{4}^{\prime \prime} \ldots \ldots \ldots \ldots \ldots \ldots$

Figura 7.40 Mapa de intensidades de riscos de infestação por plantas daninhas por regiões referente à matriz Risco2.

Figura 7.41 Mapa dos agrupamentos de riscos de infestação de acordo com as intensidades da matriz RGrupos2.

Figura 7.42 Mapa de perda de rendimento na geração $t$. . . . . . . . . 126

Figura 7.43 Mapa de perda de rendimento na geração $t+2 . \quad$. . . . . . . 127

Figura 7.44 (a) Mapa dos agrupamentos dos riscos de infestação na geração t; (b) Mapa dos agrupamentos de perda de rendimento na geração $t$. . 127 
Figura 7.45 (a) Mapa dos agrupamentos dos riscos de infestação na geração $t+2$; (b) Mapa dos agrupamentos de perda de rendimento na geração

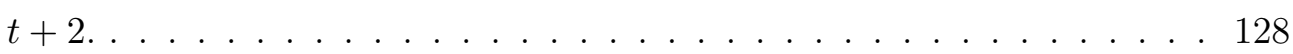

Figura 8.1 Aprendizado da rede com BayesRule para o atributo da competitividade. . . . . . . . . . . . . . . . . . . 131

Figura 8.2 Inferência da Biomassa. . . . . . . . . . . . . . . . . . . . 132

Figura 8.3 Rede de classificação Bayesiana irrestrita para a competitividade. 132

Figura 8.4 Rede de classificação naïve Bayes para a competitividade. . . . . 133

Figura 8.5 Aprendizado da rede com BayesRule para o risco de infestação. 142

Figura 8.6 Inferência do risco de infestação. . . . . . . . . . . . . . . . . 142

Figura 8.7 Rede de classificação Bayesiana irrestrita para o risco de infestação.143

Figura 8.8 Rede de classificação naïve Bayes para o risco de infestação. . . 143

Figura B.1 Fis editor . . . . . . . . . . . . . . . . . . 164

Figura B.2 Editor de funções de pertinência . . . . . . . . . . . . . . 165

Figura B.3 Visualizador das regras e simulador do sistema . . . . . . . . 166

Figura B.4 Ambiente anfis. . . . . . . . . . . . . . . . 170 


\section{Lista de Tabelas}

Tabela 3.1 Espécies de plantas daninhas encontradas nas parcelas experimentais. . . . . . . . . . . . . . . . . . . 2

Tabela 6.1 Base de regras fuzzy para o risco de infestação por plantas daninhas. O primeiro subscrito denota a classe de infestação: 1 - baixa infestação, 2 - média infestação e 3 - alta infestação. O segundo subscrito denota quantas vezes a classe do primeiro subscrito está sendo citada.

Tabela 7.1 Índice de ajuste para os modelos teóricos de variogramas. . . . . 86

Tabela 7.2 Resultados dos variogramas. . . . . . . . . . . . . . . 87

Tabela 7.3 Índice de ajuste para os modelos teóricos de variogramas. . . . . 98

Tabela 7.4 Resultados dos variogramas. . . . . . . . . . . . . . . . . 100

Tabela 7.5 Validação cruzada para a estimação por Krigagem. ..... 100

Tabela 7.6 Saídas do sistema neurofuzzy e resíduo obtido. . . . . . . . . . 106

Tabela 7.7 Estatísticas dos resíduos de estimação dos dados de teste do sistema neurofuzzy. . . . . . . . . . . . . . . . . . . 107

Tabela 7.8 Estatísticas descritivas para os riscos utilizando-se funções triangulares e gaussianas. . . . . . . . . . . . . . . . . . 111

Tabela 7.9 Coeficientes de variação para os agrupamentos identificados pelo algoritmo da Seção 6.4.1. . . . . . . . . . . . . . . . . . . . . . . . . 111

Tabela 7.10 Índice de ajuste para os modelos teóricos de variogramas. . . . . 114

Tabela 7.11 Resultados dos variogramas. . . . . . . . . . . . . . 116 
Tabela 7.12 Validação cruzada para a estimação por Krigagem da geração posterior.

Tabela 7.13 Saídas do sistema neurofuzzy e resíduo obtido para os dados coletados na geração posterior.

Tabela 7.14 Estatísticas dos resíduos de estimação dos dados de teste do sistema neurofuzzy da geração posterior.

Tabela 7.15 Coeficientes de variação para os agrupamentos identificados pelo algoritmo da Seção 6.4.1 . . . . . . . . . . . . . . . . . . . . . . . . 124

Tabela 7.16 Estatísticas descritivas das matrizes de riscos agrupadas de duas gerações.

Tabela 8.1 Intervalos de discretização para as variáveis que definem a rede que infere sobre o atributo da competitividade.

Tabela 8.2 Probabilidades condicionais dos nós DensFL and DensFE na rede irrestrita. . . . . . . . . . . . . . . . . 133

Tabela 8.3 Probabilidades condicionais do nó DensTotal na rede irrestrita. . 133

Tabela 8.4 Probabilidades condicionais do nó Biomassa na rede irrestrita. 134

Tabela 8.5 Probabilidades condicionais do nó Biomassa na rede naïve. . . . 135

Tabela 8.6 Probabilidades condicionais do nó DensFL dada Biomassa na rede naïve. . . . . . . . . . . . . . . . . . . . . . 135

Tabela 8.7 Probabilidades condicionais do nó DensFE dada Biomassa na rede naïve. . . . . . . . . . . . . . . . . . . . . . . . . 135

Tabela 8.8 Probabilidades condicionais do nó DensTotal dada Biomassa na rede naïve. . . . . . . . . . . . . . . . . . . . . . . . . . . 136

Tabela 8.9 Conjunto de regras Bayesianas da rede irrestrita. D: regra De-

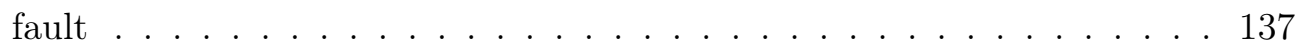

Tabela 8.10 Conjunto de regras Bayesianas da rede naïve. D: regra Default 138

Tabela 8.11 Resultados do conjunto de teste da rede Bayesiana irrestrita para a competitividade. 
Tabela 8.12 Conjunto reduzido de regras Bayesianas da rede irrestrita para a competitividade. D: regra Default . . . . . . . . . . . . . . 139

Tabela 8.13 Resultados do conjunto de teste da rede Bayesiana irrestrita para a competitividade usando o conjunto reduzido de regras. D: regra Default 140

Tabela 8.14 Resultados do conjunto de teste da rede naïve Bayes para a competitividade. . . . . . . . . . . . . . . . . . . . 140

Tabela 8.15 Conjunto reduzido de regras Bayesianas da rede naïve para a competitividade. D: regra Default . . . . . . . . . . . . . . . . . . 141

Tabela 8.16 Resultados do conjunto de teste da rede Bayesiana naïve para a competitividade usando o conjunto reduzido de regras. D: regra Default 141

Tabela 8.17 Resultados da classificação com redes Bayesianas irrestrita e naïve para a competitividade . . . . . . . . . . . . . . . . . . . . 141

Tabela 8.18 Intervalos de discretização para os atributos que definem a rede que infere sobre o risco de infestação. . . . . . . . . . . . . . . . . . . . 141

Tabela 8.19 Probabilidades condicionais do nó Competitividade na rede irrestrita. . . . . . . . . . . . . . . . . . . . 143

Tabela 8.20 Probabilidades condicionais do nó Cobertura Foliar na rede irrestrita. . . . . . . . . . . . . . . . . . . . . . . . 144

Tabela 8.21 Probabilidades condicionais do nó Densidade de Sementes na rede irrestrita. . . . . . . . . . . . . . . . . . . . . . . . . . . . 144

Tabela 8.22 Probabilidades condicionais do nó Extensão dos Agrupamentos de Sementes na rede irrestrita. . . . . . . . . . . . . . . . . . . . . . . 144

Tabela 8.23 Probabilidades condicionais do nó Perda de Rendimento na rede irrestrita. . . . . . . . . . . . . . . . . . . . 145

Tabela 8.24 Probabilidades condicionais do nó Perda de Rendimento na rede naïve.

Tabela 8.25 Probabilidades condicionais do nó Densidade de Sementes na rede naïve. . . . . . . . . . . . . . . . . . . . . . . . . . . . 146

Tabela 8.26 Probabilidades condicionais do nó Cobertura Foliar na rede naïve.146 
Tabela 8.27 Probabilidades condicionais do nó Extensão dos Agrupamentos de Sementes na rede naïve. . . . . . . . . . . . . . . . . . . . . . . . 147

Tabela 8.28 Probabilidades condicionais do nó Competitividade na rede naïve.147

Tabela 8.29 Conjunto de regras Bayesianas da rede irrestrita para o risco de infestação. . . . . . . . . . . . . . . . . . . . . . . . . 148

Tabela 8.30 Conjunto de regras Bayesianas da rede naïve para o risco de infestação.

Tabela 8.31 Resultados do conjunto de teste da rede Bayesiana irrestrita para o risco de infestação. . . . . . . . . . . . . . . . . . . . . . . . . . . 152

Tabela 8.32 Resultados do conjunto de teste da rede naïve Bayes para o risco de infestação.

Tabela 8.33 Comparação entre as regras Fuzzy e BayesRule. A: alto, M: médio, B: baixo.

Tabela D.1 Densidade de plantas daninhas total de cada parcela, a correspondente proporção em folha larga e folha estreita e biomassa na geração

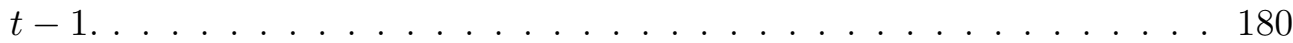

Tabela D.2 Densidade de plantas daninhas total de cada parcela, a correspondente proporção em folha larga e folha estreita e biomassa na geração

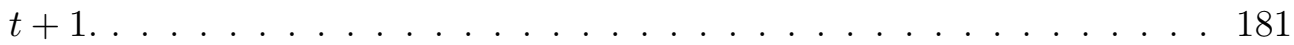

Tabela D.3 Densidade de sementes por metro quadrado na geração $t$ e proporção de cobertura foliar na geração $t-1 \ldots$. . . . . . . . . . . 182

Tabela D.4 Densidade de sementes por metro quadrado na geração $t+2 \mathrm{e}$ proporção de cobertura foliar na geração $t+1 \ldots$. . . . . . . . . 183 


\section{Conteúdo}

Lista de Figuras

$\begin{array}{ll}\text { Lista de Tabelas } & \text { ix }\end{array}$

Resumo $\quad$ xvii

Abstract $\quad$ xviii

1 Introdução 1

1.1 Justificativa do Trabalho . . . . . . . . . . . . . . . . . . 2

1.2 Objetivos . . . . . . . . . . . . . . . . . . 3

1.3 Organização do Trabalho . . . . . . . . . . . . . . . . . . 4

2 Revisão Bibliográfica $r$

2.1 Dinâmica de Populações . . . . . . . . . . . . . . . . . . . . . . . . . . 6

2.2 Geoestatística e Mapas . . . . . . . . . . . . . . . . . . . . 8

2.3 Sistemas de Classificação Fuzzy . . . . . . . . . . . . . . . . . 11

2.4 Redes Bayesianas . . . . . . . . . . . . . . . . . . . . . . 13

3 Descrição dos Experimentos de Campo $\quad 15$

3.1 Descrição da Área Experimental . . . . . . . . . . . . . . . . . . . . . . 15

3.2 Procedimentos para Obtenção dos Dados . . . . . . . . . . . . . 16

3.3 Principais Espécies Encontradas . . . . . . . . . . . . . . . . . . 19

4 Geoestatística e Modelos de Populações de Plantas 23

4.1 Análise Variográfica . . . . . . . . . . . . . . . . . . . . . 25

4.2 O Estimador de Krigagem . . . . . . . . . . . . . . . . . . . . 31

$4.2 .1 \quad$ Krigagem Simples . . . . . . . . . . . . . . . . . . . . . 34

$4.2 .2 \quad$ Krigagem Ordinária . . . . . . . . . . . . . . . . . . . . . . . . 34

4.3 Validação Cruzada . . . . . . . . . . . . . . . . . . . . . . . 40 
4.4 Modelos Dinâmicos de Populações de Plantas Daninhas . . . . . . . . . 42

5 Conceitos de Lógica Fuzzy, Classificação e Processamento de Imagens 46

5.1 Fundamentos da Lógica Fuzzy . . . . . . . . . . . . . . . . . . . 46

5.1 .1 Funções de Pertinência . . . . . . . . . . . . . . . . . . . . . . 48

5.1 .2 Conjuntos . . . . . . . . . . . . . . . . . . . . 50

5.1 .3 Operações de Agregação . . . . . . . . . . . . . . . . . . . . 52

5.1 .4 Relações entre Conjuntos Fuzzy . . . . . . . . . . . . . . . . . 53

5.1 .5 Inferência Fuzzy . . . . . . . . . . . . . . . . . . . . . . 54

5.2 Métodos de Classificação Baseados em Regras . . . . . . . . . . . . . 56

5.2 .1 Sistema de Classificação Fuzzy . . . . . . . . . . . . . . . 56

5.2 .2 Redes de Classificação Bayesianas . . . . . . . . . . . . . . . 58

5.2 .3 Algoritmo BayesRule . . . . . . . . . . . . . . . . . . . . . 61

5.3 Sistemas Neurofuzzy . . . . . . . . . . . . . . . . . . . . . 62

5.4 Representação de Imagens Digitais . . . . . . . . . . . . . . . . . . . 63

5.4.1 Passos Fundamentais em Processamento de Imagens . . . . . . . 63

5.4 .2 Um Modelo Simples de Imagem . . . . . . . . . . . . . . . . . . 64

5.4 .3 Amostragem e Quantização . . . . . . . . . . . . . . . . . . . 65

5.4 .4 Conectividade . . . . . . . . . . . . . . . . . 66

6 Proposta de Classificação Fuzzy do Risco de Infestação 68

6.1 Definição dos Atributos da Infestação . . . . . . . . . . . . . . . . . 68

6.2 Obtenção dos Atributos da Infestação Usando Análise de Imagens .. 70

6.2.1 Algoritmo para Extração de Objetos Conectados . . . . . . . . . 71

6.2 .2 Cálculo dos Atributos da Infestação . . . . . . . . . . . . . . . 72

6.3 Base de Regras e Funções de Pertinência . . . . . . . . . . . . . . . . . 74

6.4 Agrupamento K-médias dos Riscos de Infestação . . . . . . . . . . . 76

6.4.1 Algoritmo K-médias com Coeficiente de Variação . . . . . . . . . 78

7 Resultados da Classificação Fuzzy do Risco de Infestação de Regiões 80

7.1 Simulação de Dados Utilizando Modelos de Populações . . . . . . . . . 81

7.2 Mapas com Dados Simulados . . . . . . . . . . . . . . . . . . . 82

7.2.1 Análise Exploratória dos Dados . . . . . . . . . . . . . . . 82

7.2 .2 Ajuste dos Variogramas . . . . . . . . . . . . . . . . . 83

7.2 .3 Estimação por Krigagem . . . . . . . . . . . . . . . . . . . 86

7.2 .4 Validação Cruzada . . . . . . . . . . . . . . . . . . . . . 87

7.3 Resultados do Sistema de Classificação com Dados Simulados . . . . . . 90 
7.3.1 Cálculo dos Atributos da Infestação . . . . . . . . . . . . . . . . 90

7.3.2 Riscos de Infestação por Regiões . . . . . . . . . . . . . . . . . . 94

7.4 Mapas com Dados Coletados em Campo . . . . . . . . . . . . . . . . . . 96

7.4.1 Análise Exploratória dos Dados . . . . . . . . . . . . . . . 96

7.4 .2 Ajuste dos Variogramas . . . . . . . . . . . . . . . . . . 97

7.4 .3 Estimação por Krigagem . . . . . . . . . . . . . . . . . . . 98

7.4 .4 Validação Cruzada . . . . . . . . . . . . . . . . . . . . . . . 99

7.5 Resultados do Sistema de Classificação Fuzzy com Dados Coletados em Campo . . . . . . . . . . . . . . . . . . . . . . . . 101

7.5.1 Cálculo dos Atributos da Infestação . . . . . . . . . . . . . . . 101

7.5.2 Riscos de Infestação por Regiões . . . . . . . . . . . . . . . . . . 108

7.5.3 Agrupamento dos Riscos de Infestação . . . . . . . . . . . . . . . 111

7.6 Estudo do Comportamento da Infestação em Gerações Subsequentes . 112

7.6.1 Análise Exploratória dos Dados . . . . . . . . . . . . . . . . . 112

7.6 .2 Ajuste dos Variogramas . . . . . . . . . . . . . . . . . . . 113

7.6 .3 Estimação por Krigagem . . . . . . . . . . . . . . . . . . . . 114

7.7 Resultados do Sistema de Classificação com Dados Coletados em Campo em uma Geração Posterior . . . . . . . . . . . . . . . . . . . . . . . . 116

7.7.1 Cálculo dos Atributos da Infestação . . . . . . . . . . . . . 116

7.7.2 Riscos de Infestação por Regiões na Geração $t+2$. . . . . . 122

7.7.3 Agrupamento dos Riscos de Infestação em uma Geração Posterior 124

7.8 Análise Comparativa do Comportamento da Infestação nas Gerações . . 124

7.9 Avaliação do Desempenho do Sistema de Classificação Fuzzy . . . . . 126

8 Extração de Regras a partir de Redes de Classificação Bayesianas

8.1 Modelagem de Redes de Classificação Bayesianas Aplicadas à Classificação da Competitividade . . . . . . . . . . . . . . . . . . . . . . 130

8.1.1 Resultados da Classificação da Competitividade a partir das Redes Bayesianas . . . . . . . . . . . . . . . . 132

8.2 Modelagem das Redes de Classificação Bayesiana Aplicadas à Classificação do Risco de Infestação . . . . . . . . . . . . . . . . . . . . . . . 137

8.2.1 Resultados da Classificação do Risco de Infestação a partir das Redes Bayesianas . . . . . . . . . . . . . . . . . 139

8.3 Comparação Entre a Base de Regras Fuzzy e o Conjunto de Regras Bayesiano . . . . . . . . . . . . . . . . . . . . . . . 147

9 Conclusões $\quad 154$

9.1 Contribuições . . . . . . . . . . . . . . . . . . . . 157 
10 Perspectivas de Continuidade do Trabalho

A Pacote de Geoestatística para MATLAB: Geomatlab

B Sistemas Fuzzy e Neurofuzzy utilizando o Toolbox do MATLAB 163

B.1 FIS Editor . . . . . . . . . . . . . . . . . . . . . . . 163

B.2 Editor de Funções de Pertinência . . . . . . . . . . . . . . . . . 165

B.3 Editor de Regras . . . . . . . . . . . . . . . . . . . 165

B.3.1 Visualizador de Regras e Visualizador de Superfície . . . . . . 166

B.4 Sistemas de Inferência Fuzzy - Mamdani . . . . . . . . . . . . . . 166

B.4.1 Fuzzificação das Entradas . . . . . . . . . . . . . . . . . . . 167

B.4.2 Aplicação do Operador Fuzzy . . . . . . . . . . . . . . 167

B.4.3 Aplicação do Método de Implicação . . . . . . . . . . . . . . . . 167

B.4.4 Agregação das Saídas . . . . . . . . . . . . . . . . . . . . 168

B.4.5 Defuzzificação . . . . . . . . . . . . . . . . . . 168

B.5 Inferência Fuzzy do Tipo Sugeno . . . . . . . . . . . . . . . . 168

B.6 Editor Anfis . . . . . . . . . . . . . . . . . . . . . . . . . . . . 169

$\begin{array}{ll}\text { C Alguns Conceitos Estatísticos } & 171\end{array}$

C.1 Teste de Hipóteses . . . . . . . . . . . . . . . . . . . . . . . . . . . . 171

C.1.1 P-valor . . . . . . . . . . . . . . . . . . . 172

C.2 Experimento de Comparação Simples . . . . . . . . . . . . . . . . 172

C.2.1 Teste de igualdade das variâncias: Teste F . . . . . . . . . . 172

C.2.2 Teste de Levene . . . . . . . . . . . . . . . . . . . . . . . 173

C.2.3 Teste de média com variância conhecida . . . . . . . . . . . . . . 174

C.2.4 Teste de média com variância desconhecida: Teste t . . . . . . . 175

C.3 Teste de Correlação de Pearson . . . . . . . . . . . . . . . . . . . . . 177

C.4 Teste de Anderson-Darling . . . . . . . . . . . . . . . . . . . . 178

D Tabelas de Dados Coletados em Campo 179

$\begin{array}{lr}\text { Bibliografia } & 184\end{array}$ 


\section{Resumo}

O presente trabalho tem como objetivo principal a classificação do risco de infestação por regiões de culturas vegetais por plantas daninhas. Os riscos por regiões são obtidos por um sistema de classificação fuzzy, usando métodos de Krigagem e análise de imagens. A infestação é descrita por atributos da cobertura foliar, densidade de sementes, extensão dos agrupamentos de sementes e competitividade, obtidos a partir das amostras de densidades de sementes e de plantas daninhas, da cobertura foliar e da biomassa de plantas daninhas. O atributo da cobertura foliar indica a porcentagem de ocupação das plantas emergentes e é obtido a partir de um mapa de cobertura foliar, construído usando Krigagem. O atributo da densidade de sementes caracteriza a localização das sementes que podem germinar e é obtido a partir de um mapa da distribuição da produção de sementes das plantas daninhas, também construído usando Krigagem. O atributo da extensão dos agrupamentos de sementes reflete a influência das sementes vizinhas em uma certa localização e também é obtido a partir do mapa de distribuição da produção de sementes. O atributo da competitividade entre plantas daninhas e cultura é obtido a partir de um sistema neurofuzzy, utilizando amostras de densidade e de biomassa das plantas daninhas. Para reunir os riscos de infestação semelhantes, os valores de risco inferidos por região pelo sistema fuzzy são agrupados considerando valores e localizações próximas utilizando o método k-médias com coeficiente de variação. Uma abordagem probabilística com redes de classificação Bayesianas é também empregada para a obtenção de um conjunto de regras linguísticas para classificar a competitividade e o risco de infestação, por motivo de comparação. Resultados para o risco de infestação são obtidos para uma área experimental em uma cultura de milho indicando a existência de riscos diferenciados que são explicados pela perda de rendimento da cultura.

Palavras-chave: Classificação fuzzy, Krigagem, mapas, processamento de imagens, plantas daninhas, redes Bayesianas. 


\section{Abstract}

The goal of this work is the classification of the risk of infestation per regions of a crop by weeds. The risks per regions are obtained by a fuzzy classification system, using Kriging and image analysis. The infestation is described by attributes of the weed coverage, weed seed density, weed seed patches and competitiveness, obtained from weed seeds and weed densities, weed coverage and biomass. The attribute of the weed coverage indicates the percentage of infested surface of the emergent weeds which is obtained from a weed coverage map built with Kriging. The attribute of the weed seed density is obtained from a weed seed production map also built with Kriging which caracterizes the locations of seeds which can germinate. The attribute of the weed seed patches is also obtained by the weed seed production map which reflects how the seeds contribute to weed proliferation in the surroundings. The attribute of the competitiveness among weeds and crop is obtained from a neurofuzzy system, using the weeds density and biomass of the plants. In order to aggregate the similar risks of infestation, the values of risks per region inferred by the fuzzy system are clustered according to similar values and locations using the $k$-means method with a variation coefficient. A probabilistic approach with Bayesian networks classifiers is also considered to obtain a set of linguistic rules to classify the competitivenees and the risk of infestation, for comparison purposes. Results for the risk of infestation are obtained for an experimental area in a corn crop which indicate the existence of different risks, explained by the yield loss of the crop.

Palavras-chave: Fuzzy classification, Kriging, maps, image processing, weeds, Bayesian networks. 


\section{Capítulo 1}

\section{Introdução}

Procedimentos agrícolas podem modificar o equilíbrio ecológico devido à maneira como a terra é preparada, tornando propícia a explosão populacional de certas plantas, ocasionando uma infestação. A presença destas plantas pode interferir na operacionalização do sistema de produção, causando prejuízos na produtividade (Baio e Balastreire, 2001). Por isto, estas plantas recebem o nome de plantas daninhas. A partir da planta já instalada, é possível inferir a capacidade de dispersão da mesma pela cultura. O conhecimento da dinâmica das populações de plantas daninhas pode ser eficientemente utilizado na prevenção de infestações com a aplicação localizada de defensivos agrícolas.

Nos primórdios da agricultura, percebeu-se que a presença de plantas daninhas provocava diminuição na produtividade da cultura. Para que a infestação por plantas daninhas seja eficientemente controlada, é necessário o desenvolvimento de técnicas de análise e controle de infestação de culturas por plantas daninhas, através de uma modelagem matemática da dinâmica da infestação. Desta forma é necessário caracterizar essas populações de plantas daninhas para poder inferir um modo de controle mais eficiente. Esta linha de estudos tem despertado a atenção de pesquisadores de todo o mundo e de diversas áreas, preocupados com o grande número de trabalhos em controle químico e poucos relacionados à biologia das plantas (Shiratsuchi et al., 2004; Rizzardi et al., 2003; Balastreire e Baio, 2001; Doyle, 1997). 


\subsection{Justificativa do Trabalho}

As culturas agrícolas podem estar sujeitas a uma série de fatores do ambiente que influenciam no crescimento, desenvolvimento e produtividade econômica. Por exemplo, no Brasil as perdas estimadas na cultura da soja devido à competição com plantas daninhas incorrem da ordem de 13,5\% ao ano, o que equivale a 15,75 ton/ano (Gazziero et al., 1998). As perdas aliadas ao alto custo de controle e o pouco conhecimento da dinâmica das plantas daninhas motivam o desenvolvimento deste projeto. Plantas daninhas correspondem a um dos maiores problemas que o agricultor tem que enfrentar ao cultivar uma área, pois muitas espécies possuem altíssima capacidade de competição pelos nutrientes da cultura.

A predição da ocorrência de plantas daninhas ajuda a combatê-las, pois a partir desta informação, o agricultor saberá antecipadamente o quanto e onde estas podem ocasionar infestação, e assim, medidas de prevenção podem ser aplicadas. Desta forma, sabendo a quantidade de plantas daninhas que aparecem em determinado local, implica uma tomada de decisão quanto ao controle destas plantas. Procedimentos para diminuir a utilização de herbicidas contribuem para a redução da contaminação do ambiente e promover o aumento da margem de lucro do agricultor.

A infestação das plantas daninhas normalmente não ocorre de modo uniforme nas áreas agrícolas, por isso, mapear a variabilidade espacial das plantas daninhas é fundamental para o estudo de seu comportamento e para a predição das áreas de maior ocorrência (Baio e Balastreire, 2001). É possível mapear esta variabilidade espacial com a utilização de ferramentas de agricultura de precisão que consideram o comportamento dos diversos fatores que interferem na produção agrícola, como fertilidade, temperatura, plantas daninhas e doenças. A agricultura de precisão é um sistema de gerenciamento da produção agrícola que utiliza tecnologias para que a lavoura seja otimizada, tendo como elemento chave o gerenciamento da variabilidade da produção (Committee, 1997). Desta forma, a detecção e o mapa das áreas de ocorrência de plantas daninhas possibilita a tomada de decisão sobre o melhor manejo para cada local do campo pela identificação da variabilidade espacial das plantas daninhas, permitindo o controle somente nas áreas de infestação das mesmas, com aplicações de herbicida de forma mais racional quando comparada com pulverizações que se baseiam na média das infestações, sem considerar o grau de distribuição das plantas daninhas na área (Shiratsuchi et al., 2004). 
Com o aumento da competitividade e decréscimo dos preços dos produtos agrícolas no mercado mundial globalizado, a agricultura se depara com a necessidade de otimizar a utilização dos recursos de produção. Altas produtividades vêm sendo observadas em áreas agrícolas onde grandes investimentos em tecnologias e produtos têm sido aplicados. Porém, mais importante que altas produtividades é a utilização racional e econômica destes recursos e de técnicas de produção agrícola. Neste contexto, a utilização e desenvolvimento de novas ferramentas gerenciais, como o manejo localizado, se tornam necessárias. Portanto, informações da variabilidade espacial nas áreas agrícolas devem ser analisadas com um nível maior de detalhamento para a racionalização e otimização das práticas de manejo localizado nas áreas agrícolas. Porém, a aplicação de herbicidas a taxas variáveis necessita ainda de muitas pesquisas, o que também motiva o desenvolvimento deste trabalho. Neste cenário, nossa contribuição é elaborar um sistema de classificação de culturas sítio-específico, de acordo com o risco de infestação das regiões da cultura, para uma correta aplicação localizada de herbicida. A originalidade do trabalho está no sistema de classificação fuzzy, usando a dinâmica da infestação e atributos invariantes obtidos através de mapas e análise de imagens, e também na aplicação de redes de classificação Bayesiana na agricultura, a partir das quais é possível extrair regras linguísticas e probabilísticas para a classificação do risco de infestação.

\subsection{Objetivos}

O objetivo principal deste trabalho é a classificação do risco de infestação por plantas daninhas considerando regiões de uma cultura. Os riscos de infestação por regiões são obtidos por um sistema de classificação fuzzy, que considera incertezas nas fronteiras de classes de infestação e utiliza geoestatística e análise de imagens. Os atributos mais relevantes da infestação, calculados por região, são entradas do sistema de classificação fuzzy e são obtidos a partir da densidade de sementes e de plantas daninhas, da biomassa e da cobertura foliar. Portanto, a infestação é descrita por atributos da cobertura foliar, que indica a porcentagem de ocupação das plantas emergentes, da densidade de sementes, associado ao mapa da produção de sementes por metro quadrado, da extensão dos agrupamentos de semente, que refle a influência das sementes vizinhas na proliferação de uma determinada localização, e da competitividade das plantas daninhas com a cultura, obtido a partir da ocupação de gramíneas e de um sistema neurofuzzy. A 
saída do sistema de classificação infere sobre o risco de infestação de regiões por plantas daninhas, o que está associado à perda de rendimento da cultura. Para comparação, uma abordagem probabilística utilizando redes Bayesianas é utilizada para classificar o risco de infestação, por considerar incertezas e extrair um conjunto de regras linguísticas a partir de um classificador Bayesiano. Resultados da classificação são apresentados para uma área experimental em uma cultura de milho.

Este trabalho insere-se no projeto multidisciplinar apoiado pela CAPES PROCAD: "Modelagem Matemática e Computacional Aplicada na Agricultura de Precisão", cujos integrantes são professores, pesquisadores, graduandos e pós-graduandos ligados ao Departamento de Engenharia Elétrica/EESC/USP, Departamento de Ciência da Computação e Estatística/IBILCE/UNESP e Empresa Brasileira de Pesquisa Agropecuária (Embrapa).

\subsection{Organização do Trabalho}

Este trabalho está dividido em 10 capítulos e 4 apêndices. O Capítulo 2, seguido desta introdução, apresenta uma revisão bibliográfica sobre os temas relevantes relacionados ao desenvolvimento deste trabalho. O Capítulo 3 traz a descrição da área experimental e dos procedimentos para obtenção dos dados. No Capítulo 4 é introduzida a teoria geoestatística, incluindo a análise variográfica e o método de estimação por Krigagem para obtenção de mapas, bem como os modelos matemáticos de população de plantas. O Capítulo 5 descreve os conceitos de lógica fuzzy, de processamento de imagens e de métodos de classificação baseados em regras, incluindo sistemas fuzzy e redes Bayesinas. No Capítulo 6 é proposta a classificação do risco de infestação de plantas daninhas por regiões de uma cultura de milho pelo sistema de classificação fuzzy. O Capítulo 7 descreve os resultados obtidos da classificação fuzzy do risco de infestação de regiões a partir da simulação de modelos matemáticos e dos experimentos em campo. O Capítulo 8 apresenta os resultados obtidos para o risco de infestação utilizando a abordagem probabilística utilizando redes de classificação Bayesinas. Os Capítulos 9 e 10, apresentam, respectivamente, as conclusões e as perspectivas de continuidade do trabalho. O Apêndice A apresenta o pacote de geoestatística, chamado GEOMATLAB, utilizado na obtenção de mapas. O Apêndice B descreve o procedimento para a utilização do toolbox de sistemas fuzzy e neurofuzzy no MATLAB. O Apêndice C descreve os con- 
ceitos estatísticos utilizados e o Apêndice D traz as tabelas de dados coletados na área experimental. 


\section{Capítulo 2}

\section{Revisão Bibliográfica}

Perdas na produção de culturas vegetais se agravam devido à competição no solo com plantas daninhas. Estas plantas correspondem a um dos maiores problemas que o agricultor tem que enfrentar ao cultivar uma área, pois muitas espécies possuem alta capacidade de proliferação. Neste contexto, o desenvolvimento de técnicas de controle tem motivado muitas pesquisas no sentido de otimizar a produtividade. Este capítulo apresenta uma revisão bibliográfica sobre os principais temas abordados no desenvolvimento deste trabalho.

\subsection{Dinâmica de Populações}

As plantas daninhas invadem os ecossistemas naturais e apresentam sérias ameaças para a biodiversidade. Portanto, uma abordagem estratégica, integrada, ecológica e econômica para o manejo de plantas daninhas se faz necessária. Modelos matemáticos podem ser instrumentos úteis para entender, predizer e simular os impactos causados pela interferência das plantas daninhas em uma certa cultura (Lotz et al., 1996). Em Odom et al. (2003), um modelo de programação dinâmica determinístico é desenvolvido para este propósito. Um caso de estudo para a planta daninha vassoura foi analisado, avaliando-se as maneiras nas quais o modelo de programação dinâmica pode levar em conta as questões políticas associadas ao manejo de uma planta daninha em um parque nacional. A vassoura (Cytisus scoparius, L.) é um arbusto exótico nativo na Europa, que invade a mata e o pasto e se desenvolve perto de rios, em regiões chuvosas do sul da Austrália. O modelo considera a dinâmica da população de plantas daninhas, o custo e 
efeito das medidas de controle, incluindo a densidade das plantas daninhas e o banco de semente como variáveis de estado. Uma regra de decisão ótima fornece um conjunto de medidas de controle que pode ser usado para tratar o problema a cada ano, dependendo da densidade de plantas daninhas.

Foi descrito em Sakai (2001) a dinâmica populacional de plantas daninhas através de fatores dependentes e independentes da densidade de plantas daninhas. O número de sementes por área nos sucessivos anos pode ser obtido sequencialmente a partir do número de sementes do ano inicial medido. Um dos principais mecanismos de sobrevivência das plantas daninhas é a alta produção de sementes (Lacerda, 2003), que, aliada à longevidade e capacidade de sobreviver sob condições adversas e em baixo nível de atividade metabólica, podem garantir grandes reservas de sementes de plantas daninhas no solo, as quais podem germinar em gerações futuras (Lorenzi, 2000). Em Gonzalez-Andujar (1996) foi mostrado como a persistência de populações de plantas daninhas no campo pode ser explicada pelo comportamento dinâmico de suas populações apesar do uso de altas taxas de aplicação de herbicida.

Em Doyle (1997) é discutido o papel da modelagem matemática no desenvolvimento de estratégias integradas, envolvendo a redução de defensivos químicos, para o controle de plantas daninhas, pestes e doenças na colheita. Tem ocorrido uma grande preocupação em simular e modelar os impactos de herbicidas e identificar os limiares para aplicá-los, com especial atenção a questões como a interferência de plantas na colheita e sistemas de manejo. Além disso, no caso de algumas formas de controle, tais como genética e biológica, modelar as consequências antes da aplicação prática é imprescindível, dados o potencial ecológico e os riscos ambientais envolvidos.

Modelos dinâmicos para populações de plantas daninhas descrevem o tamanho da população na geração $t$ como uma função do tamanho da população na geração $t-1$ utilizando equações diferenciais (Sakai, 2001; Cousens e Mortimer, 1995). A geração das plantas, também chamada de ciclo de vida, é definida em Cousens e Mortimer (1995). Os modelos dinâmicos indicam que a infestação não é apenas dependente da densidade de plantas daninhas mas também da produção de sementes e competitividade das espécies (Park et al., 2003; Firbank e Watkinson, 1985; Kropff e Spitters, 1991). Usando um modelo hiperbólico, Cousens (1985) descreveu a perda de rendimento causada pela competição de plantas daninhas em uma cultura. 
O trabalho de Vismara et al. (2005) apresenta uma revisão dos modelos encontrados na literatura que descrevem o comportamento dinâmico do banco de sementes de plantas daninhas. Nesse trabalho, são apresentados modelos que descrevem os processos intrínsecos da população e modelos para espécies de daninhas que coexistem em diferentes estádios de desenvolvimento.

\subsection{Geoestatística e Mapas}

As plantas daninhas provocam um declínio na produção e no lucro ao competirem com os nutrientes da cultura (Bicudo et al., 1998). Para reduzir a população destas plantas, herbicidas são em geral aplicados. Tradicionalmente, o manejo das plantas daninhas é realizado levando-se em consideração a infestação média destas plantas nas áreas agrícolas, sendo então adotadas estratégias de manejo de forma homogênea em toda a área (Shiratsuchi e Christoffoleti, 2001). Porém, as plantas daninhas não se distribuem uniformemente, sendo comum os locais de maior e menor ocorrência, formando reboleiras (Nordmeyer et al., 1997). Essa distribuição desigual pode ser devida a certos aspectos da biologia das plantas daninhas, ou por fatores locais, tais como fertilidade e teor de água do solo, umidade e luz. Desta forma, confinar as pulverizações às manchas de infestação pode permitir consideráveis economias de herbicida (Esquerdo, 2002). O manejo integrado surge como uma alternativa ao manejo tradicional, o qual envolve a seleção e integração de práticas de controle, com resultados favoráveis do ponto de vista agronômico e econômico. Neste contexto, os mapas de distribuição de plantas daninhas vem sendo utilizados como auxílio na tomada de decisões, principalmente nos tratamentos com defensivos agrícolas, orientando pulverizadores capazes de realizar a aplicação localizada segundo a variabilidade das populações de plantas daninhas.

Em Baio e Balastreire (2001) foi apresentada a comparação de duas metodologias para a construção de mapas de distribuição de plantas daninhas, visando economia de herbicida com a aplicação localizada. A primeira, a metodologia de mapeamento de plantas daninhas pelo contorno das reboleiras, consiste em percorrer as áreas de ocorrência de plantas daninhas identificando as espécies. Esta metodologia mostrou-se rápida, exigindo apenas 30 minutos para o levantamento dos dados em uma área de 8ha. Porém, exige a habilidade de um especialista para identificar o perímetro das reboleiras. Desta forma, seria pouco aplicável em uma cultura com estágio avançado de desenvolvi- 
mento devido à barreira visual causada pela cultura. A segunda, a metodologia de mapeamento por amostragens sistemáticas, a qual consiste em coletar informações sobre as espécies de plantas em pontos previamente estabelecidos em todo o campo, exigiu 14 horas para ser executada. Esta última metodologia fornece maior detalhamento da variabilidade espacial das plantas daninhas, mas mostrou-se pouco prática em áreas extensas. Técnicas geoestatísticas foram aplicadas aos dados e os mapas resultantes foram interpolados pelo método de Krigagem. O sistema para aplicação localizada de defensivos permitiu economia considerável de $31,6 \%$ do produto quando comparado à aplicação em todo o campo.

O propósito do trabalho de Balastreire e Baio (2001) foi a avaliação de uma metodologia prática para o mapeamento de plantas daninhas pelo contorno das reboleiras com um quadriciclo. Foram realizados dois mapas em um mesmo campo agrícola com quinze dias de intervalo, em que o primeiro foi realizado em condições onde não seria possível a aplicação de herbicida, devido à baixa umidade do solo, e o segundo em boas condições de umidade devido às chuvas. Foi possível a obtenção dos mapas de plantas daninhas com três níveis de infestação: baixa (até uma planta por $m^{2}$ ), média (até 5 plantas por $m^{2}$ de guanxuma e até 2 plantas por $m^{2}$ de trapoeraba) e alta (mais de 5 plantas por $m^{2}$ de guanxuma e mais de 2 plantas por $m^{2}$ de trapoeraba). O primeiro mapa apresentou 13,4\% de reboleiras de alta infestação de plantas daninhas, $82,8 \%$ de média infestação e 1,67\% de baixa infestação. Já o segundo mapa apresentou $48 \%$ de reboleiras de alta infestação, 46,86\% de média infestação e $5 \%$ de baixa infestação. Verificou-se a necessidade de um planejamento para a construção dos mapas, levando-se em consideração a posterior aplicação localizada de defensivos.

Com o objetivo de estudar o comportamento da variabilidade espacial das plantas daninhas e seu respectivo banco de sementes com a utilização de ferramentas da agricultura de precisão, Shiratsuchi e Christoffoleti (2001) realizaram quatro experimentos. O primeiro consistiu no mapeamento do banco de sementes por dois anos consecutivos, concluindo-se que existe correlação entre o banco de sementes e a flora emergente, bem como entre bancos de sementes de anos consecutivos. No segundo experimento foram feitos dois mapeamentos de Panicum maximum, um durante e um após a colheita do milho. Constatou-se uma subestimação de $6 \%$ da área infestada durante a colheita. No terceiro experimento avaliou-se a eficácia da aplicação localizada de herbicidas pós- 
emergentes na cultura da soja, baseada em mapas de infestação das plantas daninhas. Foi obtida uma economia de produto da ordem de 18 e $44 \%$. No quarto experimento foi realizada uma pulverização localizada de herbicida pré-emergente baseada no mapeamento prévio do banco de sementes, sendo verificada uma eficácia igual à convencional e uma economia de $22 \%$ do produto. Concluiu-se que as técnicas de mapeamento da variabilidade espacial das plantas daninhas são importantes ferramentas para que melhores decisões sejam tomadas nos sistemas de produção agrícola.

O experimento apresentado em Shiratsuchi et al. (2004) tem como objetivo comparar mapas do capim-colonião com base na avaliação visual durante e após a colheita da cultura de milho. Durante a colheita foi conduzido o monitoramento com avaliação visual, feito por especialista. Após a colheita, a avaliação visual foi feita por amostragens, numa grade de 20 por $20 \mathrm{~m}$. Foi observada uma subestimação de $6 \%$ da área infestada, com uma infestação de mais de $80 \%$ da cobertura pelo mapa estimado durante a colheita, quando comparado com o mapa estimado após a colheita.

Para caracterizar a variabilidade espacial e temporal da densidade de Convolvulus arvensis, variogramas foram utilizados em Exposito et al. (2004). Os dados apresentaram forte dependência espacial e os mapas estimados por Krigagem foram usados para inferir a porcentagem da superfície a ser tratada com aplicação localizada de herbicida baseada em um limiar econômico estimado para cada ano. Concluiu-se que, se um dado herbicida for aplicado apenas em áreas que excedem o limite econômico, a redução média no custo de herbicida pode alcançar cerca de $81 \%$.

O objetivo de Yang et al. (2000) foi o desenvolvimento de uma metodologia para processamento de imagens digitais obtidas de uma plantação de milho para determinar um mapa de plantas daninhas. Baseado neste mapa, um programa foi então desenvolvido para simular a aplicação localizada de herbicida. Dado que a informação sobre o limiar econômico do impacto da planta daninha sobre a produtividade da colheita não pode ser facilmente adaptado para uma região dada, concluiu-se que a lógica fuzzy deveria ser usada para associar os dados de cobertura foliar, obtidos por imagens fotografadas em campo, em 3 níveis de aplicação localizada de herbicida.

Em Faechner et al. (2002) um modelo matemático fornece a taxa de aplicação ótima de herbicida usando modelos geoestatísticos de incerteza em densidade de plantas daninhas combinados com uma tomada de decisão. Foram considerados estudos publicados 
na literatura para a resposta à taxa de aplicação de herbicida. Como a incerteza na distribuição de plantas daninhas permite uma avaliação de risco para a tomada de decisão, o controle destas plantas é realizado com uma redução significativa no uso total de herbicida.

Com o objetivo de racionalizar o uso de herbicidas em áreas de produção agrícola, Shiratsuchi et al. (2002) idealizou a realização de um ensaio de aplicação localizada a partir de mapas de densidade de sementes. Neste trabalho, a determinação da densidade de sementes das plantas daninhas foi obtida pela emergência de plantas em casa de vegetação durante 90 dias. A densidade durante este período foi mapeada e serviu de base para a construção de mapas de aplicação. Uma economia de $22 \%$ do produto comercial foi obtida comparada à pulverização convencional. Também visando a redução da quantidade de herbicida aplicada na cultura, Gerhards e Oebel (2006) apresenta um sistema para controle localizado de plantas daninhas baseado em análises de imagens digitais das plantas e mapas de distribuição das plantas do tipo folha larga e folha estreita. Em dois anos, o uso de herbicidas com aplicação baseada no mapa de distribuição de plantas do tipo folha larga atingiu uma redução de até $81 \%$ e o uso de herbicidas com aplicação baseada no mapa de distribuição de plantas do tipo folha estreita atingiu uma redução de até $79 \%$.

\subsection{Sistemas de Classificação Fuzzy}

Como a maioria das técnicas de tomadas de decisão avalia a taxa de fatores de risco por valores linguísticos, como alto, médio, baixo, muito baixo, a teoria fuzzy fornece uma ferramenta útil para tratar a ambiguidade envolvida no processo de avaliação dos dados. Muitos problemas em várias aplicações envolvem uma grande quantidade de dados que precisam ser classificados. Em particular, as fronteiras entre as classes não são sempre claramente definidas e os sistemas de classificação fuzzy podem tratar desta questão (Chiang e Hsu, 2002). Sistemas fuzzy baseado em regras são aplicados em problemas de classificação onde vetores de entrada não fuzzy são atribuídos a um dos conjuntos de classes (Ishibuchi e Nakashima, 2001).

Em Nurnberger et al. (2001) foram discutidas as formas das fronteiras da classificação fuzzy considerando-se diferentes tipos de funções de pertinência e bases de regras. 
Desta forma, foram determinadas quais as formas que as classes podem assumir dependendo das funções e regras utilizadas. É discutido como a exclusão de antecedentes de regras fuzzy influencia no comportamento da classificação.

A classificação é vital para a avaliação do processo agrícola. Em Kavdir e Guyer (2003) a lógica fuzzy foi aplicada como um suporte à tomada de decisão para classificar maçãs com respeito à sua qualidade. Os atributos de qualidade tais como cor, tamanho e manchas das maçãs foram medidos por diferentes equipamentos. Como os altos custos, a subjetividade e a inconsistência associadas com a classificação manual têm forçado as indústrias a automatizarem o processo, o mesmo conjunto de maçãs foi classificado por um especialista e pelo sistema fuzzy. Os resultados obtidos pelo sistema fuzzy mostraram $89 \%$ de concordância com os resultados do especialista.

Em Peixoto et al. (2004) é elaborado um modelo do tipo presa-predador que descreve a interação de pulgões (presas) e joaninhas (predador) na citricultura, em que os pulgões são considerados agentes transmissores da morte súbita de citros (doença causada por vírus). A dispersão dos pulgões se dá através do vento, sendo que o espaço percorrido por este inseto e a intensidade dos ventos são informações linguísticas. Portanto, é utilizado um sistema fuzzy baseado em regras linguísticas para estabelecer a relação entre estas duas variáveis de entrada. Considerando a quantidade média de pulgões e joaninhas em um ramo de laranjeira, simulações foram feitas observando-se a variação da quantidade de presas e do potencial de predação, que são as variáveis de saída do sistema fuzzy.

No trabalho de Hu et al. (1998) é apresentada a aplicação de uma técnica de classificação fuzzy para avaliação da qualidade de peixes. A avaliação é uma importante operação desempenhada rotineiramente em indústrias de processamento de alimentos para o controle de qualidade e atribuição de preços. Os classificadores fuzzy e convencional são examinados usando um conjunto realístico de ova de peixe para comparar a classificação em termos de precisão e custo computacional. Os resultados desta aplicação mostram que o classificador fuzzy é $89 \%$ mais preciso do que a classificação convencional.

Em Puente et al. (2002) é apresentada uma maneira alternativa de classificar os ítens produtivos de uma indústria. É descrito um modelo fuzzy para as variáveis envolvidas: custo do produto e demanda. Esse modelo contrasta com a classificação ABC de Pareto, que classifica os defeitos de um produto de acordo com a sua importância em termos de 
frequência e custo de reparação. A frequência é o número de ocorrência dos defeitos de um produto e A, B e C denotam os tipos de defeitos, os quais apresentam um custo para sua reparação. Diferindo da classificação de Pareto, a qual é baseada nas informações sobre custo e demanda em um período no passado, o modelo fuzzy proposto faz com que uma previsão sobre custo e demanda seja incluída, permitindo o controle mais eficiente dos produtos defeituosos que resultam desta nova classificação.

\subsection{Redes Bayesianas}

Métodos de classificação baseados em probabilidades têm sido intensamente aplicados. Estes métodos são baseados na probabilidade que um dado conjunto de medidas seja proveniente de objetos pertencentes a uma certa classe. Usando um classificador naïve Bayes, Granitto et al. (2002) identificaram um conjunto de 12 características das sementes para serem usadas como parâmetros de classificação de sementes, as quais incluem morfologia, cor e textura. Considerando o problema de identificação de sementes, Granitto et al. (2005) comparou o classificador naïve Bayes com redes neurais. Neste experimento, o classificador Bayesiano baseado em um conjunto adequadamente selecionado de atributos apresenta excelente desempenho quando comparado a um classificador baseado em redes neurais. Resultados similares foram obtidos também por Marchant e Onyango (2003) na tarefa de discriminar imagens de plantas daninhas, cultura e solo.

O conhecimento representado por classificadores Bayesianos não é tão compreensível como algumas outras formas de representação, tais como as regras de classificação. Tentando superar esta dificuldade, um método chamado BayesRule proposto em Hruschka et al. (2007), usa o conceito de probabilidade máxima a posteriori (MAP) para extrair um conjunto de regras probabilísticas do tipo SE-ENTÃO que descrevem a classificação. Além disso, o conceito de Markov blanket é aplicado para reduzir o número e a complexidade de regras de classificação geradas pelo processo de extração.

O método BayesRule foi aplicado com sucesso para traduzir um classificador Bayesiano em um conjunto de regras linguísticas probabilísticas no trabaho descrito em Bressan et al. (2007a). O classificador Bayesiano foi construído buscando a classificação automática dos graus de competitividade entre plantas daninhas e cultura. Neste tra- 
balho, porém, o conceito de Markov blanket não foi suficiente para podar (reduzir) o conjunto de regras extraído da rede Bayesiana de classificação. Neste sentido, o trabalho de Bressan et al. (2007b) implementa e discute uma nova estratégia de poda para otimizar o conjunto de regras extraído pelo método BayesRule. 


\section{Capítulo 3}

\section{Descrição dos Experimentos de Campo}

Para validar os métodos apresentados neste trabalho, plantas daninhas e sua produção de sementes por metro quadrado, juntamente com a cobertura foliar e a biomassa são coletadas em parcelas experimentais de uma cultura de milho. Os experimentos são conduzidos em campo, na área experimental da Embrapa Milho e Sorgo ${ }^{1}$, localizada no município de Sete Lagoas, MG.

\subsection{Descrição da Área Experimental}

O milho é uma cultivar (BRS1030) do tipo híbrido simples, cultivado em uma área de 38 hectares, numa área com pivô central em sistema de plantio direto, onde o solo não é revolvido após a colheita nem antes do próximo plantio. Ao longo do tempo, o sistema de plantio direto tende a diminuir o banco de sementes, devido ao controle aplicado nas plantas emergentes, à dificuldade de germinação das sementes nas camadas mais profundas do solo e à predação. Desta forma, há uma maior concentração de sementes em reboleiras na superfície do solo. A foto aérea da área experimental pode ser vista na Figura 3.1.

Neste trabalho, dados coletados provenientes de dois diferentes plantios realizados

\footnotetext{
${ }^{1}$ Embrapa - Projeto 55.2004.509.00: Rede de Conhecimento em Agricultura de Precisão para Condições do Cerrado e dos Campos Gerais.
} 
na área da Figura 3.1 são utilizados. Os plantios ocorreram de 16 a 20 de novembro de 2004 e de 15 a 19 de maio de 2006 e, concomitantemente, foi realizada uma adubação

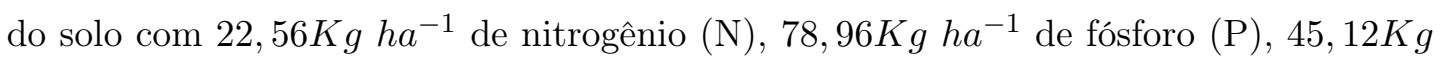
$h a^{-1}$ de potássio $(\mathrm{K})$ e $0,564 K g h a^{-1}$ de Zinco.

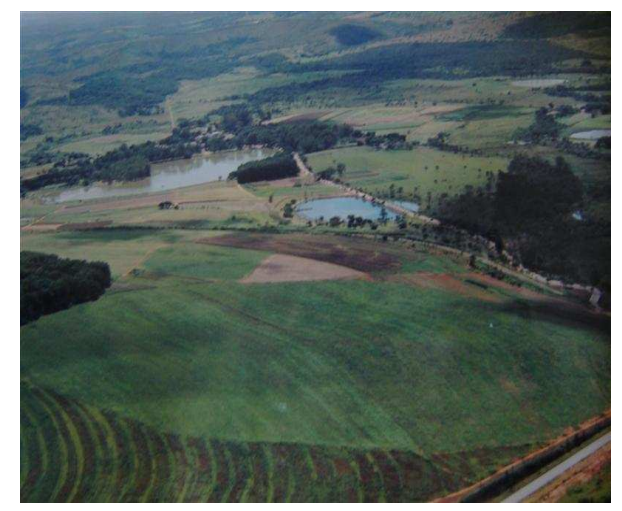

Figura 3.1: Foto aérea da área experimental - Sete Lagoas, MG.

Dentro da cultura são consideradas 41 parcelas de amostragem distando cem metros uma das outras em cada direção (leste-oeste e norte-sul). Cada parcela possui forma retangular, medindo $12 m^{2}$, sendo $4 m$ de comprimento e $3 m$ de largura, com 5 linhas de cultura equiespaçadas $0,7 m$, com $0,1 m$ nas bordas superior e inferior, conforme mostra a Figura 3.2. Durante a aplicação de herbicidas, estas parcelas foram cobertas com lona para que estas não sofressem a ação do defensivo. As plantas daninhas presentes nestas parcelas são de geração espontânea, ou seja, não são semeadas. O tratamento com herbicidas foi realizado em aplicação pré-emergente (antes do desenvolvimento da cultura) e pós-emergente (depois do desenvolvimento da cultura). A aplicação préemergente ocorreu logo após o plantio com dessecantes glifosato $\left(2,4 K g h a^{-1}\right)$. A aplicação pós-emergente foi realizada com nicosulfuron $\left(0,04 \mathrm{Kg} \mathrm{ha}^{-1}\right)$ e atrazine $(1 \mathrm{Kg}$ $\left.h a^{-1}\right)$. Foi realizada também, a aplicação de inseticidas $(0,6$ litros por hectare de Lannat).

\subsection{Procedimentos para Obtenção dos Dados}

Nos dias 17, 18 e 21 de março de 2005 e de 16 a 18 de outubro de 2006 foram coletados em campo os seguintes dados nas 41 parcelas experimentais da cultura: 


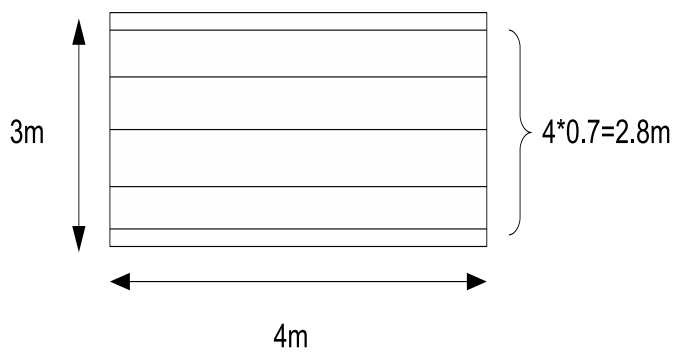

Figura 3.2: Representação de uma parcela experimental.

1. cobertura foliar total da parcela e sua porcentagem em folha larga e folha estreita, obtida através da análise visual de especialistas. A cobertura foliar é definida como a proporção de área do solo ocupada pela projeção vertical da parte área de uma espécie (Rizzardi e Fleck, 2004);

2. densidade de plantas daninhas, ou número de plantas por metro quadrado em cada parcela, obtida com o auxílio de um quadro de madeira de $0.5 \mathrm{~m}$ por $0.5 \mathrm{~m}$, que pode ser visualizado na Figura 3.3. Este quadro foi colocado aleatoriamente quatro vezes dentro das 3 linhas centrais de cultura em cada parcela. Dentro deste, foram colhidas e contadas todas as espécies de plantas daninhas encontradas;

3. produção de sementes por espécie em cada parcela, obtida coletando-se uma planta daninha de cada espécie com semente de cada parcela, com o objetivo de estimar a produção de sementes por planta por espécie;

O número de espécies de plantas daninhas encontradas em cada quadro fornece o valor da densidade de plantas por $0.25 \mathrm{~m}^{2}$, correspondente à área do quadro. Estes valores são agrupados em número de espécies de plantas daninhas encontradas em cada parcela, obtendo-se a densidade de plantas por espécie, ou seja, o número de espécies por metro quadrado encontrado em cada parcela. Como as plantas daninhas são classificadas em folha estreita e folha larga, obtém-se a densidade de plantas por metro quadrado do tipo folha larga e folha estreita.

As espécies de plantas daninhas coletadas nos quadros em cada parcela foram separadas em embalagens e levadas à uma estufa à temperatura de $105^{\circ} C$, durante três dias, até que o peso permanecesse constante, ou seja, até que toda a água tivesse sido extraída das plantas. Neste ponto, a biomassa das plantas daninhas, definida como a matéria seca da parte aérea das plantas por metro quadrado, é medida. 
Como a área é cultivada em sistema de plantio direto, o banco de sementes pode conter sementes de outras espécies de plantas daninhas, diferentes das espécies que estão sobre o solo, o que não acontece em plantio convencional no qual o solo é revolvido. Desta forma, as sementes do banco de sementes de um sistema de plantio direto dificilmente germinarão pela dificuldade de virem à tona. Portanto, as sementes que indicam a probabilidade de infestação da geração seguinte correspondem às sementes presentes nas plantas daninhas, que cairão sobre o solo ${ }^{2}$, ou seja, a produção de sementes. Uma porcentagem destas sementes germinam e constituem a próxima geração de plantas. Portanto, foi coletada nas parcelas, em 2005 e em 2006, a produção de sementes de cada espécie de planta daninha encontrada e, multiplicando a produção de cada espécie na parcela pela sua respectiva densidade de planta encontrada nos quadros, a produção de sementes total por metro quadrado de cada parcela é obtida.

Em abril de 2005 e em novembro de 2006 o milho foi colhido manualmente. Os grãos foram separados e pesados. Foi feita também a colheita do milho para todas as plantas nas parcelas testemunhas, onde há aplicação de herbicida. Da mesma forma que nas outras parcelas os grãos foram separados e pesados e os rendimentos foram obtidos pela massa calculada. Os valores das massas dos grãos são ajustados para a umidade de $13 \%$ e as unidades foram convertidas de $\mathrm{gm}^{-2}$ para $\mathrm{kgha}^{-1}$. Na primeira colheita, em 2005, foram coletadas espigas de dez plantas em cada parcela. Com a massa dos grãos obtida para dez plantas foi estimada a massa em cada parcela. Uma vez que o rendimento foi calculado a partir de uma estimativa das massas dos grãos para as parcelas experimentais ao invés da massa propriamente dita, como foi feita nas parcelas testemunhas, foi adotada uma depreciação da massa dos grãos nas parcelas experimentais com base em uma análise da cobertura foliar e da densidade das plantas daninhas em cada parcela. Os valores de perda de rendimento são obtidos com o cálculo da perda de rendimento relativa dada por

$$
P_{R R_{i}}=\frac{R_{0}-R_{i}}{R_{0}}, i=1, \ldots, 41
$$

onde $R_{0}$ é o máximo rendimento das parcelas testemunhas, e $R_{i}$ é o rendimento de cada parcela experimental.

\footnotetext{
${ }^{2}$ Fenômeno conhecido como chuva de sementes
} 


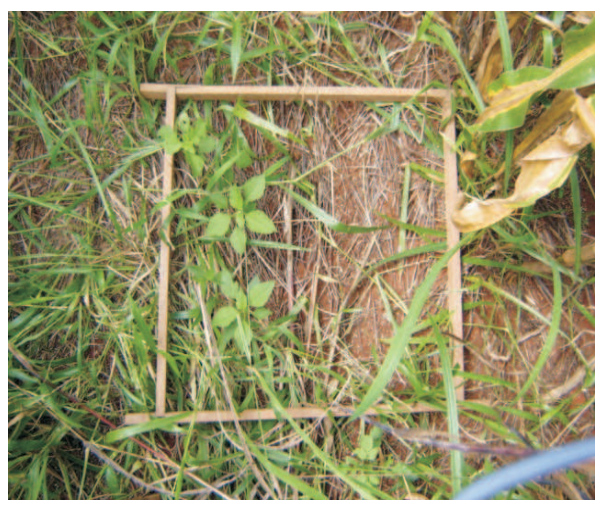

Figura 3.3: Quadro utilizado em campo para coletar amostras de plantas daninhas.

\subsection{Principais Espécies Encontradas}

Dentre as plantas daninhas mais frequentes coletadas em campo, pode-se destacar suas principais características (Lorenzi, 2000):

- Mentrasto: planta anual, ereta, ramificada, com caules revestidos de pelos alvos, de 30 a $80 \mathrm{~cm}$ de altura, nativa da América do Sul. Propaga-se exclusivamente por sementes, infestando tanto lavouras anuais como perenes, hortas e terrenos baldios. Uma única planta chega a produzir 40 mil sementes.

- Capim colchão: planta anual e subereta, de 40 a $80 \mathrm{~cm}$ de altura, propaga-se exclusivamente por sementes. É uma planta daninha medianamente frequente nas regiões mais tropicais do território brasileiro, onde infesta lavouras anuais e perenes, beira de estradas e terrenos baldios. Prefere solos férteis, formando infestações densas.

- Capim marmelada: planta anual, ereta, de 50 a $80 \mathrm{~cm}$ de altura, mais frequentes nos solos cultivados das regiões Centro e Sul do país. Propaga-se apenas por sementes, infesta todas as culturas, sendo mais importante em lavouras de milho e soja. Vegeta somente no período quente do ano.

- Trapoeraba: planta perene, semi prostrada, de 30 a $70 \mathrm{~cm}$ de altura. Propaga-se por sementes normais e por sementes especiais formadas nos rizomas. Infestante de lavouras anuais e perenes, hortas, margens de canais e terrenos baldios de todo o país. Apresenta preferência por solos férteis, com boa umidade e sombreados, como o milho. 
- Capim guiné: planta perene e robusta, de 1 a $2 m$ de altura, originária da África. Propaga-se por sementes e rizomas, infestando beira de estradas e solos cultivados. Muito vigorosa e de grande porte, interfere significativamente com a culturas infestadas.

- Picão preto: planta anual, ereta, de 40 a $120 \mathrm{~cm}$ de altura e com odor característico. Propaga-se apenas por sementes, sendo uma das mais sérias infestantes encontradas em lavouras anuais e perenes do Centro-Sul do país. Muito prolífera e de geração curta, é capaz de produzir até três gerações por ano.

- Leiteiro: planta anual, ereta, leitosa e de folhas variáveis, de 30 a $80 \mathrm{~cm}$ de altura. Propaga-se por sementes e é bastante frequente em todo o país. É mais temida pelos plantadores de soja devido a dificuldade de controle. Suas sementes germinam durante o verão, emergindo de até $12 \mathrm{~cm}$ de profundidade e mantendo sua viabilidade germinativa por alguns anos.

- Sorgo selvagem: planta anual ou perene, ereta e propaga-se exclusivamente por meio de sementes. É uma planta daninha medianamente frequente em quase todo o país, infestando principalmente lavouras perenes, beira de estradas e terrenos baldios. É uma planta de introdução recente e que vem aumentando sua área infestada ano após ano. É ocasionalmente utilizada como forrageira.

- Caruru: planta anual e ereta, muito ramificada, de 50 a $100 \mathrm{~cm}$ de altura, originária da América Tropical. Propaga-se exclusivamente por sementes. É uma planta bastante frequente e típica de solos cultivados. Infesta principalmente culturas anuais, pomares e hortas caseiras, possuindo grande capacidade reprodutiva. É hospedeiro de nematóides e vírus, mas também pode ser utilizada como alimento.

As espécies de plantas daninhas encontradas nas 41 parcelas experimentais identificadas pelo tipo de folha, larga e estreita, são relacionadas na Tabela 3.1.

A porcentagem de ocorrência de cada planta daninha coletada nas parcelas pode ser observada no gráfico da Figura 3.5. O mentrasto (folha larga) e o capim colchão (folha estreita) foram as plantas que apresentaram maior número de indivíduos nas parcelas percorridas, resultando cerca de $25 \%$ e $22 \%$ de ocupação, respectivamente. A Figura 3.4 exibe o mentrasto e o capim colchão. 
Tabela 3.1: Espécies de plantas daninhas encontradas nas parcelas experimentais.

\begin{tabular}{c|c} 
Folha Larga & Folha Estreita \\
\hline caruru branco (Amaranthus hybridus) & timbête (Cenchrus echinatus L.) \\
picão preto (Bidens pilosa) & sorgo selvagem (Sorghum arundinaceum) \\
trapoeraba (Commelina benghalensis) & braquiária (Brachiaria decumbens) \\
mentrasto (Ageratum conyzoides) & capim colchão (Digitaria ciliaris) \\
erva de touro (Tridax procumbens) & capim guiné (Panicum maximum) \\
erva de santa luzia (Euphorbia hirta L.) & capim marmelada (Brachiaria plantaginea) \\
erva quente (Spermacoce latifolia) & pé de galinha (Eleusine indica) \\
poaia (Richardia brasiliensis) & tiririca (Cyperus rotundus) \\
botão de ouro (Melampodium perfoliatum) & \\
leiteiro (Euphorbia heterophylla) & \\
\hline
\end{tabular}
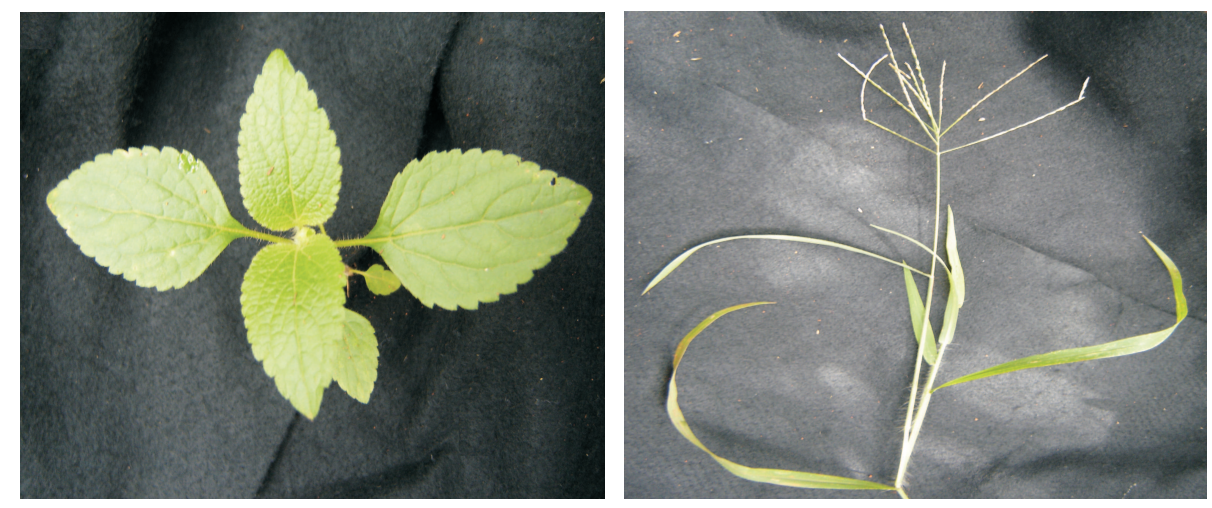

Figura 3.4: Plantas daninhas: mentrasto (esquerda) e capim colchão (direita).

As parcelas que se localizam na periferia da cultura apresentam maior número de espécies de plantas daninhas por possuírem maior incidência de luz. Este fato pode ser verificado pelo gráfico da Figura 3.6. A última coluna do gráfico representa a somatória das parcelas que contêm menos de $2 \%$ de plantas daninhas do total da cultura.

No próximo capítulo é introduzida a teoria de Geoestatística, que considera a variabilidade espacial e a dependência dos dados. São definidos os conceitos de variograma e o método de estimação por Krigagem, bem como da validação cruzada, procedimento que avalia a qualidade da estimação. 

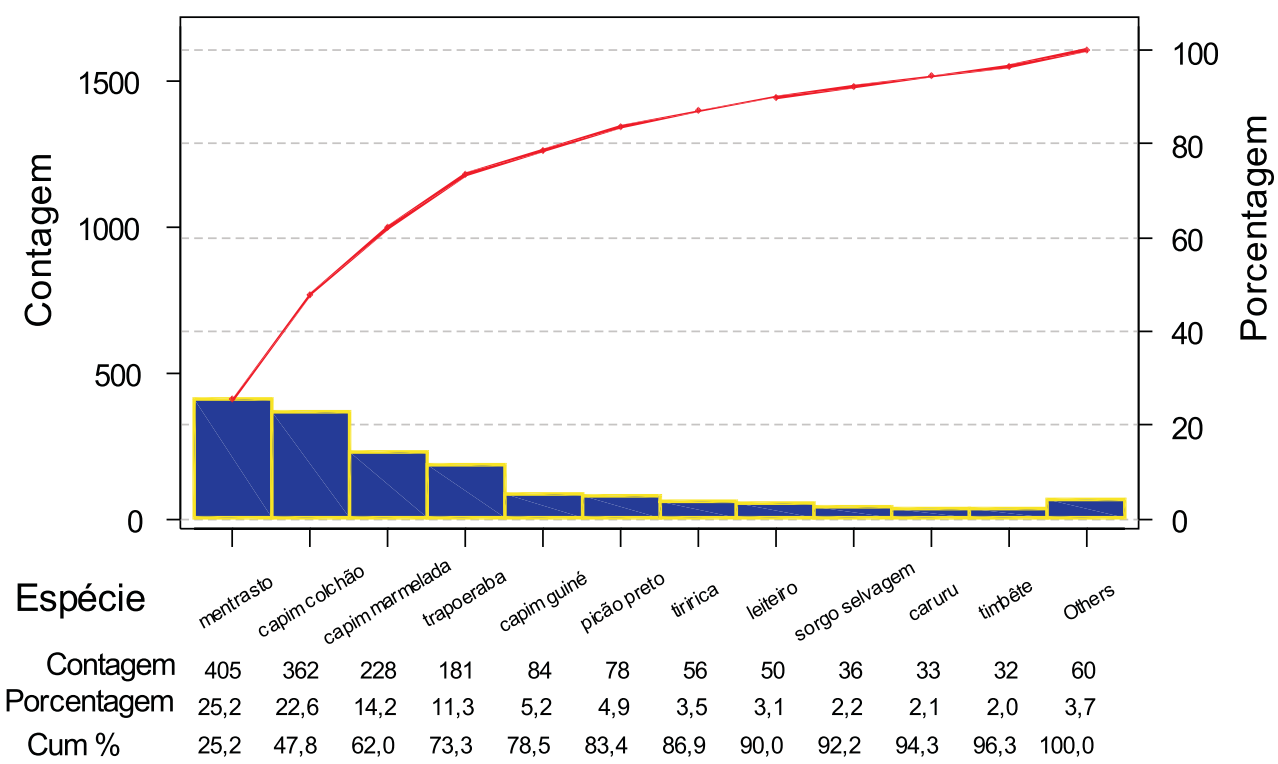

Figura 3.5: Contagem de espécies de plantas daninhas nas parcelas.

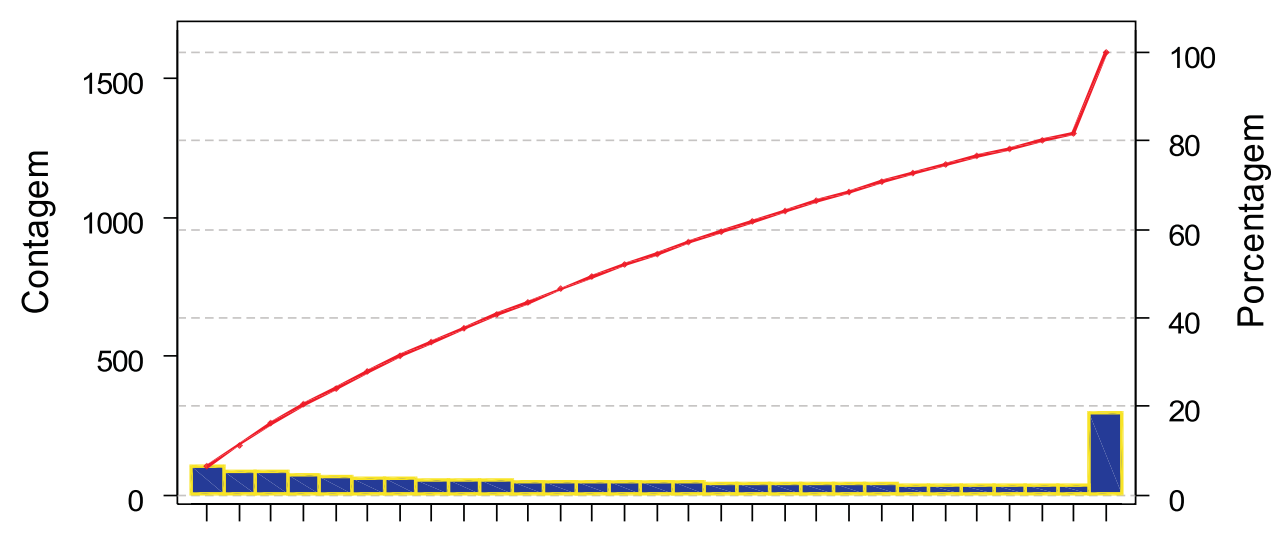

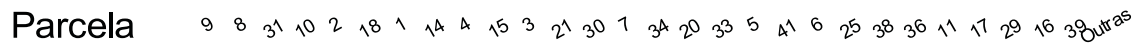

Contagem $98 \quad 797966 \quad 6059575149 \quad 48 \quad 46 \quad 46 \quad 45 \quad 43 \quad 42 \quad 41 \quad 38 \quad 37 \quad 37 \quad 35 \quad 35 \quad 35 \quad 34 \quad 292929 \quad 28 \quad 28292$

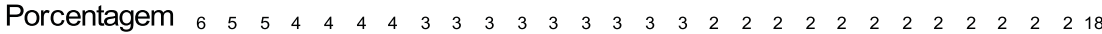
Acumulado $\quad \begin{array}{llllllllllllllllllllllllllll}6 & 11 & 16 & 20 & 24 & 28 & 31 & 34 & 37 & 41 & 43 & 46 & 49 & 52 & 54 & 57 & 59 & 62 & 64 & 66 & 68 & 71 & 73 & 75 & 76 & 78 & 80 & 82100\end{array}$

Figura 3.6: Número de plantas daninhas por parcela. 


\section{Capítulo 4}

\section{Geoestatística e Modelos de Populações de Plantas}

Atualmente, as técnicas de interpolação têm sido utilizadas em agricultura de precisão para inferir valores em locais não amostrados. A agricultura de precisão fundamentase na coleta sistemática e no processamento de dados georreferenciados para produzir informações que permitam manter os processos produtivos sob controle, orientando-os ao aprimoramento contínuo. Dentro desse contexto objetiva-se utilizar técnicas de estimação a partir de elementos pontuais, de localização conhecida, com a finalidade de obter mapas para que os profissionais da área da agricultura tenham ferramentas precisas de auxílio ao processo de tomada de decisão. Estes mapas constituem ferramentas necessárias para o cálculo dos atributos da infestação, que são entradas do sistema de classificação fuzzy desenvolvido neste trabalho.

O controle de plantas daninhas pode ser feito de acordo com a abordagem da Agricultura de Precisão desde que sejam conhecidas as áreas que necessitem de aplicação de herbicidas. Nesse sentido, é feito o mapa dessas plantas para aplicação posterior de herbicida (Imai et al., 2003). Nesse caso, necessita-se que amostras sejam coletadas em campo, o que para uma grande área se torna difícil e dispendioso, como no caso de contagem de plantas daninhas. Assim, torna-se indispensável realizar inferências em locais onde não foram obtidas informações.

Quando uma determinada propriedade ou parâmetro varia de um local para outro com algum grau de organização ou continuidade, expresso através de dependência espa- 
cial, a estatística tradicional deve ser complementada pela geoestatística (Vieira, 2000). A geoestatística estima valores cujo objeto em estudo apresenta distribuição no espaço e, desse modo, supõe que os valores das variáveis, consideradas como regionalizadas, sejam espacialmente correlacionados.

A teoria geoestatística difere da estatística clássica, basicamente, na forma de avaliar a variação dos dados. Por estatística clássica entende-se aquela que assume que a variabilidade do valor de uma propriedade do solo em torno da média é aleatória e independente da posição espacial dos dados coletados. No entanto, a variabilidade de propriedades do solo é espacialmente dependente, ou seja, dentro de um certo domínio, as diferenças entre os valores de uma propriedade do solo podem ser expressas em função da sua distância de separação (Exposito et al., 2004; Wallinga et al., 1998; Isaaks e Srivastana, 1989). Consequentemente, os valores em locais mais próximos entre si são mais semelhantes, até um determinado limite, que aqueles tomados a maiores distâncias. Desta forma, cada valor carrega consigo uma forte interferência dos valores de sua vizinhança, ilustrando a continuidade espacial (Isaaks e Srivastana, 1989). Consequentemente, os dados provenientes do solo não podem ser tratadas como independentes e um tratamento estatístico mais adequado, que considere a dependência espacial e a localização geográfica, se faz necessário (Vieira, 2000).

A base da geoestatística vem da teoria das variáveis regionalizadas que são distribuídas no espaço (ou tempo) e cujos valores são considerados como realizações de uma função aleatória. Considera-se aspectos espaciais, ou seja, as posições relativas onde foram coletados os diversos valores a serem utilizados nos modelos. As variáveis regionalizadas possuem características qualitativas estreitamente ligadas à estrutura do que representam, tais como, a localização e a continuidade.

A teoria das variáveis regionalizadas foi elaborada a partir do pressuposto que uma variável pode ser expressa pela soma de três componentes:

1. componente estrutural associada a um valor médio constante ou a uma tendência constante.

2. componente aleatória espacialmente correlacionada.

3. ruído aleatório ou erro residual. 
Desta forma, se $i$ representa uma posição então o valor de uma variável $Z$ em $i$ é dado por:

$$
Z(i)=m(i)+e^{\prime}(i)+e^{\prime \prime}
$$

onde $m(i)$ é uma função determinística que descreve a componente estrutural de $Z$ em $i, e^{\prime}(i)$ é um processo estocástico que varia localmente e depende espacialmente de $m(i)$ e $e^{\prime \prime}$ é o ruído aleatório não correlacionado, que segue distribuição normal com média zero e variância $\sigma^{2}$.

De uma forma geral, a metodologia geoestatística procura extrair, de uma aparente aleatoriedade dos dados, as características estruturais probabilísticas do fenômeno regionalizado, ou seja, uma função de correlação entre os valores situados numa determinada vizinhança e direção no espaço amostral. O método de estimativa básico utilizado é o da Krigagem (Isaaks e Srivastana, 1989), que consiste de uma técnica de interpolação que faz ótima a estimação de variáveis regionalizadas, utilizando parâmetros dos chamados variogramas (descritos na Seção 4.2) e os valores das amostras (Shiratsuchi e Christoffoleti, 2001). A existência ou não de continuidade espacial e, se houver, quais os parâmetros que caracterizam este comportamento regionalizado, são verificados pela análise variográfica, descrita a seguir.

\subsection{Análise Variográfica}

As ferramentas da geoestatística permitem a análise de dependência espacial, a partir do ajuste de variogramas experimentais a uma função simples, segundo um modelo matemático, e a caracterização da variabilidade espacial, por meio dos mapas da variabilidade a partir da estimativa não enviesada de valores das variáveis em locais não amostrados. Com a utilização destas ferramentas pode-se analisar dados experimentais, com a possibilidade de obter informações não reveladas pela estatística clássica. Para o ajuste de variogramas a normalidade dos dados não é necessária, mas desejável. Caso a distribuição não seja normal, mas seja razoavelmente simétrica, pode-se admitir as hipóteses necessárias à construção do variograma. Os cálculos utilizados em geoestatística não requerem o conhecimento da distribuição de freqüências da variável analisada (Vieira, 1995). 
A estimativa da dependência entre amostras vizinhas no espaço pode ser realizada através da autocorrelação que é de grande utilidade quando se está fazendo amostragem em uma direção. Quando a amostragem envolve duas direções o instrumento mais indicado na estimativa da dependência entre amostras é a análise variográfica, a qual analisa o grau de dependência espacial entre amostras dentro de um campo experimental, e define parâmetros necessários para a estimativa de valores para locais não amostrados, através da técnica de Krigagem (Isaaks e Srivastana, 1989).

$\mathrm{Na}$ teoria das variáveis regionalizadas, $Z(i)$ pode ser definida como uma variável aleatória que assume diferentes valores $Z$ em função da posição $i$ dentro de uma certa região, com certa aparência de continuidade. O conjunto de variáveis $Z(i)$ medidas em toda a área pode ser considerado uma função aleatória $Z(i)$, uma vez que são variáveis aleatórias, regionalizadas e considera-se que a dependência entre estas é regida por algum mecanismo probabilístico (Isaaks e Srivastana, 1989).

Desta forma, seja $z(i)$ o valor coletado de uma variável em uma localização $i$ e $z(i+h)$ o valor da mesma variável em um ponto distante $h$ da anterior, sendo $h$ também um par de coordenadas representando uma distância de $i$. Geralmente, são muitas as localizações que distam $h$ entre si. Uma forma de mostrar as similaridades ou as diferenças entre os valores é mediante um gráfico que represente os valores de $z(i)$ frente aos $z(i+h)$, denominado gráfico de dispersão-h. Se os valores são parecidos, a nuvem de dados estará próxima à bissetriz do primeiro quadrante, existindo uma autocorrelação nessa variável. Com distâncias $h$ reduzidas, a nuvem de dados se dispõem muito próximas da bissetriz, aumentando a dispersão a medida que $h$ cresce. Isto coincide com a idéia intuitiva que as amostras mais próximas são mais parecidas entre si (Isaaks e Srivastana, 1989).

Se a distância $h$ for pequena, uma dada realização da variável regionalizada $z(i)$ ficará mais próxima de uma outra realização $z(i+h)$, proporcionando uma variabilidade pequena e consequentemente, características regionais semelhantes. Caso contrário, a medida que a distância entre as unidades amostrais aumenta, a variabilidade também aumenta, pois ocorre progressivamente maior independência entre os pontos. Assim, o valor absoluto da diferença entre duas amostras deve crescer à medida que aumenta a distância entre estas, até um valor no qual os efeitos locais não têm mais influência.

O variograma mostra a medida do grau de dependência espacial entre amostras e 
para sua construção são usadas simplesmente as diferenças ao quadrado de pares dos valores obtidos, supondo uma estacionariedade nos incrementos. Supondo que no local $i$ onde cada $i$ representa um par de coordenadas $(x, y), z(i)$ é o valor coletado para um atributo do solo e para o local $i+h$ o valor $z(i+h)$ para o mesmo atributo, a variância para este par de valores é a soma do quadrado da diferença de cada valor com a média $\bar{z}:$

$$
S^{2}=[z(i)-\bar{z}]^{2}+[z(i+h)-\bar{z}]^{2} .
$$

Desenvolvendo-se esta equação, onde a média $\bar{z}=[z(i)+z(i+h)] / 2$, obtêm-se:

$$
S^{2}=1 / 2[z(i)-z(i+h)]^{2}
$$

Esta é a variância para esse par de dados. Se houver $N$ pares de dados separados pela distância $h$, tem-se então a equação do variograma experimental ${ }^{1}$ :

$$
\gamma^{*}(h)=\frac{1}{2 N_{h}} \sum_{(i, j) \mid h_{i j}=h}[Z(j)-Z(i)]^{2},
$$

onde $i$ e $j$ representam a localização $i$ e $j$, respectivamente, $Z(i)$ é o valor da variável na localização $i, h_{i j}$ é o vetor que vai do ponto $i$ ao ponto $j$ e $N_{h}$ é o número de pares de pontos cujas localizações são separadas por $h$. Também chamado de semivariância, $\gamma^{*}$ é o valor do variograma e mede o grau de dependência espacial entre os dados.

Cada ponto do variograma experimental dado por (4.1) representa pares de pontos igualmente espaçados. Normalmente, o variograma é uma função monótona crescente, alcançando um valor limite, obtido para um valor de $h$ conhecido como alcance. Os dados correspondentes à distâncias maiores que este alcance possuem correlação nula. Desta forma, a dependência espacial diminui a medida que a distância $h$ aumenta e se anula a uma certa distância, após o alcance.

O variograma expressa o comportamento espacial da variável regionalizada basicamente por três parâmetros:

\footnotetext{
${ }^{1}$ Como no cálculo do variograma a somatória de diferenças ao quadrado é dividida por $2 *$ número de pares de valores, o termo correto seria semivariograma, porém é usual o emprego do termo variograma (Landim e Sturaro, 2002).
} 
1. O alcance (range) indica a distância até a qual os dados apresentam correlação espacial. Para distâncias maiores que o alcance, não se pode garantir a dependência espacial entre os dados. Desta forma, todo dado cuja distância ao ponto a ser estimado for menor ou igual ao alcance fornece informações sobre o ponto.

2. O patamar $(C+C 0)$ é o valor da assíntota do modelo ajustado aos dados. Indica o valor em que a função se estabiliza no campo aleatório. É o valor do variograma correspondente a seu alcance. Deste ponto em diante, considera-se que não existe mais dependência espacial entre as amostras, porque a variabilidade da diferença entre pares de amostras torna-se aproximadamente constante.

3. O intercepto representa o valor no variograma para $h=0$. Idealmente, $\hat{\gamma}(0)=0$. Entretanto, na prática, à medida que $h$ tende para zero, $\hat{\gamma}(h)$ se aproxima de um valor positivo chamado Efeito Pepita $(\mathrm{C} 0)$, que revela a descontinuidade do variograma para distâncias menores do que a menor distância entre os dados. O efeito pepita representa a componente da variabilidade espacial que não pode ser relacionado com uma causa específica. Parte desta descontinuidade pode ser também devida a erros de medição, sendo impossível quantificar se a maior contribuição provem dos erros de medição ou da variabilidade de pequena escala não captada pela amostragem.

Amostras separadas por distâncias menores do que o alcance, são espacialmente dependentes, enquanto aquelas separadas por distâncias maiores, não são, ou seja, um variograma igual à variância dos dados implica em variação aleatória. É necessário verificar se o variograma estabiliza-se ou não em um patamar com o aumento de $h$, quando isto não ocorre há evidências de não estacionariedade e de uma tendência dos dados.

Uma vez definidos os pontos experimentais do variograma, gerados por (4.1), estes pontos são ajustados a um modelo de variograma teórico. Este modelo teórico é uma curva que proporciona a máxima correlação com os pontos experimentados. Dependendo do comportamento do variograma para grandes valores de $h$, o modelo a ser usado pode ser classificado em duas categorias: modelo sem patamar e modelo com patamar. Os modelos com patamar normalmente representam a estacionariedade de segunda ordem, onde o valor do variograma aumenta com o aumento da distância entre amostras, 
até atingir o patamar, onde se estabiliza. Segundo (Vieira, 1995), a estacionariedade de segunda ordem se verifica quando a função aleatória atende a estacionariedade de primeira ordem, onde o valor esperado da função aleatória é o mesmo para toda a área, independente da posição que ocupa ou da distância de separação $h$, e a covariância espacial, para cada par de valores $z(i), z(i+h)$ separados por uma distância $h$, é igual em toda a área estudada e depende apenas de $h$. Já os modelos sem patamar satisfazem apenas uma hipótese intrínseca e os variogramas podem ser ajustados mas não se estabilizam em nenhum patamar (Isaaks e Srivastana, 1989). Esta hipótese intrínseca considera que a média dos valores $z(i)$ e a variância dos incrementos $z(i)-z(i+h)$ são funções apenas do valor de $h$.

Existem diversos modelos teóricos de variograma com patamar, mas os mais utilizados são o esférico, o gaussiano e o exponencial, apresentados respectivamente por (4.2), (4.3), (4.4). Ao fazer a escolha do modelo teórico e de seus parâmetros (patamar e alcance), a interpolação por Krigagem será baseada nos valores estimados pelo modelo escolhido. Embora seja possível criar novos modelos de ajuste, não vale a pena o esforço, pois as funções seguintes são suficientes para permitir um ajuste satisfatório para a maioria dos variogramas experimentais encontrados na prática (Isaaks e Srivastana, 1989).

Modelo Esférico (de Matheron)

$$
\gamma(h)=\left\{\begin{array}{r}
C_{0}+C\left[1,5 \frac{h}{a}-0,5\left(\frac{h}{a}\right)^{3}\right], 0<h \leq a \\
C_{0}+C, h>a
\end{array}\right.
$$

Modelo Gaussiano (ou Parabólico)

$$
\gamma(h)=\left\{\begin{array}{r}
C_{0}+C\left[1-\exp \left(\frac{-h^{2}}{a^{2}}\right)\right], 0<h \leq a \\
C_{0}+C, h>a
\end{array}\right.
$$

Modelo Exponencial (de Formery)

$$
\gamma(h)=\left\{\begin{array}{r}
C_{0}+C\left[1-\exp \left(\frac{-h}{a}\right)\right], 0<h \leq a \\
C_{0}+C, h>a
\end{array}\right.
$$

onde 
$C_{0}:$ efeito pepita;

$C$ : variância espacial;

$h:$ passo básico;

$a$ : alcance;

Para que os parâmetros do variograma possam ser visualizados graficamente, a Figura 4.1 exibe como exemplo o modelo exponencial descrito por (4.4) com possíveis valores para os parâmetros citados.

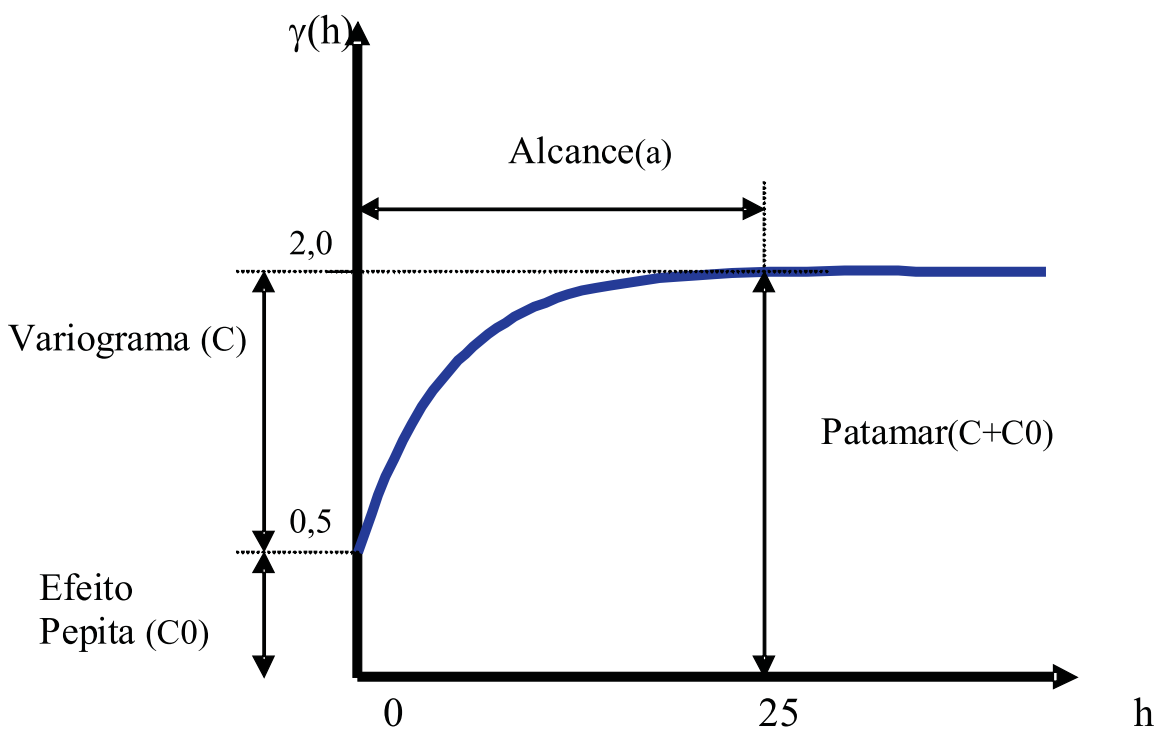

Figura 4.1: Modelo variográfico exponencial.

Na prática, pode-se fazer a hipótese adicional de que o fenômeno é isotrópico, ou seja, com comportamento igual em todas as direções (Vieira, 1995). Desta forma, a determinação experimental do variograma depende apenas da distância entre as amostras e não da direção relativa entre estas. Outra hipótese seria a anisotropia, a qual considera que a estrutura espacial varia conforme a direção.

O estudo da estrutura espacial dada pela análise variográfica não constitui o objetivo final da análise espacial. É necessário estimar valores das variáveis em locais não amostrados visando o conhecimento da distribuição espacial de certa variável em estudo. Desta forma, a análise da estrutura espacial deve ser vista como um passo fundamental, mas não final, que precede as técnicas de estimação, de qualquer valor em qualquer posição da área em estudo, sem tendência e com variância mínima (Carvalho 
e Vieira, 2001).

Identificando-se a dependência espacial após a análise dos variogramas, pode-se obter estimadores de valores da propriedade em estudo para locais não amostrados, não enviesados e com a variância mínima através da Krigagem.

\subsection{O Estimador de Krigagem}

Como já mencionado, o método de estimação geoestatístico é conhecido como Krigagem, nomeado em homenagem a Danie Krige, que formulou pela primeira vez esta metodologia em 1951 (Brooker, 1979). A Krigagem é um método fundamentado na teoria das variáveis regionalizadas, que usa informações a partir do variograma para encontrar os pesos ótimos a serem associados aos dados com valores conhecidos os quais irão estimar pontos desconhecidos. Em outras palavras, a Krigagem é um processo de estimativa semelhante ao de interpolação por média móvel ponderada, porém na Krigagem os pesos dados a cada dado são determinados a partir de uma pré-análise espacial utilizando os variogramas, que determinam a dependência espacial entre as amostras. Desta forma, a Krigagem leva em consideração as características espaciais de autocorrelação de variáveis regionalizadas, as quais devem apresentar uma certa continuidade espacial, permitindo que os dados obtidos por amostragem de certos pontos possam ser usados para parametrizar a estimativa de pontos onde o valor da variável seja desconhecido. Os passos num estudo empregando técnicas de Krigagem incluem: análise exploratória dos dados; análise estrutural (modelagem da estrutura de correlação espacial); interpolação estatística da superfície.

Os mapas gerados por métodos convencionais de estimação podem oferecer resultados diferentes, dependendo do método utilizado. Alguns destes métodos foram comparados em Tieppo et al. (2001), e constatou-se que o método do vizinho mais próximo é o que pior representa a variabilidade espacial de uma determinada variável; por isso, não é aconselhável utilizá-lo para estimativa de variáveis. Concluiu-se também que o método do inverso da distância ao quadrado pode ser uma opção de interpolador a ser utilizado em monitores de colheita, uma vez que os dados são coletados em pequenos intervalos de tempo, com pontos amostrais bem próximos entre si, mas não é indicado para ser utilizado com pontos amostrais mais distantes. A Krigagem apresenta mel- 
hores resultados de estimação para valores de variáveis em locais não amostrados do que as técnicas normalmente usadas para classificação de solo, devido à maneira pela qual as variáveis regionalizadas interpretam a natureza da variação dos atributos do solo (Carvalho e Vieira, 2001). As principais características que fazem a Krigagem ser um método de estimação superior aos tradicionais são:

- Os métodos convencionais utilizam o conceito Euclidiano da distância para o cálculo dos pesos atribuídos aos dados, enquanto a Krigagem considera tanto a distância como a geometria da localização dos dados. Assim, os vizinhos agrupados têm importância individual relativamente menor do que aqueles isolados.

- Mediante a Krigagem, é minimizada a variância do erro esperado (diferença entre o valor real e o valor estimado).

- Os métodos geoestatísticos mostram uma grande flexibilidade para a interpolação, podendo-se estimar valores pontuais ou em blocos. Todos estes métodos dão lugar a superfícies suaves e a estimação da variância em todos os pontos, o que não pode ser realizado com outros métodos de interpolação.

- A Krigagem estima uma matriz de covariância espacial que determina os pesos atribuídos às diferentes amostras. Os pesos são atribuídos de acordo com a variabilidade espacial expressa no variograma. No entanto, o que torna a Krigagem um interpolador ótimo é a maneira como os pesos são distribuídos e a minimização da variância (Vieira, 1995). A partir dos pontos dados, estima-se o ponto não amostrado por meio da média móvel ponderada dos valores vizinhos observados, obtendo-se diferentes pesos para os dados.

Desta forma, a Krigagem é uma técnica usada na geoestatística com o objetivo de estimar valores de variáveis para locais onde as mesmas não foram medidas a partir de valores adjacentes interdependentes. Para que esta ferramenta seja usada é necessário que exista a dependência espacial definida pelo variograma.

Para a definição dos estimadores de Krigagem considera-se a situação de estimar o valor de uma variável $Z$ para qualquer local não amostrado $u$, usando os dados de $Z$ que foram coletados na área de estudo. Os estimadores de Krigagem são variantes do estimador básico de regressão linear $Z^{*}(u)$, que é definido por: 


$$
Z^{*}(u)-m(u)=\sum_{i=1}^{N} \lambda_{i}(u)\left[Z\left(u_{i}\right)-m\left(u_{i}\right)\right]
$$

onde $\lambda_{i}(u)$ são os pesos dos dados $z\left(u_{i}\right)$ interpretados como uma realização da variável aleatória $Z\left(u_{i}\right)$. As quantidades $m(u)$ e $m\left(u_{i}\right)$ são os valores esperados das variáveis aleatórias $Z(u)$ e $Z\left(u_{i}\right)$. A interpretação de $z(u)$ e $z\left(u_{i}\right)$ como realizações das variáveis aleatórias $Z(u)$ e $Z\left(u_{i}\right)$ permitem a definição do erro de estimação como uma variável aleatória $Z^{*}(u)-Z(u)$. A estimação por Krigagem baseia-se na minimização da variância do erro $\sigma_{\varepsilon}^{2}(u)$ supondo que o estimador é não enviesado, ou seja:

$$
\min \sigma_{\varepsilon}^{2}(u)=\operatorname{var}\left\{Z^{*}(u)-Z(u)\right\}
$$

Espera-se que o erro de estimação seja mínimo, isto é:

$$
E\left\{Z^{*}(u)-Z(u)\right\}=0 .
$$

A variável aleatória $Z(u)$ é usualmente decomposta em um componente residual $R(u)$ e a média $m(u)$, ou seja:

$$
Z(u)=R(u)+m(u) .
$$

O resíduo é modelado como uma função aleatória estacionária com média zero e covariância $C_{R}(h)$, ou seja:

$$
\begin{gathered}
E\{R(u)\}=0 \\
C_{R}(h)=\operatorname{cov}\{R(u), R(u+h)\}=E\{R(u) R(u+h)\} .
\end{gathered}
$$

O valor esperado de $Z$ no local $u$ é o valor da média neste local, isto é:

$$
E\{Z(u)\}=m(u) .
$$


Os estimadores de Krigagem se diferenciam conforme o modelo considerado para $m(u)$. As formas mais usuais de estimadores de Krigagem são a Krigagem simples, utilizada quando a média $m$ é considerada como estatisticamente constante para toda a área, a Krigagem ordinária, que considera a média flutuante (ou móvel) por toda a área e a Krigagem indicativa, onde o enfoque não é estimar um valor, como na Krigagem ordinária, mas sim definir áreas com maior ou menor probabilidade de ocorrência de um determinado evento. O método mais utilizado é a Krigagem ordinária, por considerar flutuações locais da média, limitando o domínio de estacionariedade da mesma a um âmbito local: $m(u)$ constante, mas desconhecida.

\subsubsection{Krigagem Simples}

A Krigagem simples considera a média $m(u)$ como conhecida e constante em toda a área de estudo. O estimador linear $Z_{K S}^{*}(u)$ é definido como:

$$
Z_{K S}^{*}(u)=\sum_{i=1}^{N} \lambda_{i}(u) Z\left(u_{i}\right)+\left[1-\sum_{i=1}^{N} \lambda_{i}(u)\right] m
$$

onde $m$ denota a média. Os $N$ pesos $\lambda_{i}(u)$ são determinados de tal forma que a variância do erro $\sigma_{\varepsilon}^{2}(u)=\operatorname{var}\left\{Z_{S K}^{*}(u)-Z(u)\right\}$ seja mínima e o estimador não enviesado.

\subsubsection{Krigagem Ordinária}

Na Krigagem ordinária as flutuações locais da média são consideradas, limitando o domínio de sua estacionariedade para a vizinhança local. Desta forma, a Krigagem ordinária é semelhante ao de interpolação por média móvel ponderada, porém os pesos de cada dado são determinados a partir de uma pré-análise espacial utilizando variogramas experimentais.

A Krigagem ordinária é linear porque suas estimativas são combinações lineares ponderadas dos dados, é não enviesada porque leva a média residual a zero e, além disso, minimiza a variância dos erros, o que a difere dos outros métodos de estimação (Isaaks e Srivastana, 1989).

O estimador linear é definido por (Carvalho e Vieira, 2001): 


$$
Z_{K O}^{*}(u)=\sum_{i=1}^{N} \lambda_{i}(u) Z\left(u_{i}\right)
$$

sujeito a

$$
\sum_{i=1}^{N} \lambda_{i}(u)=1
$$

onde os $N$ pesos $\lambda_{i}(u)$ são determinados de tal forma que a variância do erro seja mínima e $Z\left(u_{i}\right)$ são os dados de uma vizinhança que é usada para a obtenção de $Z(u)$. Se a soma dos pesos for igual a 1 e não ocorrer tendência local, esse estimador é o melhor e não enviesado, pois o que se pretende é, a partir dos pesos $\lambda_{i}, i=1,2, \ldots, N$, atribuídos a cada dado, minimizar a variância do erro denotada por $\sigma_{\varepsilon}^{2}$. A minimização de uma função de $n$ variáveis $\left(\lambda_{1}, \lambda_{2}, \lambda_{3}, \ldots \lambda_{N}\right)$ é usualmente realizada igualando as suas $N$ derivadas parciais primeiras a zero. Isto fornece um sistema de $N$ equações com $N$ incógnitas que pode ser resolvido por qualquer método para resolução de sistemas de equações lineares. Infelizmente, este procedimento não é correto para a minimização da expressão para o estimador da variância do erro $\tilde{\sigma}_{\varepsilon}^{2}$, pois tem-se uma restrição na solução. Isto significa que não se pode aceitar qualquer conjunto de $N$ pesos como solução, mas sim uma solução restrita, na qual a soma dos pesos é igual a 1. Tais problemas de otimizaçao restrita podem ser resolvidos pela técnica de Lagrange, pois igualando as $N$ derivadas primeiras de $\tilde{\sigma}_{\varepsilon}^{2}$ a zero, produzirá $N$ equações e $N$ incógnitas. A condição de ser não enviesado acrescenta uma outra equação sem adicionar qualquer outra variável. Isto produz um sistema de $N+1$ equações e apenas $N$ variáveis, cuja solução não é simples. Para resolver este problema, introduz-se uma outra variável na equação de $\tilde{\sigma}_{\varepsilon}^{2}$, chamada $\mu$, que é o parâmetro de Lagrange (Isaaks e Srivastana, 1989):

$$
\tilde{\sigma}_{\varepsilon}^{2}=\tilde{\sigma}^{2}+\sum_{i=1}^{N} \sum_{j=1}^{N} \lambda_{i} \lambda_{j} \gamma_{i j}-2 \sum_{i=1}^{N} \lambda_{i} \gamma_{i 0}+2 \mu\left(\sum_{i=1}^{N} \lambda_{i}-1\right),
$$

$\operatorname{com} \gamma_{i j}, i=1, \ldots, N$ o valor predito pelo modelo teórico de variograma, dado por $\gamma_{i j}=$ $C+C o-\gamma(h), \gamma_{i 0}$ o valor na posição em que se pretende estimar e $\tilde{\sigma}^{2}$ a variância da variável aleatória $Z$. Note que em (4.6) o termo $2 \mu\left(\sum_{i=1}^{N} \lambda_{i}-1\right)$ adicionado no final é zero, uma vez que devido à condição de não enviesado tem-se 


$$
\sum_{i=1}^{N} \lambda_{i}=1
$$

A adição do último termo em (4.6), que não afeta a igualdade, converte o problema de minimização restrita em um problema irrestrito. A variância do erro (4.6) é agora uma função de $N+1$ variáveis, que são os $N$ pesos e $\mu$. Igualando as $N+1$ derivadas parciais primeiras a zero em relação a cada uma dessas variáveis, obtém-se um sistema de $N+1$ equações e $N+1$ variáveis. Desta forma, a condição de ser não enviesado é satisfeita igualando a zero a derivada parcial primeira em relação a $\mu$. Os primeiros três termos de (4.6) não contém $\mu$, e não afetam a derivada com respeito a $\mu$, dada por:

$$
\frac{\partial\left(\tilde{\sigma}_{\varepsilon}^{2}\right)}{\partial \mu}=\frac{\partial 2 \mu\left(\sum_{i=1}^{N} \lambda_{i}-1\right)}{\partial \mu}=2 \sum_{i=1}^{N} \lambda_{i}-2 .
$$

Igualando (4.7) a zero, tem-se a condição de não enviesado:

$$
\sum_{i=1}^{N} \lambda_{i}=1
$$

que já está incluída nas $N+1$ equações resultantes das diferenciações de $\tilde{\sigma}_{\varepsilon}^{2}$. Logo, a solução destas $N+1$ equações produz o conjunto de pesos que minimiza $\tilde{\sigma}_{\varepsilon}^{2}$ sob a restrição de que estes pesos devem somar 1. Esta solução também fornece, além dos pesos, o valor do parâmetro de Lagrange $\mu$.

Em resumo, para minimizar $\tilde{\sigma}_{\varepsilon}^{2}$ em (4.6), calcula-se as $N+1$ derivadas parciais primeiras e iguala-se cada uma a zero. O cálculo da derivada em relação a $\lambda_{1}$ é feito com detalhes; as derivadas em relação aos outros pesos podem ser calculadas de maneira similar.

O primeiro termo do lado direito de (4.6) não depende de $\lambda_{1}$, e portanto não afeta a diferenciação. Expandindo o somatório duplo do segundo termo de (4.6) e abandonando os termos que não incluem $\lambda_{1}$, tem-se:

$$
\frac{\partial\left(\sum_{i=1}^{N} \sum_{j=1}^{N} \lambda_{i} \lambda_{j} \gamma_{i j}\right)}{\partial \lambda_{1}}=\frac{\partial\left(\lambda_{1}^{2} \gamma_{11}+2 \lambda_{1} \sum_{j=2}^{N} \lambda_{j} \gamma_{1 j}\right)}{\partial \lambda_{1}}
$$




$$
\begin{aligned}
& =2 \lambda_{1} \gamma_{11}+2 \sum_{j=2}^{N} \lambda_{j} \gamma_{1 j} \\
& =2 \sum_{j=1}^{N} \lambda_{j} \gamma_{1 j} .
\end{aligned}
$$

O terceiro termo do lado direito de (4.6) contém apenas um termo que envolve $\lambda_{1}$. Assim,

$$
\frac{\partial\left(\sum_{i=1}^{N} \lambda_{i} \gamma_{i 0}\right)}{\partial \lambda_{1}}=\frac{\partial \lambda_{1} \gamma_{10}}{\partial \lambda_{1}}=\gamma_{10}
$$

E a derivada do último termo de (4.6) em relação a $\lambda_{1}$ é dada por

$$
\frac{\partial\left(\mu\left(\sum_{i=1}^{3} \lambda_{i}-1\right)\right)}{\partial \lambda_{1}}=\frac{\partial\left(\mu \lambda_{1}\right)}{\partial \lambda_{1}}=\mu .
$$

Desse modo, a primeira derivada da variância da Krigagem (4.6) em relação a $\lambda_{1}$ pode ser escrita como:

$$
\frac{\partial\left(\tilde{\sigma_{\varepsilon}^{2}}\right)}{\partial \lambda_{1}}=2 \sum_{j=1}^{N} \lambda_{j} \gamma_{1 j}-2 \gamma_{10}+2 \mu .
$$

Finalmente, igualando (4.8) a zero, tem-se:

$$
2 \sum_{j=1}^{N} \lambda_{j} \gamma_{1 j}-2 \gamma_{10}+2 \mu=0
$$

$\mathrm{Ou}$

$$
\sum_{j=1}^{N} \lambda_{j} \gamma_{1 j}+\mu=\gamma_{10}
$$

Repetindo-se este processo para as derivadas parciais em relação a $\lambda_{2}, \ldots, \lambda_{N}$, obtémse as seguintes equações:

$$
\frac{\partial\left(\tilde{\sigma_{\varepsilon}^{2}}\right)}{\partial \lambda_{2}}=0 \text { o que fornece } \sum_{j=1}^{N} \lambda_{j} \gamma_{2 j}+\mu=\gamma_{20}
$$




$$
\frac{\partial\left(\tilde{\sigma_{\varepsilon}^{2}}\right)}{\partial \lambda_{i}}=0 \text { o que fornece } \sum_{j=1}^{N} \lambda_{j} \gamma_{i j}+\mu=\gamma_{i 0}
$$

$$
\frac{\partial\left(\tilde{\sigma_{\varepsilon}^{2}}\right)}{\partial \lambda_{N}}=0 \text { o que fornece } \sum_{j=1}^{N} \lambda_{j} \gamma_{N j}+\mu=\gamma_{N 0} .
$$

O conjunto de pesos que minimiza a variância do erro sob a restrição de que estes devem somar 1 satisfaz as seguintes $N+1$ equações (Isaaks e Srivastana, 1989):

$$
\sum_{j=1}^{N} \lambda_{j} \gamma_{i j}+\mu=\gamma_{i 0}
$$

sujeito a

$$
\sum_{i=1}^{N} \lambda_{i}=1
$$

onde

$\gamma_{i j}$ : valor predito pelo modelo teórico de variograma, dado a distância entre dados;

$\lambda_{i}$ : peso, a ser determinado, para cada interpolação.

Em notação matricial, pode-se escrever o seguinte sistema para obtenção dos pesos $\lambda_{i}, i=1, \ldots, N$ :

$$
A \lambda=B
$$

com

$$
A=\left[\begin{array}{cccc}
\gamma_{11} & \ldots & \gamma_{1 N} & 1 \\
\vdots & \ldots & \vdots & \vdots \\
\gamma_{N 1} & \ldots & \gamma_{N N} & 1 \\
1 & 1 & 1 & 0
\end{array}\right], \lambda=\left[\begin{array}{c}
\lambda_{1} \\
\vdots \\
\lambda_{N} \\
\mu
\end{array}\right], B=\left[\begin{array}{c}
\gamma_{10} \\
\vdots \\
\gamma_{N 0} \\
1
\end{array}\right]
$$

Finalmente, usando propriedades matriciais é possível encontrar os valores de $\lambda_{i}$ da seguinte forma: 


$$
\begin{gathered}
A \lambda=B \\
A^{-1} A \lambda=A^{-1} B \\
I \lambda=A^{-1} B \\
\lambda=A^{-1} B
\end{gathered}
$$

Exemplo 4.1 (Krigagem) Considere os pontos seguintes e suas respectivas coordenadas: $u_{0}=(50,100) ; u_{1}=(50,150) ; u_{2}=(100,200) ; u_{3}=(200,100) ; u_{4}=(0,50)$ Suponha que se deseja estimar o valor da variável $Z$ no ponto $u_{o}$, a partir de $Z\left(u_{1}\right), Z\left(u_{2}\right), Z\left(u_{3}\right)$ e $Z\left(u_{4}\right)$. Considere ainda, que o variograma experimental foi ajustado através de um modelo esférico, com $C=20$, efeito pepita $C_{0}=2$ e alcance $a=200$. Aplicando (4.9), tem-se:

$$
\left[\begin{array}{l}
\lambda_{1} \\
\lambda_{2} \\
\lambda_{3} \\
\lambda_{4} \\
\mu
\end{array}\right]=\left[\begin{array}{ccccc}
\gamma_{11} & \gamma_{12} & \gamma_{13} & \gamma_{14} & 1 \\
\gamma_{21} & \gamma_{22} & \gamma_{23} & \gamma_{24} & 1 \\
\gamma_{31} & \gamma_{32} & \gamma_{33} & \gamma_{34} & 1 \\
\gamma_{41} & \gamma_{42} & \gamma_{43} & \gamma_{44} & 1 \\
1 & 1 & 1 & 1 & 0
\end{array}\right]^{-1} \cdot\left[\begin{array}{c}
\gamma_{10} \\
\gamma_{20} \\
\gamma_{30} \\
\gamma_{40} \\
1
\end{array}\right]
$$

Os elementos da matriz são calculados da seguinte forma: $\gamma_{i j}=C+C_{0}-\gamma(h)$, $i, j=1,2,3,4$, onde $\gamma(h)$ segue o modelo esférico dado por (4.2) e h é o vetor distância entre os pontos $u_{i}$ e $u_{j}$. Então obtém-se:

$$
\gamma_{12}=\gamma_{21}=\gamma_{40}=C+C_{0}-\gamma(50 \sqrt{2})=20+2-\left[2+20\left(1,5 \frac{50 \sqrt{2}}{200}-0,5 \frac{(50 \sqrt{2})^{3}}{200^{3}}\right)\right]=
$$
9,84

$$
\begin{aligned}
& \gamma_{13}=\gamma_{31}=C+C_{0}-\gamma\left(\sqrt{150^{2}+50^{2}}\right)=1,23 \\
& \gamma_{14}=\gamma_{41}=\gamma_{20}=C+C_{0}-\gamma\left(\sqrt{100^{2}+50^{2}}\right)=4,98 \\
& \gamma_{23}=\gamma_{32}=C+C_{0}-\gamma\left(\sqrt{100^{2}+100^{2}}\right)=2,33 \\
& \gamma_{24}=\gamma_{42}=C+C_{0}-\gamma\left(\sqrt{150^{2}+100^{2}}\right)=0,29 \\
& \gamma_{34}=\gamma_{43}=C+C_{0}-\gamma\left(\sqrt{200^{2}+50^{2}}\right)=0
\end{aligned}
$$




$$
\begin{aligned}
& \gamma_{10}=C+C_{0}-\gamma(50)=12,66 \\
& \gamma_{30}=C+C_{0}-\gamma(150)=1,72 \\
& \gamma_{11}=\gamma_{22}=\gamma_{33}=\gamma_{44}=C+C_{0}-\gamma(0)=22
\end{aligned}
$$

Substituindo os valores de $\gamma_{i j}$ na matriz, encontra-se os seguintes pesos: $\lambda_{1}=$ $0,518, \lambda_{2}=0,022, \lambda_{3}=0,089$ e $\lambda_{4}=0,371$. Finalmente, o estimador de $u_{o}$ é dado por:

$$
Z_{K O}^{*}\left(u_{o}\right)=0,518 Z\left(u_{1}\right)+0,022 Z\left(u_{2}\right)+0,089 Z\left(u_{3}\right)+0,371 Z\left(u_{4}\right)
$$

\subsection{Validação Cruzada}

No ajuste de variogramas experimentais, sempre existe um certo grau de incerteza sobre as hipóteses de estacionariedade assumidas, modelos selecionados, parâmetros ajustados e qualidade da Krigagem. Esta incerteza representa o erro da estimativa que pode ser avaliado utilizando-se a estratégia da validação cruzada (Isaaks e Srivastana, 1989; Vieira et al., 1981), que permite avaliar a qualidade do método de estimação. A validação cruzada verifica a diferença entre o valor amostrado em um certo ponto e o valor que é estimado neste mesmo ponto, onde o dado é existente, com o auxílio dos demais valores amostrados. Para cada ponto da malha de dados é feita uma estimativa e, para tanto, um valor amostrado de uma localização é temporariamente descartado do conjunto de dados e efetua-se a Krigagem como se aquele ponto fosse desconhecido. Desse modo é possível calcular o resíduo, ou seja, calcular a diferença entre o valor observado e o estimado. Este procedimento é repetido para todos os valores amostrados.

Como a estimação por Krigagem está fortemente associada ao modelo de variograma escolhido, a validação cruzada pode ser usada para avaliar a qualidade do modelo ajustado (Vieira et al., 1981). Se o modelo variográfico adotado for correto, o processo de Krigagem estima valores adequados e uma análise residual pode comprovar este fato. Se o resíduo for positivo, significa que foi obtida uma superestimativa para o valor amostrado e, se for negativo, foi obtida uma subestimativa para o valor amostrado. Desta forma, deseja-se que estas estimativas sejam balanceadas, resultando que os resíduos devem apresentar média próxima a zero e comportamento probabilístico normal. Para verificar isto, é construído o intervalo de confiança para a média dos resíduos, 
testando a hipótese desta média ser igual a zero ou não. Outra característica que os resíduos devem apresentar para que haja uma boa estimativa é apresentar variância constante, pois atendendo a esta propriedade, pode-se afirmar que os resíduos apresentam estatisticamente o mesmo tamanho.

Para verificar se os resíduos seguem comportamento probabilístico normal, pode-se aplicar o teste de normalidade de Anderson-Darling, apresentado no Apêndice C, e analisar o gráfico de probabilidade normal. Através deste, se os resíduos seguem distribuição normal, os pontos devem se encontrar em torno de uma linha reta. Do contrário, temse a evidência contra a normalidade dos resíduos. Para construir este gráfico, tem-se a coluna chamada $R_{w}$, que contém os resíduos originais: $r_{1}, \ldots, r_{n}, \operatorname{com} w=1, \ldots, n$ o número de resíduos, e a coluna chamada $R_{w}^{\prime}$, cujos elemento, $r_{1}^{\prime}, \ldots, r_{n}^{\prime}$, apresentam os resíduos ordenados, do menor para o maior valor. No gráfico de probabilidade normal, cada ponto em torno da reta apresenta como coordenada $x$ os elementos da coluna $R_{w}^{\prime}$, isto é, os resíduos ordenados, e como coordenada y os valores da chamada frequência acumulada amostrada, exibida a seguir:

$$
\phi=\frac{w-1 / 2}{n},
$$

onde $\phi$ é a frequência acumulada amostrada.

A reta ajustada a estes pontos pode ser descrita em termos de $a$ e $b$ como $\phi=$ $a+b r_{w}^{\prime}$. Os parâmetros $a$ e $b$ são estimados pelo método dos mínimos quadrados (Aguirre, 2004; Bussab e Morettin, 2005). Para finalizar a análise, resta verificar o quanto este modelo é capaz de aproximar da frequência amostrada (4.10). Para isso, obtém-se a frequência acumulada amostrada predita, denotada $\hat{\phi}$, aplicando-se $r_{w}^{\prime}$ na equação da reta utilizando os parâmetros estimados $a$ e $b$. Desta forma, a reta ajustada possue como coordenada $x$ os elementos da coluna $R_{w}^{\prime}$ e como coordenada $y$ os valores da frequência acumulada amostrada predita $\hat{\phi}$. 


\subsection{Modelos Dinâmicos de Populações de Plantas Danin- has}

A utilização de técnicas químicas em conjunção à estratégias integradas de controle têm despertado interesse no controle eficiente de populações de plantas daninhas . Neste contexto, modelos matemáticos são ferramentas valiosas na simulação do comportamento de sistemas, predição e controle. Um modelo matemático representa as características de um sistema real, além de ser mais barato e versátil, uma vez que diferentes variações nas características e entradas de um sistema podem ser analisadas pelo comportamento de suas respostas (Sakai, 2001).

O comportamento da dinâmica populacional depende especialmente da taxa de germinação da semente, e a densidade de sementes nas sucessivas gerações, definida como o número de sementes por unidade de área, pode ser obtida recursivamente a partir do número de sementes do ano inicial amostrado (Gonzalez-Andujar, 1996):

$$
X_{t}=s g X_{t-1}\left(1+a g X_{t-1}\right)^{-b}
$$

onde:

$X_{t}:$ densidade de sementes (sementes $\left./ m^{2}\right)$;

$t$ : gerações das plantas ou ciclos de vida;

$g$ : taxa de germinação das sementes, qual varia de 0 , quando nenhuma semente germina, a 1, quando todas as sementes germinam;

$s:$ número de sementes por planta em ausência de competição;

$a$ : taxa de declínio da população de sementes com o aumento da densidade de plantas;

$b:$ taxa que reflete a intensidade do efeito da densidade de plantas na produção de sementes.

A taxa de controle da população $c$ pode ser introduzida como uma redução na sobrevivência das sementes, ou melhor, no número de plântulas (sementes que germinam). Portanto, (4.11) pode ser modificada como segue: 


$$
X_{t}=(1-c) \operatorname{sg} X_{t-1}\left(1+a g X_{t-1}\right)^{-b}
$$

onde a taxa de controle $c$ permite a predição do número de plantas que irá se desenvolver. Portanto, quantificando a produção de sementes e sabendo quais espécies estão presentes, pode-se fazer um planejamento de manejo de regiões, reduzindo o número de sementes no solo.

A partir de medidas de controle com o uso de herbicidas e dentro da margem de extinção da população de acordo com a taxa de germinação $g$, a extinção pode ser obtida somente com $100 \%$ de controle, ou seja, $c=1$ em (4.12). Porém, o controle médio alcançado nas condições do campo em geral não ultrapassa $90 \%(c=0.9)$, dada a situação paradóxica de que não se pode erradicar a população apesar do alto nível de controle introduzido (Gonzalez-Andujar, 1996).

A quantificação da cobertura foliar relativa de plantas daninhas pode ser feita utilizando os métodos de avaliação visual ou por análise de imagens. A cobertura foliar na geração $t-1$, denotada por $Y_{t-1}$, pode ser obtida a partir das sementes que germinaram em $t-1$ (Sakai, 2001):

$$
Y_{t-1}=g X_{t-1}
$$

Exemplo 4.2 Para observar o comportamento das dinâmicas descritas acima, (4.11) $e$ (4.12) foram simuladas com os seguinte parâmetros: $s=248, a=4,0 \times 10^{-3}, b=$ $2,77, g=0,5, c=0,9, X_{0}=1$ e com a suposição de uma densidade limite de 4000 sementes $/ m^{2}$ em que não há produção de sementes por planta (Gonzalez-Andujar, 1996). As Figuras 4.2 e 4.3 representam respectivamente os resultados obtidos.

A partir de (4.12) varia-se a taxa de germinação $g$ de 0,1 até 1, com o objetivo de, havendo um controle, gerar vários valores de densidades (10 valores), correspondentes aos valores de $g$, em uma mesma geração t. A Figura 4.4 exibe os 10 valores de densidade simulados a partir de (4.12), respectivos aos valores de $g=0.1: 0.1: 1$ para a geração $t=5$.

De acordo com Cousens (1985), em baixas densidades de plantas daninhas $Y_{t}$, a perda de rendimento pode ser descrita por um modelo linear 4.14 que representa o 


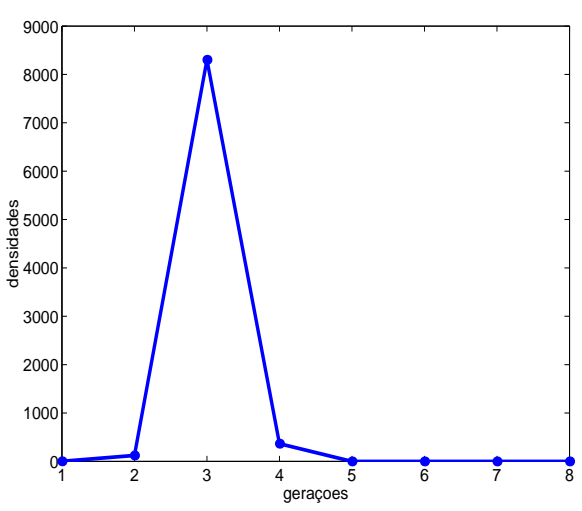

Figura 4.2: Dinâmica simulada a partir de (4.11).

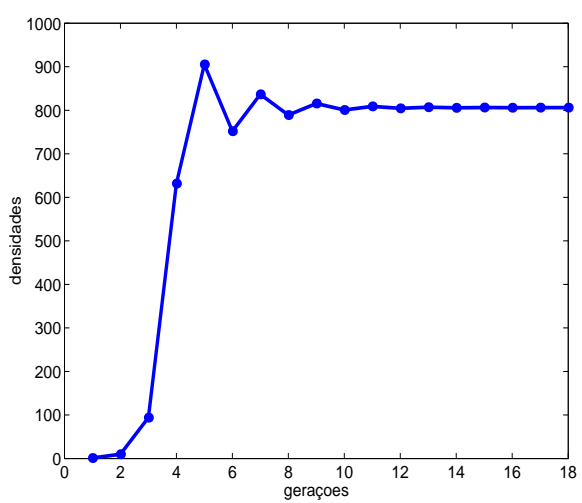

Figura 4.3: Dinâmica simulada a partir de (4.12).

efeito da competitividade das plantas daninhas.

$$
P_{r}\left(Y_{t}\right)=\theta_{1} Y_{t}
$$

com $\operatorname{Pr}$ a perda de rendimento em porcentagem e $\theta_{1}$ um parâmetro estimado que indica a perda de rendimento da cultura quando a densidade de plantas daninhas tende a zero.

Como o efeito de cada planta daninha diminuirá com o aumento da densidade, Cousens (1985) sugeriu um modelo não linear para descrever os efeitos da densidade de plantas daninhas em uma cultura. Para o desenvolvimento deste modelo, foi introduzido um segundo parâmetro $\theta_{2}$ na perda de rendimento (4.14) obtendo-se o modelo hiperbólico (Adati, 2006)

$$
P_{r}\left(Y_{t}\right)=\frac{\theta_{1} Y_{t}}{1+\left[\frac{\theta_{1}}{\theta_{2}}\right] Y_{t}}
$$

onde $P_{r}$ é a perda de rendimento para cada valor de $Y_{t}, Y_{t}$ é a densidade de plantas 


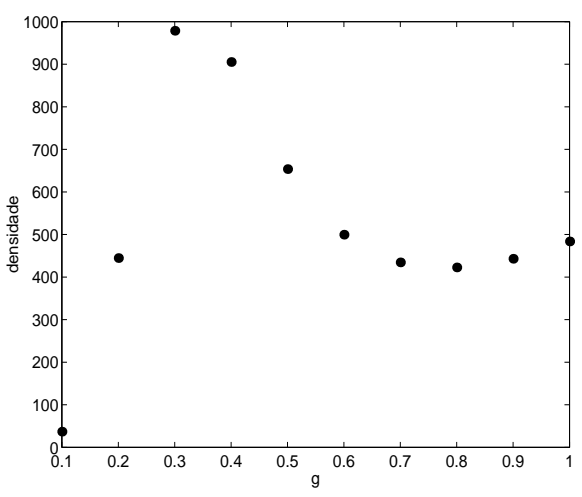

Figura 4.4: Densidade de sementes em função da taxa de germinação.

daninhas por $m^{2}, \theta_{1}$ é o parâmetro que representa a perda de rendimento causada a cada adição de uma planta daninha por $m^{2}$ (baixas densidades de plantas daninhas) e $\theta_{2}$ é o parâmetro que indica a perda de rendimento quando a densidade de plantas daninhas tende ao infinito (altas densidades de plantas daninhas). Os valores destes parâmetros podem portanto, ser usados para comparar a competitividade entre cultura e plantas daninhas em experimentos sob diferentes condições (Cousens e Mortimer, 1995).

Uma explicação biológica para a representação matemática do modelo hiperbólico 4.15, é que em densidades baixas, o efeito provocado pelo aumento da densidade é aditivo. Isso ocorre porque as áreas de influência de plantas individuais não chegam a se sobrepor. Em densidades altas, o efeito da competição decorrente de cada unidade de planta que é adicionada à cultura diminui. Isso ocorre porque as áreas de influência já começam a se sobrepor e, como consequência desse aumento na intensidade da competição intra-específica, as perdas no rendimento tendem a se estabilizar.

No próximo capítulo são introduzidos os principais conceitos de lógica fuzzy e de classificação, fundamentais para o desenvolvimento do sistema de classificação para inferir o risco de infestação por regiões da cultura. Também são introduzidos os conceitos de processamento de imagens digitais e como os procedimentos computacionais referentes podem ser aplicados às imagens constituídas pelos mapas. 


\section{Capítulo 5}

\section{Conceitos de Lógica Fuzzy, Classificação e Processamento de Imagens}

Levando em conta a natureza dos problemas a serem tratados neste trabalho e tendo em vista as incertezas associadas à infestação por plantas daninhas, bem como as incertezas nas fronteiras das classes de infestação, uma técnica de classificação baseada em lógica fuzzy e análise de imagens é utilizada.

\subsection{Fundamentos da Lógica Fuzzy}

A lógica fuzzy está mais próxima da forma do pensamento e da linguagem natural humana do que a lógica tradicional (Queiroz et al., 1997) e um sistema baseado em fuzzy dispõe de ferramental mais apropriado para a descrição dos critérios de decisão humana, sugerindo a possibilidade de obtenção de menores erros num processo classificatório.

Os conhecimentos disponíveis que se tem sobre uma situação qualquer são geralmente imperfeitos, seja por alguma dúvida sobre sua validade, portanto são incertos, seja porque é colocada uma dificuldade para que sejam expressados claramente, sendo portanto imprecisos. Esses dois tipos de imperfeição do conhecimento estão frequentemente interligados. A matemática clássica nem sempre consegue modelar essas imperfeições. Zadeh (1965) criou a teoria fuzzy que fornece meios de representação e de 
manipulação de conhecimentos imperfeitamente descritos, vagos ou imprecisos. A lógica fuzzy (ou nebulosa) estabelece uma interface entre os dados descritos simbolicamente (com palavras) e numericamente (com algarismos, ou valores).

A lógica fuzzy conduz ao tratamento racional de tais conhecimentos. A teoria das possibilidades introduzida em 1978, também por Zadeh, constitui um contexto que permite tratar dos conceitos de incerteza de um modo não probabilista.

Um número importante de cientistas se interessou muito por essa nova teoria e as pesquisas sobre os aspectos matemáticos e as aplicações dos conjuntos fuzzy, da lógica fuzzy e da teoria das possibilidades se desenvolveram após os anos 60, tanto na Europa como nos Estados Unidos, na China e no Japão, como testemunham as revistas científicas e os congressos internacionais sobre o assunto.

Deve-se alertar que a Lógica Fuzzy não invalida a Teoria das Probabilidades, Lógica Matemática ou Teoria dos Conjuntos, sendo apenas uma poderosa ferramenta que, juntamente com Redes Neurais, Algoritmos Genéticos, Programação Dinâmica, obtém soluções viáveis para questões geralmente intratáveis por técnicas convencionais.

Segundo Lotfi Zadeh, considerado o pai da lógica fuzzy, usar sistemas fyzzy é a solução mais rápida e barata em termos computacionais. Algumas vantagens de usar sistemas fuzzy são relacionadas a seguir:

- Os conceitos matemáticos existentes por trás do raciocínio fuzzy são muito simples. Não há uma complexidade longe de se alcançar.

- A lógica fuzzy é flexível e tolerante a dados imprecisos. Além disso, pode modelar funções não lineares de complexidade arbitrária.

- A lógica fuzzy pode ser combinada com técnicas de controle convencionais, sem necessariamente substituí-las. Os sistemas fuzzy podem simplificar as implementações de controle.

- A lógica fuzzy é baseada na linguagem natural, como a linguagem ordinária. A lógica fuzzy é construída sobre as estruturas de descrição qualitativa usada na linguagem do dia-dia, e portanto, é fácil de ser usada.

A lógica fuzzy é fundamentada na teoria dos conjuntos, absorvendo as principais características desta última, mas apresentando as suas próprias características que lhe 
permitem ser vista como uma nova abordagem no tratamento de problemas inexatos. Enquanto na teoria dos conjuntos um determinado elemento pertence ou não a um conjunto e a cada elemento é associado o valor 1 ou 0 , descriminando um elemento como membro ou não membro, respectivamente, na lógica fuzzy a um elemento pode ser associado qualquer valor dentro do intervalo fechado de 0 a 1 , de tal forma que esse número indica o grau de pertinência do elemento dentro de um conjunto. Isto é, um elemento pode não pertencer a um conjunto (valor 0 ), pertencer ao conjunto (valor 1) ou pode pertencer parcialmente ao conjunto $(0<$ valor $<1)$.

\subsubsection{Funções de Pertinência}

O grau de pertinência de um elemento é obtido pela função de pertinência (membership function), que pode ser definida da seguinte forma (Shaw e Simões, 1999):

Definição 5.1.1 Uma função de pertinência é uma curva que define como cada ponto no conjunto entrada é relacionado a um valor de pertinência, ou grau de pertinência entre 0 e 1. A única condição que uma função de pertinência realmente deve satisfazer é variar entre 0 e 1.

Ou mais formalmente como:

Definição 5.1.2 Seja $\Gamma$ o conjunto universal e $X(X=x \mid x \in \Gamma)$ um subconjunto de $\Gamma$, então a função de pertinência do subconjunto $X$ é definida por:

$$
\mu_{X}(x): \Gamma \rightarrow[0,1] .
$$

Onde $\mu_{X}(x)$ retorna o grau de pertinência do elemento $x$, pertencente ao universo de discurso $X$, em relação ao conjunto fuzzy $X$.

Nota-se que o grau de pertinência é um valor normalizado entre 0 e 1 , ou seja, $\mu_{X}(x) \in[0,1]$ onde os valores limites 0 e 1 indicam respectivamente exclusão total e inclusão total no conjunto.

Tipos de funções de pertinência:

\section{Funções Triangulares}




$$
A(x)=\left\{\begin{array}{rll}
0, & \text { se } & x \leq a \\
\frac{x-a}{m-a}, & \text { se } & x \in] a, m] \\
\frac{b-x}{b-m}, & \text { se } & x \in] m, b] \\
0, & \text { se } & x>b
\end{array}\right.
$$

onde $m$ é um valor modal, e $a$ e $b$ denotam o menor e o maior limitantes, respectivamente, para valores não nulos de $A(x)$.

\section{Função $\Gamma$}

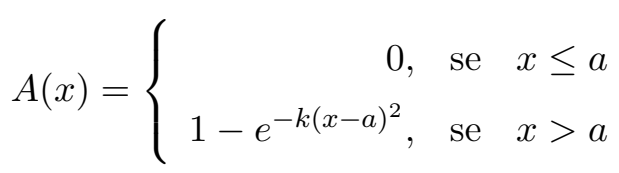

$\mathrm{ou}$

$$
A(x)=\left\{\begin{array}{rll}
0, & \text { se } & x \leq a \\
\frac{k(x-a)^{2}}{1+k(x-a)^{2}}, & \text { se } & x>a
\end{array}\right.
$$

onde $k>0$.

\section{Função S}

$$
A(x)=\left\{\begin{array}{rll}
0, & \text { se } & x \leq a \\
2\left(\frac{x-a}{b-a}\right)^{2}, & \text { se } & x \in] a, m] \\
1-2\left(\frac{x-b}{b-a}\right)^{2}, & \text { se } & x \in] m, b] \\
1, & \text { se } & x>b
\end{array}\right.
$$

\section{Função Trapezoidal}

$$
A(x)=\left\{\begin{array}{rll}
0, & \text { se } & x<a \\
\frac{x-a}{m-a}, & \text { se } & x \in[a, m[ \\
1, & \text { se } & x \in[m, n] \\
\frac{b-x}{b-n}, & \text { se } & x \in] n, b] \\
0, & \text { se } & x>b
\end{array}\right.
$$

\section{Função Gaussiana}




$$
A(x)=e^{-k(x-m)^{2}}, k>0
$$

A próxima subseção define os conjuntos fuzzy algumas de suas operaçõe mais essenciais.

\subsubsection{Conjuntos}

Foi Aristóteles quem primeiro formulou a Lei do Meio Excluído, que diz que $X$ deve pertencer a $A$ ou não pertencer a $A$. Em lógica fuzzy, a verdade sobre qualquer sentença se torna uma questão de grau. A ferramenta que o raciocínio fuzzy fornece é a capacidade de responder a uma questão sim-não com uma resposta não absolutamentesim-não. É apenas uma questão de generalizar a lógica Booleana sim-não. Se a pergunta é se $X$ pertence a $A$, a resposta pode ser sim (1), não (0), ou qualquer um dos valores intermediários entre eles. Desta forma, $X$ pode ter uma pertinência parcial em $A$.

Diferentemente dos conjuntos clássicos, que incluem ou excluem completamente um elemento dado, um conjunto fuzzy não possui limites claramente definidos. Os conjuntos fuzzy são formalmente definidos por (Pedrycz e Gomide, 1998):

Definição 5.1.3 Um conjunto fuzzy é caracterizado por uma função de pertinência mapeando os elementos de um domínio, espaço ou universo de discurso $X$ para o intervalo $[0,1]$, isto é, $A: X \rightarrow[0,1]$.

Portanto, um conjunto fuzzy $A$ em $X$ pode ser representado como um conjunto de pares ordenados de um elemento genérico $x \in X$ e seu grau de pertinência: $A=$ $\{(A(x) / x) \mid x \in X\}$.

A terminologia utilizada para denotar um conjunto fuzzy pode ser especificada de diferentes maneiras. Para um conjunto fuzzy $A$ discreto e finito, tendo elementos definidos em um universo de discurso $X$, o mesmo conjunto pode ser denotado da seguinte forma:

$$
A=\mu_{A}\left(x_{1}\right) / x_{1}+\mu_{A}\left(x_{2}\right) / x_{2}+\ldots+\mu_{A}\left(x_{n}\right) / x_{n}=\sum_{i=1}^{n} \mu_{A}\left(x_{i}\right) / x_{i}
$$

onde o sinal de adição indica a composição de todos os elementos do conjunto $A$ e $n$ 
especifica a cardinalidade deste conjunto. Portanto, para cada termo $\mu_{A}\left(x_{i}\right) / x_{i}$ fornece o grau de pertinência $\mu_{A}\left(x_{i}\right)$ do elemento $x_{i}$ em relação ao conjunto $A$.

A utilização dos conjunto fuzzy é feita por operações herdadas da teoria dos conjuntos. A seguir são apresentadas as principais operações com conjuntos fuzzy, assumindose as premissas: $X$ é o conjunto universal, $x$ é um elemento de $X$ e $A$ e $B$ são subconjuntos fuzzy de $X$.

- Comparação: A operação de comparação é utilizada para definir se dois subconjuntos são iguais, ou seja, se as funções de pertinência são equivalentes: $A=B$ se $\mu_{A}(x)=\mu_{B}(x) \forall x \in X$.

- União: Utilizada para associar dois subconjuntos, a união de $A$ com $B$ resulta em um subconjunto abrangendo os pontos máximos dos dois subconjuntos unidos: $A \cup B$ se $\mu_{A}(x) \cup \mu_{B}(x)=\max \left(m u_{A}(x), m u_{B}(x)\right) \forall x \in X$.

- Interseção: Utilizada para definir a região comum entre dois subconjuntos, a interseção de $A \operatorname{com} B$ resulta em um subconjunto abrangendo os pontos que pertencem tanto a $A$ como a $B: A \cap B$ se $\mu_{A}(x) \cap \mu_{B}(x)=\min \left(m u_{A}(x), m u_{B}(x)\right) \forall x \in X$.

$\mathrm{Na}$ teoria de conjuntos fuzzy, as normas triangulares desempenham um papel importante proporcionando modelos genéricos para as operações de interseção e união de conjuntos fuzzy, que devem possuir as propriedades de comutatividade, associatividade e monotonicidade. As normas triangulares são definidas a seguir:

Definição 5.1.4 Uma norma triangular t-norma é uma operação binária $t:[0,1]^{2} \rightarrow$ $[0,1]$ satisfazendo as seguintes condições:

comutatividade: $x t y=y t x$

associatividade: $x t(y t z)=(x t y) t z$

monotonicidade: se $x \leq y$ e $w \leq z$, então $x t w \leq y t z$

elementos neutros: $0 t x=0$ e $1 t x=x$.

Definição 5.1.5 Uma co-norma triangular s-norma é uma operação binária s $:[0,1]^{2} \rightarrow$ $[0,1]$ satisfazendo as seguintes condições:

comutatividade: $x s y=y s x$ 
associatividade: $x s(y s z)=(x s y) s z$

monotonicidade: se $x \leq y$ e $w \leq z$, então $x s w \leq y s z$

elementos neutros: $x s 0=x$ e $x s 1=1$.

O operador min $(\wedge)$ é t-norma, ao passo que o operador max $(\vee)$ é uma s-norma. Eles correspondem aos operadores de interseção e união, respectivamente, quando os graus de pertinência são restritos ao conjunto $\{0,1\}$.

O processo de fuzzificação compreende a transformação de variáveis numéricas abruptas crisp em variáveis linguísticas, que se apresentam como a base das proposições difusas. É um mapeamento do domínio dos números reais para o domínio fuzzy e representa que há uma atribuição de valores linguísticos definidos por funções de pertinência às variáveis de entrada.

O processo de inferência avalia os níveis de compatibilidade das entradas com as condições impostas pelas várias regras, resultando em um conjunto fuzzy.

O processo de defuzzificação pode ser definido como uma função que associa a cada conjunto fuzzy um elemento (de um conjunto crisp) que o represente, podendo ser efetuado de infinitas maneiras, como o centro de gravidade, médias dos máximos e centro de área. O ser humano naturalmente trabalha com características incertas, mas as máquinas precisam de um número real que represente o valor de referência necessário. Dessa maneira, a defuzzificação é o processo que converte o valor fuzzy para um número real.

\subsubsection{Operações de Agregação}

As operações de agregação consistem em combinar um ou mais conjuntos fuzzy visando a obtenção de um único conjunto fuzzy. Admitindo-se $N$ conjuntos fuzzy dados por $A_{1}, \ldots, A_{N}$ definidos em um universo de discurso $X$, então a função de pertinência $\mu_{B}$ representando o conjunto fuzzy $B$, o qual é resultante da aplicação da agregação sobre os elementos de $A_{1}, \ldots, A_{N}$ é dada por:

$$
\mu_{B}(x)=\operatorname{agr}\left(\mu_{A_{1}}(x), \ldots, \mu_{A_{N}}(x)\right), \quad x \in X .
$$


Para que uma função seja classificada como uma função de agregação, esta deve obedecer as condições de contorno, $\operatorname{agr}(0,0, \ldots, 0)=\operatorname{0eagr}(1,1, \ldots, 1)=1$, e a condição de monotonicidade $\operatorname{agr}\left(a_{1}, a_{2}, \ldots, a_{N}\right) \geq \operatorname{agr}\left(b_{1}, b_{2}, \ldots, b_{N}\right)$ onde $a_{i} \geq b_{i}$.

De fato, as operações min e max são então classificadas como funções de agregação. Estas condições também são verificadas quando utilizamos os operadores t-norma e s-norma. Há operadores de agregação denominados compensatórios, que combinam operadores de intersecção e união, e medianos, cujos valores de pertinência resultantes sempre estão entre os valores mínimos e máximos das funções de pertinência que constituem o argumento de $\operatorname{agr}($.$) .$

\subsubsection{Relações entre Conjuntos Fuzzy}

Uma relação fuzzy indica como estão associados os elementos de um conjunto em relação aos elementos de um outro conjunto. O nível de associação entre dois conjuntos fuzzy é fornecida através de graus de associação que possuem valores entre 0 e 1 . Uma relação entre conjuntos fuzzy indica o grau de pertinência existente entre os elementos pertencentes aos conjuntos. Este relacionamento é definido no subespaço constituído pelo produto cartesiano dos respectivos universos de discurso. Os valores atribuídos aos relacionamentos entre os elementos $\mu_{R}(x, y)$ estão sempre entre 0 e 1 . As relações fuzzy podem ser representadas por:

$$
R(x, y)=\sum_{(x, y) \in X \times Y} \mu_{R}(x, y) /(x, y) .
$$

Dadas duas relações fuzzy $R(x, y)$ e $S(x, y)$ onde $x \in X$ e $y \in Y$, as principais operações efetuadas entre estas são:

-União: $\mu_{R(x, y) \cup S(x, y)}=\max _{(x, y) \in X \times Y}\left\{\mu_{R(x, y)}, \mu_{S(x, y)}\right\}$

。 Intersecção: $\mu_{R(x, y) \cap S(x, y)}=\min _{(x, y) \in X \times Y}\left\{\mu_{R(x, y)}, \mu_{S(x, y)}\right\}$

- Complemento: $\mu_{\bar{R}(x, y)}=1-\mu_{R(x, y)}$

A combinação de duas ou mais relações fuzzy, definidas em espaços distintos, podem ser feitas através de operadores que permitem a composição das respectivas relações. Deve-se ressaltar que a composição de relações fuzzy possui um papel fundamental 
nos precedimentos envolvendo a computação baseada em regras. Sejam duas relações $R(x, y), S(y, z)$, definidas respectivamente nos produtos cartesianos discretos $X \times Y \mathrm{e}$ $Y \times Z$. As principais técnicas de composição de relações fuzzy são dadas por:

- max-min: A composição max-min efetuada entre as matrizes $R(x, y)$ e $S(y, z)$, denotada por $R \circ S(x, z)$ é definida por $R \circ S(x, z)=\max \left\{\min \left(\mu_{R}(x, y), \mu_{s}(y, z)\right)\right\}$.

- max-prod: A composição max-prod efetuada entre as matrizes $R(x, y)$ e $S(y, z)$, denotada por $R \bullet S(x, z)$ é definida por $R \bullet S(x, z)=\max \left\{\mu_{R}(x, y) * \mu_{s}(y, z)\right\}$.

- Complemento: A composição max-média efetuada entre as matrizes $R(x, y)$ e $S(y, z)$, denotada por $R \oplus S(x, z)$ é definida por $R \oplus S(x, z)=\max \left\{1 / 2\left(\mu_{R}(x, y)+\right.\right.$ $\left.\left.\mu_{s}(y, z)\right)\right\}$.

\subsubsection{Inferência Fuzzy}

Há dois tipos de sistemas de inferência fuzzy: Mamdani e Sugeno. O método de inferência fuzzy de Mamdani é o mais comumente visto na metodologia fuzzy. Proposto por Mamdani em 1975, foi um dos primeiros sistemas de controle construído utilizando a teoria dos conjuntos fuzzy. Este sistema espera que as funções de pertinência de saída sejam conjuntos fuzzy. Já os sistemas do tipo Sugeno podem ser usados para modelar qualquer sistema de inferência no qual as saídas são lineares ou constantes. Este sistema de inferência fuzzy foi introduzido em 1985 e pode também ser chamado de Takagi-Sugeno-Kang.

O processo de inferência fuzzy permite o mapeamento do conhecimento a respeito de um sistema através de regras fuzzy do tipo SE-ENTÃO. Através de um conjunto finito dessas regras pode-se determinar, por intermédio do processo de inferência, o comportamento das variáveis de saída do sistema. As regras associadas ao processo de inferência fuzzy são expressões linguísticas que descrevem a relação entre as variáveis de entrada e a de saída. As regras possuem a seguinte forma:

$$
\text { Se }<\text { condição }>\text { então }<\text { consequência }>\text {. }
$$

em que a parte SE da regra é chamada de premissa e a parte ENTÃO é chamada de consequente.

Estas regras se-então são usadas para formular as condições da lógica fuzzy. Mais 
formalmente, uma regra fuzzy simples se-então assume a forma: se $x$ é $A$ então $y$ é $B$, onde $A$ e $B$ são valores linguísticos definidos por conjuntos fuzzy nos espaços entrada $X$ e $Y$, respectivamente. A parte "se" é chamada de antecedente, que retorna um número entre 0 e 1 e a parte "então" é a conclusão ou consequente, que transfere o conjunto fuzzy $B$ para a variável de saída $y$. Em geral, a entrada para uma regra se-então é o valor corrente da variável de entrada e a saída é um conjunto fuzzy, o qual é defuzzyficado, designando um valor para a saída.

Os principais componentes de um sistema fuzzy são a fuzzificação, a base de conhecimento, a inferência e a defuzzificação. A fuzzificação consiste em caracterizar as variáveis de entrada em termos de um conjunto fuzzy. Para fuzzificar uma entrada ordinária (que representa uma variável) é necessário estabelecer uma relação entre os valores numéricos associados a termos linguísticos de conjuntos fuzzy, definindo graus de pertinência de um valor a um conjunto fuzzy através de funções de pertinência. A base de conhecimento é constituída de uma base de dados juntamente com uma base de regras fuzzy lingüísticas do tipo SE-ENTÃO. A base de dados fornece as definições numéricas necessárias às funções de pertinência usadas no conjunto de regras fuzzy. A base de regras contém todas as situações possíveis relativas às entradas e saídas. As entradas são combinadas usando operadores fuzzy (E corresponde ao operador de mínimo e OU corresponde ao operador de máximo). A inferência processa os dados fuzzy de entrada, junto com as regras, de modo a inferir as ações de saída fuzzy, aplicando um operador de implicação fuzzy e as respectivas regras. $\mathrm{O}$ principal operador de implicação fuzzy utilizado é o de Mamdani: dadas duas variáveis linguísticas $x$ e $y$ com valores $A$ e $B$, respectivamente, a função de pertinência $\mu_{R_{A \rightarrow B}}(x, y)$ é obtida por $\mu_{R_{A \rightarrow B}}(x, y)=\min \left\{\mu_{A}(x), \mu_{B}(y)\right\}$, onde $R_{A \rightarrow B}$ é uma relação de implicação do conjunto $A$ para $B$. Todas as saídas, inferidas por cada regra, são agregadas por algum dos métodos de agregação vistos anteriormente obtendo-se um único conjunto fuzzy de saída. Finalmente, a defuzzificação realiza transformações de ações fuzzy em ações não fuzzy, ou seja, obtém um único valor discreto. Este procedimento é ilustrado na Figura 5.1 .

No 'toolbox'de lógica fuzzy do MATLAB, há 5 partes do processo de inferência fuzzy, que podem ser vistos com mais detalhes no Apêndice B: fuzzificação das variáveis de entrada, aplicação dos operadores fuzzy de implicação da premissa para o consequente, 


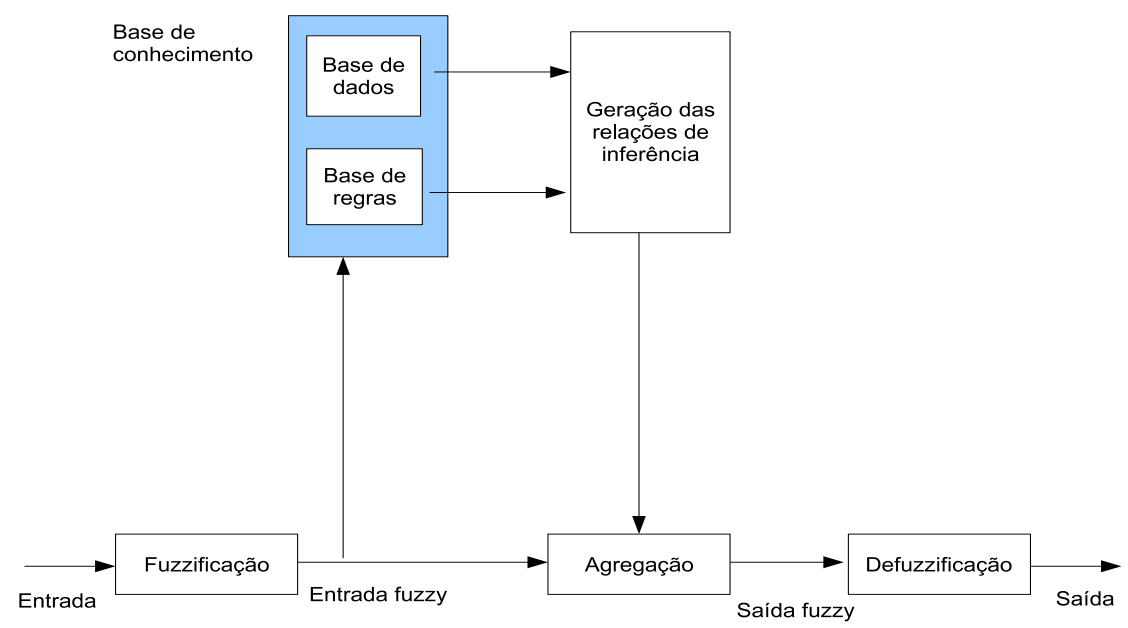

Figura 5.1: Procedimento pra inferência fuzzy.

agregação dos consequentes através de regras e defuzzificação. Mais detalhes sobre os componentes de um sistema fuzzy podem ser vistos no Apêndice B.

\subsection{Métodos de Classificação Baseados em Regras}

Os sistemas de classificação possuem aplicações em vastas áreas de conhecimento e em virtualmente todas as ciências da natureza. Muitas são as áreas em que as classificações inauguram suas atividades e não raro estas são feitas por humanos, sob critérios subjetivos, sem relação direta com a diversidade dos fenômenos ali estudados.

\subsubsection{Sistema de Classificação Fuzzy}

Em geral, os métodos de classificação permitem reduzir a dimensionalidade de um complexo conjunto de dados agrupando-as em classes. Com os métodos de classificação tradicionais, cada dado ou amostra é colocada em uma classe ou em outra, isto é, um dado é membro de uma classe ou não. Na classificação fuzzy, um dado pode ter pertinência em muitas classes diferentes com graus diferentes. Tipicamente, todos os valores de pertinência, se normalizados, devem somar 1. É comum verificar que as grandezas usadas para a classificação variam continuamente e torna-se difícil decidir onde definir a fronteira entre duas classificações contíguas. Neste contexto é que se inserem os novos 
algoritmos de classificação fuzzy considerados nas áreas da matemática, física, ciências biológicas, etc. Desta forma, os problemas de classificação preocupam-se em determinar classes para os exemplos dados. Cada exemplo pode ser descrito em termos de um conjunto de atributos, que são usados como base para a classificação. Portanto, dado um conjunto arbitrário de dados, a questão mais importante é identificar seus atributos chaves.

As entradas são combinadas logicamente utilizando operadores para produzir valores de saída para todas as entradas esperadas. As conclusões são então combinadas em uma soma lógica para cada função de pertinência. Estas somas lógicas devem ser combinadas em um processo de defuzificação para produzir a saída numérica. Para tanto, as saídas fuzzy para todas as regras são finalmente agregadas em um conjunto fuzzy. Para obter uma decisão numérica desta saída fuzzy, deve-se defuzzificar o conjunto fuzzy. Portanto escolhe-se um valor representativo como a saída final. A construção de sistemas de classificação fuzzy baseados em regras utilizando o MATLAB pode ser vista com detalhes no Apêndice B.

Suponha que um conjunto de dados descreve uma situação em termos dos pares atributo/valor. O problema é construir um modelo de classificação do conjunto de dados que seja preciso e eficiente, e capaz de classificar corretamente novos casos. A primeira coisa que deve ser feita é definir os atributos e seus valores possíveis correspondentes. Na tarefa de classificação deve-se identificar as variáveis linguísticas relevantes, e definir as funções de pertinência correspondentes. Então, é necessário construir o conjunto de regras fuzzy e definir qual tipo de mecanismo de implicação será usado.

Um sistema de classificação consiste na construção de um modelo que prediz uma saída, que consiste em um conjunto de classes, para a qual um conjunto de atributos é designado. O classificador fuzzy baseado em regras consiste de regras fuzzy, sendo que cada uma descreve uma das classes de saída. A regra antecedente é uma descrição fuzzy no espaço atributo n-dimensional e a regra consequente é um elemento do conjunto de classes.

As regras fuzzy SE-ENTÃO são determinadas da seguinte forma:

Se atributo $v_{j}$ é condiçãoo $O_{i j}$ então classe $c_{i}$

onde $v_{j} \in\left\{v_{1}, \ldots, v_{m}\right\}, O_{i j} \in\left\{O_{i 1}, \ldots, O_{i n}\right\}$ e $c_{i} \in\left\{c_{1}, \ldots, c_{C}\right\}, i=1, \ldots, C, \operatorname{com} C$ o 
número de classes e $j=1, \ldots, m$, com $m$ o número de atributos (Pedrycz e Gomide, 1998).

\subsubsection{Redes de Classificação Bayesianas}

Redes Bayesianas e classificadores Bayesianos aprendem relações de causa e consequência e podem combinar conhecimento a priori com padrões aprendidos a partir dos dados. Porém, o conhecimento representado por um classificador Bayesiano não é tão compreensível como algumas outras formas de representação, como as regras de classificação. A combinação de classificadores Bayesianos e um conjunto de regras pode tornar os resultados mais compreensíveis, além de facilitar o processo de depuração conduzido por um especialista humano. Esta combinação é proposta por Hruschka et al. (2007), no método chamado BayesRule, que, além de explorar o potencial dos classificadores Bayesianos em relação à tarefa de classificação, transforma o classificador Bayesiano em um conjunto de regras de classificação do tipo SE-ENTÃO. Estas, são consideradas como mais compreensíveis e mais aceitáveis para usuários do que as recomendações dadas por sistemas caixa preta, pois proporcionam melhor entendimento e explicações, e podem ser validadas por inspeção humana. Além disso, a rede Bayesiana permite que o usuário ou especialista interfira nos nós da rede e insira um conhecimento que se propaga nos outros nós, o que seria dificultoso em um sistema como uma rede neural, por exemplo.

Uma rede Bayesiana pode ser considerada como uma forma de modelo gráfico probabilístico usado para representar conhecimento sobre um domínio de dados. É composta por uma estrutura de rede, que consiste em um grafo acíclico direcionado, e um conjunto de tabelas de probabilidade. Os nós da estrutura da rede representam as variáveis e os arcos entre os nós representam relações de dependência entre as variáveis correspondentes. Um arco começando em um nó $X$ e terminando em um nó $Y$ estabelece $X$ como pai de $Y$ e $Y$ como filho de $X$. Uma rede Bayesiana pode ser utilizada como um classificador, calculando a probabilidade condicional de um nó, chamado nó classe, dados os valores das probabilidades dos outros nós.

Em Cheng et al. (2002) uma rede Bayesiana é representada por $B N=<N, A, \Theta>$, onde $<N, A>$ é um grafo acíclico direcionado em que cada nó $x_{i} \in N$ representa uma variável e cada arco $a \in A$ entre nós representa uma dependência probabilística entre os nós associados. Uma distribuição de probabilidade condicional $\theta_{i}$ é associada com cada 
nó $x_{i} \in N, i=1, \ldots, n$, coletivamente representado por $\Theta=\theta_{i}$, que quantifica o quanto um nó depende de seus pais. A independência condicional, que é a condição de Markov, permite o cálculo da distribuição conjunta de todas as variáveis, dado por (5.1)

$$
P\left(x_{1}, x_{2}, \ldots, x_{n} \mid B K\right)=\prod_{i=1}^{n} P\left(x_{i} \mid \pi_{x_{i}}, B K\right)
$$

onde BK representa o conhecimento antecedente, $x_{i}$ é a i-ésima variável ou nó, e $\pi_{x_{i}}$ é o conjunto de pais de $x_{i}$. Portanto, uma rede Bayesiana pode ser usada como uma representação do conhecimento que permite inferências. As redes Bayesianas podem ser construídas a partir do conhecimento de especialista humano ou podem ser aprendidas a partir dos dados. Na construção de uma rede Bayesiana baseada em conhecimento humano, o maior problema é a definição da distribuição de probabilidade condicional (Tversky e Kahneman, 1974). Para evitar esta dificuldade, é possível usar o conhecimento humano para construir apenas a estrutura da rede Bayesiana e utilizar algoritmos de aprendizado para induzir $\Theta$ a partir dos dados.

Na estrutura da rede Bayesiana com $\lambda_{A}$ o conjunto de filhos do nó $A$ e $\pi_{A}$ o conjunto de pais do nó $A$, o subconjunto de nós contendo $\pi_{A}, \lambda_{A}$ e os pais de $\lambda_{A}$ é chamado Markov blanket de $A$. Como descrito em Pearl (1988), os únicos nós que têm influência na distribuição de probabilidade condicional de um dado nó $A$ são os nós que pertencem ao Markov blanket de $A$. Desta forma, o Markov blanket do nó que representa a classe pode ser usado como um critério de seleção de padrões para identificar, dentre os nós que definem a rede, aqueles que influenciam o nó classe.

No método BayesRule proposto por Hruschka et al. (2007), um classificador Bayesiano com $n$ variáveis pode ser construído e então qualquer das variáveis pode ser definida como classe. Este método é baseado no conceito de probabilidade máxima a posteriori (Henrion e Druzdzel, 1990; Pearl, 1988) para extrair um conjunto de regras probabilísticas que descrevem a classificação. O subconjunto de nós de Markov blanket é usado para reduzir o número e a complexidade das regras de classificação, selecionando os padrões a serem usados no antecedente das regras do tipo SE-ENTÃO. Isto permite a redução no tempo requerido para construir modelos quando mais de uma variável é designada como classe. Seguindo esta aproximação, um classificador Bayesiano evidencia que o algoritmo de propagação deve ser usado para propagar os valores das variáveis e inferir 
o valor da variável classe. O algoritmo de inferência descrito em Lauritzen e Spiegelhalter (1988) é usado na implementação do método BayesRule. A confiança da regra pode ser definida utilizando resultados inferenciais. Com isso, a probabilidade dada à classe inferida pode ser usada como um valor de confiança e é embutido no algoritmo de inferência.

Uma rede de classificação Bayesiana irrestrita (Cheng et al., 2002) apresenta uma estrutura de grafo acíclico direcionado. Como mencionado anteriormente, cada nó corresponde a uma variável aleatória discreta no domínio do conhecimento e é associado a uma tabela de probabilidade condicional que especifica a probabilidade de cada condição possível do nó, dada cada combinação possível das condições de seus pais. Se o nó não tem pai, sua tabela de probabilidade condicional fornece as probabilidades marginais da variável que o nó representa. Portanto, uma rede Bayesiana representa a distribuição de probabilidade conjunta sobre um conjunto de variáveis aleatórias e pode ser usada para fazer inferências em qualquer nó. Desta forma, uma rede de classificação Bayesiana prediz o valor da variável classe discreta, dado o valor de um vetor de variáveis padrões.

Um classificador naïve Bayes é um caso especial de uma rede de classificação Bayesiana irrestrita. Em particular, é uma rede Bayesiana na qual o nó classe não tem pais. Além disso, cada padrão tem o nó classe como seu único pai. A estrutura da rede é fixa, ou seja, não é necessário aprender a estrutura da rede naïve Bayes a partir dos dados, apenas os parâmetros numéricos. Desta forma, apenas as informações sobre os padrões e seus correspondentes valores são necessários para estimar as probabilidades.

A complexidade computacional do aprendizado de uma rede naïve Bayes é linear com relação à quantidade de instâncias de treinamento. A construção requer também apenas a informação fornecida por tabelas bi-dimensionais, nas quais cada entrada corresponde à probabilidade estimada para um dado valor de um padrão. Porém, o método naïve Bayes faz uma forte afirmação: todos os padrões são condicionalmente independentes dado o valor da classe.

O algoritmo BayesRule para extração de regras de classificação a partir de um classificador Bayesiano é descrito na subseção seguinte. 


\subsubsection{Algoritmo BayesRule}

Entradas :

$B C$ : Classificador Bayesiano com $N$ nós

$X_{1}$ : Variável classe

Saída:

$C R$ : Conjunto de regras

Inicialize

1. $C R \leftarrow \emptyset$

2. $C M B \leftarrow M B\left(X_{1}\right) \quad / \star$ Markov blanket de $X_{1}$ */

3. PARA $i=2$ até $N$

$V_{i} \leftarrow$ todos os valores que $X_{i}$ pode assumir

4. PARA $i=2$ até $N ; j_{1} \leftarrow\left|V_{1}\right|$

5. $I R \leftarrow 1 / \star$ Índice da regra*/

6. PARA $k_{2}=1$ até $j_{2}$

PARA $k_{3}=1$ até $j_{3}$

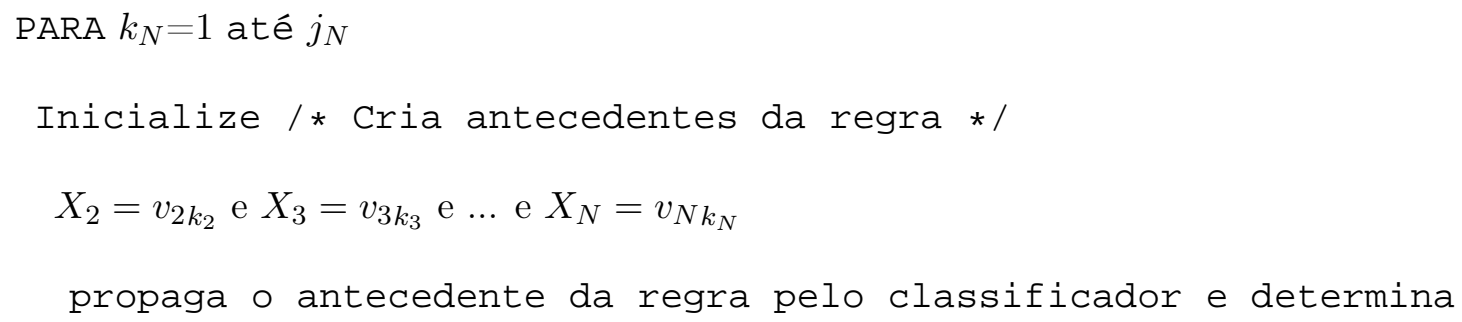

- valor da classe

Val Class

defina a regra $R_{I R}$ como:

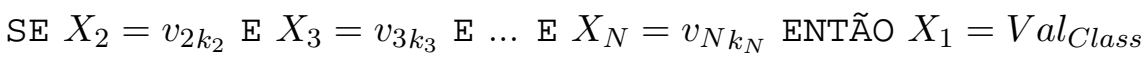

$C R \leftarrow C R \cup\left\{R_{I R}\right\}$

$I R \leftarrow I R+1$ 
FIM

7. $C R \leftarrow$ remove-regra-irrelevantes (CR)

FIM

\subsection{Sistemas Neurofuzzy}

A lógica fuzzy providencia os fundamentos teóricos para a captura de incertezas associadas com os processos de pensamento humano através do emprego de definições linguísticas de variáveis utilizadas em um sistema com uma base de regras que expressa o comportamento de um processo através de relações do tipo SE...ENTÃO. Redes neurais podem extrair tais regras e passá-las ao sistema fuzzy (Shaw e Simões, 1999). O objetivo de uma rede neural é processar a informação de acordo com seu prévio treinamento. Para o procresso de treinamento, a rede utiliza um conjunto de dados, correspondente a sinais de entrada e saída do sistema, e algum algoritmo de aprendizado, o qual modifica individualmente os pesos das interconexões de seus elementos individuais, os neurônios, de tal forma que o comportamento da rede reflita a ação desejada. Por isso, diz-se que as redes neurais possuem a capacidade de aprender a partir de dados, apresentando boa generalização e robustez. Mais detalhes sobre as redes neurais podem ser encontrados em Haykin (1999).

Uma vez que a criação de regras do tipo SE-ENTÃO e de funções de pertinência é um processo trabalhoso, os sistemas neurofuzzy podem se encarregar de automatizar a geração destes componentes do sistema fuzzy utilizando estratégias de treinamento das redes neurais. Por exemplo, os parâmetros que definem a forma das funções de pertinência (valores de pertinência máxima e mínima) podem ser determinados automaticamente por técnicas de aprendizagem e os cálculos podem ser facilitados por um vetor gradiente, que produz uma medida de como o sistema de inferência fuzzy está modelando as entradas e saídas para um dado conjunto de parâmetros. A partir do vetor gradiente, qualquer rotina de otimização pode ser aplicada para ajustar os parâmetros a fim de minimizar erros de estimativa. O treinamento é validado pela representação dos valores de entrada e saída apresentados. Os sistemas neurofuzzy consistem portanto em uma rede neural que possa de alguma forma gerar as regras e as funções de pertinência para o sistema fuzzy. A designação neurofuzzy significa a incorporação de uma rede neural em 
um sistema fuzzy existente. Assim, a combinação de redes neurais e lógica fuzzy pode proporcionar soluções promissoras para problemas envolvendo sistemas inteligentes.

Para a geração automática das funções de pertinência e das regras fuzzy pode ser utilizado o aplicativo ANFIS (sistema de inferência neurofuzzy adaptativo) do MATLAB 1. O procedimento para a utilização deste aplicativo é descrito no Apêndice B.

\subsection{Representação de Imagens Digitais}

Dentre os principais conceitos de processamento de imagens destacam-se os de pixels (abreviação de "picture element ", elementos da imagem), que é o alicerce do imageamento; o de representação da imagem como uma matriz, onde cada elemento representa o valor de um pixel, e o de segmentação, que é o processo que descreve uma imagem em suas partes básicas constituintes. Também são fundamentais os conceitos de amostragem uniforme e quantização dos níveis de cinza (Gonzalez e Woods, 2000).

O termo imagem refere-se à função bidimensional de intensidade da luz $f(x, y)$, onde $x$ e $y$ denotam as coordenadas espaciais e o valor de $f$ em qualquer ponto $(x, y)$ é proporcional ao tom de cinza da imagem naquele ponto. Às vezes se torna útil a visualização da função da imagem em perspectiva com um terceiro eixo representando o tom de cinza. Utilizando-se a convenção de se atribuir proporcionalmente valores mais altos para áreas mais claras fará a altura dos componentes da figrura proporcional ao tom de cinza correspondente na imagem.

Uma imagem digital é uma imagem $f(x, y)$ discretizada tanto em coordenadas espaciais quanto em tons de cinza. Uma imagem digital pode ser considerada como sendo uma matriz cujos índices de linhas e de colunas identificam um ponto na imagem, e o correspondente valor do elemento da matriz identifica o nível de cinza naquele ponto. Os elementos dessa matriz são os "pixels" (ou células) (Gonzalez e Woods, 2000).

\subsubsection{Passos Fundamentais em Processamento de Imagens}

Os passos fundamentais necessários para executar uma tarefa de processamento de imagem são os seguintes (Gonzalez e Woods, 2000):

\footnotetext{
${ }^{1}$ www.mathworks.com
} 
1. Aquisição da imagem: consiste na obtenção de uma imagem digital a partir de um sensor de imageamento e da digitalização do sinal produzido pelo sensor. Por exemplo, o sensor poderia ser uma câmera de TV.

2. Pré-processamento da imagem: consiste em melhorar a imagem de forma a aumentar as chances para o sucesso dos processos seguintes. Por exemplo, realce de contrastes, remoção de ruídos.

3. Segmentação: consiste em dividir uma imagem de entrada em partes ou objetos constituintes. A saída é constituída por dados em forma de pixel, correspondendo tanto à fronteira de uma região como a todos os pontos dentro da mesma. É necessário converter os dados para uma forma adequada ao processamento computacional. Os dados podem ser representados como fronteiras (quando o interesse é a característica da forma externa, como cantos e pontos de inflexão) ou como regiões (quando o interesse se concentra em propriedades internas, como textura e forma do esqueleto).

4. Reconhecimento e interpretação: consiste na atribuição de um rótulo a um objeto, baseado na informação fornecida pelo seu descritor. O descritor procura extrair características que resultem em alguma informação quantitativa de interesse ou que seja básica para discriminação entre classes de objetos. A interpretação atribui significado a um conjunto de objetos reconhecidos.

\subsubsection{Um Modelo Simples de Imagem}

A imagem refere-se a uma função de intensidade de luz bidimensional, denotada por $f(x, y)$, em que o valor ou amplitude de $f$ nas coordenadas espaciais $(x, y)$ dá a intensidade (tons de cinza) da imagem naquele ponto. Como a luz é uma forma de energia, $f(x, y)$ deve ser positiva e finita:

$$
0<f(x, y)<\infty
$$

A natureza de $f(x, y)$ pode ser caracterizada pela quantidade de luz incidindo na cena sendo observada e pela quantidade de luz refletida pelos objetos na cena. Esses componentes são chamados, respectivamente, de iluminação e reflectância e são repre- 
sentados por $i(x, y)$ e $r(x, y)$. Desta forma, tem-se:

$$
f(x, y)=i(x, y) r(x, y)
$$

onde:

$$
\begin{aligned}
& 0<i(x, y)<\infty \\
& 0<r(x, y)<1
\end{aligned}
$$

A reflectância é limitada entre 0 (absorção total) e 1 (reflectância total). A natureza de $i(x, y)$ é determinada pela fonte de luz, e $r(x, y)$ pelas características dos objeto na cena.

Geralmente, denomina-se a intensidade de uma imagem nas coordenadas $(x, y)$ de nivel de cinza $(l)$ da imagem naquele ponto. Dos limites de $i(x, y)$ e $r(x, y), l$ fica restrito ao intervalo:

$$
L_{\min } \leq l \leq L_{\max }
$$

Em teoria, a única restrição sobre $L_{\min }$ é que seja um valor positivo e sobre $L_{\max }$ é que seja finito. Na prática, $L_{\min }=i_{\min } r_{\min }$ e $L_{\max }=i_{\max } r_{\max }$. O intervalo $\left[L_{\min }, L_{\max }\right]$ é denominado escala de cinza. A prática comum é deslocar esse intervalo para $[0, L]$ onde $l=0$ é considerado negro e $l=L$ é considerado branco. Todos os valores itermediários são tons de cinza variando continuamente entre o branco e o negro (Gonzalez e Woods, 2000).

\subsubsection{Amostragem e Quantização}

Para ser adequada para o processamento computacional, uma função $f(x, y)$ precisa ser digitalizada tanto espacialmente quanto em amplitude. A digitalização das coordenadas espaciais $(x, y)$ é denominada amostragem da imagem e a digitalização da amplitude é chamada quantização em níveis de cinza.

Suponha que uma imagem contínua $f(x, y)$ é aproximada por amostras igualmente espaçadas, arranjadas na forma de uma matriz $N \times M$, em que cada elemento é uma quantidade discreta: 


$$
f(x, y) \cong\left[\begin{array}{cccc}
f(0,0) & f(0,1) & \cdots & f(0, M-1) \\
f(1,0) & f(1,1) & \cdots & f(1, M-1) \\
\vdots & \vdots & & \vdots \\
f(N-1,0) & f(N-1,1) & \cdots & f(N-1, M-1)
\end{array}\right]
$$

Esta matriz representa uma imagem digital e cada elemento denomina-se um pixel. O processo de amostragem pode ser compreendido como a partição do plano $x y$ em uma grade, com as coordenadas de cada cruzamento da grade sendo um par de elementos obtido do produto cartesiano $\mathbf{Z} \times \mathbf{Z}$, que é o conjunto de todos os pares ordenados $(a, b)$, com $a$ e $b$ sendo elementos de $\mathbf{Z}$. Portanto, $f(x, y)$ é uma imagem digital se $(x, y)$ forem elementos de $\mathbf{Z} \times \mathbf{Z}$ e $f$ uma função que atribui um valor de nível de cinza a cada par de coordenadas $(x, y)$ distinto. Esta atribuição funcional é o processo de quantização.

A prática comum em processamento de imagens digitais é assumir que $N$ e $M$ são potências inteiras de dois, isto é,

$$
N=2^{n}, M=2^{k}, G=2^{m}
$$

onde $G$ é o número de níveis de cinza. O número $b$, de bits necessários para armazenar uma imagem digitalizada é obtido por:

$$
b=N \times M \times m .
$$

Por exemplo, uma imagem de $128 \times 128$ pixels com 64 níveis de cinza requer 98.304 bits para armazenamento.

\subsubsection{Conectividade}

Um pixel $p$ nas coordenadas $(x, y)$ possui quatro vizinhos horizontais e verticais, cujas coordenadas são dadas por:

$$
(x+1, y),(x-1, y),(x, y+1),(x, y-1) .
$$

Esse conjunto de pixels é chamado 4 conectado de $p$ e pode ser representado por $N_{4}(p)$. 
Cada pixel está a uma unidade de distância de $(x, y)$, sendo que alguns dos vizinhos de $p$ ficarão fora da imagem digital se $(x, y)$ estiver na borda da imagem.

Os quatro vizinhos diagonais de $p$ possuem como coordenadas:

$$
(x+1, y+1),(x+1, y-1),(x-1, y+1),(x-1, y-1)
$$

e são denotados por $N_{D}(p)$. Esses pontos, junto com os 4 conectado, são chamados de 8 conectado de $p$, representada por $N_{8}(p)$. Alguns dos pontos de $N_{D}(p)$ e $N_{8}(p)$ cairão fora da imagem quando $(x, y)$ se encontrar na borda da imagem.

A conectividade entre pixels é um conceito importante usado no estabelecimento das bordas de objetos e componentes de regiões em uma imagem. Para estabelecer se dois pixels estão conectados, é preciso determinar se estes são de alguma forma adjacentes e se seus níveis de cinza satisfazem um certo critério de similaridade. Por exemplo, em uma imagem binária com valores 0 e 1, dois pixels podem ser vizinhos, mas serão conectados apenas se tiverem o mesmo valor.

Seja $V$ o conjunto dos valores de níveis de cinza usados para definir conectividade. Por exemplo, em uma imagem em níveis de cinza, para a conectividade de pixels com uma escala de valores de intensidade, como entre 32 e 64 , segue que $V=$ $\{32,33, \ldots, 63,64\}$. Em uma imagem binária, $V=\{1\}$ para a conectividade de pixels com valor 1 . Neste caso, os pixels serão conectados se possuirem o mesmo valor 0 ou 1. No caso da imagem em níveis de cinza, os pixels podem ser conectados se estes pertencerem a uma determinada faixa de tolerância entre os níveis de cinza.

Geralmente, o primeiro passo em análise de imagens é a segmentação da imagem. A segmentação, como já mencionado, subdivide uma imagem em suas partes ou objetos constituintes. O nível até o qual essa subdivisão deve ser realizada depende do problema que está sendo tratado, ou seja, a segmentação deve parar quando os objetos de interesse tiverem sido identificados (Gonzalez e Woods, 2000).

No próximo capítulo, é apresentada uma proposta para o sistema de classificação fuzzy da infestação de culturas por plantas daninhas. As entradas do sistema são atributos da infestação, obtidos a partir de mapas gerados por Krigagem e da identificação de objetos que constituem as imagens associadas aos mapas. 


\section{Capítulo 6}

\section{Proposta de Classificação Fuzzy do Risco de Infestação}

Neste capítulo, são definidos atributos relevantes que descrevem a infestação da cultura, escolhidos junto aos membros da equipe do projeto multidisciplinar o qual envolve este trabalho, e é proposto um sistema de classificação fuzzy do risco de infestação por regiões, utilizando análise de imagens. Os mapas gerados por Krigagem são tratados como imagens e os objetos que as constituem são identificados para obtenção dos atributos da infestação. O algoritmo de extração dos objetos que constituem a imagem associada aos mapas é apresentado.

Dada a relevância do problema de risco de infestação por plantas daninhas, utilizando mapas gerados por geoestatística e análise de imagens, propõe-se desenvolver uma técnica de classificação fuzzy do risco de infestação de regiões por plantas daninhas.

Para que a base de regras do sistema de classificação seja estabelecida, são selecionados os atributos adequados que descrevem a infestação, cada qual com suas condições, observando-se o funcionamento de uma lavoura. A Figura 6.1 ilustra a arquitetura do sistema de classificação fuzzy que estima o risco de infestação por regiões da cultura.

\subsection{Definição dos Atributos da Infestação}

A partir do conhecimento existente de uma determinada região da cultura e do especialista, foram estabelecidos 4 atributos mais relevantes da infestação, isto é, $m=4$, 


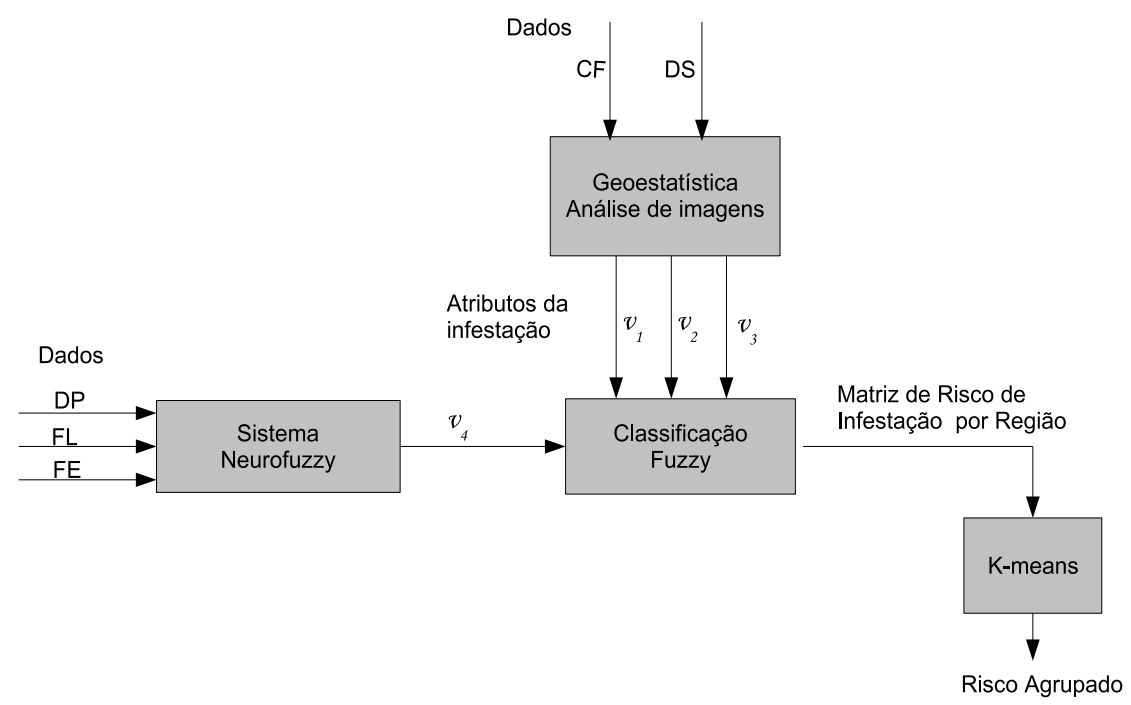

Figura 6.1: Arquitetura do sistema de classificação fuzzy com $D P$ a densidade de plantas, $F L$ a densidade de plantas folha larga, $F E$ a densidade de plantas folha estreita, $v_{1} \circ$ atributo da cobertura foliar de plantas daninhas por região, $v_{2} \circ$ atributo da densidade de sementes por região, $v_{3} \circ$ atributo da extensão média dos agrupamentos de sementes e $v_{4} \circ$ atributo da competitividade entre plantas e cultura por região.

os quais são definidos a seguir. Os atributos 1 e 4 são calculados na geração atual da cultura e os atributos 2 e 3 são calculados na geração seguinte, a partir de populações de plantas daninhas que se reproduzem por sementes. Estes atributos são obtidos a partir da densidade de sementes e de plantas por metro quadrado, da cobertura foliar e da biomassa.

- $v_{1}$ : Atributo da cobertura foliar de plantas daninhas na geração atual por região. Este atributo indica a porcentagem de ocupação na região das plantas daninhas emergentes, ou seja, a porcentagem de sementes que germinaram, cujas plantas estão nesta geração. É obtido a partir de um mapa de cobertura foliar, a qual é medida por avaliação visual de especialistas, e por análise de imagens. Também pode ser obtido tomando-se a densidade de sementes na geração atual multiplicada pela taxa de germinação $g$, como em (4.13). A avaliação visual feita por especialistas utiliza uma escala percentual de zero (ausência de cobertura) a cem (cobertura completa do solo). Condições do atributo: rala, moderada e densa.

- $v_{2}$ : Atributo da densidade de sementes de plantas daninhas na geração seguinte por região. Este atributo reflete os focos de maior e menor produção de sementes 
de plantas daninhas de toda a cultura, ou seja, as sementes presentes nas plantas daninhas, que cairão sobre o solo podendo germinar e influenciar na infestação da geração seguinte. É obtido a partir de um mapa de distribuição da produção de sementes, que pode ser coletada em campo, e por análise de imagens. Condições do atributo: baixa, média e alta.

- $v_{3}$ : Atributo da extensão dos agrupamentos de sementes na geração seguinte por região. Este atributo é obtido por análise de imagens, calculando-se o tamanho dos objetos identificados no mapa de distribuição de sementes e representa como estas sementes contribuem para a proliferação na sua vizinhança. Reflete o tamanho do agrupamento de um determinado valor de densidade de sementes, de forma que pode ser encontrada uma alta densidade de sementes mas com um pequeno agrupamento ou mancha. Condições do atributo: pequena, regular, grande.

- $v_{4}$ : Atributo da competitividade das plantas daninhas na geração atual por região. Este atributo reflete a habilidade de produção de sementes das espécies de plantas daninhas. Dependendo da espécie presente na região, esta pode ser bastante agressiva à cultura, como por exemplo, as espécies de gramíneas. Uma grande porcentagem de ocupação desse tipo de planta na região pode indicar um alto risco de infestação devido à sua alta proliferação. Condições: baixa, média, alta.

\subsection{Obtenção dos Atributos da Infestação Usando Análise de Imagens}

Os mapas de densidade de sementes e cobertura foliar, estimados por Krigagem, são tratados como imagens. A cultura é dividida em $n$ células de tamanho $p \times p$ metros por eixo, com $p$ a distância de interpolação selecionada. Uma matriz $A$ de dimensão $n \times n$ formada pelos valores das intensidades de cada célula da cultura, é então obtida, associada às imagens. Para reduzir o esforço computacional, a distância de interpolação $p$ é escolhida significativamente menor que o alcance do variograma.

Objetos identificados na matriz $A$ fornecem atributos para a infestação e são obtidos como segue. Primeiramente estipula-se os limitantes de cada uma das 3 intensidades da matriz $A$, começando pelo mínimo valor de intensidade encontrado e terminando pelo máximo. São escolhidas 3 intensidades de acordo com o número de condições dos 
atributos. Desta forma, gera-se uma matriz $I$, cujos elementos são 0,1 ou 2 , formando diferentes objetos. Estes, mesmo podendo apresentar a mesma intensidade,podem constituir objetos diferentes da imagem. Em seguida, para identificar os objetos conectados adota-se um modelo de vizinhança 4-conectado (Gonzalez e Woods, 2000) para a agregação de cada pixel a um objeto. Este modelo é implementado primeiramente convertendo-se a matriz $I$ em uma matriz binária denotada $I 1$. Então, os 4 vizinhos mais próximos de um pixel são analisados e os que possuírem o mesmo valor, 0 ou 1, são agregados. Finalmente, os objetos conectados são rotulados e organizados em uma matriz denotada $J$, também de dimensão $n \times n$, representada em escala de cinza, cujos elementos são valores inteiros maiores ou iguais a 0 . Os pixels rotulados como 0 constituem um objeto conectado, os rotulados como 1 constituem um segundo objeto conectado, e assim por diante.

Seja $A$ a matriz cujos elementos foram estimados por Krigagem e NumGrupos o número de grupos de intensidade desejado (quantização), o algoritmo proposto para a determinação do número de objetos conectados associados aos mapas é dado a seguir.

\subsubsection{Algoritmo para Extração de Objetos Conectados}

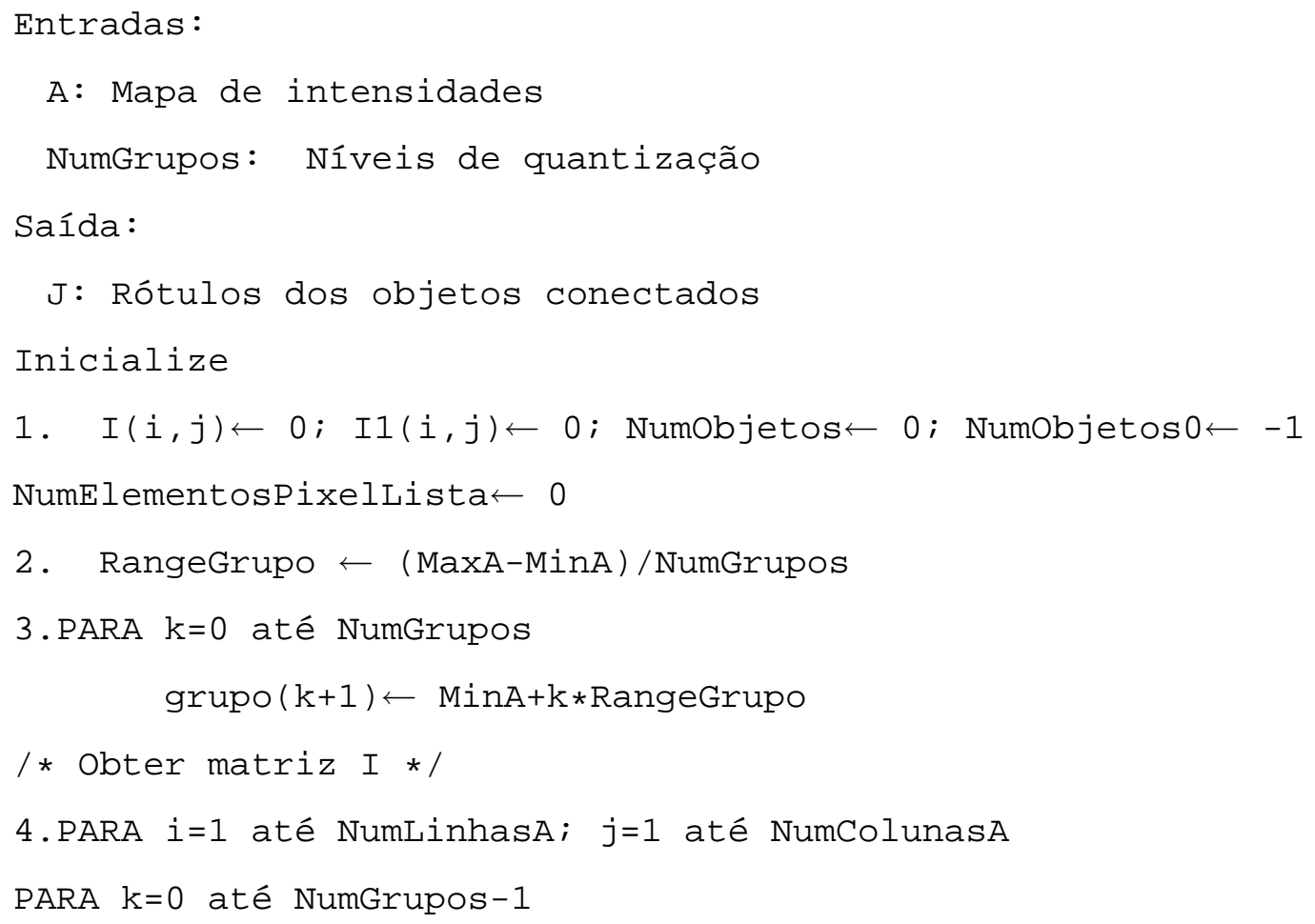




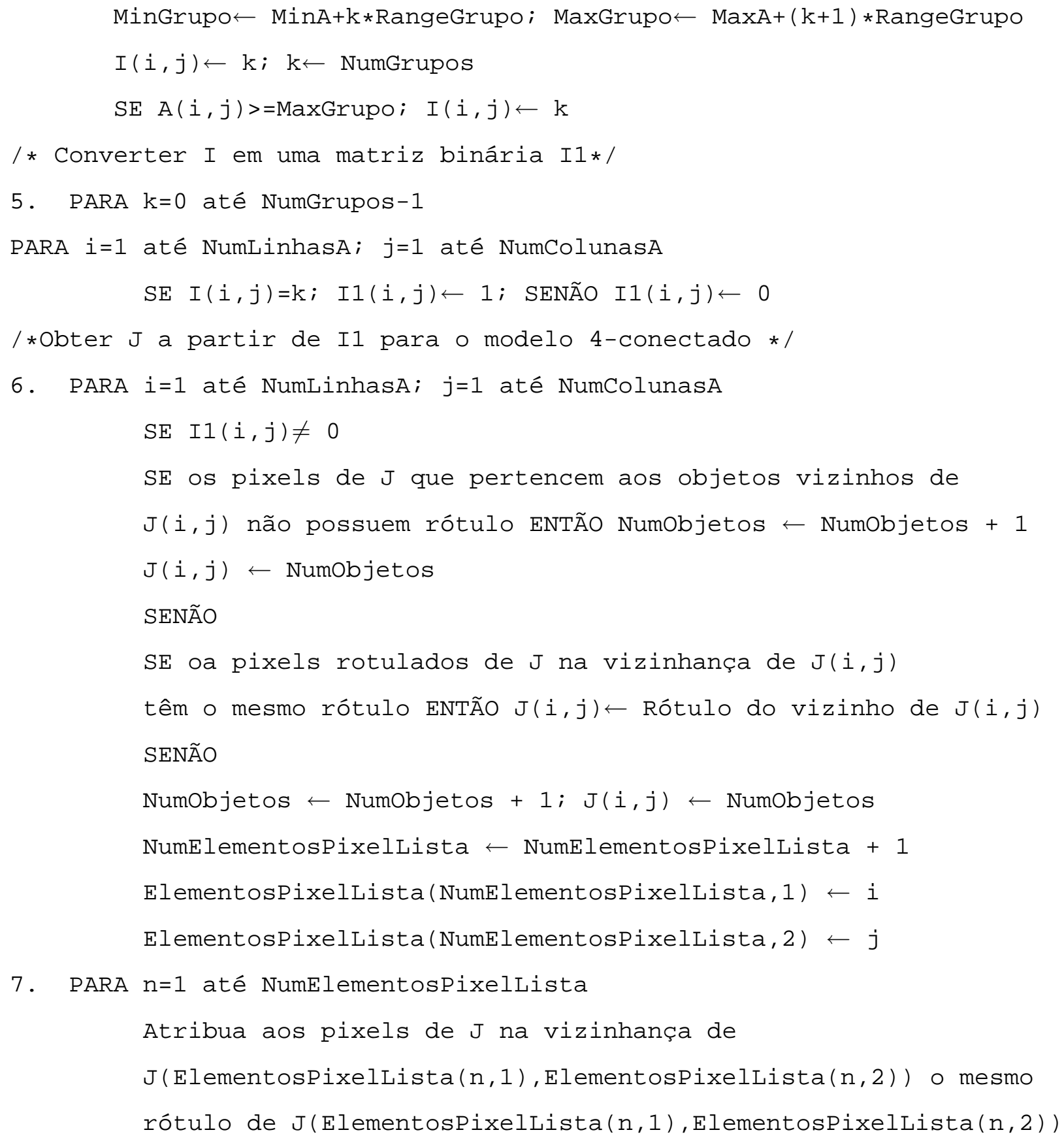

7. PARA $\mathrm{n}=1$ até NumElementosPixelLista

Atribua aos pixels de J na vizinhança de $\mathrm{J}($ ElementosPixelLista $(\mathrm{n}, 1)$, ElementosPixelLista $(\mathrm{n}, 2))$ o mesmo rótulo de $J$ (ElementosPixelLista $(n, 1)$,ElementosPixelLista $(n, 2)$ )

FIM

\subsubsection{Cálculo dos Atributos da Infestação}

Os atributos da infestação por plantas daninhas são entradas do sistema de classificação fuzzy e a saída deste sistema fornece o risco de infestação por plantas daninhas de cada região considerada da cultura. O procedimento para a obtenção dos valores dos $v_{j}, j=1,2,3,4$ atributos em cada região é descrito a seguir. 
$v_{1}: \mathrm{O}$ atributo da cobertura foliar por região é obtido a partir da média ponderada entre as intensidades da matriz $I$ correspondentes aos objetos conectados, identificados no mapa de cobertura foliar, e o número de pixels ocupados por estes em cada região. Do ponto de vista da distribuição das reboleiras, o pior caso seria uma só reboleira preenchendo todos os pixels da região, representando $100 \%$ de ocupação.

$v_{2}$ : O atributo da densidade de sementes por região, associado à produção de sementes, é obtido a partir da média ponderada entre as intensidades da matriz $I$ correspondentes aos objetos conectados, identificados no mapa de densidade de sementes, e o número de pixels ocupados por estes, pois cada região pode conter vários objetos que representam uma mesma densidade.

$v_{3}:$ O atributo da extensão média dos agrupamentos de sementes em cada região é obtido a partir da média ponderada do número de células ocupadas por cada objeto por região. A extensão média se refere ao tamanho dos objetos cujos pixels contêm valores de densidades de sementes. Se um determinado valor de densidade de sementes estiver ocupando uma grande parte da região, isto é, grande número de pixels, então este objeto, constituído por estes pixels, terá maior influência no cálculo da extensão dos objetos em cada região, através da média ponderada.

$v_{4}: \mathrm{O}$ atributo da competitividade das plantas daninhas presentes em cada região pode ser obtido considerando a porcentagem de ocupação de gramíneas em cada região (dados simulados) ou a partir de um sistema neurofuzzy (dados coletados na cultura). Determinadas espécies de plantas daninhas, como as do tipo folha estreita (gramíneas), possuem alta capacidade de produção de sementes, compete com os nutrientes da cultura e portanto, são agressivas à mesma. Se um determinado valor de densidade de sementes for baixo, por exemplo, e apresentar uma cobertura foliar densa, indica que esta espécie de planta daninha apresenta alta proliferação, contribuindo para aumentar o nível de infestação da cultura.

Os Atributos $v_{1}-v_{3}$ são obtidos diretamente a partir de dados da infestação por plantas daninhas, normalizados entre [0 1 1] e então representados na forma de mapas. O Atributo $v_{4}$, que trata da competitividade das plantas daninhas presentes em cada região, não pode ser inferido diretamente e pode ser obtido considerando a porcentagem de ocupação de gramíneas em cada região, o que foi aplicado aos dados simulados, ou a partir de um sistema neurofuzzy, o que foi aplicado aos dados coletados na cultura. 
Neste, a densidade total de plantas e a correspondente proporção de plantas do tipo folha larga e folha estreita são entradas do sistema, pois, dependendo do tipo de folha, a planta daninha pode ser mais ou menos competitiva à cultura. A saída fornecida ao sistema neurofuzzy supervisionado consiste na biomassa das plantas, pois, quanto maior a biomassa da planta daninha, maior sua competitividade com a cultura.

O toolbox ANFIS do MATLAB é utilizado para efetuar o treinamento do sistema neurofuzzy com um sistema de inferência do tipo Sugeno. O método de treinamento da rede neural contida no sistema é um algoritmo baseado em uma abordagem híbrida (Jang, 1993), o qual combina o método backpropagation com o método dos mínimos quadrados. O conjunto de dados no editor ANFIS deve ser uma matriz com dados de entrada arranjados como vetores. A última coluna desta matriz deve apresentar os dados de saída. O conjunto de dados deve ser particionado em dois subconjuntos: de treinamento e de teste. Os dados do subconjunto de treinamento, geralmente $80 \%$ dos dados disponíveis, são utilizados para o treinamento da rede, cujo objetivo é o ajuste das funções de pertinência. Os dados do subconjunto de teste, geralmente $20 \%$ dos dados disponíveis, são utilizados para avaliar se a rede está generalizando de forma satisfatória. Este procedimento é denominado validação cruzada. A diferença entre a saída desejada, que é fornecida ao sistema, e a saída estimada pela rede é chamada de resíduo. Para avaliar o desempenho do sistema neurofuzzy, a análise dos resíduos é feita no subconjunto de teste, já que os dados de treinamento já foram utilizados no processo de ajuste das funções de pertinência.

\subsection{Base de Regras e Funções de Pertinência}

A combinação de todos os atributos em suas diversas condições fornece uma base de regras fuzzy. A saída do sistema de classificação, $c_{i}, \mathrm{i}=1, \ldots, \mathrm{C}$, é o risco de infestação por região, que pode ser alto, médio ou baixo. O conectivo E é modelado pelo operador mínimo produto, permitindo a interação entre as proposições no antecedente. O método do máximo é usado para agregar as regras e o centro de massa, também chamado de centróide (ver Apêndice B), é utilizado para a deffuzificação. A base de regras para o sistema de classificação é construída considerando todas as possibilidades das condições dos diversos atributos, definidas na Seção 6.1. A Tabela 6.1 exibe a base de regras fuzzy, construída com a ajuda de especialistas, para a determinação do risco de infestação de 
cada região da cultura.

Por exemplo, a regra destacada na Tabela 6.1 representa a seguinte descrição:

$\mathrm{SE}$ a densidade de sementes na célula é baixa $\mathrm{E}$ a extensão dos agrupamentos de sementes em cada célula é pequena $\mathrm{E}$ a cobertura foliar na célula é rala $\mathrm{E}$ a competitividade da planta daninha é baixa ENTÃO risco de infestação é baixo

Prossegue-se da mesma forma para a construção de outras regras, combinando as condições dos atributos.

Tabela 6.1: Base de regras fuzzy para o risco de infestação por plantas daninhas. O primeiro subscrito denota a classe de infestação: 1 - baixa infestação, 2 - média infestação e 3 - alta infestação. O segundo subscrito denota quantas vezes a classe do primeiro subscrito está sendo citada.

Densidade de Sementes/ Extensão do Agrupamento

Cobertura/baixa/ baixa/baixa/ média/ média/média/ alta/ alta/ alta/
Competitividade pequena regular grande pequena regular grande pequena regular grande

\begin{tabular}{cccccccccc}
\hline rala/baixa & $\mathbf{c}_{\mathbf{1 1}}$ & $c_{16}$ & $c_{110}$ & $c_{113}$ & $c_{116}$ & $c_{117}$ & $c_{118}$ & $c_{119}$ & $c_{120}$ \\
\hline rala/média & $c_{12}$ & $c_{17}$ & $c_{28}$ & $c_{211}$ & $c_{215}$ & $c_{219}$ & $c_{23}$ & $c_{22}$ & $c_{231}$ \\
\hline rala/alta & $c_{13}$ & $c_{24}$ & $c_{29}$ & $c_{212}$ & $c_{38}$ & $c_{312}$ & $c_{316}$ & $c_{320}$ & $c_{324}$ \\
\hline moderada/baixa & $c_{14}$ & $c_{18}$ & $c_{111}$ & $c_{114}$ & $c_{216}$ & $c_{220}$ & $c_{224}$ & $c_{22}$ & $c_{232}$ \\
\hline moderada/média & $c_{21}$ & $c_{25}$ & $c_{210}$ & $c_{213}$ & $c_{217}$ & $c_{221}$ & $c_{225}$ & $c_{22}$ & $c_{233}$ \\
\hline moderada/alta & $c_{22}$ & $c_{26}$ & $c_{33}$ & $c_{36}$ & $c_{39}$ & $c_{313}$ & $c_{317}$ & $c_{321}$ & $c_{325}$ \\
\hline densa/baixa & $c_{15}$ & $c_{19}$ & $c_{112}$ & $c_{115}$ & $c_{218}$ & $c_{222}$ & $c_{226}$ & $c_{230}$ & $c_{234}$ \\
\hline densa/média & $c_{23}$ & $c_{27}$ & $c_{34}$ & $c_{214}$ & $c_{310}$ & $c_{314}$ & $c_{318}$ & $c_{322}$ & $c_{326}$ \\
\hline densa/alta & $c_{31}$ & $c_{32}$ & $c_{35}$ & $c_{37}$ & $c_{311}$ & $c_{315}$ & $c_{319}$ & $c_{323}$ & $c_{327}$ \\
\hline
\end{tabular}

Para a classificação fuzzy das regiões da cultura segundo o risco de infestação por plantas daninhas é utilizado o editor de sistemas de inferência fuzzy do MATLAB (FIS Editor) descrito no Apêndice B. A Figura 6.2 exibe as funções de pertinência das variáveis de entrada e de saída e suas respectivas variáveis linguísticas para os dados simulados. A função de pertinência adotada para a saída inclui uma faixa de valores negativos para a parte inferior da função "baixa" e uma faixa de valores acima de $100 \%$ para a parte superior da função "alta" somente para efeito de cálculo, para garantir que a menor infestação seja nula e a maior seja 100\% (Yang et al., 2003).

Para o sistema de classificação fuzzy utilizando dados reais coletados em campo, foram utilizadas as funções de pertinência da Figura 6.3 e a base de regras da Tabela 6.1, construídas com ajuda de especialistas especificamente para a área em estudo. Funções de pertinência do tipo triangulares também foram aplicadas e avaliadas no Capítulo 7. 


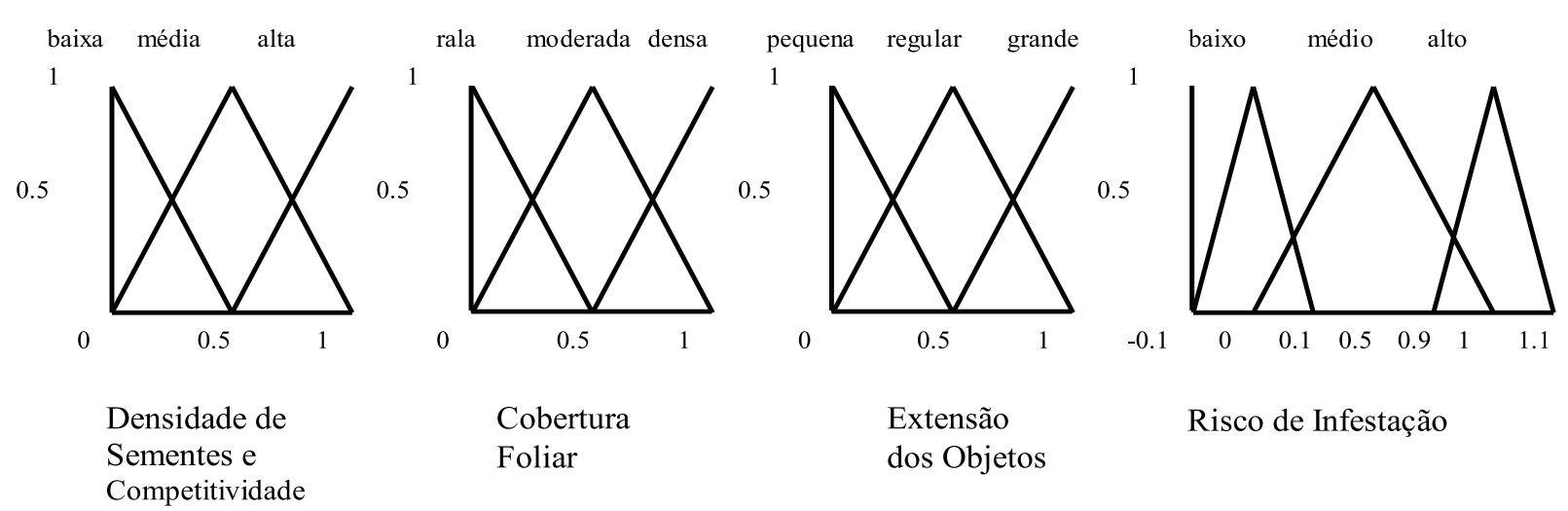

Figura 6.2: Funções de pertinência das entradas (atributos da densidade de semente, da cobertura foliar, da extensão dos agrupamentos de semente e da competitividade) e da saída (risco de infestação) do sistema de classificação fuzzy simulado.

Aplicando este sistema de classificação fuzzy para cada região considerada, os valores dos atributos são entradas do sistema e a saída é a matriz Risco que representa a porcentagem do risco de infestação de cada região.

\subsection{Agrupamento K-médias dos Riscos de Infestação}

Os valores de risco de infestação obtidos para cada região da cultura são reunidos em agrupamentos semelhantes, considerando a localização e o valor estimado para o risco, com o objetivo de indicar níveis diferentes de aplicação localizada de herbicida.

Um dos mais simples algoritmos de busca de agrupamento de dados é o algoritmo k-médias (Hartigan e Wong, 1979). Inicialmente define-se o número de agrupamentos $k$ desejado. Em seguida, atribui-se arbitrariamente os dados aos agrupamentos $X^{j}, j=$ $1, \ldots, k$ e calcula-se os correspondentes centróides, que representam a média de todos os pontos pertencentes ao agrupamento $X^{j}$, obtidos da seguinte forma:

$$
c_{j}=\frac{1}{m_{j}} \sum_{x_{i}^{j} \in X^{j}} x_{i}^{j} .
$$

com $m_{j}$ o número de elementos do agrupamento $X^{j}$. Finalmente, recalcula-se o centróide para cada agrupamento, até que seja minimizado o funcional (Bezdek, 1999) 

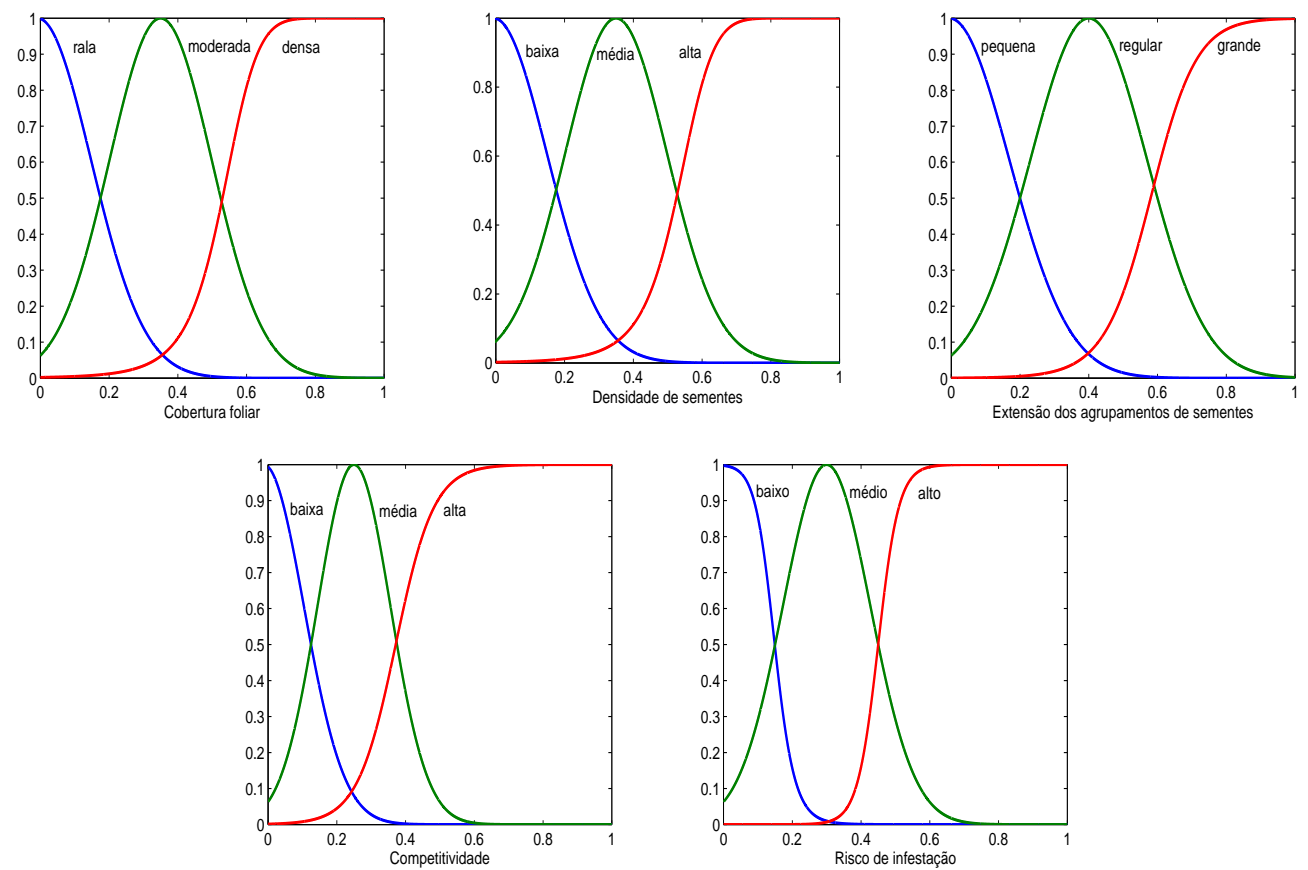

Figura 6.3: Funções de pertinência das entradas (atributos da densidade de sementes, da cobertura foliar, da extensão dos agrupamentos de sementes e da competitividade) e da saída (risco de ifestação) do sistema de classificação fuzzy com dados coletados em campo.

$$
J=\sum_{j=1}^{k} \sum_{i=1}^{m} J_{i j}, \quad x_{i}^{j} \in X^{j}
$$

onde $J_{i j}=\left\|x_{i}^{j}-c_{j}\right\|^{2}$ é uma medida de distância entre um ponto $x_{i}^{j}$ e o centróide $c_{j}, \operatorname{com} j=1, \ldots, k$ e $i=1, \ldots, m$, com $m$ o número de elementos da matriz Risco. A métrica utilizada é a distância euclidiana. O funcional $J$ fornece o erro quadrático total ao representar os dados $x_{i}^{j}$ por $k$ agrupamentos com seus respectivos centróides $c_{j}$.

Para automatizar a seleção do número ideal de agrupamentos para o risco de infestação, considera-se o uso de um coeficiente para medir a dispersão da variabilidade dos riscos em relação ao centróide. O coeficiente de variação utilizado, denotado $c v$, é definido por (Bussab e Morettin, 2005):

$$
c v=\frac{S}{\bar{X}}
$$

onde $S$ e $\bar{X}$ são o desvio padrão e a média dos riscos por agrupamento, respectivamente, com $\bar{X} \neq 0$. O coeficiente de variação $c v$ é usualmente expresso em porcentagem. Quanto mais próximo de 1, maior a dispersão dos riscos e menos homogêneos estes 
serão. Como deseja-se que os elementos de cada agrupamento sejam o mais semelhante possível, se o coeficiente de variação for maior que 0,2 (Clemente e Muniz, 2002), o algoritmo k-médias é reiniciado com um número maior de agrupamentos, até que todos estes possuam um coeficiente de variação menor que 0,2 .

\subsubsection{Algoritmo K-médias com Coeficiente de Variação}

Entradas:

Risco: Matriz risco

$X^{j}:$ Agrupamento, $j=1, \ldots, k$

Saídas:

$J$ : Erro quadrático

$k$ : Número de agrupamentos

$c v$ : Coeficientes de variação

Inicialize

1. $k \leftarrow 2$;

2. $c_{j} \leftarrow(6.1) ;$

3. $c v \leftarrow(6.3) ;$

4. ENQUANTO $c v>0,2$ para pelo menos 1 agrupamento

$$
\begin{gathered}
J_{i j} \leftarrow\left\|x_{i}^{j}-c_{j}\right\|^{2} \\
\operatorname{SE} J_{i j}>\left\|x_{i}^{j}-c_{l \neq j}\right\|^{2} \\
x_{i}^{j} \in X^{l} \\
c_{j} \leftarrow(6.1) ; \\
\operatorname{SENÃO} x_{i}^{j} \in X^{j} \\
\operatorname{FIM} \\
k \leftarrow k+1 ; \\
c v \leftarrow \quad(6.3) ;
\end{gathered}
$$

5. $J \leftarrow(6.2)$ 
FIM

No próximo capítulo, a estimação por Kriagem, bem como a validação cruzada, são aplicadas na construção de mapas da cobertura foliar na geração atual e da distribuição de sementes de plantas daninhas na geração seguinte. Os mapas, bem como o risco de infestação por regiões pelo sistema fuzzy proposto, são obtidos para os dados simulados e para os dados reais coletados na cultura em dois plantios diferentes. 


\section{Capítulo 7}

\section{Resultados da Classificação}

\section{Fuzzy do Risco de Infestação de Regiões}

Inicialmente, dados de cobertura foliar e de densidade de sementes são simulados e organizados em um arquivo de dados com o objetivo de obter mapas de estimativa via Krigagem utilizados para interpretação das condições dos atributos. Para verificar se o método de Krigagem utilizado infere bons resultados é feita a análise dos resíduos pela validação cruzada. Em seguida, os mesmos mapas são gerados a partir de dados coletados na área experimental descrita no Capítulo 3. Os objetos que constituem as imagens dos mapas gerados por Krigagem são identificados, utilizando o algoritmo da Seção 6.2, para obter os valores dos atributos correspondentes a cada região considerada da cultura. O sistema de classificação fuzzy proposto no Capítulo 6 é então aplicado para os dados simulados e para os dados coletados, obtendo-se diferentes riscos de infestação para cada região. Para os dados coletados, estes riscos são reunidos em agrupamentos pelo método k-médias, descrito na Seção 6.4.1, a fim de reunir os riscos semelhantes. Os resultados para os dados coletados em campo são exibidos para duas coletas de dados de dois plantios diferentes da cultura de milho: a coleta realizada em março de 2005, usada para inferir o risco de infestação na geração denotada $t$, e a realizada em outubro de 2006, usada para inferir o risco de infestação na geração denotada $t+2$. 


\subsection{Simulação de Dados Utilizando Modelos de Populações}

A partir da teoria geoestatística apresentada no Capítulo 4, são obtidos mapas de estimativa para a cobertura foliar e para a densidade de sementes de plantas daninhas, a partir da simulação de dados das dinâmicas (4.13) e (4.12).

Como mencionado na Seção 2.2, devido à variabilidade espacial das plantas daninhas nas áreas agrícolas, é possível através de mapas detectar as reboleiras destas plantas e controlar somente as áreas de ocorrência (Baio e Balastreire, 2001).

$\mathrm{Na}$ tentativa de tornar o modelo (4.12) mais representativo de uma cultura real e aplicar as técnicas de mapeamento geoestatísticas, o parâmetro taxa de germinação, denotado $g$, foi gerado aleatoriamente pelo método de Monte Carlo a partir de uma distribuição normal em torno do ponto $g=0,1$ com um desvio de média 0 e variância 0,04 , ou seja, $g \sim N(0,1 ; 0,04)$. O comportamento da densidade de sementes de plantas daninhas em função da geração da planta, dada por (4.12), com taxa de germinação média $g=0,1$, pode ser observado na Figura 7.1, onde pode-se notar a estabilização da densidade em níveis baixos, por efeito da taxa de controle $c$.

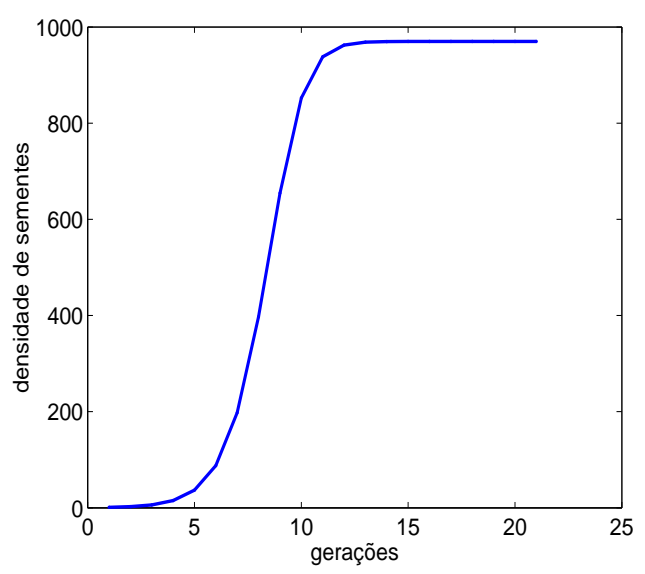

Figura 7.1: Densidade de sementes em função da geração da planta para os parâmetros $X_{0}=1$ semente $m^{-2}, g=0,10, s=248, a=4,0 \times 10^{-3}$ e $b=2,77$ usando (4.12).

Para simular um mapa de densidade de sementes, são simulados dados da geração $t=6$ das plantas, com o objetivo de ilustrar o comportamento no início da curva de crescimento das sementes, como pode ser visto na Figura 7.1. Para simular um mapa de cobertura foliar, os dados são simulados para $t=5$, usando (4.13). Para simular a presença de espécies de plantas daninhas do tipo folha estreita, que produzem mais sementes do que as do tipo folha larga, o modelo (4.12) foi executado com o parâmetro 
$s=500$ nas seguintes coordenadas: $(40,20),(40,30),(50,40),(40,60),(40,50),(70,30)$, $(70,40),(70,20),(60,10),(60,30),(40,40),(30,40),(20,40),(20,20),(90,80),(80,80)$, $(100,30)$ e $(90,30)$.

A simulação dos dados de densidade de sementes, obtidos a partir de (4.12), é feita uma variação aleatória do parâmetro $g$ da seguinte forma:

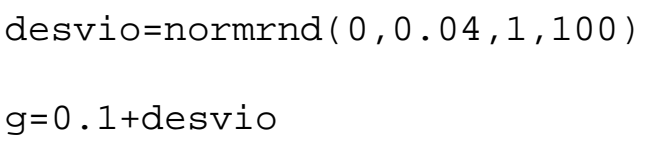

o que gera com média 0 e variância $0,04,100$ valores de densidade de sementes para a geração $t=6$ e 100 valores de cobertura foliar para a geração $t=5$, sendo então, $N=100$ dados.

\subsection{Mapas com Dados Simulados}

\subsubsection{Análise Exploratória dos Dados}

A análise exploratória objetiva verificar o padrão de distribuição espacial dos dados, com a finalidade de evitar agrupamentos indesejáveis; identificar a possível ocorrência de valores anômalos (outliers); eventual presença de tendências; verificar distribuição normal dos dados e se os mesmos provém de uma mesma população. Para realizar as análises geoestatísticas, é utilizado um aplicativo chamado GEOMATLAB, baseado na linguagem do MATLAB, desenvolvido por Iwashita e Landim (2003). As funções utilizadas presentes no aplicativo GEOMATLAB, bem como o procedimento para utilização, estão descritas no Apêndice A.

A função 'normal' do GEOMATLAB gera um histograma, um gráfico da distribuição espacial dos dados e suas intensidades e apresenta os valores da média, desvio padrão, valor máximo e valor mínimo para cada variável. Desta forma, é feita a análise exploratória dos dados de cobertura foliar e de densidade de sementes para que seja verificada a distribuição espacial e a distribuição normal dos dados. A Figura 7.2a apresenta a distribuição dos 100 dados de cobertura foliar obtidas por (4.13) na geração $t=5$ e a Figura $7.2 \mathrm{~b}$ mostra as intensidades dos 100 dados de densidade de sementes 
obtidas por (4.12) após a geração $t=6$.

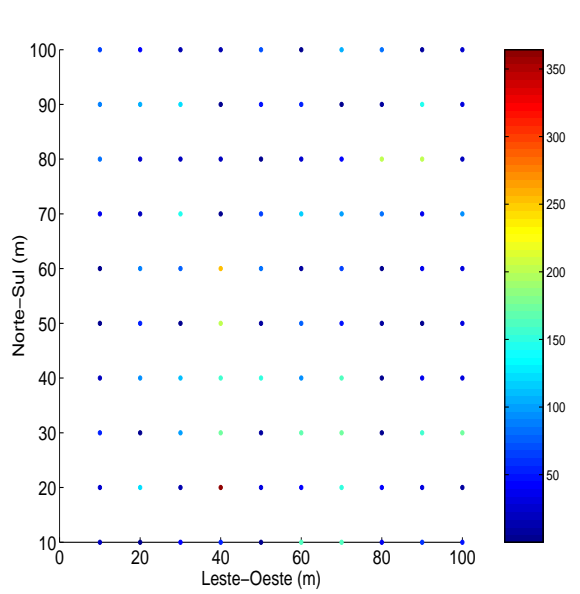

(a)

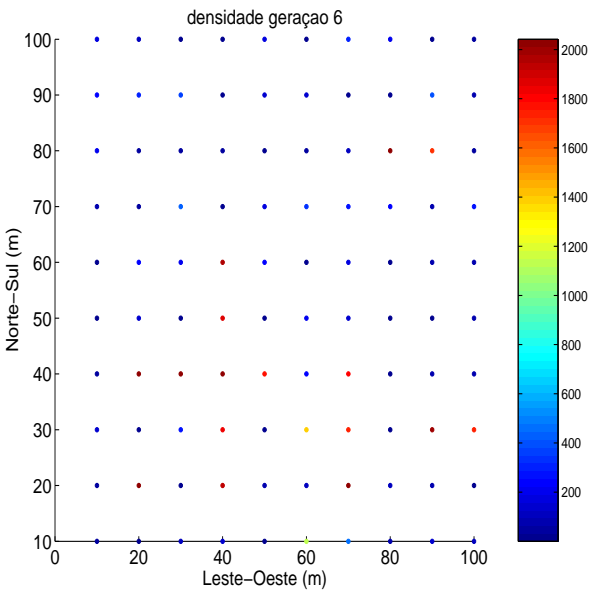

(b)

Figura 7.2: (a) Distribuição dos dados simulados de cobertura foliar; (b) Distribuição dos dados simulados de densidade de sementes.

A Figura 7.3a exibe o histograma para os dados de cobertura foliar, onde podese observar as ocorrências de cada valor e as estatísticas descritivas do conjunto de dados. O histograma para os dados da geração de sementes de plantas daninhas $t=6$ é apresentado na Figura 7.3b.

Pelo Teorema do Limite Central, quando o tamanho do conjunto de dados é maior que 30, independentemente da forma da distribuição da população, a distribuição da média amostral aproxima-se de uma distribuição normal (Bussab e Morettin, 2005). Desta forma, não é necessário verificar a normalidade dos dados.

\subsubsection{Ajuste dos Variogramas}

Algumas das funções utilizadas para a aplicação da análise geoestatística pertencem ao pacote BMELib (Christakos et al., 2002). Assim, para confeccionar o variograma experimental e seu ajuste a um modelo teórico, foi utilizada a função variograma1 do GEOMATLAB, que acessa e combina as funções do BMELib. Esta função exibe o variograma experimental de um arquivo de dados escolhido e ajusta um modelo teórico de variograma aos pontos experimentais.

O índice de ajuste do modelo teórico de variograma ao modelo experimental dado por (4.1) é calculado a partir de (Iwashita e Landim, 2003) como segue. 


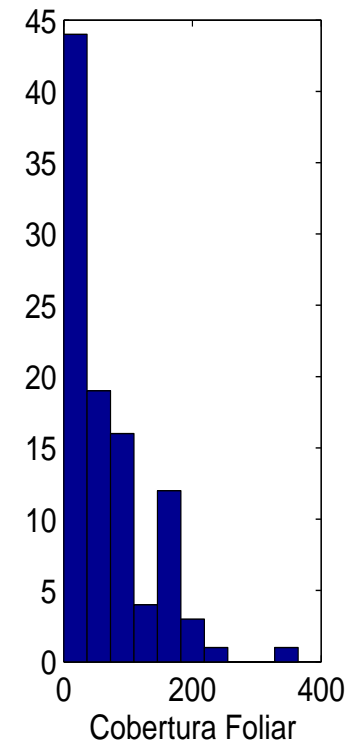

(a)

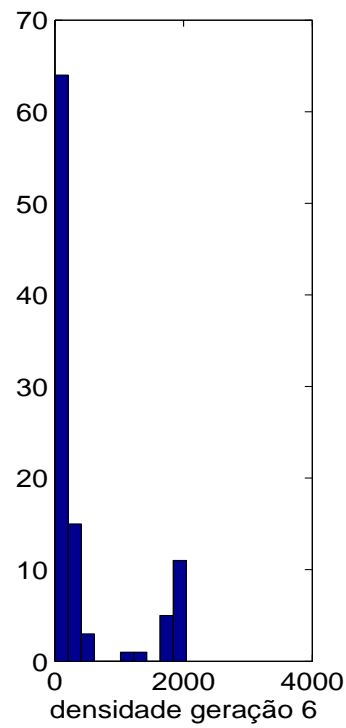

(b)

Figura 7.3: (a) Histograma para os dados simulados de cobertura foliar. Estatísticas descritivas: Média $=$ 67,512, Desvio padrão $=66,900$, Máximo $=364,310$ e Mínimo $=0,0114$; (b) Histograma para os dados da geração de sementes $t=6$. Estatísticas descritivas: Média $=424,437$, Desvio padrão $=681,980$, Máximo $=2042,100$ e Mínimo $=0,0037$.

$$
F I=\frac{1}{N} \sum_{k=1}^{N} \frac{\sqrt{\left(\gamma^{*}\left(h_{k}\right)-\gamma\left(h_{k}\right)\right)^{2}}}{\gamma\left(h_{k}\right)} .
$$

onde

FI: índice de ajuste calculado, e quanto menor, melhor o ajuste;

$N$ : número de elementos no domínio de $\gamma$;

$\gamma^{*}(h)$ : valores do variograma experimental;

$\gamma(h)$ : valores do modelo teórico de variograma adotado para o ajuste.

Para a confecção dos variogramas experimentais são calculados os valores de $\gamma^{*}(h)$ confrontando-os com os respectivos $h$. As somatórias necessárias para o cálculo de $\gamma^{*}(h)$ devem ser constituídas por um número suficiente de pares, que tornem o resultado consistente, o que pode ser conseguido com um tamanho adequado de $h$ (Landim, 2003).

A análise variográfica é feita com um variograma "omnidirecional ", ou seja, com um ângulo de tolerância de 90 graus para ambos os lados de uma direção qualquer considerada. Isto maximiza o número de pares para cada intervalo de distância e, usualmente, apresenta o variograma mais suavizado, com as melhores estimativas para 
o efeito pepita, o patamar e o alcance, definidos na Seção 4.2.

O ajuste de um variograma experimental a um modelo teórico é o passo mais importante na análise variográfica, sendo um processo que envolve várias tentativas. O ajuste é manual por comparação visual, mais sujeito a erros, e não com auxílio de algoritmos, para ajustes automáticos. Um primeiro ajuste é feito e verifica-se a adequação ao modelo teórico segundo o resultado de (7.1). Dependendo do ajuste, pode-se redefinir o modelo, até que seja obtido um resultado satisfatório e com o menor índice de ajuste (Iwashita e Landim, 2003).

A função 'variograma1' foi executada para a cobertura foliar e para a de densidade de sementes na geração $t=6$, a fim de obter os parâmetros da análise variográfica e analisar a correlação espacial entre os dados. O ajuste do variograma para a cobertura foliar na geração das plantas daninhas $t=5$ é obtido com parâmetros como segue:

variograma1 (' cobertura.dat', 1,2,3, [0:10:80],1, 'exponentialV', 0, [4800 $21],-90,90,1)$

E o ajuste do variograma teórico para a densidade de sementes na geração de plantas daninhas $t=6$ é obtido, respectivamente, com a função variograma1 e parâmetros como segue:

variogramal ('sementes.dat', 1,2,3, [0:10:75],1, 'exponentialV',0, [500000 $21],-90,90,1)$

Os modelos teóricos de variograma (4.2), (4.3) e (4.4) foram testados e o modelo exponencial foi escolhido por ter apresentado o menor índice de ajuste, dado por (7.1), como pode ser verificado na Tabela 7.1. A Figura 7.4a exibe a curva do variograma para os dados de cobertura foliar e a Figura 7.4b exibe a curva do variograma para os dados de densidade de sementes, ajustadas aos pontos que representam os pares de pontos de mesma distância. A partir do variograma pode-se notar a dependência espacial entre os dados até o alcance de 21 metros. Além do alcance, o variograma permanece constante, com patamar de 4800 para a cobertura foliar e 500000 para a densidade de sementes, não havendo mais correlação entre os dados.

A Tabela 7.2 exibe os resultados obtidos para cada ponto dos variogramas experimentais, ou seja, o número de pares de pontos separados por $h$, o valor da distância $h$ e de $\gamma^{*}(h)$. 


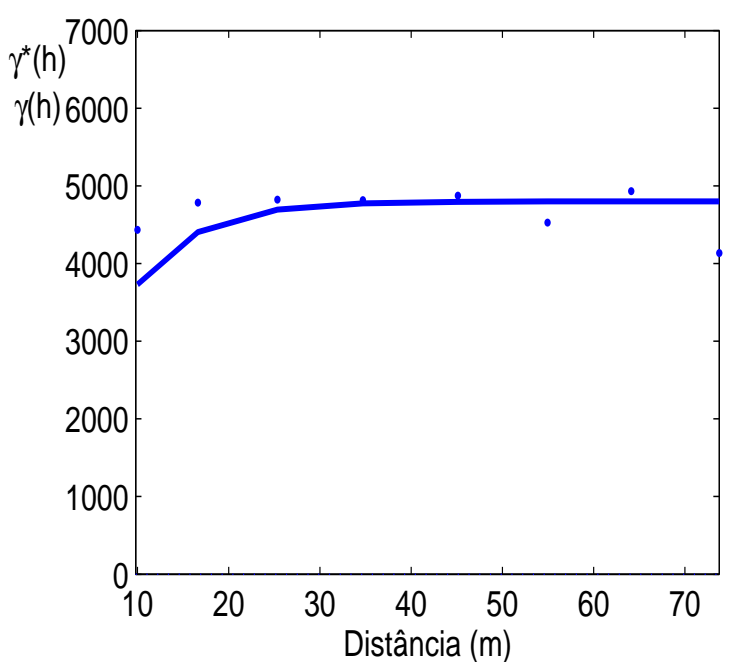

(a)

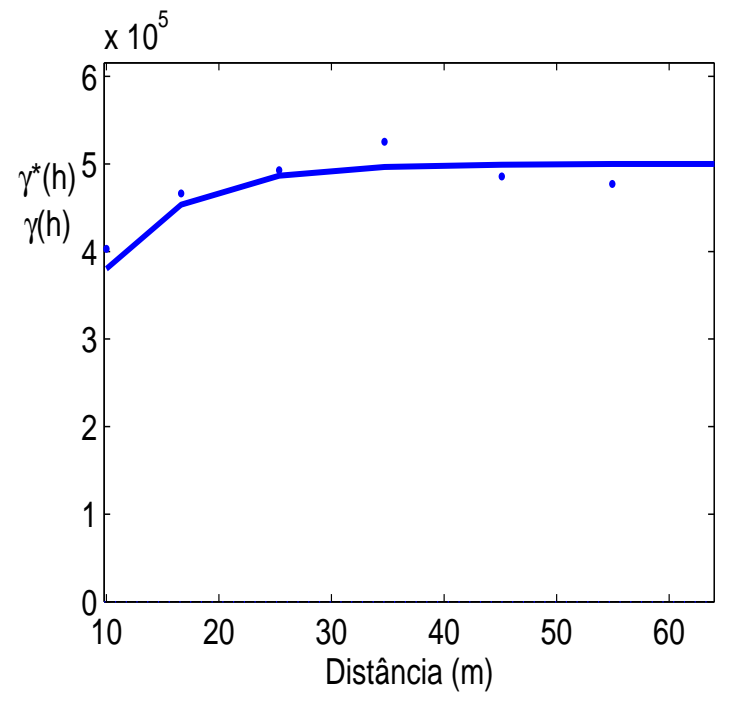

(b)

Figura 7.4: Ajuste dos variogramas teóricos obtido com o modelo exponencial (linha contínua) para os dados de (a) cobertura foliar na geração $t=5 \mathrm{com} C_{0}=3,75 \times 10^{3}, C_{0}+C_{1}=4,8 \times 10^{3}$ e (b) densidade de sementes na geração $t=6 \mathrm{com} C_{0}=3,8 \times 10^{5}, C_{0}+C_{1}=5,0 \times 10^{5}$ e os correspondentes variogramas experimentais (pontos).

Tabela 7.1: Índice de ajuste para os modelos teóricos de variogramas.

\begin{tabular}{ccc} 
Modelo & Densidade de semente & Cobertura foliar \\
\hline Exponencial & 0,04 & 0,07 \\
Gaussiano & 0,12 & 0,14 \\
Esférico & 0,07 & 0,09
\end{tabular}

\subsubsection{Estimação por Krigagem}

Os mapas de estimativas são gerados utilizando a função 'krigagem1' do GEOMATLAB, descrita no Apêndice A, a qual exibe o mapa de valores estimados por Krigagem ordinária. Os mapas inferem os valores de cobertura foliar e de densidades de sementes de populações de plantas daninhas e exibem os valores estimados. A cultura simulada, que possui $10000 \mathrm{~m}^{2}$, é dividida em 33 pixels de $3 \mathrm{~m} \times 3 \mathrm{~m}$ por eixo. Assim, obtém-se uma matriz $A$ de dimensão $33 \times 33$, cujos elementos são os valores da intensidade em cada pixel. O mapa de estimativa de valores de cobertura foliar a partir dos dados na geração das plantas daninhas $t=5$, é obtido pelos parâmetros seguintes:

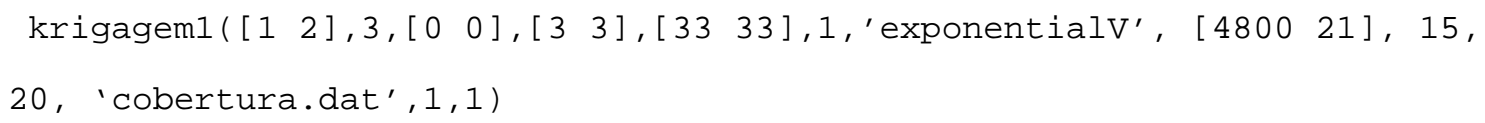

E o mapa de estimativa de valores da densidade de sementes para a geração $t=6$ é 
Tabela 7.2: Resultados dos variogramas.

\begin{tabular}{lccc} 
& Pares de pontos & distância $h$ & $\gamma^{*}(h)$ \\
\hline Densidade de sementes & 135 & 10,00 & $4,03 \times 10^{5}$ \\
& 282 & 16,63 & $4,66 \times 10^{5}$ \\
& 521 & 25,35 & $4,93 \times 10^{5}$ \\
& 566 & 34,71 & $5,25 \times 10^{5}$ \\
& 749 & 45,13 & $4,85 \times 10^{5}$ \\
& 612 & 54,96 & $4,77 \times 10^{5}$ \\
Cobertura foliar & 549 & 64,12 & $5,60 \times 10^{5}$ \\
\hline 135 & 10,00 & $4,43 \times 10^{3}$ \\
& 282 & 16,63 & $4,79 \times 10^{3}$ \\
& 521 & 25,35 & $4,82 \times 10^{3}$ \\
& 566 & 34,71 & $4,81 \times 10^{3}$ \\
& 749 & 45,13 & $4,87 \times 10^{3}$ \\
612 & 54,96 & $4,53 \times 10^{3}$ \\
& 549 & 64,12 & $4,93 \times 10^{3}$ \\
& 544 & 73,76 & $4,13 \times 10^{3}$
\end{tabular}

obtido da seguinte forma:

krigagem1 ([1 2], 3, [0 0], [3 3], [33 33],1,' exponentialV', [500000 21], 15, 20, 'sementes.dat', 1,1)

O parâmetro que define a distância máxima entre o ponto a ser estimado e o ponto dado é escolhido de forma a não ultrapassar o alcance, estabelecido pelos parâmetros do variograma, respeitando desta forma a dependência espacial entre os dados.

O mapa de estimativa da cobertura foliar na geração das plantas daninhas $t=5$, tendo como amostras os 100 pontos gerados por (4.13) e distribuídos como na Figura 7.2a, é exibido na Figura 7.5a. O mapa de estimativa de valores da densidade de sementes utilizando como dados os 100 pontos na geração $t=6$, extraídos por (4.12) e distribuídos conforme Figura 7.2b, é exibido na Figura 7.5b com os seguintes parâmetros para (4.12): $s=248$ ou $s=500, a=4.0 \times 10^{-3}, b=2.77, c=0.9, X_{0}=1, g \sim$ $N(0.1,0.04)$ e um limiar máximo de 4000 sementes $/ m^{2}$ para a produção de sementes por planta na próxima geração.

\subsubsection{Validação Cruzada}

Para verificar a eficiência do modelo geoestatístico (4.5), calcula-se a diferença entre o valor amostrado e o valor estimado por Krigagem, cuja diferença é o resíduo. Utiliza-se 


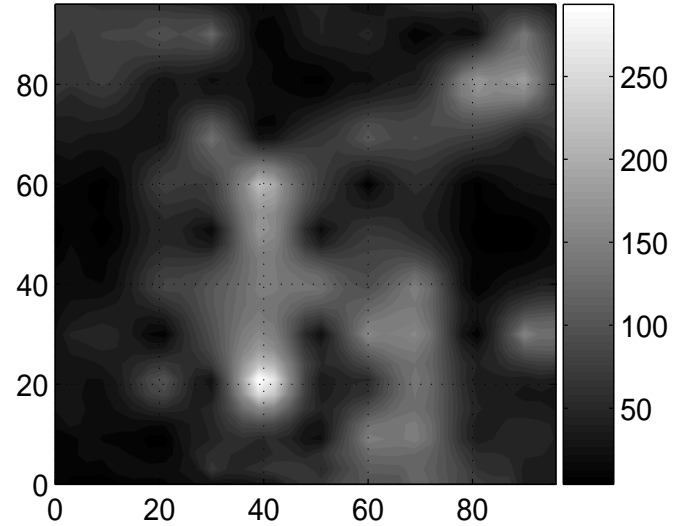

(a)

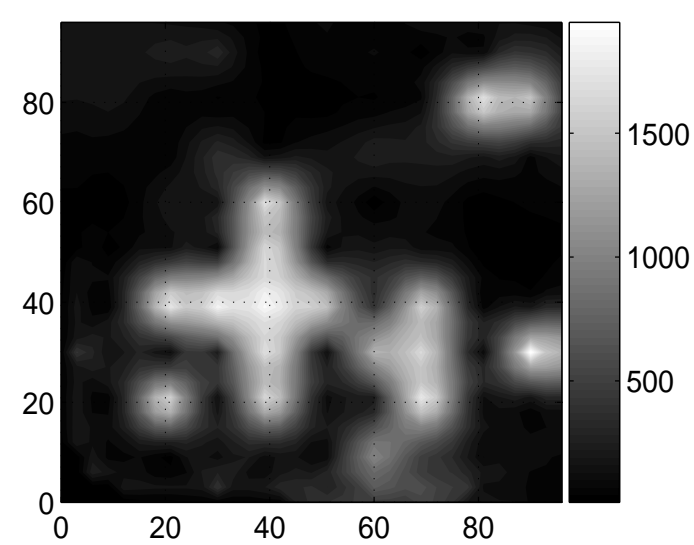

(b)

Figura 7.5: (a) Mapa de cobertura foliar de plantas daninhas estimado por Krigagem na geração $t=5$; (b) Mapa da densidade de sementes de plantas daninhas estimado por Krigagem na geração $t=6$.

a função 'validacao1', contida no GEOMATLAB, para calcular os valores estimados e os resíduos. Esta função efetua a validação cruzada, consistindo em descartar um dado de uma determinada localização e estimar este valor, através da Krigagem, a partir dos dados restantes, como se este valor não tivesse sido medido. Desta forma, esta função fornece os valores medidos, os valores estimados para estas mesmas localizações e os resíduos.

Após a validação cruzada, foi utilizado o aplicativo estatístico MINITAB $13^{1}$ para realizar a análise dos resíduos. Para avaliar a eficiência do método de estimação por Krigagem, a análise de resíduos é feita para a estimação dos dados de cobertura foliar, na geração $t=5$ das plantas daninhas, e para a densidade de sementes na geração $t=6$.

Como descrito na Seção 4.4, é construído o intervalo de confiança para a média dos resíduos das estimativas da cobertura foliar e da densidade de sementes, testando a hipótese desta média ser igual a zero ou não. Com 95\% de confiança, a média dos resíduos da estimativa da cobertura foliar está entre -0,1216 e 0,1417 e dos resíduos da estimativa da densidade na geração $t=6$ está entre -0,1166 e 0,1420, não rejeitando a hipótese de que os resíduos apresentam média zero em ambos os casos. Os histogramas para as médias dos resíduos podem ser visualizados na Figura 7.6a, para os dados de cobertura foliar, e na Figura 7.6b para a densidade de sementes.

O comportamento da variância dos resíduos pode ser visualizado na Figura 7.7a

\footnotetext{
${ }^{1}$ www.minitab.com
} 


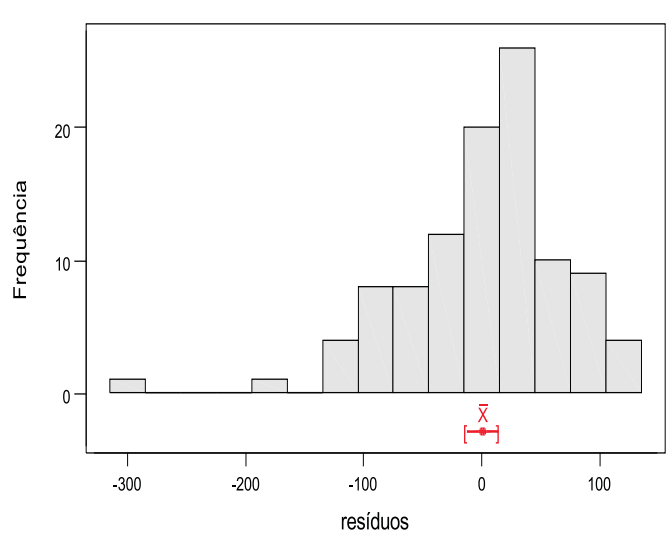

(a)

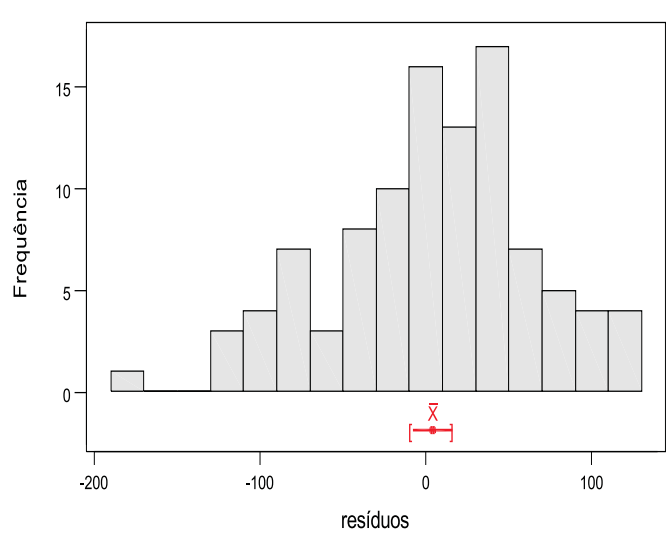

(b)

Figura 7.6: Histograma para média do resíduo da estimativa com 95\% de confiança: (a) cobertura foliar $(t=5)$; (b) densidade de sementes $(t=6)$.

para a variância dos resíduos de cobertura foliar e na Figura 7.7b para a variância dos resíduos de densidade de sementes.

Pela observação gráfica, como não houve pontos fora dos limites superior (UCL) e inferior (LCL), pode-se concluir que, para ambas as variáveis cobertura foliar e densidade de sementes, os resíduos possuem variância constante, com tamanho igual a $\bar{R}$. Este valor consiste na média, dois a dois, da variância dos resíduos. Além disso, os gráficos da Figura 7.7 também fornecem informações quanto aos valores dos resíduos, confirmando que a média é estatisticamente próxima a zero.

Para finalizar a análise dos resíduos da estimação por Krigagem, é realizado o teste de Anderson-Darling, também no MINITAB 13, para verificar se os resíduos seguem distribuição normal. A verificação da normalidade é feita através da análise do gráfico de probabilidade normal, verificando se os pontos se encontram em torno de uma linha reta, conforme descrito na Seção 4.4, e pelo teste de Anderson-Darling, testando a hipótese dos resíduos seguirem a distribuição normal. Mais detalhes sobre o teste de normalidade de Anderson-Darling e os conceitos estatísticos envolvidos podem ser encontrados no Apêndice C. O teste de normalidade é apresentado na Figura 7.8a para a normalidade dos resíduos da estimativa de cobertura foliar e na Figura 7.8b para a normalidade dos resíduos de estimativa da densidade de sementes. Em ambos os casos, como o p-valor é maior ou igual a 0,05, não rejeita-se a hipótese de que os resíduos seguem distribuição 

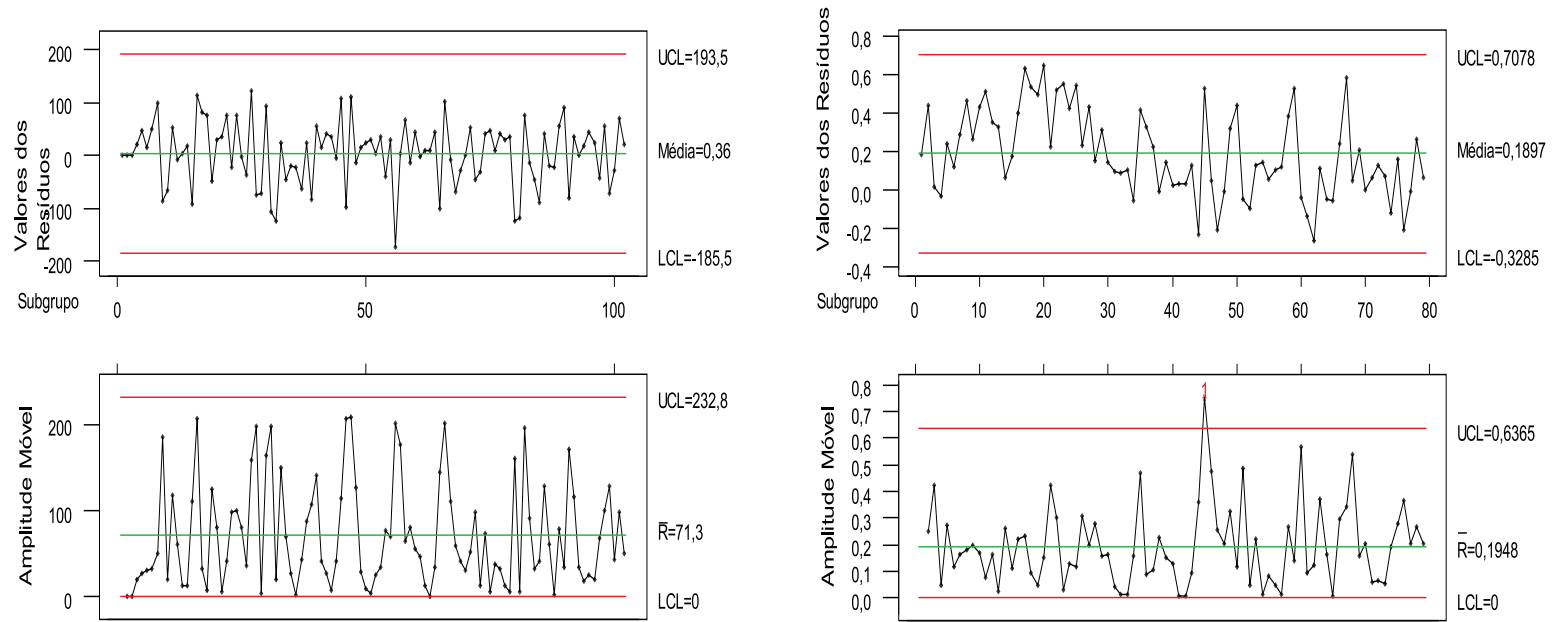

(a)

(b)

Figura 7.7: (a) Variância dos valores dos resíduos para a cobertura foliar $(t=5)$ e (b) para a densidade de sementes $(t=6)$.

normal.

\subsection{Resultados do Sistema de Classificação com Dados Si- mulados}

\subsubsection{Cálculo dos Atributos da Infestação}

A partir da análise de imagem descrita na Seção 6.2 é obtido o número de objetos que constituem as imagens $7.5 \mathrm{a}$ e $7.5 \mathrm{~b}$, formadas por 33 pixels nas direções horizontal e vertical, cada um medindo $3 \mathrm{~m}$ por $3 \mathrm{~m}$. Para o cálculo dos atributos, considera-se uma região da imagem de tamanho $7 \times 7$ pixels, cuja medida não ultrapassa a dependência espacial determinada pelas análises variográficas. Portanto, a cultura é dividida em 25 regiões e os atributos da infestação são calculados por regiões. Se o tamanho de cada região for tal que as últimas regiões das direções norte-sul e leste-oeste ultrapasse o número de pixels do mapa, estes pixels excedentes de cada região são desconsiderados e o cálculo dos atributos é feito, para estas específicas regiões, considerando um número menor de pixels, respeitando as dimensões do mapa. Os atributos são calculados conforme procedimento descrito na Seção 6.2.2 e os valores obtidos para os dados simulados 


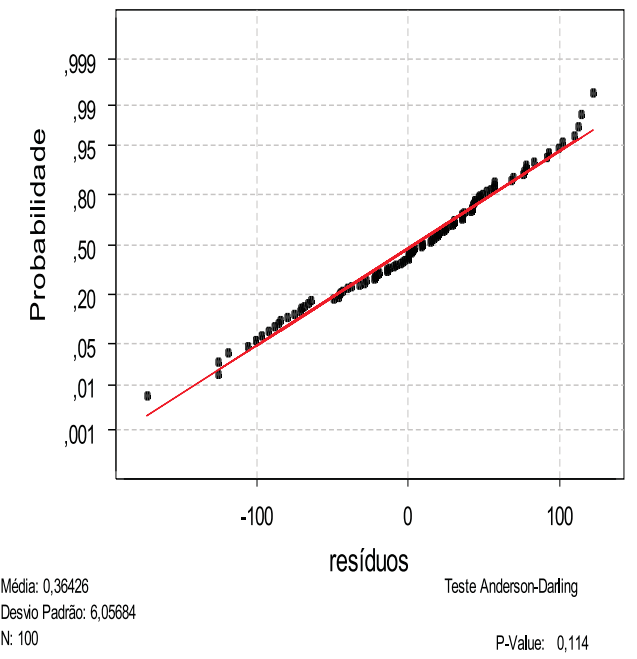

(a)

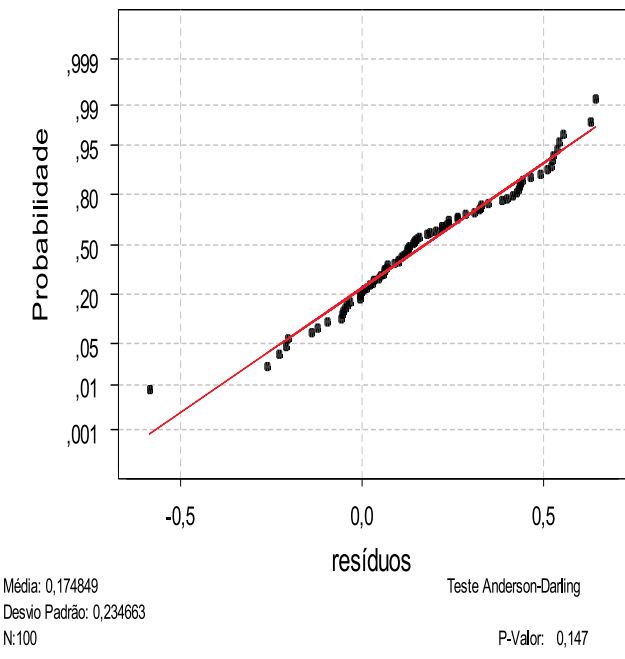

(b)

Figura 7.8: Teste da probabilidade normal dos resíduos: (a) cobertura foliar; (b) densidade de sementes para a geração $t=6$. Na margem inferior à esquerda são fornecidos a média dos resíduos, o desvio padrão e o número de dados. Na margem inferior à direita é dado o p-valor.

são apresentados a seguir.

$v_{1}: \mathrm{O}$ atributo da cobertura foliar por região é organizado na matriz denotada $\Upsilon_{1}$ como segue.

$$
\Upsilon_{1}=\left[\begin{array}{lllll}
0,4810 & 0,3571 & 0,2381 & 0,2571 & 0,4533 \\
0,2755 & 0,3401 & 0,3265 & 0,4320 & 0,4143 \\
0,2007 & 0,4286 & 0,4320 & 0,3061 & 0,1667 \\
0,2551 & 0,4490 & 0,4592 & 0,4286 & 0,4048 \\
0,1837 & 0,3163 & 0,4116 & 0,4660 & 0,3238
\end{array}\right]
$$

Na Figura 7.9 pode ser observado o mapa dos objetos que constituem a imagem da Figura 7.5a, representando diferentes valores de cobertura em tons de cinza, totalizando 35 objetos. A Figura 7.10 exibe as correspondentes 25 regiões, cada uma representando um valor médio de cobertura foliar, de acordo com a matriz $\Upsilon_{1}$.

$v_{2}: \mathrm{O}$ atributo da densidade de sementes para as 25 regiões da cultura para a geração $t=6$, é organizado como na matriz $\Upsilon_{2}$ apresentada a seguir. 


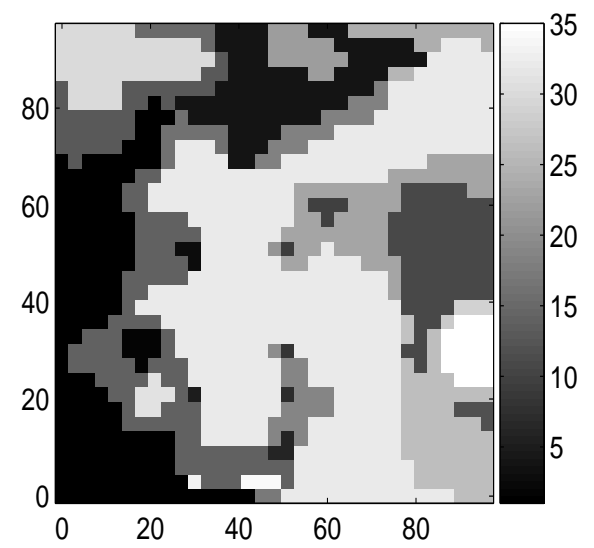

Figura 7.9: Mapa dos objetos conectados identificados no mapa de cobertura foliar simulado.

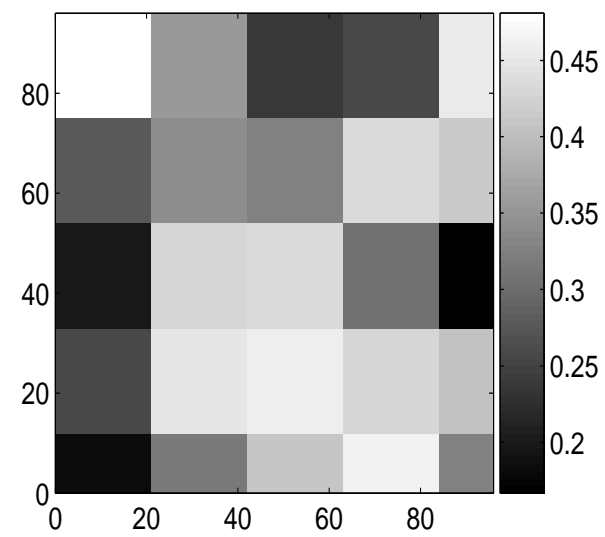

Figura 7.10: Mapa de regiões de valor médio ponderado de cobertura foliar de acordo com a matriz $\Upsilon_{1}$.

$$
\Upsilon_{2}=\left[\begin{array}{lllll}
0,1667 & 0,1667 & 0,1667 & 0,1905 & 0,2400 \\
0,1667 & 0,1871 & 0,1803 & 0,2143 & 0,2714 \\
0,1837 & 0,3537 & 0,2959 & 0,2007 & 0,1667 \\
0,2007 & 0,3878 & 0,3537 & 0,3741 & 0,3238 \\
0,1837 & 0,2007 & 0,2211 & 0,2721 & 0,1667
\end{array}\right]
$$

Na Figura 7.11 pode-se observar o mapa dos objetos que constituem a imagem da Figura 7.5b, representando diferentes valores de densidade em tons de cinza, totalizando 21 objetos.

A Figura 7.12 exibe as correspondentes 25 regiões, cada uma representando um valor médio de densidade de sementes, de acordo com a matriz $\Upsilon_{2}$. 


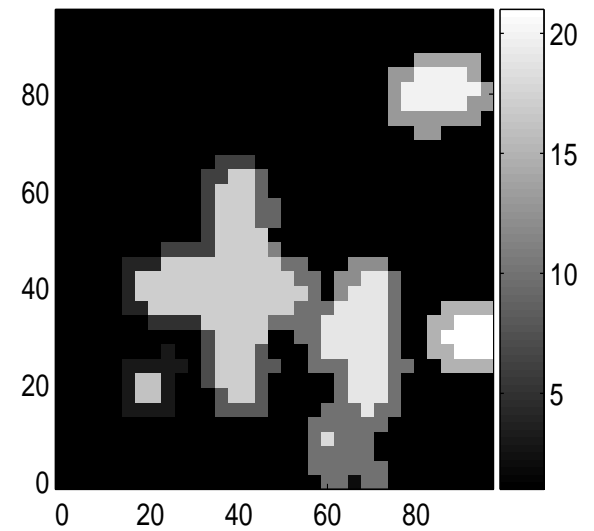

Figura 7.11: Mapa dos objetos conectados identificados no mapa de densidade de sementes simulado.

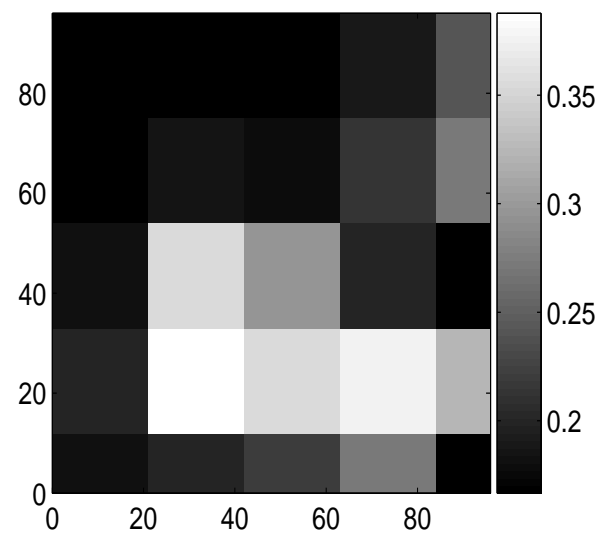

Figura 7.12: Mapa de regiões de valor médio ponderado de densidade de sementes de acordo com a matriz $\Upsilon_{2}$.

$v_{3}: \mathrm{O}$ atributo da extensão dos agrupamentos de sementes em cada região é obtido a partir do número de pixels de cada objeto da Figura 7.11 nesta região. Obtém-se a matriz de extensão média dos objetos denotada $\Upsilon_{3}$ como segue.

$$
\Upsilon_{3}=\left[\begin{array}{lllll}
0,1667 & 0,1667 & 0,1667 & 0,1762 & 0,2400 \\
0,1667 & 0,1871 & 0,1735 & 0,2143 & 0,2714 \\
0,1837 & 0,3231 & 0,2466 & 0,1803 & 0,1667 \\
0,1701 & 0,1956 & 0,1990 & 0,3367 & 0,3238 \\
0,1837 & 0,1701 & 0,1701 & 0,2347 & 0,1667
\end{array}\right]
$$

A Figura 7.13 exibe as 25 regiões referentes à extensão média dos objetos que representam a ocupação da densidade de sementes em cada região da cultura, de acordo 
com os valores das médias de extensão dadas pela matriz $\Upsilon_{3}$.

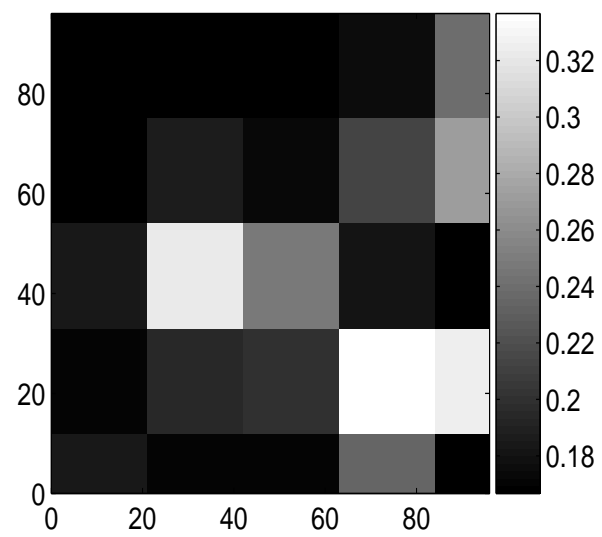

Figura 7.13: Mapa de regiões de valor médio de extensão dos agrupamentos de densidade de sementes de acordo com a matriz $\Upsilon_{3}$.

$v_{4}: \mathrm{O}$ atributo da competitividade das plantas daninhas presentes em cada região é disposto como nos casos anteriores na matriz denotada $\Upsilon_{4}$ e é obtido considerando a porcentagem de ocupação de gramíneas em cada região, calculada como a média das porcentagens das amostras de gramíneas contidas em cada região. Esta porcentagem é obtida com o modelo (4.12) mas alterando o número de sementes por planta por $m^{2}$ para $s=500$ em determinadas localidades, conforme descrito na Seção 7.1.

$$
\Upsilon_{4}=\left[\begin{array}{lllll}
0,0000 & 0,0000 & 0,0000 & 0,0000 & 0,0000 \\
0,0000 & 0,0000 & 0,0000 & 0,2500 & 0,2500 \\
0,0000 & 0,5000 & 0,0000 & 0,0000 & 0,0000 \\
0,2500 & 0,7500 & 0,5000 & 0,5000 & 0,5000 \\
0,2500 & 0,2500 & 0,2500 & 0,2500 & 0,0000
\end{array}\right]
$$

A Figura 7.14 exibe as regiões referentes à porcentagem de ocupação de plantas do tipo folha estreita, cujo número de sementes por planta, $s=500$, é maior do que das outras espécies do tipo folha larga, $s=248$.

\subsubsection{Riscos de Infestação por Regiões}

A classificação do risco de infestação da cultura vegetal descrita pelos atributos obtidos acima foi realizada para dois casos. O primeiro, dividindo a cultura em 25 regiões, conforme descrito anteriormente e o segundo, considerando toda a cultura como uma 


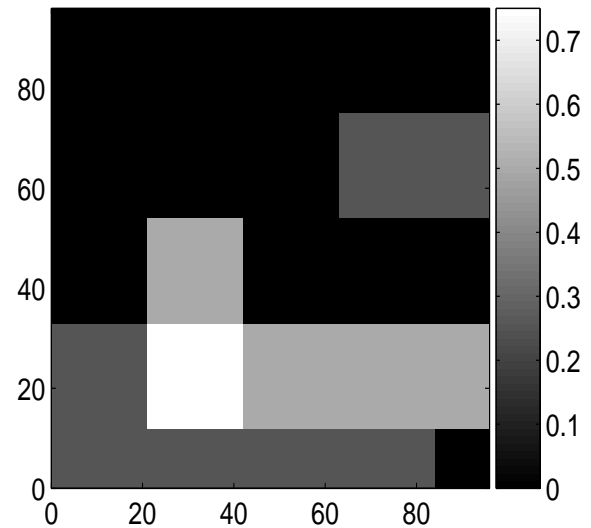

Figura 7.14: Mapa de regiões de ocupação de gramíneas em porcentagem referentes à $\Upsilon_{4}$.

só região, obtendo apenas um risco de infestação.

Aplicando o modelo de classificação fuzzy regionalmente, segundo os valores dos atributos calculados na seção anterior, obtém-se 25 valores diferentes de risco de infestação por plantas daninhas na cultura, um para cada região considerada. Estes valores constituem a matriz denotada Risco

$$
\text { Risco }=\left[\begin{array}{lllll}
0,2437 & 0,2537 & 0,2537 & 0,2534 & 0,2754 \\
0,2537 & 0,2566 & 0,2561 & 0,4476 & 0,4114 \\
0,2568 & 0,6477 & 0,2773 & 0,2537 & 0,2537 \\
0,2864 & 0,5348 & 0,5380 & 0,6567 & 0,6518 \\
0,2650 & 0,2977 & 0,4154 & 0,4799 & 0,2537
\end{array}\right],
$$

onde cada elemento corresponde ao risco de infestação da respectiva região. Desta forma, tem-se que a primeira região da cultura, $\operatorname{Risco}(1,1)$, apresenta um risco de infestação de $24,37 \%$, enquanto que a segunda região apresenta $25,37 \%$ e assim por diante.

Por outro lado, considerando-se toda a cultura homogeneamente, como uma única região, tem-se um único risco de infestação por plantas daninhas em toda a área considerada. Os valores dos atributos calculados para toda a cultura são os seguintes: $\Upsilon_{1}=0,2365, \Upsilon_{2}=0,3523, \Upsilon_{3}=0,0705, \Upsilon_{4}=0,5000$. A combinação destes atributos no sistema de classificação fuzzy resulta num risco de infestação de 40,8\% para toda a cultura, sugerindo um tratamento médio homogêneo. Se este risco é assumido para a tomada de decisão quanto à aplicação de herbicida, algumas regiões como as 
das posições $(3,2),(4,5)$ e $(4,4)$ da matriz Risco, que representam risco de infestação acima de $60 \%$, seriam subestimadas e não estariam eficientemente controladas. Por outro lado, as regiões com risco de infestação inferior a 40\%, poderiam estar recebendo mais defensivos do que o necessário.

\subsection{Mapas com Dados Coletados em Campo}

Nesta seção, a partir de dados coletados em campo, é gerado um mapa de estimativa por Krigagem de cobertura foliar na geração atual, denotada $t-1$ e um mapa de estimativa da densidade de sementes na geração seguinte, denotada $t$. Os dados foram coletados na área experimental da Embrapa Milho e Sorgo, Sete Lagoas, MG. A segunda coluna da Tabela D.3 exibe os valores dados, em porcentagem, de cobertura foliar de cada parcela e a primeira coluna da Tabela D.3 exibe os valores de densidade de sementes por metro quadrado, associada à produção de sementes, de cada espécie de planta daninha presente nas parcelas.

\subsubsection{Análise Exploratória dos Dados}

Os dados coletados em campo estão organizados em um arquivo de dados, onde as duas primeiras colunas contêm, respectivamente, as coordenadas $x$ e $y$ de cada parcela de onde foram coletados os dados conforme descrito no Capítulo 3. A terceira coluna deste arquivo de dados é a segunda coluna da Tabela D.3, correspondente aos dados de porcentagem de cobertura foliar de cada parcela. Um outro arquivo de dados, cujas duas primeiras colunas são as mesmas anteriores, possui como terceira coluna a primeira coluna da Tabela D.3, que são valores amostrados da densidade de sementes por metro quadrado de cada parcela.

A Figura 7.15a apresenta a distribuição dos dados de cobertura foliar na geração $t-1$ e a Figura $7.15 \mathrm{~b}$ apresenta a distribuição dos dados de densidade de sementes na geração $t$. As barras verticais indicam as intensidades dos valores coletados. Por estas figuras também pode-se observar a localização geográfica das 41 parcelas experimentais no campo e as suas coordenadas. Também são gerados os histogramas dos dados de cobertura foliar, exibido na Figura 7.16a e de densidade de sementes, exibido na Figura 7.16b. Por estas figuras pode-se observar o número de ocorrências dos valores das 
variáveis nas parcelas e as estatística descritivas correspondentes.

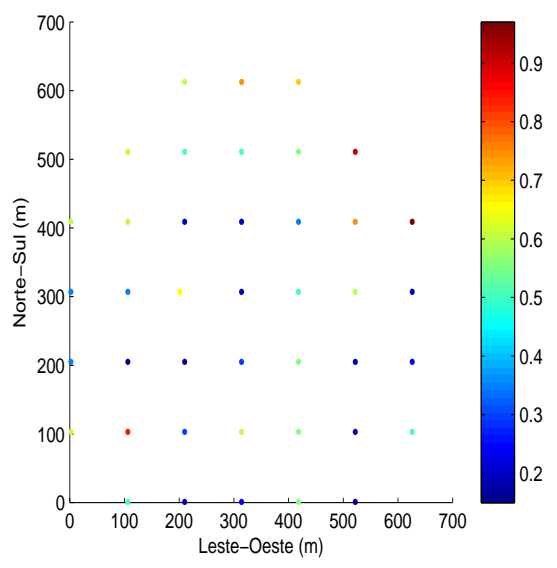

(a)

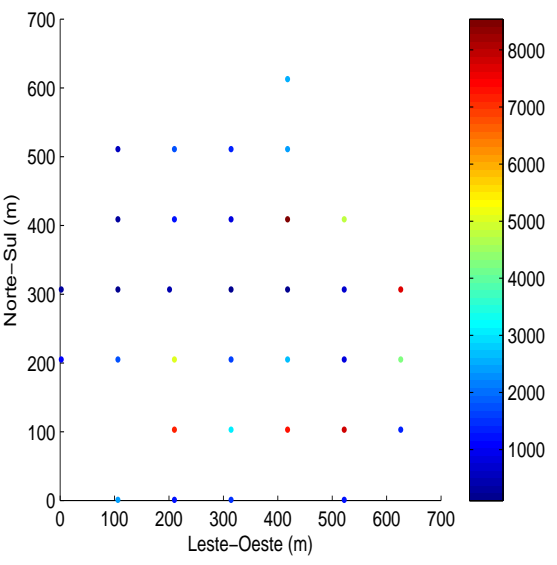

(b)

Figura 7.15: (a) Distribuição dos dados de cobertura foliar; (b) Distribuição dos dados de densidade de sementes.

Conforme mencionado anteriormente, pelo Teorema do Limite Central, não é necessária a verificação da normalidade dos dados (Bussab e Morettin, 2005).

\subsubsection{Ajuste dos Variogramas}

Os variogramas são ajustados para os dados de cobertura foliar na geração $t-1$ e de densidade de sementes na geração $t$, obtendo o melhor ajuste com o modelo teórico exponencial para ambos os atributos, como pode ser observado na Tabela 7.3, que apresenta os índices de ajuste para os modelos. Utilizando a função variograma1 o ajuste para a cobertura foliar é obtida com parâmetros como segue:

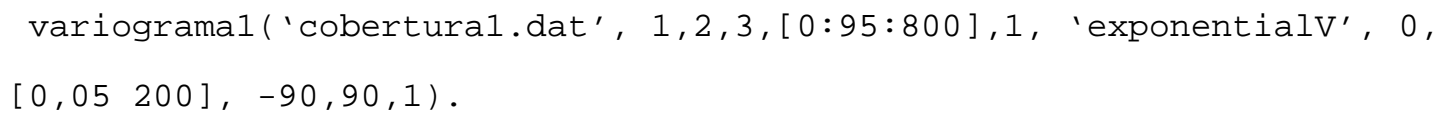

E o ajuste do variograma para os dados de densidade de sementes na geração $t$ é obtido com parâmetros como segue:

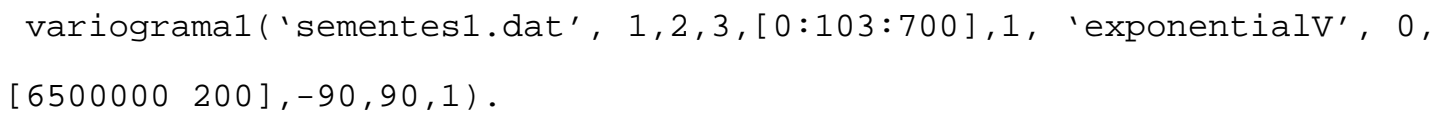

O ajuste do variograma teórico ao experimental para os dados de cobertura foliar pode ser visualizado na Figura 7.17a e para a densidade de sementes na Figura 7.17b. Os variogramas teóricos se estabilizam no alcance de $200 \mathrm{~m}$. Desta forma, cada parcela é distante $100 \mathrm{~m}$ umas das outras e os dados colectados dentro das parcelas apresentam 


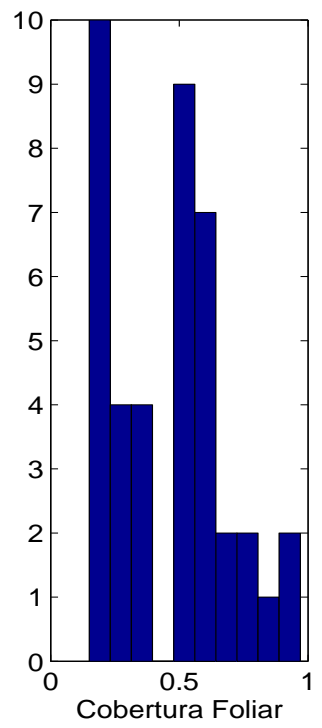

(a)

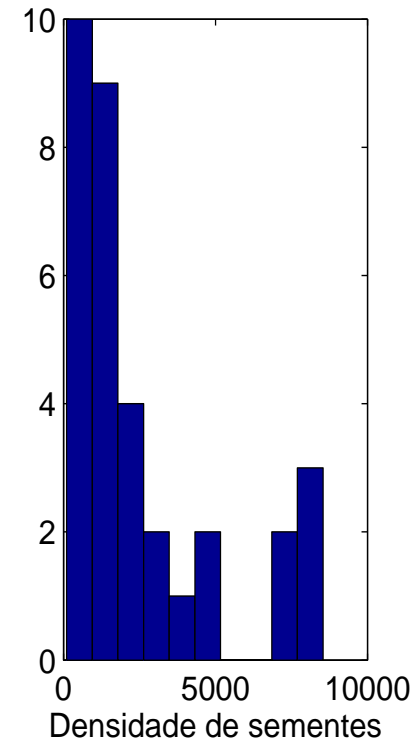

(b)

Figura 7.16: (a) Histograma para os dados coletados de cobertura foliar, com estatísticas descritivas: Média $=0,4585$, Desvio padrão =0,2239, Máximo =0,97 e Mínimo =0,15; (b) Histograma para os dados coletados de densidade de sementes, com estatísticas descritivas: Média $=2549,60$, Desvio padrão $=2543,8$, Máximo $=8540$ e Mínimo $=105$.

dependência espacial até o alcance de $200 \mathrm{~m}$. Além do alcance, o variograma permanece constante, com patamar de 0,05 para a cobertura foliar e 6,50 × $10^{6}$ para a densidade de sementes, não havendo correlação entre o ponto amostrado e o ponto estimado.

Tabela 7.3: Índice de ajuste para os modelos teóricos de variogramas.

\begin{tabular}{ccc} 
Modelo & Densidade de semente & Cobertura foliar \\
\hline Exponencial & 0,12 & 0,11 \\
Gaussiano & 0,25 & 0,22 \\
Esférico & 0,16 & 0,15
\end{tabular}

A Tabela 7.4 exibe os resultados obtidos para cada ponto dos variogramas experimentais, que são, o número de pares de pontos separados por $h$, o valor da distância $h$ e de $\gamma^{*}(h)$.

\subsubsection{Estimação por Krigagem}

Da mesma forma que no caso de dados simulados, usando Krigagem, são gerados mapas de estimativa para a cobertura foliar de plantas daninhas na geração $t-1$ e para a densidade de sementes na geração $t$ dentro das parcelas com distância de interpolação 


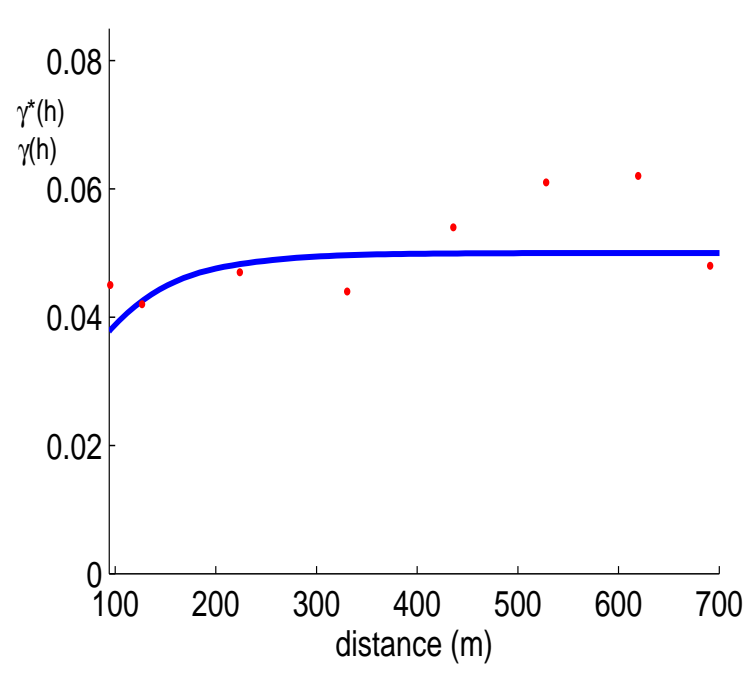

(a)

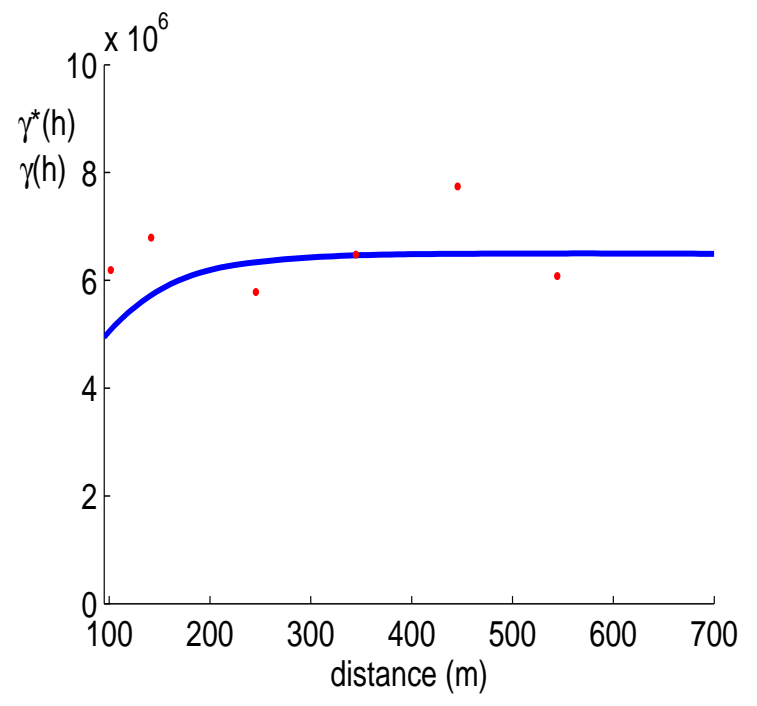

(b)

Figura 7.17: Ajuste dos variogramas teóricos obtido com o modelo exponencial (linha contínua) para os dados de (a) cobertura foliar com $C_{0}=0,038, C_{0}+C_{1}=0,05$ e (b) densidade de sementes com $C_{0}=5,09 \times 10^{6}, C_{0}+C_{1}=6,50 \times 10^{6}$ e os correspondentes variogramas experimentais (pontos).

de 200m. A função 'krigagem1' do GEOMATLAB (Apêndice A) foi utilizada com as seguintes sintaxes, respectivamente, para os mapas de cobertura foliar e densidade de sementes.

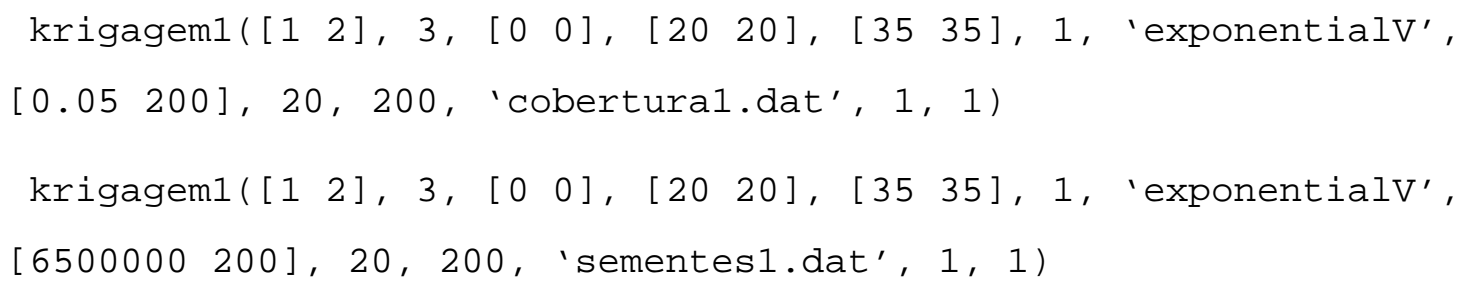

Estes mapas são exibidos respectivamente na Figura 7.18a, onde pode-se observar as reboleiras de plantas daninhas, e na Figura 7.18b, onde pode-se observar os agrupamentos de maior concentração de sementes por metro quadrado, conforme indicado pelas escalas em tons de cinza na barra vertical.

\subsubsection{Validação Cruzada}

Para avaliar a estimação por Krigagem, é feita a análise de resíduos utilizando a função validação.m do aplicativo GEOMATLAB e o aplicativo MINITAB 13. Como descrito na Seção 4.4, são analisadas as 3 características dos resíduos que indicam uma boa estimativa: média próxima a zero, variância constante e comportamento probabilístico normal. 
Tabela 7.4: Resultados dos variogramas.

\begin{tabular}{lccc} 
& Pares de pontos & distância $h$ & $\gamma^{*}(h)$ \\
\hline Densidade de sementes & 14,5 & 101,57 & $6,19 \times 10^{6}$ \\
& 80,5 & 141,64 & $6,79 \times 10^{6}$ \\
129 & 245,59 & $5,78 \times 10^{6}$ \\
& 116,5 & 344,63 & $6,47 \times 10^{6}$ \\
& 90 & 445,61 & $7,74 \times 10^{6}$ \\
& 54 & 544,41 & $6,08 \times 10^{6}$ \\
\hline Cobertura foliar & 1 & 95 & 0,045 \\
113 & 126,63 & 0,042 \\
142,5 & 223,81 & 0,047 \\
210 & 330,39 & 0,044 \\
142,5 & 435,92 & 0,054 \\
98 & 528,15 & 0,061 \\
59,5 & 619,44 & 0,062 \\
4 & 690,96 & 0,048
\end{tabular}

O intervalo de confiança para a média dos resíduos, testando a hipótese desta média estar próxima de zero, foi construído com $95 \%$ de confiança, constatando-se que a média dos resíduos das estimativas contemplam o valor zero, não rejeitando assim a hipótese de que os resíduos apresentam média zero. A variância é considerada constante e o tamanho dos resíduos é indicado por $\bar{R}$. O teste de Anderson-Darling verifica a distribuição normal dos resíduos com 95\% de confiança. Como o p-valor para ambas as variáveis é maior que 0,05 , tem-se evidências para não rejeitar a hipótese de normalidade dos resíduos. Mais detalhes sobre o teste de Anderson-Darling pode ser encontrado no Apêndice C. Os resultados da análise residual podem ser vistos na Tabela 7.5.

\begin{tabular}{cccc} 
& \multicolumn{4}{c}{ Tabela 7.5: Validação cruzada para a estimação por Krigagem. } \\
Atributos & Média dos resíduos & Variância constante & Anderson-Darling \\
\hline Cobertura & $-0,005(-0,07 ; 0,06)$ & $\bar{R}=0,25$ & p-valor $=0,61$ \\
Semente & $0,004(-0,1775 ; 0,1872)$ & $\bar{R}=0,26$ & p-valor $=0,45$ \\
\hline
\end{tabular}

Os resíduos analisados apresentam média próxima a zero, variância constante e comportamento normal. Portanto, tem-se evidências de boas estimativas pelo método de Krigagem e consequentemente, de boa qualidade dos modelos variográficos ajustados. 


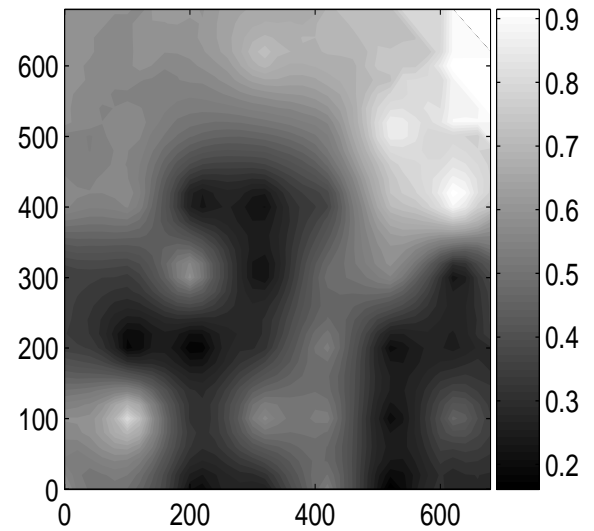

(a)

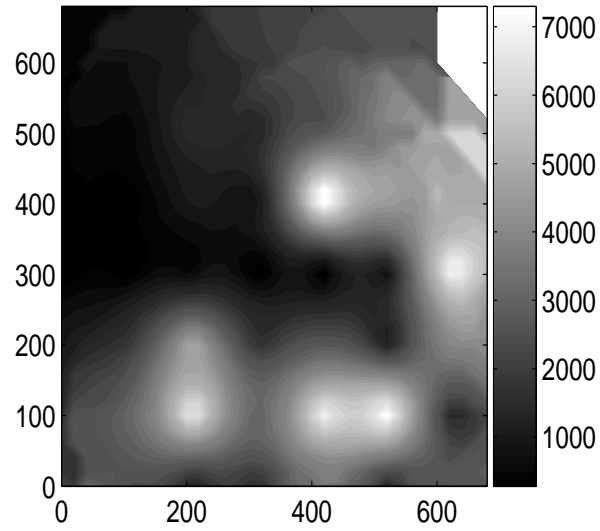

(b)

Figura 7.18: Imagens estimadas por Krigagem associadas aos mapas de (a) cobertura foliar na geração $t-1$ e (b) densidade de sementes na geração $t$.

\subsection{Resultados do Sistema de Classificação Fuzzy com Da- dos Coletados em Campo}

\subsubsection{Cálculo dos Atributos da Infestação}

Para o cálculo dos atributos que descrevem a infestação, o mesmo procedimento descrito na Seção 6.2.2 é aplicado. A partir dos mapas estimados por Krigagem exibidos nas Figuras 7.18a e 7.18b, objetos que pertencem a 3 grupos de intensidade da imagem são identificados. A área experimental é dividida em 35 pixels de 20 metros nas direções horizontal e vertical, definidos pelos parâmetros da Krigagem.

Para o cálculo dos atributos, escolhe-se regiões de tamanho $5 \times 5$ pixels, dimensão que não ultrapassa a dependência espacial de $200 m$ (alcance) dos dados, obtida pela análise do variograma. Desta forma, a cultura é dividida em 49 regiões de $100 m \times 100 m$, sendo 7 regiões na direção norte-sul e 7 regiões na direção leste-oeste e portanto, as últimas regiões de cada direção não são maiores do que a dimensão do mapa. Os resultados obtidos para cada atributo a partir da área experimental são descritos a seguir. Os valores dos atributos são normalizados entre 0 e 1.

$v_{1}: \mathrm{O}$ atributo da cobertura foliar, correspondente à geração $t-1$, é disposto na matriz $\Upsilon_{1}^{\prime}$, apresentada a seguir, onde cada elemento da matriz corresponde a uma região. 


$$
\Upsilon_{1}^{\prime}=\left[\begin{array}{lllllll}
0,3333 & 0,3333 & 0,3333 & 0,3733 & 0,4467 & 0,5000 & 0,3800 \\
0,3333 & 0,3333 & 0,3333 & 0,3333 & 0,3667 & 0,5000 & 0,5000 \\
0,3333 & 0,3133 & 0,2000 & 0,2133 & 0,3067 & 0,4800 & 0,5000 \\
0,2667 & 0,3000 & 0,2267 & 0,1667 & 0,3200 & 0,3333 & 0,2933 \\
0,1667 & 0,1800 & 0,1867 & 0,2133 & 0,3200 & 0,2067 & 0,1667 \\
0,3200 & 0,2800 & 0,1867 & 0,3133 & 0,3000 & 0,1667 & 0,1933 \\
0,3333 & 0,2933 & 0,1733 & 0,2733 & 0,2667 & 0,1667 & 0,1800
\end{array}\right]
$$

Na Figura 7.19 pode-se observar o mapa dos objetos conectados identificados no mapa de de cobertura foliar a partir dos dados coletados em campo em tons de cinza, totalizando 9 objetos. As intensidades das 49 regiões, que representam os valores médios de cobertura foliar dos dados coletados em campo, de acordo com a matriz $\Upsilon_{1}^{\prime}$, são exibidas na Figura 7.20.

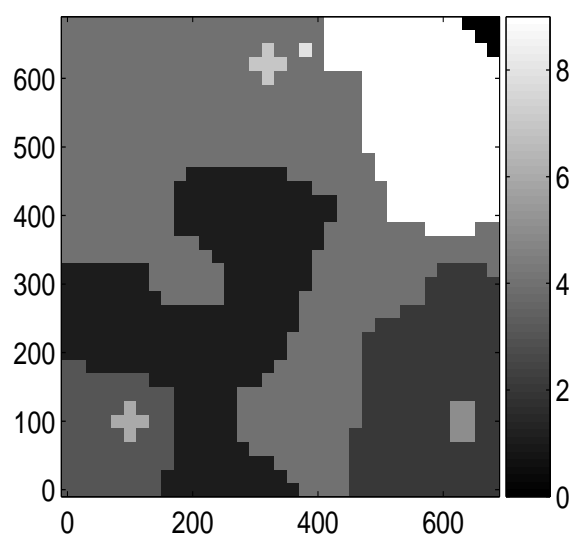

Figura 7.19: Mapa dos objetos conectados identificados no mapa de cobertura foliar dos dados coletados em campo da geração $t-1$.

$v_{2}$ : O atributo da densidade de sementes, correspondente à geração $t$, é obtido para cada região e os valores estão dispostos na matriz $\Upsilon_{2}^{\prime}$ a seguir. 


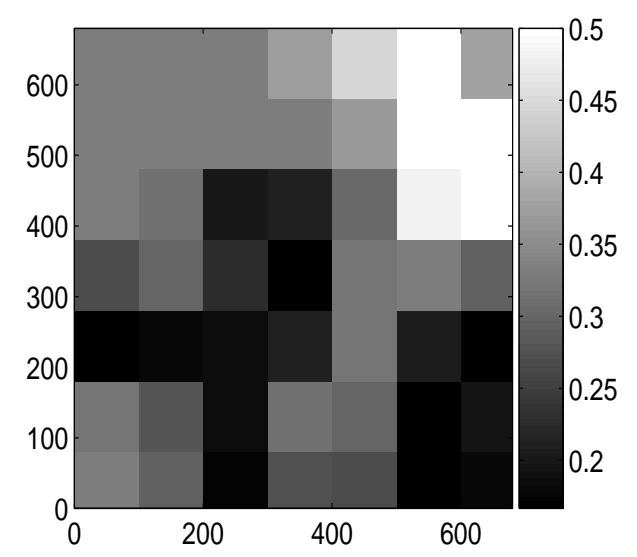

Figura 7.20: Mapa de regiões de valor médio ponderado de cobertura foliar, de acordo com a matriz $\Upsilon_{1}^{\prime}$.

$$
\Upsilon_{2}^{\prime}=\left[\begin{array}{lllllll}
0,2067 & 0,3133 & 0,3333 & 0,3333 & 0,3333 & 0,3333 & 0,0667 \\
0,1667 & 0,2467 & 0,3333 & 0,3333 & 0,3333 & 0,3400 & 0,2733 \\
0,1667 & 0,1933 & 0,3200 & 0,3267 & 0,4200 & 0,3333 & 0,4333 \\
0,1667 & 0,1667 & 0,1800 & 0,2533 & 0,3267 & 0,3267 & 0,4933 \\
0,2400 & 0,3200 & 0,3333 & 0,3133 & 0,3200 & 0,3333 & 0,3733 \\
0,3333 & 0,3467 & 0,3867 & 0,3333 & 0,4267 & 0,3867 & 0,3333 \\
0,3333 & 0,3333 & 0,3467 & 0,3333 & 0,3733 & 0,3533 & 0,3333
\end{array}\right]
$$

Esta densidade de sementes se refere à produção de sementes de plantas daninhas dentro das parcelas, onde não houve tratamento com herbicida. Conforme mencionado anteriormente, as sementes presentes nas plantas daninhas caem sobre o solo (chuva de sementes), indicando a probabilidade de infestação da geração seguinte. Na Figura 7.21 pode-se observar o mapa dos objetos conectados identificados no mapa de densidade de sementes em tons de cinza, totalizando 9 objetos, segundo procedimento da Seção 6.2. As intensidades das 49 regiões de valor médio de densidade de sementes, de acordo com a matriz $\Upsilon_{2}^{\prime}$, são exibidas na Figura 7.22.

$v_{3}$ : O atributo da extensão dos agrupamentos de sementes em cada região, correspondente à geração $t$, é obtido a partir do número de pixels de cada objeto da Figura 7.21 nesta região e seus valores estão organizados na matriz $\Upsilon_{3}^{\prime}$, apresentada a seguir. 


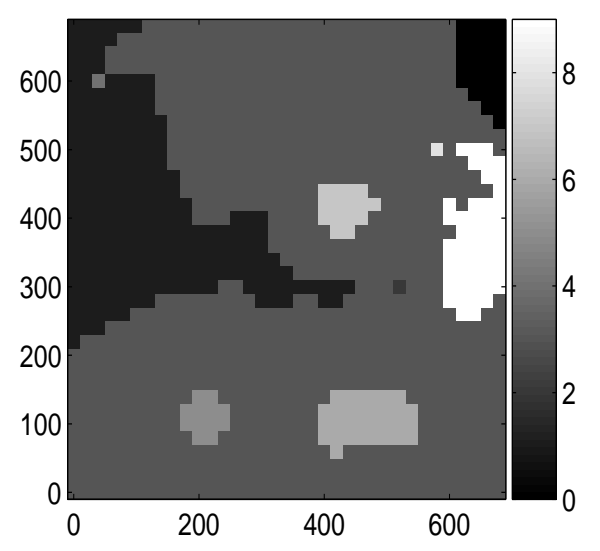

Figura 7.21: Mapa dos objetos conectados identificados no mapa de densidade de sementes dos dados coletados em campo da geração $t$.

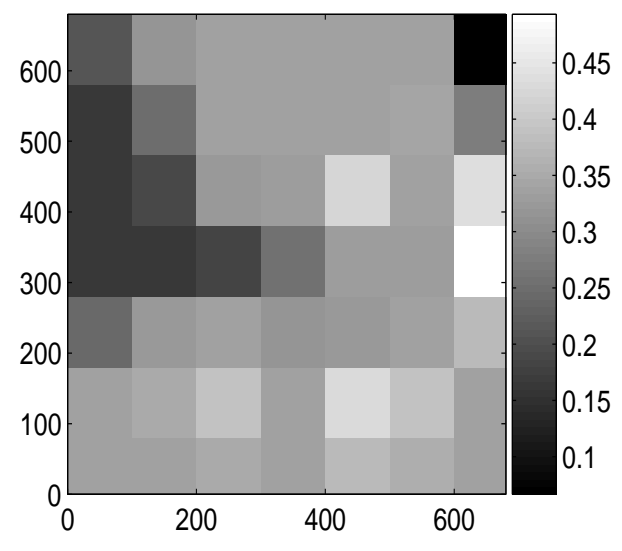

Figura 7.22: Mapa de regiões de valor médio ponderado de densidade de sementes de acordo com a matriz $\Upsilon_{2}^{\prime}$.

$$
\Upsilon_{3}^{\prime}=\left[\begin{array}{lllllll}
0,1667 & 0,3133 & 0,3333 & 0,3333 & 0,3333 & 0,3333 & 0,0667 \\
0,1667 & 0,2467 & 0,3333 & 0,3333 & 0,3333 & 0,3400 & 0,2733 \\
0,1667 & 0,1933 & 0,3200 & 0,3267 & 0,4200 & 0,3333 & 0,4333 \\
0,1667 & 0,1667 & 0,1800 & 0,2533 & 0,3267 & 0,3267 & 0,4933 \\
0,2400 & 0,3200 & 0,3333 & 0,3133 & 0,3200 & 0,3333 & 0,3733 \\
0,3333 & 0,3467 & 0,3867 & 0,3333 & 0,4267 & 0,3867 & 0,3333 \\
0,3333 & 0,3333 & 0,3467 & 0,3333 & 0,3733 & 0,3533 & 0,3333
\end{array}\right]
$$

A Figura 7.23 exibe as regiões referentes à extensão média dos objetos que representam a ocupação da densidade de sementes de cada região da cultura, segundo os dados 
coletados em campo.

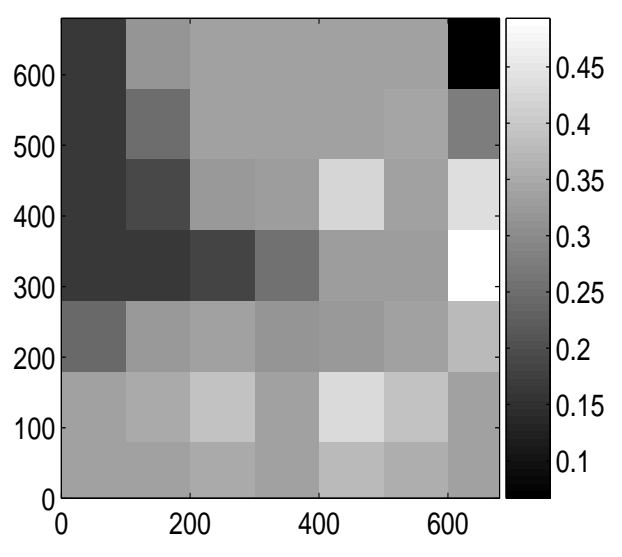

Figura 7.23: Mapa de regiões de valor médio ponderado referente à matriz $\Upsilon_{3}^{\prime}$.

$v_{4}$ : O atributo da competitividade das plantas daninhas presentes em cada região, correspondente à geração $t-1$, é obtido a partir do sistema neurofuzzy descrito na Seção 6.2.2. A quantidade de dados coletados em campo disponível para o treinamento foi suficiente para treinar adequadamente o sistema neurofuzzy, que explora as incertezas e imprecisões associadas aos dados, tratados de forma qualitativa, mas insuficientes para proporcionar um aprendizado robusto e generalizado em uma rede neural, cujos dados são quantitativos. Isto se deve ao fato de que o domínio das variáveis diminui ao serem transformadas em variáveis linguísticas. As entradas do sistema neurofuzzy são a densidade total de plantas daninhas por parcela e suas respectivas ocupações em plantas do tipo folha larga e folha estreita. Estas entradas e a saída fornecida ao sistema estão apresentadas na Tabela D.1. O sistema estima a saída através do ajuste automático das funções de pertinência das entradas e um sistema de inferência do tipo Sugeno. A estrutura da rede é ilustrada na Figura 7.24.

A Tabela 7.6 exibe os valores de teste das saídas desejada e estimada pelo sistema e o resíduo obtido, que constitui na diferença entre estas duas saídas.

Utilizando o aplicativo estatístico MINITAB 13, conclui-se que a média dos resíduos dos dados de teste é -0,102. Com 95\% de confiança, o teste de hipóteses indica que não é rejeitada a hipótese nula, a qual afirma que a média é igual a zero, com o intervalo $(-0,36 ; 0,16)$. O desvio padrão obtido é 0,28 e, segundo o teste de normalidade de Anderson-Darling, que pode ser consultado no Apêndice C, o p-valor é 0,32, não rejeitando a hipótese dos resíduos seguirem distribuição normal. Desta forma, pode-se 


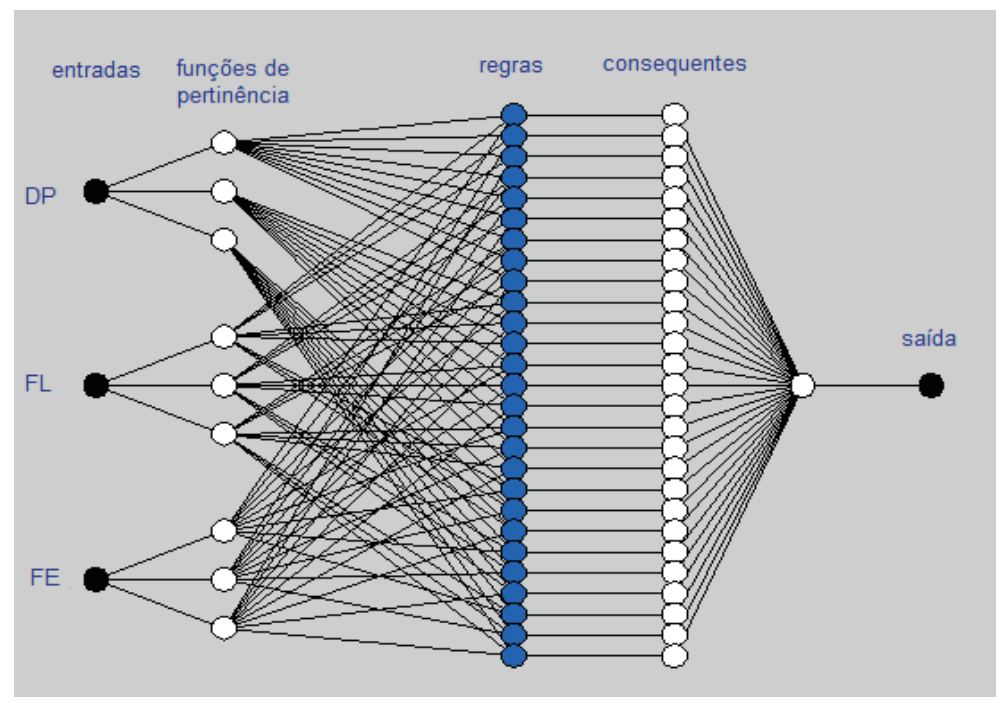

Figura 7.24: Estrutura da rede neurofuzzy com DP a densidade total de plantas daninhas, FL a densidade de plantas do tipo folha larga, FE a densidade de plantas do tipo folha estreita.

Tabela 7.6: Saídas do sistema neurofuzzy e resíduo obtido.

\begin{tabular}{ccc} 
Saída desejada & Saída estimada & Resíduo \\
\hline 0,0704 & 0,5681 & $-0,4977$ \\
0,6278 & 0,3371 & 0,2907 \\
0,1816 & 0,6399 & $-0,4584$ \\
0,2739 & 0,2310 & 0,0429 \\
0,1499 & 0,2125 & $-0,0626$ \\
0,2814 & 0,2281 & 0,0533 \\
0,4474 & 0,5357 & $-0,0883$
\end{tabular}

concluir que o sistema neurofuzzy fornece boas estimativas da saída, que constitui o atributo competitividade.

A rede neural presente no sistema fuzzy, conforme descrito na Seção 5.7, ajusta automaticamente as funções de pertinência das entradas. Para auxiliar na escolha do tipo de função de pertinência a ser adotado, foi feita uma análise estatística no aplicativo MINITAB13 para 3 tipos de funções: triangular, trapezoidal e gaussiana. Assim, o treinamento da rede é realizado com cada uma das três funções de pertinência, para avaliar a competitividade obtida, e selecionar aquela com média dos resíduos de estimação mais próxima a zero e de menor variância. A Tabela 7.7 exibe as estatísticas descritivas para o resíduo de estimação dos dados de teste do sistema neurofuzzy utilizando as três funções de pertinência citadas. Neste caso, a análise é suficiente para concluir que não existe diferença entre as médias dos resíduos e, além disto, estas são iguais a zero. Para confirmar a igualdade das variâncias dos resíduos associados às difer- 
entes funções de pertinência testadas, o teste estatístico de Levene (Levene, 1960) foi realizado. Por este teste, concluiu-se que os resultados apresentam a mesma dispersão nos resíduos, pois encontrou-se p-valor $=0,413>\alpha=0,05$, e portanto não se rejeita a hipótese de que $\sigma_{\epsilon_{t r i}}^{2}=\sigma_{\epsilon_{t r a}}^{2}=\sigma_{\epsilon_{g a u}}^{2}$, onde $\sigma_{\epsilon_{t r i}}^{2}$ é a variância do resíduo obtido com a função de pertinência triangular, $\sigma_{\epsilon t r a}^{2}$ a função trapezoidal e $\sigma_{\epsilon_{g a u}}^{2}$ a função gaussiana. A comparação entre as médias indica que não há diferenças significativas entre as médias dos resíduos das funções, apresentando p-valor $=0,376>\alpha=0,05$. Por esta análise, as três funções apresentam a mesma eficiência na estimação da saída do sistema neurofuzzy, porém, a função gaussiana é selecionada por apresentar melhores resultados na análise residual dos dados de teste. A Figura 7.25 exibe as funções de pertinência ajustadas automaticamente pela rede neural presente no sistema neurofuzzy.
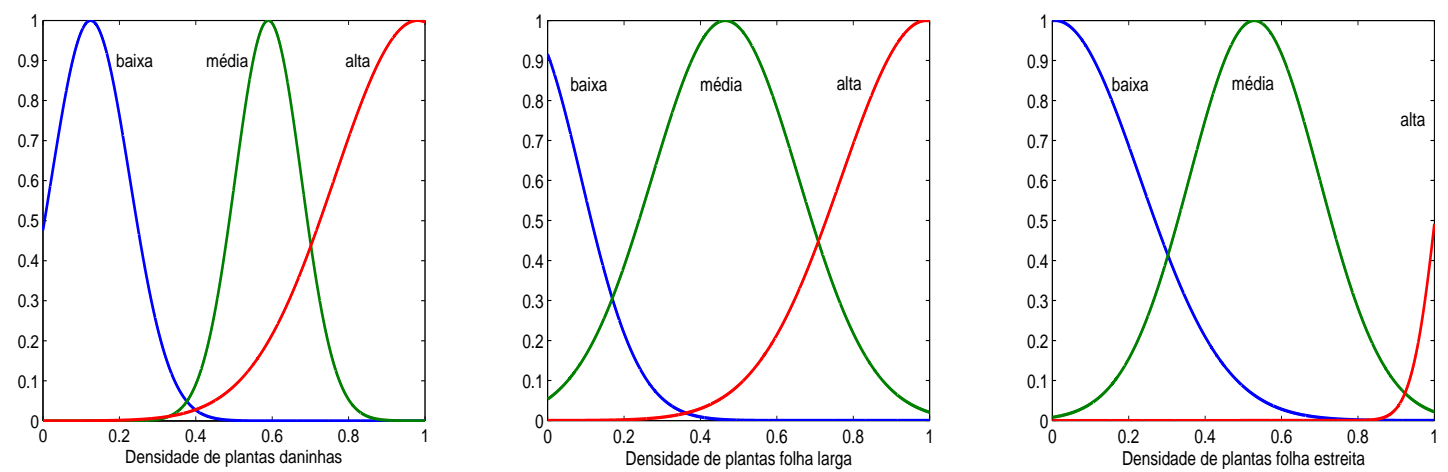

Figura 7.25: Funções de pertinência ajustadas pelo sistema neurofuzzy.

Tabela 7.7: Estatísticas dos resíduos de estimação dos dados de teste do sistema neurofuzzy.

\begin{tabular}{cccc} 
Função & Média e Intervalo 95\% & D.Padrão & Anderson Darling \\
\hline Gaussiana & $-0,102(-0,36 ; 0,16)$ & 0,28 & p-valor $=0,32$ \\
Triangular & $-0,37(-1,03 ; 0,29)$ & 0,71 & p-valor $=0,07$ \\
Trapezoidal & $-0,097(-0,519 ; 0,325)$ & 0,46 & p-valor $=0,18$
\end{tabular}

Os valores obtidos para o atributo da competitividade, para cada região, são dispostos como nos casos anteriores na matriz denotada $\Upsilon_{4}^{\prime}$. 


$$
\Upsilon_{4}^{\prime}=\left[\begin{array}{lllllll}
0,0000 & 0,0000 & 0,8304 & 0,5975 & 1,0036 & 0,0000 & 0,0000 \\
0,0000 & 0,7156 & 0,5000 & 0,4641 & 0,6977 & 0,4399 & 0,0000 \\
0,3919 & 0,6918 & 0,9351 & 0,5677 & 0,3142 & 0,2895 & 0,6176 \\
0,4213 & 0,1165 & 0,1638 & 0,4342 & 0,3214 & 0,0960 & 0,6745 \\
0,0985 & 0,3957 & 0,3939 & 0,7024 & 0,5273 & 0,3400 & 0,3475 \\
0,0325 & 0,2754 & 0,1143 & 0,6372 & 0,3079 & 0,5677 & 0,5076 \\
0,0000 & 0,2985 & 0,0944 & 0,7343 & 0,4129 & 2,0061 & 0,0000
\end{array}\right]
$$

A Figura 7.26 exibe as regiões referentes à ocupação de plantas do tipo folha estreita, segundo os dados coletados em campo.

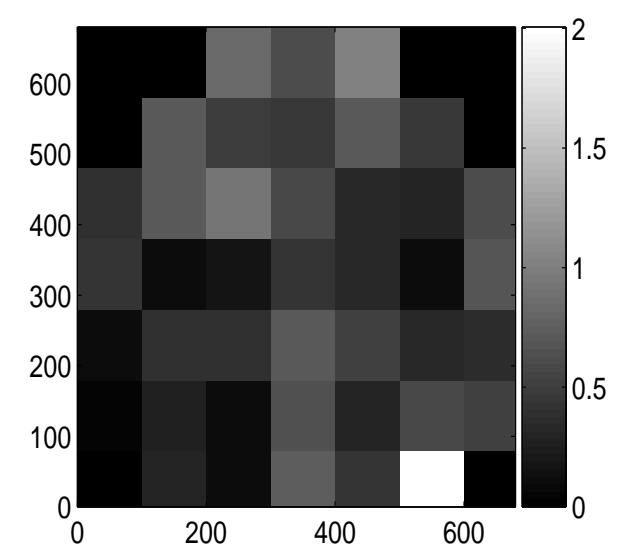

Figura 7.26: Mapa de regiões de competitividade das plantas daninhas por regiões referente à $\Upsilon_{4}^{\prime}$.

\subsubsection{Riscos de Infestação por Regiões}

O sistema de classificação fuzzy é novamente aplicado em duas situações: considerando as 49 regiões escolhidas da cultura, de tamanho $5 \times 5$ pixels, e considerando toda a cultura como uma só região. O objetivo desta comparação é demonstrar que há diferenças significativas entre os riscos de infestação de cada região da cultura por plantas daninhas do que se for obtido apenas um só risco médio para toda a cultura. A partir desta informação, pode ser adotado um manejo diferenciado para cada região, economizando defensivos, diminuindo o impacto ambiental e controlando a infestação de maneira mais eficiente. 
Para a obtenção dos riscos de infestação por região, o sistema de classificação fuzzy é composto pelas funções de pertinência da Figura 6.3 e a base de regras da Tabela 6.1. Aplicando este sistema para cada região considerada, os valores das matrizes $\Upsilon_{1}^{\prime}, \Upsilon_{2}^{\prime}, \Upsilon_{3}^{\prime}, \Upsilon_{4}^{\prime}$ são entradas do sistema e a saída é a matriz Risco que representa a porcentagem do risco de infestação de cada região, correspondente à geração $t$.

$$
\text { Risco }=\left[\begin{array}{lllllll}
0,2829 & 0,3261 & 0,6719 & 0,6724 & 0,6630 & 0,3425 & 0,2387 \\
0,2931 & 0,5970 & 0,6707 & 0,6651 & 0,6724 & 0,6252 & 0,3315 \\
0,5066 & 0,5304 & 0,6323 & 0,6434 & 0,4363 & 0,4580 & 0,6888 \\
0,4988 & 0,2828 & 0,3010 & 0,5678 & 0,4469 & 0,3317 & 0,7030 \\
0,2641 & 0,5589 & 0,5643 & 0,6346 & 0,6625 & 0,4835 & 0,5072 \\
0,3237 & 0,3835 & 0,2765 & 0,6719 & 0,4266 & 0,6645 & 0,6378 \\
0,3278 & 0,4100 & 0,2685 & 0,6679 & 0,6078 & 0,6459 & 0,2726
\end{array}\right]
$$

A Figura 7.27 exibe, em escala de cinza, as intensidades dos riscos de infestação por plantas daninhas das 49 regiões consideradas da cultura, de acordo com a matriz Risco.

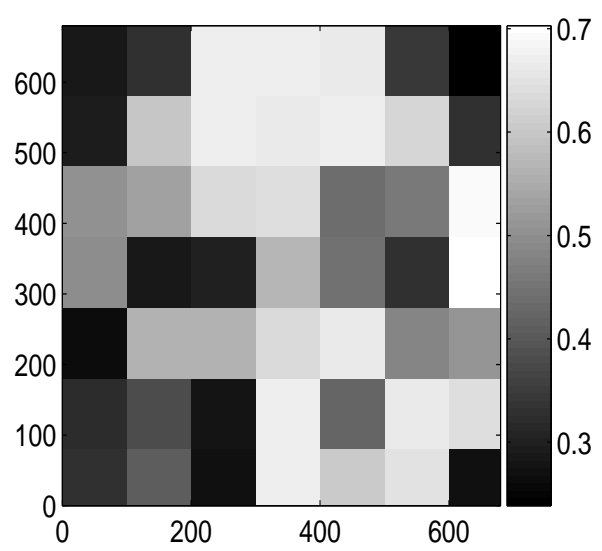

Figura 7.27: Mapa de intensidades de riscos de infestação por plantas daninhas por regiões referente à matriz Risco.

Pela matriz Risco, pode-se observar que a primeira região $\operatorname{Risco}(1,1)$ apresenta um risco de infestação de $28,3 \%$, enquanto que a segunda, $\operatorname{Risco}(1,2), 32,6 \%$, e assim por diante. Observa-se também, que a maior porcentagem de infestação é 70,3\%, encontrada na região $\operatorname{Risco}(4,7)$.

O sistema de classificação fuzzy proposto é aplicado em uma cultura de milho di- 
vidida em 49 regiões e em toda a cultura como uma só região. Para o caso em que as regiões da cultura são desconsideradas e a cultura analisada homogeneamente, com um único risco médio de infestação para toda a área, os valores dos atributos para este caso assumem então os seguintes valores: $\Upsilon_{1}^{\prime}=0,300 ; \Upsilon_{2}^{\prime}=0,311 ; \Upsilon_{3}^{\prime}=0,145 ; \Upsilon_{4}^{\prime}=0,300$. O sistema de classificação fuzzy fornece um risco de infestação de $42,2 \%$ para toda a cultura, sugerindo um manejo homogêneo com apenas uma taxa de aplicação de herbicida. Desta forma, as regiões com alto risco de infestação podem ser sub-estimadas, como a $R(4,7)$, que apresenta um risco de $70,3 \%$ e suas regiões vizinhas, não estariam eficientemente controladas. Por outro lado, as regiões com baixo risco de infestação, como a primeira, com um risco de $28,3 \%$, estariam recebendo maior quantidade de defensivos do que necessário, causando maior gasto com o produto e agressão ao solo. Além disso, se o maior risco de infestação fosse considerado e apenas uma taxa de herbicida correspondente a este fosse aplicada, outras regiões receberiam mais defensivos que o necessário para o controle da infestação.

Para avaliar o desempenho do tipo das funções de pertinência no sistema fuzzy, este é executado utilizando funções do tipo triangulares e gaussianas. Os resultados obtidos com as funções triangulares são estatisticamente comparados com os obtidos pelas funções gaussianas. Primeiramente, o teste de normalidade de Anderson-Darling indica que, com 95\% de confiança, os valores de risco seguem distribuição normal, com p-valor $=0,053$ para os obtidos com funções triangulares e p-valor $=0,06$ para os obtidos com funções gaussianas, maiores que $\alpha=0,05$. O Teste-F é realizado para testar a hipótese de igualdade de variâncias entre duas populações normais. Com pvalor $=0,631>\alpha=0,05$, conclui-se que não se rejeita a hipótese de que as variâncias entre os riscos obtidos com funções triangulares e gaussianas são estatisticamente iguais, apresentando mesma dispersão em torno da média. O mesmo pode ser concluído com o Teste-t para comparação de médias entre duas populações. Com 95\% de confiança, $\mathrm{p}$-valor $=0,11>\alpha=0,05$, não rejeitando a hipótese de igualdade de médias. A Tabela 7.8 exibe as estatísticas descritivas para os riscos obtidos utilizando-se os dois tipos de função de pertinência.

Como não há diferenças significativas entre os resultados obtidos com funções de pertinência triangulares ou gaussianas, são utilizadas neste trabalho as do tipo gaussianas, representando transações suaves entre as funções. 
Tabela 7.8: Estatísticas descritivas para os riscos utilizando-se funções triangulares e gaussianas.

\begin{tabular}{ccccc} 
Função & Média & Desvio Padrão & Mínimo & Máximo \\
\hline Gaussiana & 0,503 & 0,138 & 0,208 & 0,713 \\
Triangular & 0,457 & 0,148 & 0,182 & 0,709
\end{tabular}

\subsubsection{Agrupamento dos Riscos de Infestação}

Os valores da matriz Risco são reunidos em agrupamentos cada vez menores para cada um destes alcançar no máximo o valor especificado do coeficiente de variação $c v=0,2$. A Tabela 7.9 exibe os valores dos coeficientes de variação de cada agrupamento. Os agrupamentos com $c v=0$ são constituídos por apenas uma região que se fosse agrupada aos demais forneceria $c v>0,2$. Finalmente, os valores da matriz Risco são agrupados conforme o algoritmo da Seção 6.4.1 em 27 agrupamentos de riscos médios de infestação, cuja imagem é exibida na Figura 7.28.

Tabela 7.9: Coeficientes de variação para os agrupamentos identificados pelo algoritmo da Seção 6.4.1.

\begin{tabular}{cccccccc}
\hline grupo & 1 & 2 & 3 & 4 & 5 & 6 & 7 \\
cv & 0,0042 & 0,0059 & 0,0123 & 0,0068 & 0,2477 & 0,0005 & 0,0144 \\
\hline grupo & 8 & 9 & 10 & 11 & 12 & 13 & 14 \\
cv & 0 & 0,1434 & 0 & 0,0343 & 0,0250 & 0 & 0 \\
\hline grupo & 15 & 16 & 17 & 18 & 19 & 20 & 21 \\
cv & 0,0441 & 0 & 0,0208 & 0 & 0,0338 & 0,1123 & 0,0201 \\
\hline grupo & 22 & 23 & 24 & 25 & 26 & 27 & \\
cv & 0,0110 & 0,2302 & 0,0835 & 0,0304 & 0,2092 & 0,0100 & \\
\hline
\end{tabular}

A matriz RGrupos apresenta os valores médios obtidos por cada agrupamento encontrado, correspondentes a cada uma das regiões da cultura.

$$
\text { RGrupos }=\left[\begin{array}{lllllll}
0,2880 & 0,3261 & 0,6722 & 0,6722 & 0,6677 & 0,3425 & 0,2851 \\
0,2880 & 0,5637 & 0,6679 & 0,6679 & 0,6677 & 0,6252 & 0,2851 \\
0,5027 & 0,5637 & 0,6379 & 0,6379 & 0,4472 & 0,4472 & 0,6959 \\
0,5027 & 0,2919 & 0,2919 & 0,5678 & 0,3893 & 0,3893 & 0,6959 \\
0,2939 & 0,5616 & 0,5616 & 0,6485 & 0,6485 & 0,4953 & 0,4953 \\
0,2939 & 0,3738 & 0,2725 & 0,6699 & 0,5172 & 0,6552 & 0,6378 \\
0,3738 & 0,3738 & 0,2725 & 0,6699 & 0,5172 & 0,6552 & 0,2726
\end{array}\right] .
$$




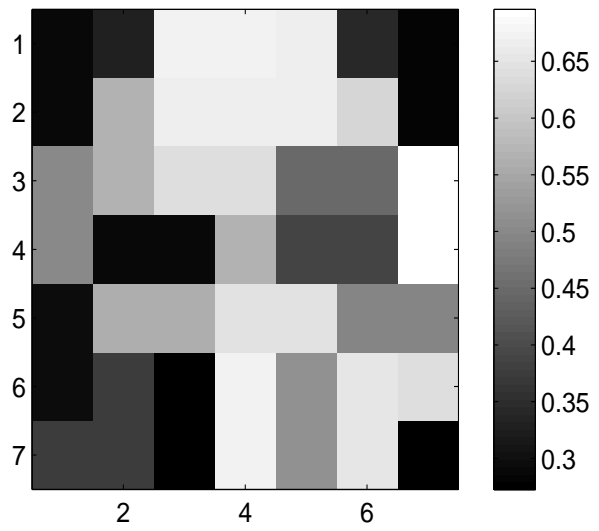

Figura 7.28: Mapa dos agrupamentos de riscos de infestação de acordo com as intensidades da matriz RGrupos.

\subsection{Estudo do Comportamento da Infestação em Gerações Subsequentes}

Para avaliar o comportamento da infestação da cultura por plantas daninhas, o sistema fuzzy proposto neste trabalho é aplicado também aos dados coletados em uma geração posterior, correspondentes à $t+1$ e $t+2$, coletados em outubro de 2006. A primeira coluna da Tabela D.4 exibe os valores de densidade de sementes por metro quadrado em cada parcela e a segunda coluna desta tabela apresenta a cobertura foliar por parcela, estimada, como anteriormente, por inspeção visual. Na Tabela D.2 estão a densidade total de plantas por metro quadrado, suas respectivas proporções em plantas do tipo folha larga e folha estreita (entradas do sistema neurofuzzy) e a biomassa (saída do sistema neurofuzzy).

\subsubsection{Análise Exploratória dos Dados}

Os dados coletados em campo são organizados em um arquivo de dados como anteriormente, utilizando a Tabela D.4. A Figura 7.29a apresenta a distribuição dos dados de cobertura foliar na geração denotada $t+1$ e a Figura $7.29 \mathrm{~b}$ apresenta a distribuição dos dados de densidade de sementes na geração denotada $t+2$. Os histogramas são exibidos na Figura 7.30a para os dados de cobertura foliar e na Figura 7.30b para os dados de densidade de sementes. 


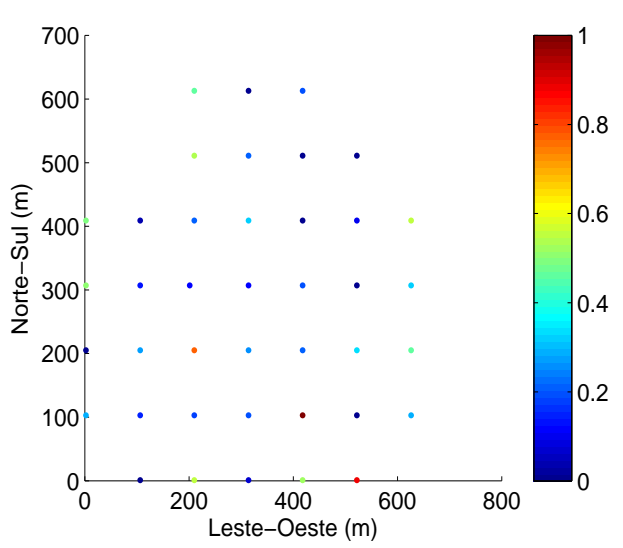

(a)

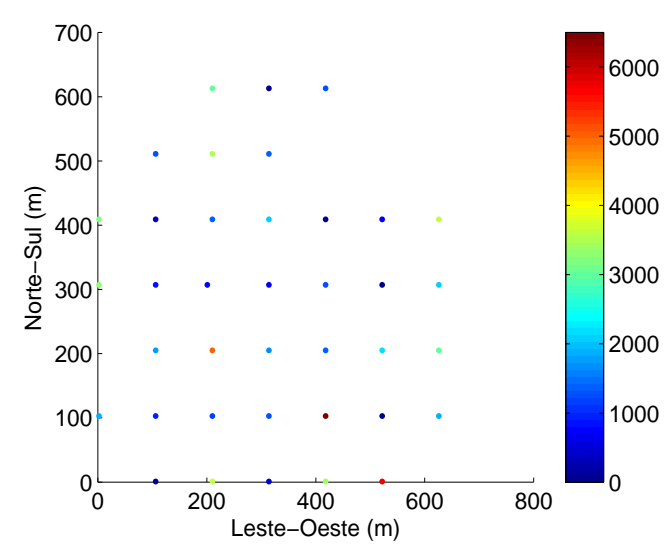

(b)

Figura 7.29: (a) Distribuição dos dados de cobertura foliar; (b) Distribuição dos dados de densidade de sementes.

\subsubsection{Ajuste dos Variogramas}

Os variogramas são ajustados para os dados coletados em campo de cobertura foliar na geração $t+1$ e de densidade de sementes na geração $t+2$, obtendo o melhor ajuste com o modelo teórico exponencial para ambos os atributos, como pode ser observado nos índices de ajuste da Tabela 7.10. Utilizando a função variograma1 os ajustes para a cobertura foliar e para a densidade de sementes são obtidos com parâmetros como segue:

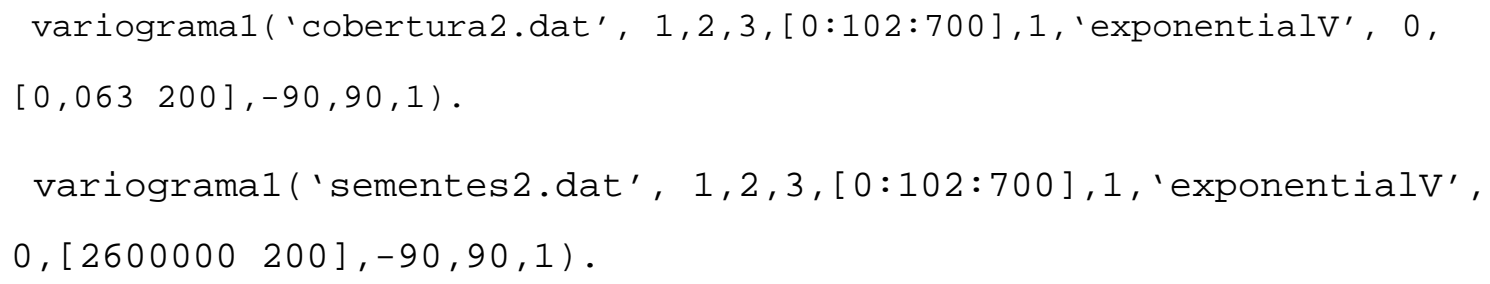

O ajuste do variograma teórico ao experimental para os dados de cobertura foliar pode ser visualizado na Figura 7.31a e para a densidade de sementes na Figura 7.31b. Os variogramas teóricos se estabilizam no alcance de 200m, com patamar de 0,063 para a cobertura foliar e $2,60 \times 10^{6}$ para a densidade de sementes.

A Tabela 7.11 exibe os resultados obtidos para cada ponto dos variogramas experimentais, incluindo o número de pares de pontos separados por $h$, o valor da distância $h$ e de $\gamma^{*}(h)$. 


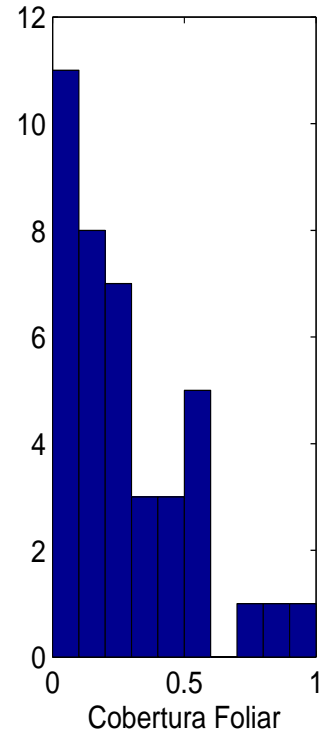

(a)

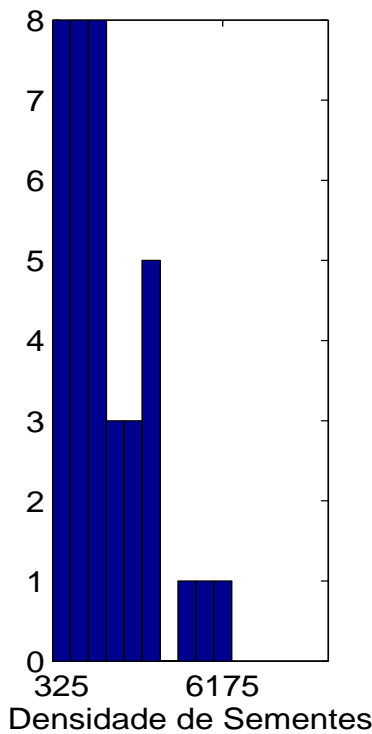

(b)

Figura 7.30: (a) Histograma para os dados coletados de cobertura foliar, com estatísticas descritivas: Média $=0,273$, Desvio padrão $=0,25$, Máximo $=1$ e Mínimo $=0 ;$ (b) Histograma para os dados coletados de densidade de sementes, com estatísticas descritivas: Média $=1905$, Desvio padrão $=1588$, Máximo $=6500$ e Mínimo =0.

Tabela 7.10: Índice de ajuste para os modelos teóricos de variogramas.

\begin{tabular}{ccc} 
Modelo & Densidade de semente & Cobertura foliar \\
\hline Exponencial & 0,05 & 0,06 \\
Gaussiano & 0,16 & 0,16 \\
Esférico & 0,08 & 0,08
\end{tabular}

\subsubsection{Estimação por Krigagem}

Da mesma forma que na geração anterior, pelo método de Krigagem, são gerados mapas de estimativa para a cobertura foliar de plantas daninhas na geração $t+1$ e para a densidade de sementes na geração $t+2$ dentro das parcelas com distância de interpolação de $200 \mathrm{~m}$. A função 'krigagem1'do GEOMATLAB é utilizada com as seguintes sintaxes, respectivamente, para os mapas de cobertura foliar e densidade de sementes.

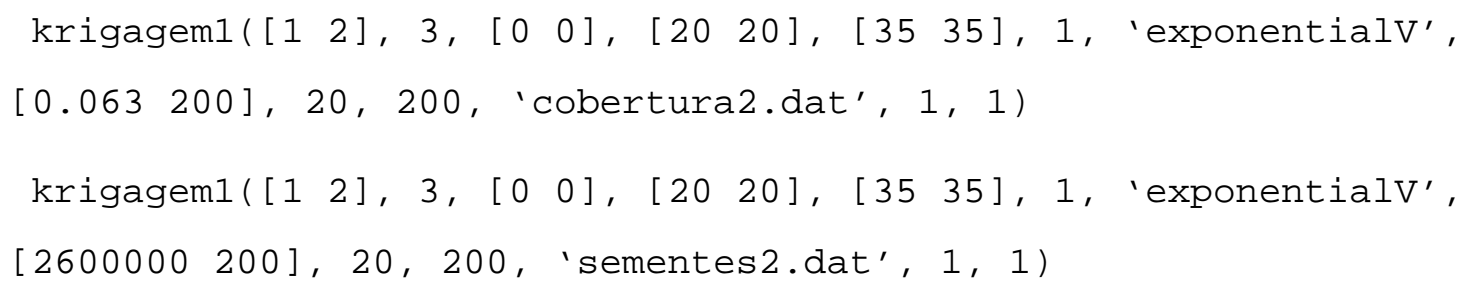

Estes mapas são exibidos respectivamente na Figura 7.32a e 7.32b, cujas intensidades 


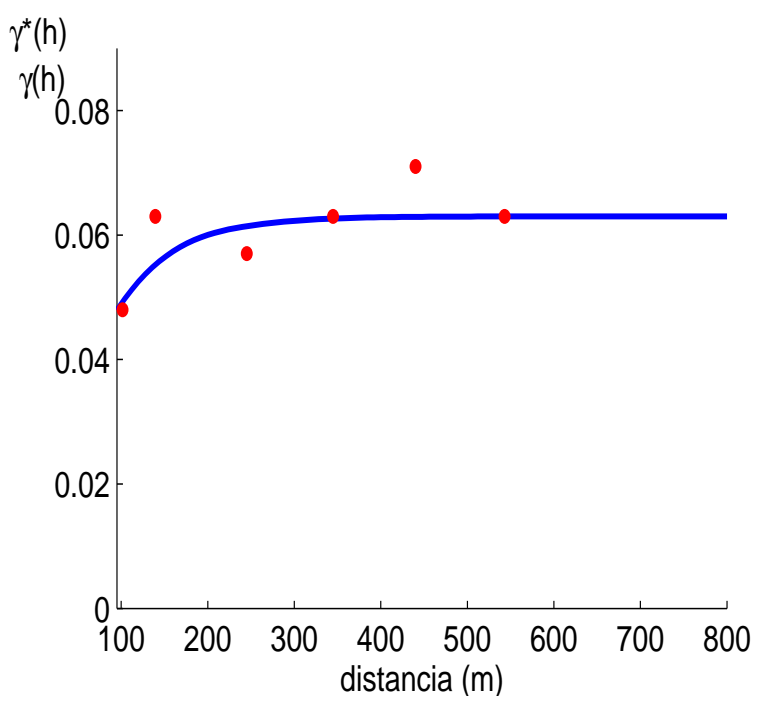

(a)

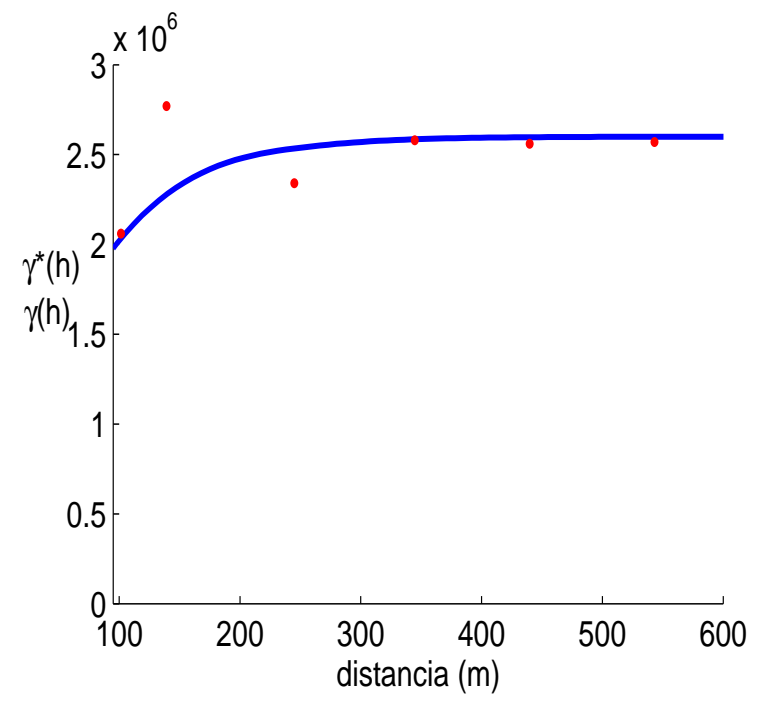

(b)

Figura 7.31: Ajuste dos variogramas teóricos obtido com o modelo exponencial (linha contínua) para os dados de (a) cobertura foliar com $C_{0}=0,048, C_{0}+C_{1}=0,063$. e (b) densidade de sementes com $C_{0}=2,0 \times 10^{6}, C_{0}+C_{1}=2,60 \times 10^{6}$ e os correspondentes variogramas experimentais (pontos).

podem ser observadas pelas escalas em tons de cinza na barra vertical.

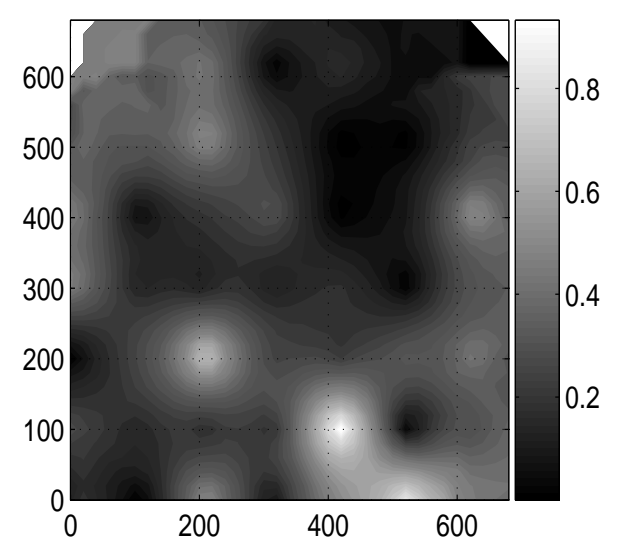

(a)

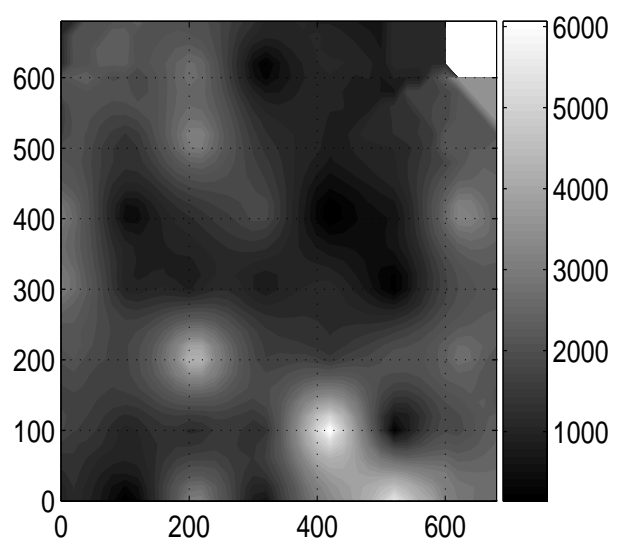

(b)

Figura 7.32: Imagens associadas aos mapas estimados por Krigagem de (a) cobertura foliar na geração $t+1$ e (b) densidade de sementes na geração $t+2$.

A validação cruzada indica, como anteriormente, evidências de boas estimações pelo método de Krigagem e consequentemente, de boa qualidade no ajuste dos variogramas, pois os resíduos apresentam média próxima a zero com $95 \%$ de confiança, variância constante (com resíduos de tamanho $\bar{R}$ ) e comportamento normal, conforme pode ser visto na Tabela 7.12 . 
Tabela 7.11: Resultados dos variogramas.

\begin{tabular}{lccc} 
& Pares de pontos & distância $h$ & $\gamma^{*}(h)$ \\
\hline Densidade de sementes & 14,5 & 101,52 & $2,06 \times 10^{6}$ \\
& 98 & 139,22 & $2,77 \times 10^{6}$ \\
& 157 & 245,06 & $2,34 \times 10^{6}$ \\
& 146,5 & 344,73 & $2,58 \times 10^{6}$ \\
& 116 & 439,74 & $2,56 \times 10^{6}$ \\
& 98,5 & 543,19 & $2,57 \times 10^{6}$ \\
\hline Cobertura foliar & 16,5 & 101,57 & 0,048 \\
& 106 & 139,47 & 0,063 \\
& 172,5 & 245,13 & 0,057 \\
161 & 344,85 & 0,063 \\
130,5 & 440,2 & 0,071 \\
& 112,5 & 543,11 & 0,063
\end{tabular}

Tabela 7.12: Validação cruzada para a estimação por Krigagem da geração posterior. \begin{tabular}{cccc} 
Atributos & Média dos resíduos & Variância constante & Anderson-Darling \\
\hline Cobertura & $-0,011(-0,101 ; 0,077)$ & $\bar{R}=0,36$ & p-valor $=0,194$
\end{tabular}

Semente $\quad-0,082(-0,680 ; 0,515) \quad \bar{R}=2,15 \quad$ p-valor $=0,162$

\subsection{Resultados do Sistema de Classificação com Dados Co- letados em Campo em uma Geração Posterior}

O procedimento descrito na Seção 7.5.1 é aplicado da mesma forma para calcular os atributos da infestação em uma geração posterior e as mesmas regiões são consideradas. Desta forma, obtém-se os seguintes resultados.

\subsubsection{Cálculo dos Atributos da Infestação}

$v_{1}: \mathrm{O}$ atributo da cobertura foliar para cada região, correspondente à geração $t+1$, é disposto na matriz $\Upsilon_{1}^{\prime \prime}$, apresentada a seguir. 


$$
\Upsilon_{1}^{\prime \prime}=\left[\begin{array}{lllllll}
0,2533 & 0,2133 & 0,1933 & 0,1667 & 0,1667 & 0,1667 & 0,1267 \\
0,1733 & 0,1933 & 0,2400 & 0,1667 & 0,1667 & 0,1667 & 0,1667 \\
0,1867 & 0,1667 & 0,1667 & 0,1667 & 0,1667 & 0,1667 & 0,2067 \\
0,2133 & 0,1667 & 0,1667 & 0,1667 & 0,1667 & 0,1667 & 0,1867 \\
0,1667 & 0,2000 & 0,2400 & 0,1667 & 0,1667 & 0,1667 & 0,1933 \\
0,1667 & 0,1733 & 0,2133 & 0,2133 & 0,3067 & 0,1667 & 0,1667 \\
0,1667 & 0,1667 & 0,1933 & 0,2133 & 0,3533 & 0,3133 & 0,2800
\end{array}\right]
$$

Na Figura 7.33 pode-se observar o mapa dos objetos conectados em tons de cinza identificados no mapa de cobertura foliar, totalizando 11 objetos. As intensidades das 49 regiões, que representam os valores médios de cobertura foliar dos dados coletados em campo, de acordo com a matriz $\Upsilon_{1}^{\prime \prime}$, são exibidas na Figura 7.34.

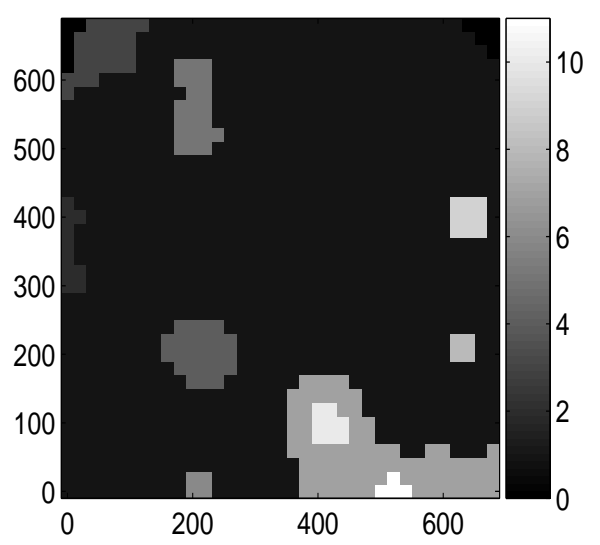

Figura 7.33: Mapa dos objetos conectados identificados no mapa de cobertura foliar dos dados coletados em campo da geração $t+1$.

$v_{2}: \mathrm{O}$ atributo da densidade de sementes, correspondente à geração $t+2$, é disposto na matriz $\Upsilon_{2}^{\prime \prime}$ a seguir, associado, como na geração anterior, à produção de sementes. 


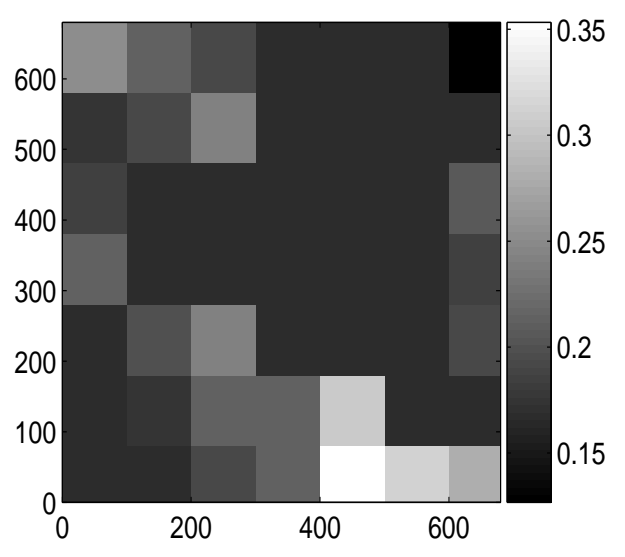

Figura 7.34: Mapa de regiões de valor médio ponderado de cobertura foliar, de acordo com a matriz $\Upsilon_{1}^{\prime \prime}$.

$$
\Upsilon_{2}^{\prime \prime}=\left[\begin{array}{lllllll}
0,3333 & 0,3333 & 0,3333 & 0,2467 & 0,2733 & 0,2800 & 0,1200 \\
0,3333 & 0,3333 & 0,3333 & 0,3133 & 0,2533 & 0,3200 & 0,3333 \\
0,3333 & 0,2933 & 0,3333 & 0,3067 & 0,1733 & 0,2933 & 0,3333 \\
0,3333 & 0,2400 & 0,3067 & 0,2800 & 0,2000 & 0,2400 & 0,3333 \\
0,3333 & 0,3333 & 0,3333 & 0,3333 & 0,3267 & 0,3133 & 0,3333 \\
0,3333 & 0,3333 & 0,3333 & 0,3333 & 0,3533 & 0,3067 & 0,3333 \\
0,2933 & 0,2933 & 0,3333 & 0,3200 & 0,3400 & 0,3400 & 0,3333
\end{array}\right]
$$

Na Figura 7.35 pode-se observar o mapa dos objetos conectados identificados no mapa de densidade de sementes em tons de cinza, totalizando 11 objetos, segundo procedimento da Seção 6.2. As intensidades das 49 regiões de valor médio de densidade de sementes, de acordo com a matriz $\Upsilon_{2}^{\prime \prime}$, são exibidas na Figura 7.36.

$v_{3}$ : O atributo da extensão dos agrupamentos de sementes em cada região, correspondente à geração $t+2$, é organizado na matriz $\Upsilon_{3}^{\prime \prime}$. 


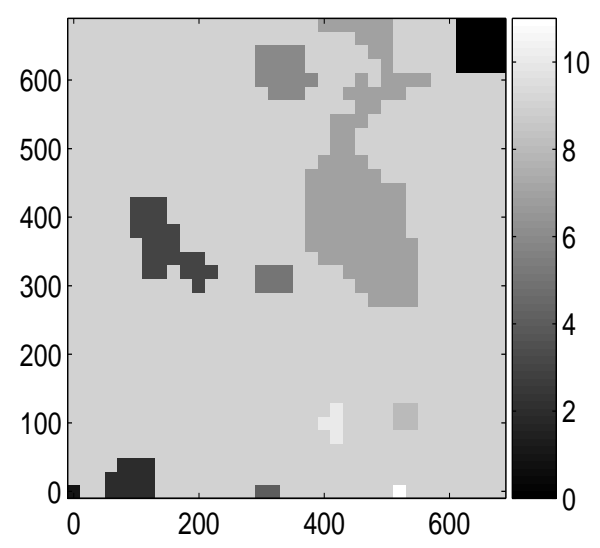

Figura 7.35: Mapa dos objetos conectados identificados no mapa de densidade de sementes dos dados coletados em campo da geração $t+2$.

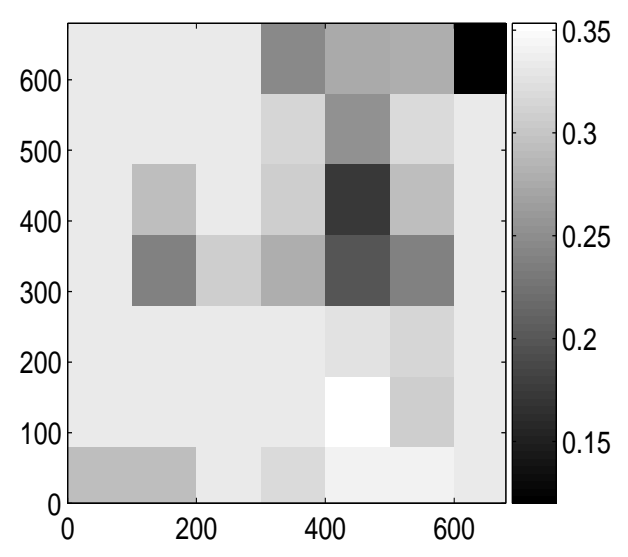

Figura 7.36: Mapa de regiões de valor médio ponderado de densidade de sementes de acordo com a matriz $\Upsilon_{2}^{\prime \prime}$.

$$
\Upsilon_{3}^{\prime \prime}=\left[\begin{array}{lllllll}
0,3333 & 0,3333 & 0,3333 & 0,2467 & 0,2733 & 0,2800 & 0,1200 \\
0,3333 & 0,3333 & 0,3333 & 0,3133 & 0,2533 & 0,3200 & 0,3333 \\
0,3333 & 0,2933 & 0,3333 & 0,3067 & 0,1733 & 0,2933 & 0,3333 \\
0,3333 & 0,2400 & 0,3067 & 0,2533 & 0,2000 & 0,2400 & 0,3333 \\
0,3333 & 0,3333 & 0,3333 & 0,3333 & 0,3267 & 0,3133 & 0,3333 \\
0,3333 & 0,3333 & 0,3333 & 0,3333 & 0,3533 & 0,3067 & 0,3333 \\
0,2733 & 0,2933 & 0,3333 & 0,3200 & 0,3400 & 0,3400 & 0,3333
\end{array}\right]
$$

A Figura 7.37 exibe as regiões referentes à extensão média dos objetos que representam a ocupação da densidade de sementes de cada região da cultura. 


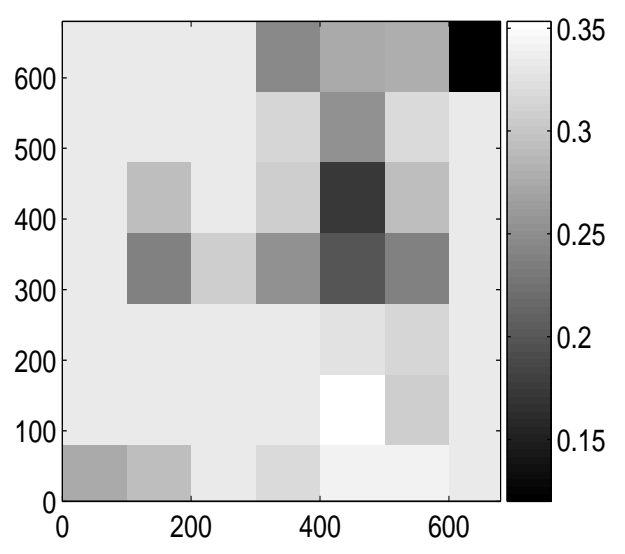

Figura 7.37: Mapa de regiões de valor médio ponderado referente à matriz $\Upsilon_{3}^{\prime \prime}$.

$v_{4}$ : O atributo da competitividade das plantas daninhas presentes em cada região, correspondente à geração $t+1$, é obtido como anteriormente, através do sistema neurofuzzy, o qual estima a saída através do ajuste automático das funções de pertinência das entradas e um sistema de inferência do tipo Sugeno.

A Tabela 7.13 exibe os valores de teste das saídas desejada e estimada pelo sistema e o resíduo obtido, que constitui na diferença entre estas duas saídas.

Tabela 7.13: Saídas do sistema neurofuzzy e resíduo obtido para os dados coletados na geração posterior.

\begin{tabular}{ccc} 
Saída desejada & Saída estimada & Resíduo \\
\hline 0,3072 & 0,1727 & 0,1345 \\
0,1952 & 0,8822 & $-0,6870$ \\
0,5472 & 0,4297 & 0,1175 \\
0,1574 & $-0,0190$ & 0,1764 \\
0,2673 & 0,3084 & $-0,0411$ \\
0,4013 & 0,0140 & 0,3872 \\
0,1685 & 0,0248 & 0,1437 \\
\hline
\end{tabular}

Com a mesma análise anterior, conclui-se que a média dos resíduos dos dados de teste é 0,033. Com 95\% de confiança, o teste de hipóteses indica que não é rejeitada a hipótese nula, a qual afirma que a média é igual a zero, com o intervalo $(-0,283 ; 0,349)$. O desvio padrão obtido é 0,34 e, segundo o teste de normalidade de Anderson-Darling o p-valor é 0,2 , não rejeitando a hipótese dos resíduos seguirem distribuição normal. Desta forma, pode-se concluir que o sistema neurofuzzy fornece boas estimativas da saída, que constitui o atributo da competitividade.

Para auxiliar na escolha do tipo de função de pertinência a ser adotado, foi feita uma análise estatística para as funções triangular, trapezoidal e gaussiana,como ante- 
riormente. A Tabela 7.14 exibe as estatísticas descritivas para o resíduo de estimação dos dados de teste do sistema neurofuzzy da geração posterior. Neste caso, a análise é suficiente para concluir que não existe diferença entre as médias dos resíduos e, além disto, estas são iguais a zero. A igualdade das variâncias dos resíduos é confirmada com o teste de Levene, pois encontrou-se p-valor $=0,88>\alpha=0,05$, e portanto não se rejeita a hipótese de que $\sigma_{\epsilon_{t r i}}^{2}=\sigma_{\epsilon_{t r a}}^{2}=\sigma_{\epsilon_{g a u}}^{2}$. A comparação entre as médias indica que não há diferenças significativas entre as médias dos resíduos das funções, apresentando $\mathrm{p}$-valor $=0,86>\alpha=0,05$. Mais uma vez, a função gaussiana é selecionada por apresentar melhores resultados na análise residual dos dados de teste. A Figura 7.38 exibe as funções de pertinência ajustadas automaticamente pela rede neural presente no sistema neurofuzzy.
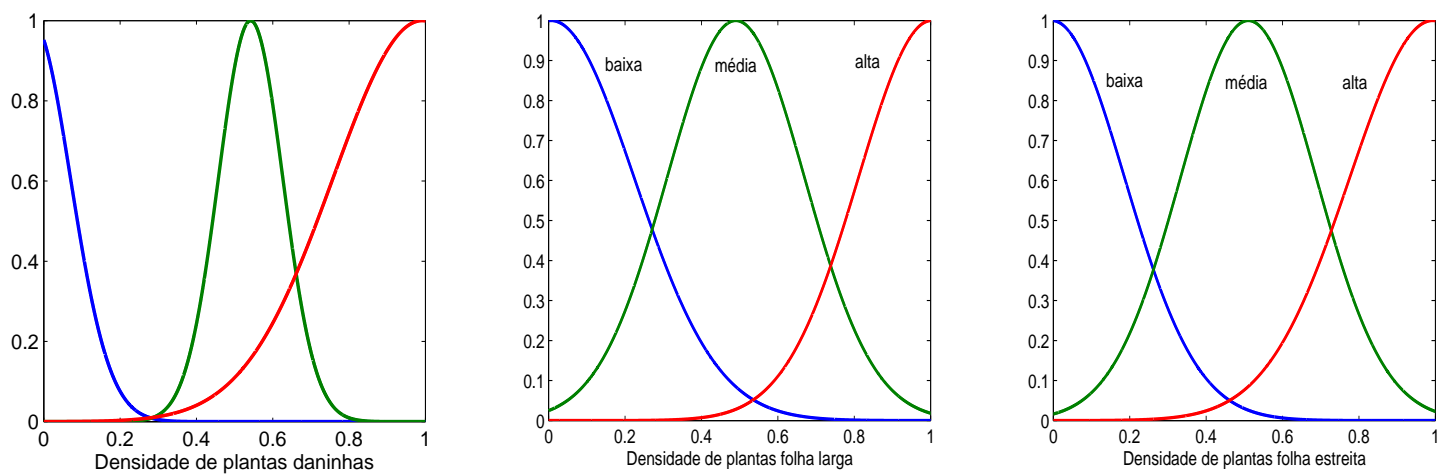

Figura 7.38: Funções de pertinência ajustadas pelo sistema neurofuzzy com os dados coletados na geração $t+1$.

Tabela 7.14: Estatísticas dos resíduos de estimação dos dados de teste do sistema neurofuzzy da geração posterior.

\begin{tabular}{cccc} 
Função & Média e Intervalo 95\% & D.Padrão & Anderson-Darling \\
\hline Gaussiana & $0,033(-0,283 ; 0,349)$ & 0,34 & p-valor $=0,2$ \\
Triangular & $-0,0012(-0,35 ; 0,347)$ & 0,37 & p-valor $=0,63$ \\
Trapezoidal & $0,26(-0,229 ; 0,749)$ & 0,53 & p-valor $=0,002$ \\
\hline
\end{tabular}

Os valores obtidos para este atributo, para cada região, são dispostos como nos casos anteriores na matriz denotada $\Upsilon_{4}^{\prime \prime}$ e a Figura 7.39 exibe o mapa de intensidades de competitividade das plantas daninhas por regiões. 


$\Upsilon_{4}^{\prime \prime}=\left[\begin{array}{ccccccc}0,0000 & 0,0000 & 0,7473 & 0,0141 & 0,4610 & 0,0000 & 0,0000 \\ 0,0000 & 0,5704 & 0,3525 & 0,1676 & 0,0058 & 0,0000 & 0,0000 \\ 0,4618 & 0,0259 & 0,2065 & 0,2197 & 0,0201 & 0,1177 & 0,2884 \\ 0,3178 & 0,5666 & 0,6930 & 0,4345 & 0,4760 & 0,2231 & 0,3033 \\ 0,6505 & 0,3119 & 0,5602 & 0,5884 & 0,6195 & 0,7118 & 0,3058 \\ 0,3511 & 0,9963 & 0,1727 & 0,1870 & 0,8577 & 0,1727 & 0,8822 \\ 0,0000 & 0,0248 & 0,0140 & 0,3084 & -0,0190 & 0,4297 & 0,0000\end{array}\right]$

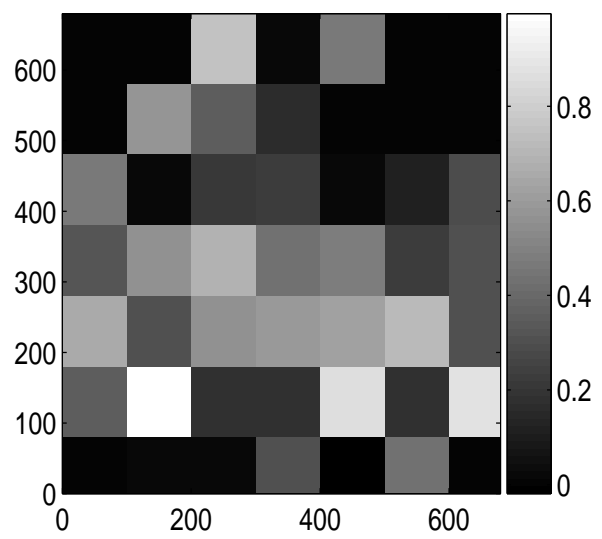

Figura 7.39: Mapa de intensidades de competitividade das plantas daninhas por regiões referente à $\Upsilon_{4}^{\prime \prime}$.

\subsubsection{Riscos de Infestação por Regiões na Geração $t+2$}

O sistema de classificação fuzzy é aplicado também em duas situações: considerando as 49 regiões escolhidas da cultura, de tamanho $5 \times 5$ pixels, e considerando toda a cultura como uma só região.

Para a obtenção dos riscos de infestação por região, o sistema de classificação fuzzy é composto pelas funções de pertinência da Figura 6.3 e a base de regras da Tabela 6.1. Aplicando este sistema para cada região considerada, os valores das matrizes $\Upsilon_{1}^{\prime \prime}, \Upsilon_{2}^{\prime \prime}, \Upsilon_{3}^{\prime \prime}, \Upsilon_{4}^{\prime \prime}$ são entradas do sistema e a saída é a matriz RiscoQ que representa a porcentagem do risco de infestação de cada região, correspondente à geração $t+2$. 


$$
\text { Risco2 }=\left[\begin{array}{lllllll}
0,3053 & 0,2901 & 0,6378 & 0,2641 & 0,5855 & 0,2641 & 0,2237 \\
0,2685 & 0,6378 & 0,4995 & 0,3041 & 0,2641 & 0,2641 & 0,2641 \\
0,6312 & 0,2641 & 0,3345 & 0,3410 & 0,2646 & 0,2655 & 0,4120 \\
0,4504 & 0,5558 & 0,6131 & 0,5701 & 0,5117 & 0,3252 & 0,4408 \\
0,6329 & 0,4473 & 0,6581 & 0,6329 & 0,6282 & 0,6183 & 0,4415 \\
0,5088 & 0,6290 & 0,3071 & 0,3169 & 0,6834 & 0,3080 & 0,6329 \\
0,2641 & 0,2641 & 0,2802 & 0,4356 & 0,3228 & 0,6308 & 0,3134
\end{array}\right] \text {. }
$$

A Figura 7.40 exibe, em escala de cinza, as intensidades dos riscos de infestação por plantas daninhas das 49 regiões consideradas da cultura, de acordo com a matriz Risco2. Pela matriz Risco2, pode-se observar que a maior porcentagem de infestação é $68,3 \%$, encontrada na região $\operatorname{Risco}(6,5)$.

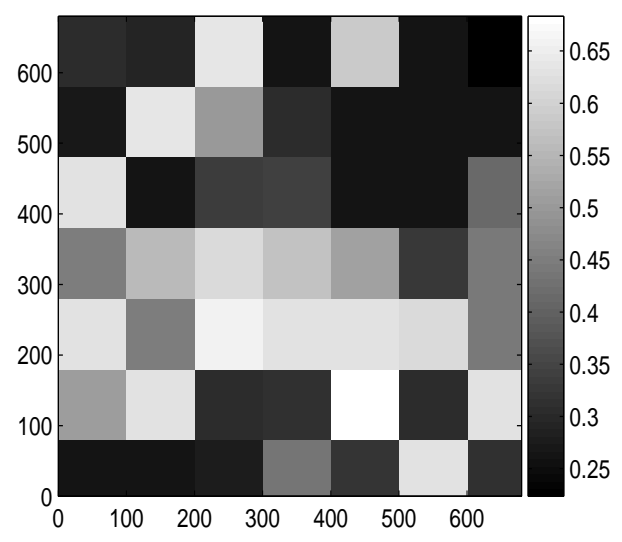

Figura 7.40: Mapa de intensidades de riscos de infestação por plantas daninhas por regiões referente à matriz Risco2.

Para o caso em que a cultura é analisada como uma só região, os valores dos atributos são $\Upsilon_{1}^{\prime \prime}=0,200 ; \Upsilon_{2}^{\prime \prime}=0,300 ; \Upsilon_{3}^{\prime \prime}=0,280 ; \Upsilon_{4}^{\prime \prime}=0,300$. O sistema de classificação fuzzy fornece um risco de infestação de $43 \%$ para toda a cultura, sugerindo um manejo com apenas uma taxa de aplicação de herbicida e as mesmas conclusões anteriores são consideradas. 


\subsubsection{Agrupamento dos Riscos de Infestação em uma Geração Poste- rior}

Os valores da matriz Risco2 são reunidos em agrupamentos como anteriormente, usando o algoritmo da Seção 6.4.1, com $c v=0,2$. A matriz RGrupos2 apresenta os valores médios obtidos por cada agrupamento encontrado, correspondentes a cada uma das regiões da cultura na geração posterior.

$$
\text { RGrupos } 2=\left[\begin{array}{lllllll}
0,2977 & 0,2977 & 0,6378 & 0,2841 & 0,5855 & 0,2439 & 0,2439 \\
0,2685 & 0,5686 & 0,5686 & 0,2841 & 0,2643 & 0,2641 & 0,2641 \\
0,5408 & 0,2641 & 0,3377 & 0,3377 & 0,2643 & 0,2954 & 0,4120 \\
0,5408 & 0,5015 & 0,6347 & 0,5409 & 0,5409 & 0,2954 & 0,4412 \\
0,6329 & 0,5015 & 0,6347 & 0,6347 & 0,6232 & 0,6232 & 0,4412 \\
0,5689 & 0,5689 & 0,3120 & 0,3120 & 0,6834 & 0,3080 & 0,6329 \\
0,2641 & 0,2641 & 0,2802 & 0,3792 & 0,3792 & 0,6308 & 0,3134
\end{array}\right] .
$$

A Tabela 7.15 exibe os valores dos coeficientes de variação de cada agrupamento. São encontrados 31 agrupamentos de riscos médios de infestação, cuja imagem é exibida na Figura 7.41.

Tabela 7.15: Coeficientes de variação para os agrupamentos identificados pelo algoritmo da Seção 6.4.1.

\begin{tabular}{ccccccccc}
\hline grupo & 1 & 2 & 3 & 4 & 5 & 6 & 7 & 8 \\
cv & 0.0355 & 0 & 0 & 0 & 0 & 0.0222 & 0 & 0 \\
\hline grupo & 9 & 10 & 11 & 12 & 13 & 14 & 15 & 16 \\
cv & 0 & 0 & 0.1429 & 0.0763 & 0 & 0.0996 & 0.1530 & 0.1171 \\
\hline grupo & 17 & 18 & 19 & 20 & 21 & 22 & 23 & 24 \\
cv & 0.2103 & 0 & 0 & 0.0112 & 0.0011 & 0 & 0.2364 & 0.0361 \\
\hline grupo & 25 & 26 & 27 & 28 & 29 & 30 & 31 & \\
cv & 0 & 0.0136 & 0.1720 & 0 & 0 & 0.0013 & 0.1494 & \\
\hline
\end{tabular}

\subsection{Análise Comparativa do Comportamento da Infestação nas Gerações}

Para avaliar o comportamento da infestação nas gerações é feita uma análise estatística nos agrupamentos representados em RGrupos e RGrupos2, os quais retratam a infestação 


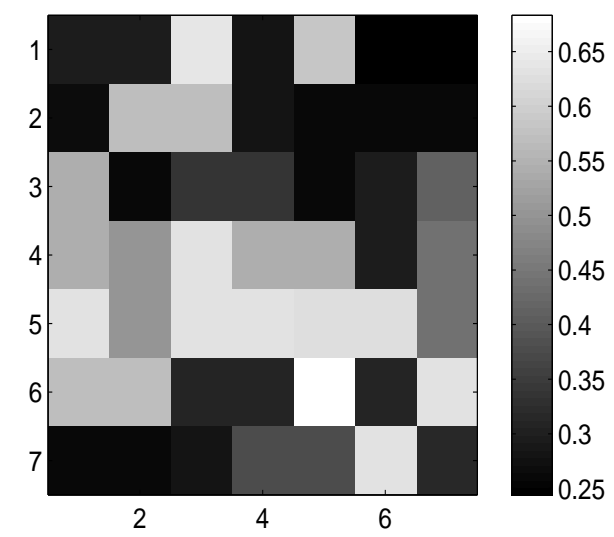

Figura 7.41: Mapa dos agrupamentos de riscos de infestação de acordo com as intensidades da matriz RGrupos2.

localizada, indicando se há ou não diferenças significativas entre os resultados das duas gerações.

Primeiramente, o coeficiente de correlação de Pearson apresenta o valor 0,2 (ver Apêndice C) e indica que, com $95 \%$ de confiança, p-valor $=0,12>\alpha=0,05$ não havendo correlação linear entre os agrupamentos das duas gerações. O teste de normalidade de Anderson-Darling indica p-valores nulos, ou seja, os dados presentes nas matrizes não seguem distribuição normal. Desta forma, o teste de igualdade de variâncias de Levene, que é livre de distribuições, apresenta $\mathrm{p}$-valor $=0,754>\alpha=0,05$, não rejeitando a hipótese de igualdade das variâncias. O teste de médias apresenta p-valor $=0,08>$ $\alpha=0,05$, também não rejeitando a hipótese de igualdade de médias entre os valores das duas matrizes. Desta forma, as matrizes de riscos agrupados apresentam a mesma dispersão em torno da média e a diferença entre as médias é nula, indicando que não há diferenças significativas entre RGrupos e RGrupos2. Portanto, o mapeamento do risco de infestação pode ser utilizado para aplicação localizada de herbicidas na geração seguinte sem perda de informação. A Tabela 7.16 exibe as estatísticas descritivas das matrizes de riscos de infestação agrupadas por k-médias nas duas gerações consideradas.

Tabela 7.16: Estatísticas descritivas das matrizes de riscos agrupadas de duas gerações.

\begin{tabular}{lccccc} 
& Média & Mediana & D.Padrão & Mínimo & Máximo \\
\hline geração 1 & 0,490 & 0,502 & 0,151 & 0,272 & 0,696 \\
geração 2 & 0,434 & 0,412 & 0,151 & 0,244 & 0,683 \\
\hline
\end{tabular}




\subsection{Avaliação do Desempenho do Sistema de Classificação Fuzzy}

O risco de infestação reflete o quanto a presença de plantas daninhas causa infestação e prejudica o rendimento da cultura. Desta forma, para avaliar a qualidade do sistema de classificação fuzzy do risco de infestação proposto, considera-se a perda de rendimento da cultura na mesma geração em que o risco é estimado. É importante observar que o sistema fuzzy proporciona a predição da infestação em cada região antes de sua ocorrência. Portanto, a vantagem é que não é necessário perder o rendimento da cultura ao longo das gerações. A perda só é empregada, neste trabalho, para explicar o risco de infestação inferido pelo sistema fuzzy. Para isto, a perda de rendimento é calculada conforme (3.1), para a colheita do milho em abril de 2005, que corresponde à geração $t$, e para a colheita em novembro de 2006, que corresponde à geração $t+2$. Os valores obtidos passam pelo processo de Krigagem, conforme parâmetros especificados a seguir, a fim de obter mapas de perda de rendimento.

[MapaPerda05]=krigagem1([1 2],3,[0 0],[20 20], [35 35], 1,'exponentialV', [0.0072 200], 30, 200, 'perdarend2005.dat', 1,1);

[MapaPerda06]=krigagem1([1 2],3,[0 0],[20 20], [35 35], 1,'exponentialV', [0.028 200] ,30, 200, 'perdarend2006.dat', 1,1);

As Figuras 7.42 e 7.43 representam, respectivamente, as matrizes MapaPerda05 e MapaPerda06, representando os mapas de perda de rendimento estimados por Krigagem das gerações $t$ e $t+2$.

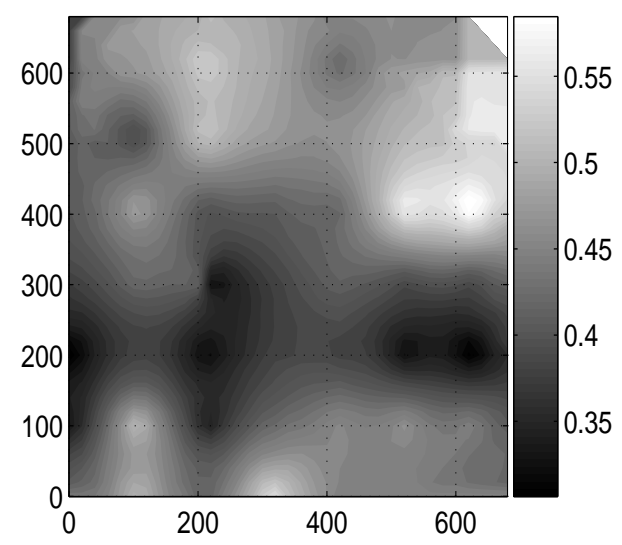

Figura 7.42: Mapa de perda de rendimento na geração $t$. 


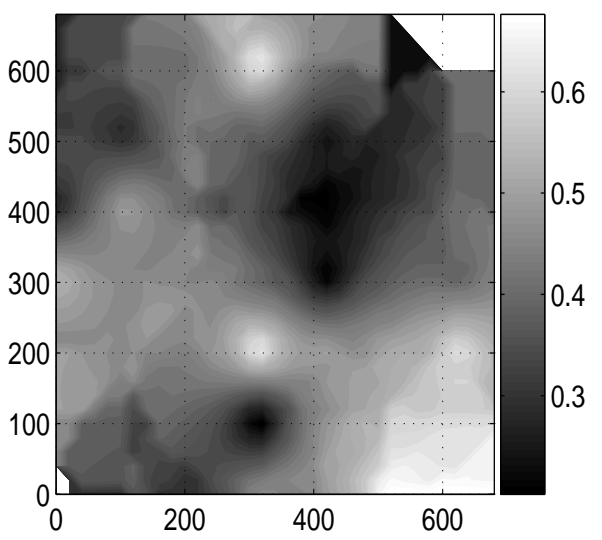

Figura 7.43: Mapa de perda de rendimento na geração $t+2$.

Em seguida, as matrizes MapaPerda05 e MapaPerda06, que possuem dimensão $35 \times 35$, são agrupadas pelo método k-médias no mesmo número de agrupamentos das matrizes RGrupo e RGrupo2, respectivamente, com o objetivo de comparar a perda de rendimento com o risco de infestação estimado para a geração correspondente. Desta forma, a matriz MapaPerda05 é agrupada em 27 agrupamentos e a matriz MapaPerda06 em 31 agrupamentos. As Figuras 7.28 e 7.41, que representam, respectivamente, as matrizes RGrupo e RGrupo2, podem então ser comparadas às Figuras 7.44 e 7.45 , que exibem, respectivamente, os mapas dos agrupamentos de perdas de rendimento para as gerações $t$ e $t+2$, e são repetidas aqui.

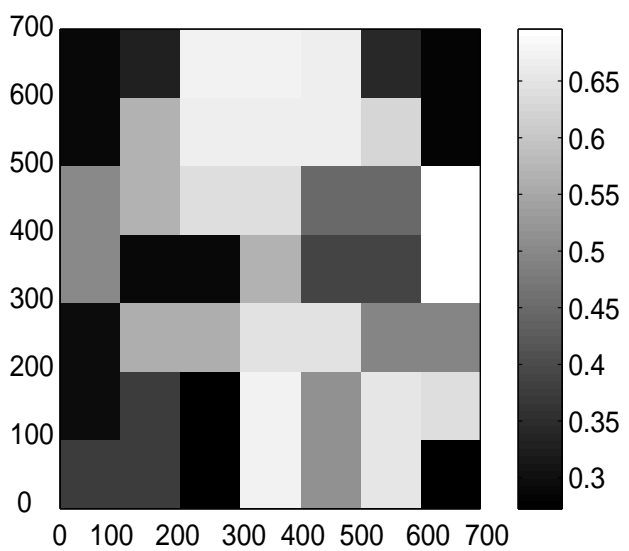

(a)

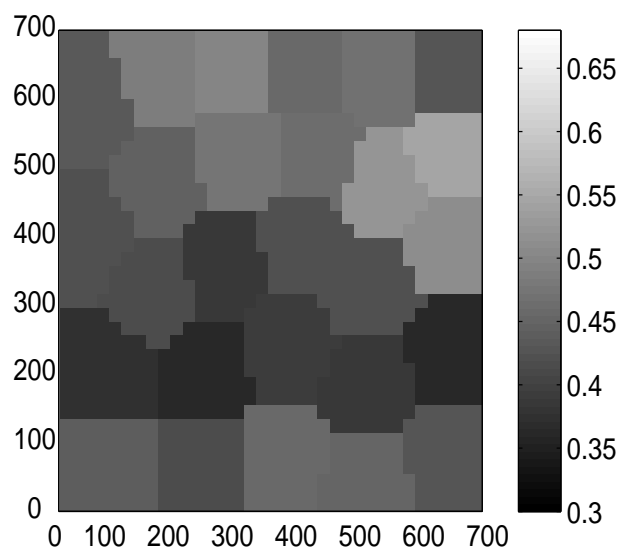

(b)

Figura 7.44: (a) Mapa dos agrupamentos dos riscos de infestação na geração $t$; (b) Mapa dos agrupamentos de perda de rendimento na geração $t$.

Os agrupamentos de cores mais claras revelam maiores perdas de rendimento e riscos de infestação, enquanto que os de cores mais escuras revelam menores. Além disso, o 


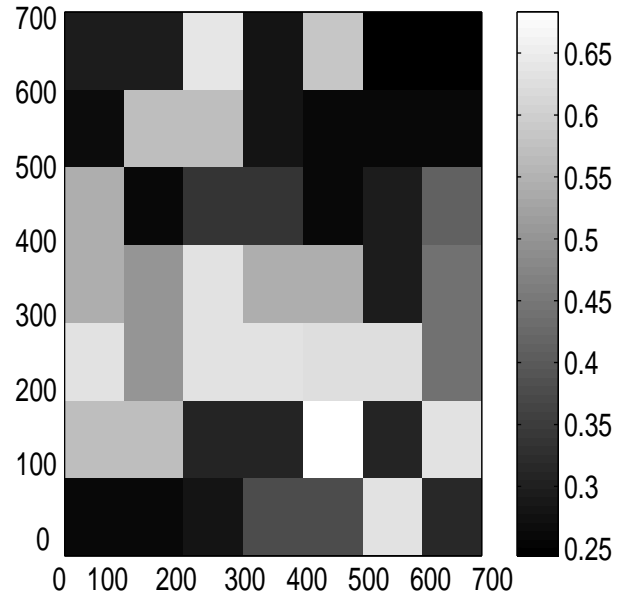

(a)

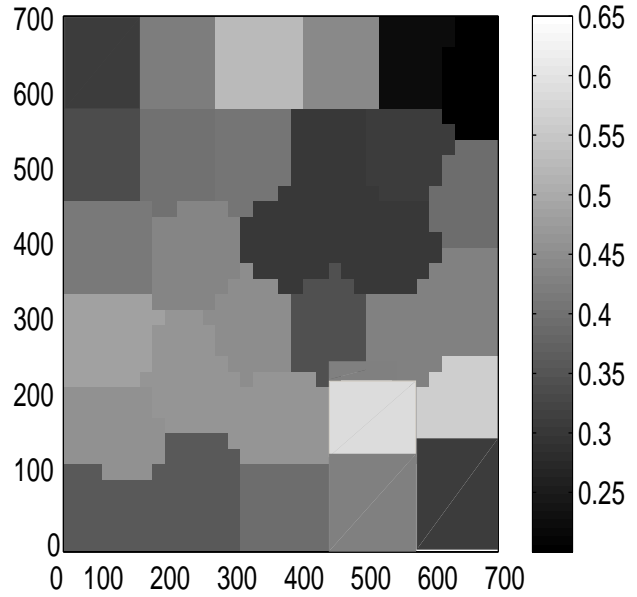

(b)

Figura 7.45: (a) Mapa dos agrupamentos dos riscos de infestação na geração $t+2$; (b) Mapa dos agrupamentos de perda de rendimento na geração $t+2$.

sistema é conservador, ou seja, em geral, o valor de risco estimado para uma região é relativamente maior do que a perda ocorrida, garantindo a eficiência do controle. Uma análise de resíduos é feita entre os valores de risco de infestação estimados e os valores de perda de rendimento ocorridos, com o auxílio do aplicativo MINITAB 13, com o objetivo de verificar se a estimativa do risco de infestação reflete a perda ocorrida no mesmo agrupamento. Para isso, são utilizados os valores dos centróides dos agrupamentos correspondentes. Para os resíduos obtidos com a perda e o risco correspondentes à geração $t$, não se rejeita a hipótese destes resíduos apresentarem média zero, com valor $-0,044$ e intervalo de confiança $(-0,103 ; 0,014)$. Pelo teste de Anderson-Darling, os resíduos seguem distribuição normal, conforme indica o p-valor 0,12 , e possuem variância constante, com $\bar{R}=0,17$. Para os resíduos obtidos com a perda e o risco correspondentes à geração $t+2$, também não se rejeita a hipótese destes resíduos apresentarem média zero, com valor $-0,022$ e intervalo de confiança $(-0,086 ; 0,043)$. Pelo teste de Anderson-Darling, os resíduos seguem distribuição normal, com p-valor 0,39, e possuem variância constante, com $\bar{R}=0,16$. Portanto, tem-se evidências de boas estimativas do risco de infestação, dado que os resíduos, de ambas as gerações, apresentam média zero, variância constante e distribuição normal. Além disso, como calculado anteriormente, se um único risco médio de infestação for inferido para toda a cultura, considerando-a como homogênea e não regionalizada, o risco de infestação para a geração $t$ é de $42 \%$ e para a geração $t+2,43 \%$. Para estas gerações, respectivamente, obteve-se uma perda de rendimento média de $43 \%$ e $41 \%$, comprovando a convergência dos resultados. 


\section{Capítulo 8}

\section{Extração de Regras a partir de Redes de Classificação Bayesianas}

Neste capítulo, regras linguísticas para a classificação da competitividade e do risco de infestação são obtidas por redes de classificação Bayesianas, por motivo de comparação. Duas redes são consideradas, sendo uma rede de classificação Bayesiana irrestrita e uma rede naïve Bayes, usualmente empregada em classificadores Bayesianos (Granitto et al., 2002; Granitto et al., 2005; Marchant e Onyango, 2003). Um método chamado BayesRule, proposto por Hruschka et al. (2007), é aplicado para extrair um conjunto de regras a partir de cada uma das redes. Este é um método híbrido que incorpora regras linguísticas às redes de classificação Bayesianas, facilitando o entendimento do usuário. O método BayesRule utiliza o conceito de Markov blanket para reduzir o número de antecedentes das regras, conforme descrito no algoritmo da Seção 5.2.3. Em seguida, a estimativa da probabilidade da classe é usada como estratégia de poda para otimizar cada conjunto de regras, quando o Markov blanket não é suficiente para reduzir o número de regras. Os dados coletados em março de 2005 e outubro de 2006 são utilizados para construir as redes de classificação Bayesianas. Finalmente, os conjuntos de regras de ambos os métodos de classificação, fuzzy e Bayesiano, são comparados. 


\subsection{Modelagem de Redes de Classificação Bayesianas Apli- cadas à Classificação da Competitividade}

Conforme feito para o sistema neurofuzzy, que também se trata de um sistema com treinamento supervisionado, os dados de biomassa são utilizados como saída, ou seja, são definidos como variável classe. Para extrair regras probabilísticas de ambas as redes, irrestrita e naïve, usando o método BayesRule, os valores de todas as variáveis envolvidas precisam ser discretizados. O processo de discretização foi conduzido por especialista humano, que propôs 3 intervalos para as variáveis que compõem a rede que infere sobre o atributo da competitividade, exibidos na Tabela 8.1. Os intervalos de discretização são representados por variáveis linguísticas: alta (A), média (M) e baixa (B).

Tabela 8.1: Intervalos de discretização para as variáveis que definem a rede que infere sobre o atributo da competitividade.

\begin{tabular}{|c|c|c|c|}
\hline & Alta & Baixa & Média \\
\hline Densidade total & {$[0,60 ; 1]$} & {$[0 ; 0,20]$} & $\mid 0,20 ; 0,60$ \\
\hline Densidade de folha estreita & {$[0,60 ; 1]$} & {$[0 ; 0,20]$} & 0,$20 ; 0,60$ \\
\hline Densidade de folha larga & {$[0,75 ; 1]$} & {$[0 ; 0,25]$} & 0,$25 ; 0,75$ \\
\hline Biomassa & {$[0,60 ; 1]$} & {$[0 ; 0,20]$} & ] 0,$20 ; 0,60[$ \\
\hline
\end{tabular}

As Figuras 8.1 e 8.2 representam o sistema de classificação Bayesiano para a competitividade entre plantas daninhas e cultura. A Figura 8.1 ilustra o aprendizado com o método BayesRule, um processo supervisionado pela biomassa. É importante ressaltar que na rede naïve Bayes, não há a inserção do conhecimento do especialista, dado que a estrutura da rede é fixa. A Figura 8.2 representa o sistema de classificação usando o conjunto de regras extraído de ambas as redes Bayesianas, irrestrita e naïve.

A estrutura da rede de classificação Bayesiana irrestrita, definida por conhecimento de especialista, é representada pela relação entre pais e filhos na Figura 8.3. O nó identificado como Biomassa é o nó classe, a partir do qual o atributo da competitividade é inferido. O Markov blanket deste nó é formado por todas as variáveis da rede, por isso, o método BayesRule não reduz os antecedentes e a quantidade de regras geradas usando o conceito de Markov blanket. A Figura 8.4 ilustra a estrutura da rede de classificação naïve Bayes, na qual a variável classe não tem pais e os padrões são condicionalmente independentes, dada a variável classe. 


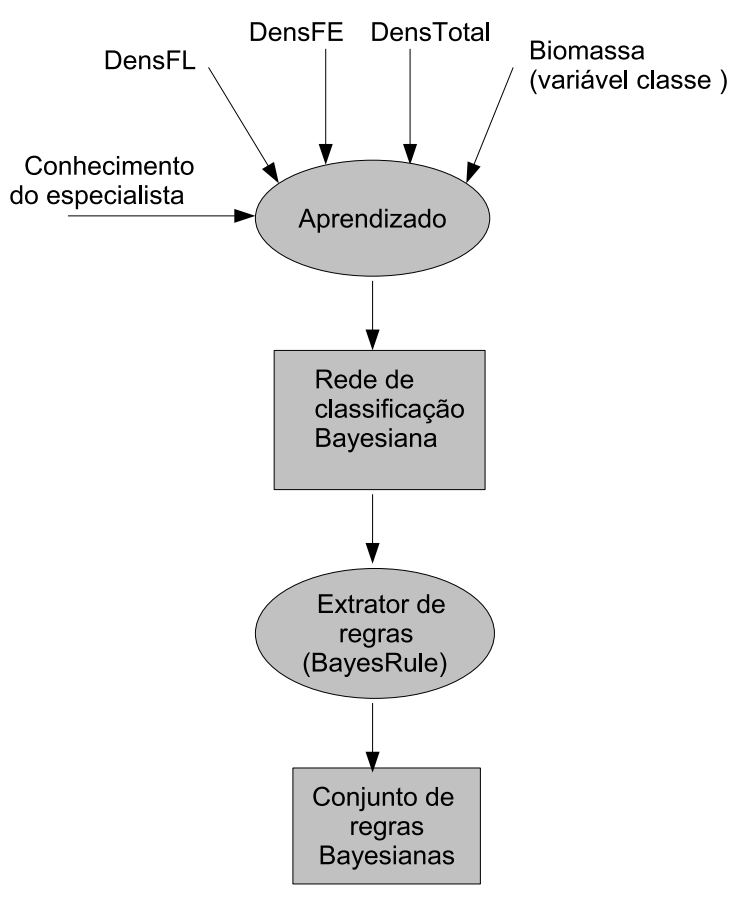

Figura 8.1: Aprendizado da rede com BayesRule para o atributo da competitividade.

Como foi descrito no Capítulo 3, as densidades de plantas e a biomassa foram medidas em cada parcela experimental da cultura em abril de 2005 e outubro de 2006, em duas gerações diferentes. Portanto, 82 instâncias de dados são obtidos, isto é, duas instâncias para cada uma das 41 parcelas. Analisando a coleta, 11 instâncias são identificadas como outliers (pontos discrepantes), seja por erro de medição ou de anotação, e são removidos. As 71 instâncias restantes são consideradas para a classificação. Para avaliar a generalização da rede, a validação cruzada é realizada como segue. As 71 instâncias são separadas aleatoriamente em dois conjuntos: um conjunto de treinamento, com $90 \%$ dos dados, para aprendizado, e um conjunto de teste, com os $10 \%$ restantes, para avaliação. Este conjunto de teste é colocado novamente com as outras instâncias para um novo treinamento e outros $10 \%$, diferentes do primeiro cojunto de teste, são aleatoriamente selecionados para um novo teste. Este procedimento é repetido 10 vezes até que todas as instâncias são consideradas para o teste (validação cruzada). Desta forma, 10 redes de classificação Bayesina irrestrita e 10 redes de classificação naïve Bayes são treinadas usando 10 diferentes conjuntos de treinamento e as regras 


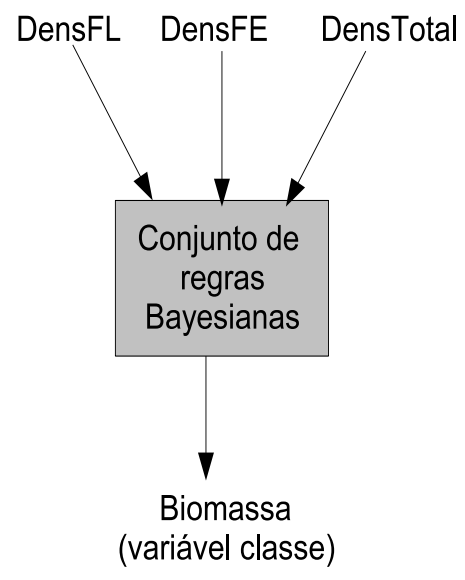

Figura 8.2: Inferência da Biomassa.

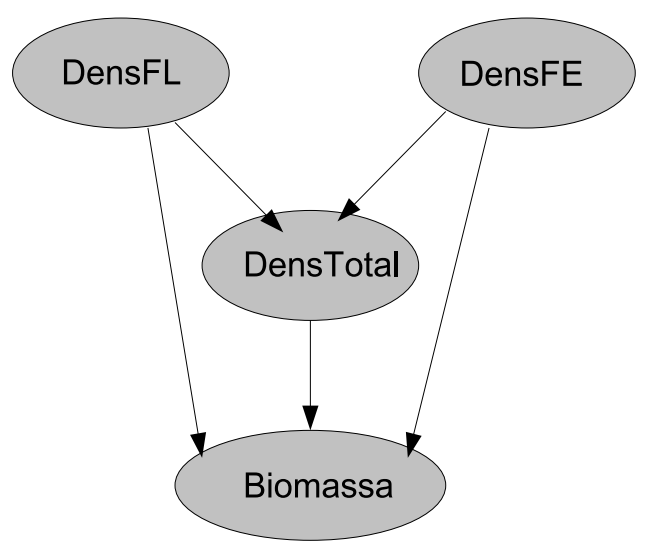

Figura 8.3: Rede de classificação Bayesiana irrestrita para a competitividade.

extraídas, usando BayesRule, são avaliadas usando cada um dos 10 conjuntos de testes correspondentes. Os mesmos conjuntos de testes são considerados para avaliar as regras extraídas de ambas as redes. Um destes 10 casos é exibido aqui, tanto para a rede irrestrita quanto para a rede naïve. O procedimento para os outros casos é similar.

\subsubsection{Resultados da Classificação da Competitividade a partir das Redes Bayesianas}

Cada nó das redes Bayesianas possui um conjunto de probabilidades condicionais associado, que depende de seus pais. As Tabelas 8.2, 8.3 e 8.4 apresentam as probabilidades das variáveis (representadas pelos nós), que constituem a rede de classificação Bayesiana irrestrita, serem A, B ou M. É importante enfatizar que a estrutura da rede (Figura 8.3) é definida por conhecimento de especialista e as estimativas das probabilidades 


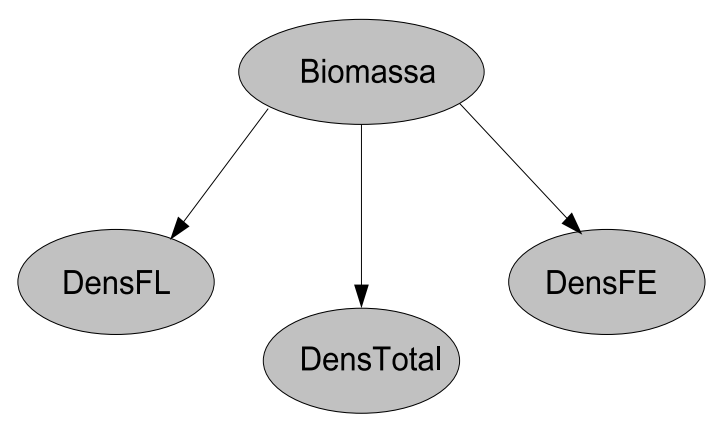

Figura 8.4: Rede de classificação naïve Bayes para a competitividade.

condicionais dos nós, os parâmetros numéricos, são obtidas a partir dos dados com o auxílio do Genie ${ }^{1}$, um aplicativo de livre acesso. As Tabelas 8.6, 8.7 e 8.8 apresentam as probabilidades das variáveis, que constituem a rede de classificação naïve Bayes, serem A, B ou M, dadas as probabilidades do nó Biomassa, exibidas na Tabela 8.5.

Tabela 8.2: Probabilidades condicionais dos nós DensFL and DensFE na rede irrestrita.

\begin{tabular}{ccc} 
& DensFL & DensFE \\
\hline A & 0,20 & 0,52 \\
B & 0,35 & 0,20 \\
M & 0,45 & 0,28
\end{tabular}

Tabela 8.3: Probabilidades condicionais do nó DensTotal na rede irrestrita.

\begin{tabular}{cccccccccc}
\multicolumn{11}{c}{ DensTotal node } \\
\hline DensFL & \multicolumn{11}{c}{ A } & \multicolumn{1}{c}{ B } & & M \\
\hline DensFE & A & B & M & A & B & M & A & B & M \\
\hline A & 0,11 & 0,25 & 1 & 0,14 & 0 & 0,08 & 0,08 & 0,15 & 0,12 \\
B & 0,31 & 0,16 & 0 & 0,27 & 1 & 0,12 & 0,16 & 0,50 & 0,29 \\
M & 0,58 & 0,58 & 0 & 0,59 & 0 & 0,79 & 0,75 & 0,35 & 0,59
\end{tabular}

${ }^{1}$ http://genie.sis.pitt.edu 
Tabela 8.4: Probabilidades condicionais do nó Biomassa na rede irrestrita. 
Tabela 8.5: Probabilidades condicionais do nó Biomassa na rede naïve.

\begin{tabular}{cc}
\multicolumn{2}{c}{ Biomassa } \\
\hline A & 0,23 \\
B & 0,21 \\
M & 0,56
\end{tabular}

Tabela 8.6: Probabilidades condicionais do nó DensFL dada Biomassa na rede naïve.

\begin{tabular}{cccc} 
Biomassa & A & B & M \\
\hline A & 0,11 & 0,19 & 0,32 \\
B & 0,39 & 0,25 & 0,35 \\
M & 0,50 & 0,56 & 0,33
\end{tabular}

Tabela 8.7: Probabilidades condicionais do nó DensFE dada Biomassa na rede naïve.

\begin{tabular}{cccc} 
Biomassa & A & B & M \\
\hline A & 0,72 & 0,32 & 0,45 \\
B & 0,06 & 0,25 & 0,3 \\
M & 0,22 & 0,44 & 0,25
\end{tabular}

O método BayesRule, descrito na Seção 5.2.3, extraiu um conjunto de 27 regras probabilísticas de cada rede de classificação Bayesiana, conforme pode ser visto na Tabela 8.9 para rede irrestrita e na Tabela 8.10 para a rede naïve. O número de regras representa todas as combinações possíveis das variáveis e suas discretizações linguísticas. Cada regra tem um valor que representa a probabilidade do valor classe, dados os valores de suas variáveis antecedentes. Para reduzir o número de regras em cada conjunto de regras, uma estratégia de poda é proposta. Usando cada um dos 10 conjuntos de treinamento da validação cruzada, as regras com probabilidade menor que 0,7 são substituídas por uma regra default, gerada a partir de uma probabilidade a priori da variável classe. Neste trabalho, o mais provável valor da variável classe é o valor linguístico Médio.

Considerando o conjunto de regras Bayesiano extraído da rede de classificação irrestrita, os resultados obtidos para o conjunto de teste exposto aqui são mostrados na Tabela 8.11. As regras apresentam um índice de acerto de 50\%, pois 3 das 6 instâncias testadas são classificadas corretamente. A Tabela 8.12 exibe o conjunto de regras podado, ou reduzido, o qual apresenta apenas as regras com probabilidade maior que 0,7 
Tabela 8.8: Probabilidades condicionais do nó DensTotal dada Biomassa na rede naïve.

\begin{tabular}{cccc} 
Biomassa & A & B & M \\
\hline A & 0,17 & 0,19 & 0,15 \\
B & 0,11 & 0,56 & 0,2 \\
M & 0,72 & 0,25 & 0,65
\end{tabular}

e a regra default. A Tabela 8.13 apresenta os resultados do conjunto de teste utilizando este cojunto de regras reduzido. Para este conjunto de testes, as regras 9 e 21 são substituídas pela regra default e o conjunto de regras podado tem um índice de acerto de 83,33\%, pois 5 das 6 instâncias testadas são classificadas corretamente. Neste caso, o índice de acerto da classificação aumentou. Para todos os 10 conjuntos de teste da validação cruzada, os resultados indicam um índice de acerto de 63,39\% usando o conjunto de regras correspondente, desde que 45 das 71 instâncias são classificadas corretamente, e um índice de acerto de 64,79\% usando os conjuntos de regras reduzidos, desde que 46 das 71 instâncias são classificadas corretamente.

Quando considerando o conjunto de regras Bayesiano extraído da rede de classificação naïve, os resultados obtidos para um dos conjuntos de teste estão na Tabela 8.14. Os resultados revelam que as regras apresentam um índice de acerto de $50 \%$, pois 3 das 6 instâncias testadas são classificadas corretamente. A Tabela 8.15 exibe o conjunto de regras reduzido e os resultados do conjunto de teste utilizando este cojunto de regras reduzido são apresentados na Tabela 8.16. Para este conjunto de testes, as regras 3, 13, 25 e 27 são substituídas pela regra default e o conjunto de regras reduzido tem um índice de acerto de $66,66 \%$, pois 4 das 6 instâncias testadas são classificadas corretamente. Neste caso, o índice de acerto da classificação também aumentou. Para todos os 10 conjuntos de teste da validação cruzada, os resultados indicam um índice de acerto de 57,75\% usando o conjunto de regras correspondente, desde que 41 das 71 instâncias são classificadas corretamente, e um índice de acerto de 61,97\% usando os conjuntos de regras reduzidos, desde que 44 das 71 instâncias são classificadas corretamente.

A Tabela 8.17 exibe os resultados da classificação utilizando os conjuntos de regras originais e reduzidos das redes de classificação Bayesianas irrestrita e naïve. 
Tabela 8.9: Conjunto de regras Bayesianas da rede irrestrita. D: regra Default

1 Se (DensFl é A) e (DensFE é A) e (DensdTotal é A) então Biomassa é A (0.720220)

2 Se (DensFl é A) e (DensFE é A) e (DensdTotal é B) então Biomassa é B (0.462965)

3 Se (DensFL é A) e (DensFE é A) e (DensdTotal é M) então Biomassa é B (0.605287)

4 Se (DensFL é A) e (DensFE é B) e (DensdTotal é A) então Biomassa é M (1.000000)

5 Se (DensFL é A) e (DensFE é B) e (DensdTotal é B) então Biomassa é B (0.500000)

6 Se (DensFL é A) e (DensFE é B) e (DensdTotal é M) então Biomassa é M (0.714286)

7 Se (DensFL é A) e (DensFE é M) e (DensdTotal é A) então Biomassa é A (0.828468)

8 Se (DensFL é A) e (DensFE é M) e (DensdTotal é B) então Biomassa é B (0.469272)

9 Se (DensFL é A) e (DensFE é M) e (DensdTotal é M) então Biomassa é B (0.516770)

10 Se (DensFL é B) e (DensFE é A) e (DensdTotal é A) então Biomassa é A (0.333333)

11 Se (DensFL é B) e (DensFE é A) e (DensdTotal é B) então Biomassa é M (1.000000) 12 Se (DensFL é B) e (DensFE é A) e (DensdTotal é M) então Biomassa é M (0.538462) $13 \mathrm{Se}$ (DensFL é B) e (DensFE é B) e (DensdTotal é A) então Biomassa é M (0.375349) 14 Se (DensFL é B) e (DensFE é B) e (DensdTotal é B) então Biomassa é B (0.558833) 15 Se (DensFL é B) e (DensFE é B) e (DensdTotal é M) então Biomassa é M (0.488885) 16 Se (DensFL é B) e (DensFE é M) e (DensdTotal é A) então Biomassa é M (0.510234) 17 Se (DensFL é B) e (DensFE é M) e (DensdTotal é B) então Biomassa é A (0.420255) 18 Se (DensFL é B) e (DensFE é M) e (DensdTotal é M) então Biomassa é M (0.419466) 19 Se (DensFL é M) e (DensFE é A) e (DensdTotal é A) então Biomassa é B (1.000000) 20 Se (DensFL é M) e (DensFE é A) e (DensdTotal é B) então Biomassa é A (0.500000) 21 Se (DensFL é M) e (DensFE é A) e (DensdTotal é M) então Biomassa é A (0.555556) 22 Se (DensFL é M) e (DensFE é B) e (DensdTotal é A) então Biomassa é M (0.449723) 23 Se (DensFL é M) e (DensFE é B) e (DensdTotal é B) então Biomassa é B (0.792353) 24 Se (DensFL é M) e (DensFE é B) e (DensdTotal é M) então Biomassa é B (0.713323) 25 Se (DensFL é M) e (DensFE é M) e (DensdTotal é A) então Biomassa é A (0.500000) 26 Se (DensFL é M) e (DensFE é M) e (DensdTotal é B) então Biomassa é B (0.800000) 27 Se (DensFL é M) e (DensFE é M) e (DensdTotal é M) então Biomassa é M (0.800000)

\subsection{Modelagem das Redes de Classificação Bayesiana Apli- cadas à Classificação do Risco de Infestação}

Da mesma forma que a rede Bayesiana da seção anterior, que infere sobre o atributo da competitividade, para inferir sobre o risco de infestação utilizando redes de classificação Bayesiana, irrestrita e naïve, e extraindo regras pelo método BayesRule, os valores das variáveis são discretizados de acordo com os intervalos representados na Tabela 8.18. Como o risco de infestação reflete a perda de rendimento da cultura, os dados de perda são definidos como a variável classe das redes.

As Figuras 8.5 e 8.6 representam o sistema de classificação Bayesiano para o risco de infestação. A Figura 8.1 ilustra o aprendizado com o método BayesRule, um processo 
Tabela 8.10: Conjunto de regras Bayesianas da rede naïve. D: regra Default

1 Se (DensFL é A) e (DensFE é A) e (DensdTotal é A) então Biomassa é M (0.693863)

2 Se (DensFL é A) e (DensFE é B) e (DensdTotal é A) então Biomassa é M (0.799344)

3 Se (DensFL é A) e (DensFE é M) e (DensdTotal é A) então Biomassa é M (0.622228)

4 Se (DensFL é B) e (DensFE é A) e (DensdTotal é A) então Biomassa é M (0.484799)

5 Se (DensFL é B) e (DensFE é B) e (DensdTotal é A) então Biomassa é M (0.729722)

6 Se (DensFL é B) e (DensFE é M) e (DensdTotal é A) então Biomassa é M (0.490745)

7 Se (DensFL é M) e (DensFE é A) e (DensdTotal é A) então Biomassa é A (0.426465)

8 Se (DensFL é M) e (DensFE é B) e (DensdTotal é A) então Biomassa é M (0.556326)

9 Se (DensFL é M) e (DensFE é M) e (DensdTotal é A) então Biomassa é B (0.459647)

10 Se (DensFl é A) e (DensFE é A) e (DensdTotal é B) então Biomassa é M (0.647883)

11 Se (DensFL é A) e (DensFE é B) e (DensdTotal é B) então Biomassa é M (0.660949)

12 Se (DensFL é A) e (DensFE é M) e (DensdTotal é B) então Biomassa é B (0.494111)

13 Se (DensFL é B) e (DensFE é A) e (DensdTotal é B) então Biomassa é M (0.517835)

14 Se (DensFL é B) e (DensFE é B) e (DensdTotal é B) então Biomassa é M (0.600634)

15 Se (DensFL é B) e (DensFE é M) e (DensdTotal é B) então Biomassa é B (0.512707)

16 Se (DensFL é M) e (DensFE é A) e (DensdTotal é B) então Biomassa é B (0.441168)

17 Se (DensFL é M) e (DensFE é B) e (DensdTotal é B) então Biomassa é B (0.583528)

18 Se (DensFL é M) e (DensFE é M) e (DensdTotal é B) então Biomassa é B (0.703950)

19 Se (DensFL é A) e (DensFE é A) e (DensdTotal é M) então Biomassa é M (0.761341)

20 Se (DensFL é A) e (DensFE é B) e (DensdTotal é M) então Biomassa é M (0.910959)

21 Se (DensFL é A) e (DensFE é M) e (DensdTotal é M) então Biomassa é M (0.778068)

22 Se (DensFL é B) e (DensFE é A) e (DensdTotal é M) então Biomassa é M (0.525055)

23 Se (DensFL é B) e (DensFE é B) e (DensdTotal é M) então Biomassa é M (0.847021)

24 Se (DensFL é B) e (DensFE é M) e (DensdTotal é M) então Biomassa é M (0.610059)

25 Se (DensFL é M) e (DensFE é A) e (DensdTotal é M) então Biomassa é A (0.496740)

26 Se (DensFL é M) e (DensFE é B) e (DensdTotal é M) então Biomassa é M (0.747573)

27 Se (DensFL é M) e (DensFE é M) e (DensdTotal é M) então Biomassa é M (0.483333)

supervisionado pela perda de rendimento. Conforme mencionado anteriormente, na rede naïve Bayes, não há a inserção do conhecimento do especialista. A Figura 8.6 representa o sistema de classificação usando o conjunto de regras extraído das redes irrestrita e naïve.

A estrutura da rede de classificação Bayesiana irrestrita para o risco de infestação, definida por conhecimento de especialista, é representada na Figura 8.7. O nó identificado como 'Perda de rendimento' é o nó classe, a partir do qual o risco de infestação é inferido. O Markov blanket deste nó é formado pelos nós Competitividade, Densidade de sementes e Extensão dos agrupamentos de sementes. A Figura 8.8 ilustra a estrutura da rede de classificação naïve Bayes.

Como foi descrito anteriormente, os atributos da infestação e a perda de rendimento 
Tabela 8.11: Resultados do conjunto de teste da rede Bayesiana irrestrita para a competitividade.

\begin{tabular}{ccccccc}
\multicolumn{2}{c}{ DensFL DensFE DensdTotal } & Biomassa & Regra & teste & Prob.regra \\
\hline A & M & M & A & 9 & errou & $52 \%$ \\
M & A & M & M & 21 & errou & $55 \%$ \\
A & B & M & M & 6 & acertou & $71 \%$ \\
A & B & M & M & 6 & acertou & $71 \%$ \\
A & M & M & M & 9 & errou & $52 \%$ \\
M & M & B & B & 26 & acertou & $80 \%$ \\
\hline
\end{tabular}

Tabela 8.12: Conjunto reduzido de regras Bayesianas da rede irrestrita para a competitividade. D: regra Default

1 Se (DensFL é A) e (DensFE é A) e (DensTotal é A) então Biomassa é A (0.72)

4 Se (DensFL é A) e (DensFE é B) e (DensTotal é A) então Biomassa é M (1.00)

6 Se (DensFL é A) e (DensFE é B) e (DensTotal é M) então Biomassa é M (0.72)

7 Se (DensFL é A) e (DensFE é M) e (DensTotal é A) então Biomassa é A (0.83)

11 Se (DensFL é B) e (DensFE é A) e (DensTotal é B) então Biomassa é M (1.00)

19 Se (DensFL é M) e (DensFE é A) e (DensTotal é A) então Biomassa é B (1.00)

23 Se (DensFL é M) e (DensFE é B) e (DensTotal é B) então Biomassa é B (0.79)

24 Se (DensFL é M) e (DensFE é B) e (DensTotal é M) então Biomassa é B (0.72)

26 Se (DensFL é M) e (DensFE é M) e (DensTotal é B) então Biomassa é B (0.80)

27 Se (DensFL é M) e (DensFE é M) e (DensTotal é M) então Biomassa é M (0.80)

D caso contrário Biomassa é M (1.00)

foram obtidos para 2005 e 2006. Os dados numéricos, discretizados na Tabela 8.18, utilizados para treinar a rede da Figura 8.7, são os dados das matrizes dos atributos de entrada do sistema fuzzy que inferem o risco de infestação por regiões de ambas as gerações $t$ (2005) e $t+2$ (2006). Desta forma, 98 instâncias de dados são considerados, isto é, duas instâncias para cada uma das 49 regiões. Para avaliar a generalização da rede, as instâncias são separadas, conforme procedimento de validação cruzada da Seção 8.1, em conjuntos de treinamento e teste. Um dos 10 casos é exibido aqui, tanto para a rede irrestrita quanto para a rede naïve.

\subsubsection{Resultados da Classificação do Risco de Infestação a partir das Redes Bayesianas}

Conforme mencionado na seção anterior, cada nó das redes Bayesianas possui um conjunto de probabilidades condicionais associado, que depende de seus pais. As Tabelas $8.19,8.20,8.21,8.22$ e 8.23 apresentam as probabilidades condicionais das variáveis da 
Tabela 8.13: Resultados do conjunto de teste da rede Bayesiana irrestrita para a competitividade usando o conjunto reduzido de regras. D: regra Default

\begin{tabular}{|c|c|c|c|c|c|c|}
\hline DensFI & DensFE & DensTotal & BiomassA & regra & Teste & Prob.regra \\
\hline $\mathrm{A}$ & $\mathrm{M}$ & $\mathrm{M}$ & $\mathrm{A}$ & $\mathrm{D}$ & errou & $100 \%$ \\
\hline M & A & M & M & $\mathrm{D}$ & acertou & $100 \%$ \\
\hline $\mathrm{A}$ & B & M & M & 6 & acertou & $71 \%$ \\
\hline A & B & M & M & 6 & acertou & $71 \%$ \\
\hline A & M & M & M & D & acertou & $100 \%$ \\
\hline M & M & B & B & 26 & acertou & $80 \%$ \\
\hline
\end{tabular}

Tabela 8.14: Resultados do conjunto de teste da rede naïve Bayes para a competitividade.

\begin{tabular}{|c|c|c|c|c|c|c|}
\hline DensFL & DensFE & DensTotal & Biomassa & regra & Teste & Prob.regra \\
\hline $\mathrm{A}$ & $\mathrm{M}$ & $\mathrm{A}$ & $\mathrm{A}$ & 3 & errou & $62 \%$ \\
\hline B & $\mathrm{H}$ & B & M & 13 & acertou & $52 \%$ \\
\hline M & M & M & M & 27 & acertou & $48 \%$ \\
\hline M & A & M & M & 25 & errou & $50 \%$ \\
\hline M & M & M & M & 27 & acertou & $48 \%$ \\
\hline $\mathrm{A}$ & B & M & B & 20 & errou & $91 \%$ \\
\hline
\end{tabular}

rede irrestrita. A estrutura da rede é definida por conhecimento de especialista e as estimativas das probabilidades condicionais dos nós são obtidas a partir dos dados com o auxílio do aplicativo Genie. As Tabelas 8.28, 8.26, 8.25 e 8.27 apresentam as probabilidades das variáveis da rede naïve Bayes serem A, B ou M, dadas as probabilidades do nó Perda de rendimento, exibidas na Tabela 8.24. 
Tabela 8.15: Conjunto reduzido de regras Bayesianas da rede naïve para a competitividade. D: regra Default

2 Se (DensFL é A) e (DensFE é B) e (DensdTotal é A) então Biomassa é M (0.80)

5 Se (DensFL é B) e (DensFE é B) e (DensdTotal é A) então Biomassa é M (0.73)

18 Se (DensFL é M) e (DensFE é M) e (DensdTotal é B) então Biomassa é B (0.71)

19 Se (DensFL é A) e (DensFE é A) e (DensTotal é M) então Biomassa é M (0.76)

20 Se (DensFL é A) e (DensFE é B) e (DensTotal é M) então Biomassa é M (0.91)

$21 \mathrm{Se}$ (DensFL é A) e (DensFE é M) e (DensTotal é M) então Biomassa é M (0.78)

23 Se (DensFL é B) e (DensFE é B) e (DensTotal é M) então Biomassa é M (0.85)

D caso contrário Biomassa é M (1.00)

Tabela 8.16: Resultados do conjunto de teste da rede Bayesiana naïve para a competitividade usando o conjunto reduzido de regras. D: regra Default

\begin{tabular}{ccccccc}
\multicolumn{2}{l}{ DensFL DensFE DensTotal Biomassa } & regra & Teste & Prob.regra \\
\hline A & M & A & A & D & errou & $62 \%$ \\
B & A & B & M & D & acertou & $100 \%$ \\
M & M & M & M & D & acertou & $100 \%$ \\
M & A & M & M & D & acertou & $100 \%$ \\
M & M & M & M & D & acertou & $100 \%$ \\
A & B & M & B & 20 & errou & $91 \%$ \\
\hline
\end{tabular}

Tabela 8.17: Resultados da classificação com redes Bayesianas irrestrita e naïve para a competitividade

\begin{tabular}{c|c|c|c|c} 
& $\begin{array}{c}\text { Índice de acerto } \\
\text { conj. regras } \\
\text { original }\end{array}$ & $\begin{array}{c}\text { Índice de acerto } \\
\text { conj. regras } \\
\text { reduzido }\end{array}$ & $\begin{array}{c}\text { Número de regras } \\
\text { conj. regras } \\
\text { original }\end{array}$ & $\begin{array}{c}\text { Número de regras } \\
\text { conj. regras } \\
\text { reduzido }\end{array}$ \\
\hline Irrestrita & $63,39 \%$ & $64,79 \%$ & 27 & 11 \\
Naïve & $57,75 \%$ & $61,97 \%$ & 27 & 8
\end{tabular}

Tabela 8.18: Intervalos de discretização para os atributos que definem a rede que infere sobre o risco de infestação.

\begin{tabular}{cccc} 
Atributo & \multicolumn{3}{c}{ Intervalos de discretização } \\
\hline Cobertura & rala(Ra) & moderada(Mo) & densa(Ds) \\
foliar & {$[0,70 ; 1]$} & {$[0 ; 0,35]$} & ] 0,$35 ; 0,70[$ \\
\hline Densidade de & baixa(B) & média(M) & alta(A) \\
sementes & {$[0,70 ; 1]$} & {$[0 ; 0,35]$} & ] 0,$35 ; 0,70[$ \\
\hline Extensão dos & pequena(P) & regular(R) & grande(G) \\
agrupamentos de semente & {$[0,80 ; 1]$} & {$[0 ; 0,40]$} & ] 0,$40 ; 0,80[$ \\
\hline Competitividade & baixa(B) & média(M) & alta $(\mathrm{A})$ \\
& {$[0,50 ; 1]$} & {$[0 ; 0,25]$} & ] 0,$25 ; 0,50[$ \\
\hline Perda de & baixa(B) & média $(\mathrm{M})$ & alta $(\mathrm{A})$ \\
rendimento & {$[0,45 ; 1]$} & {$[0 ; 0,15]$} & ] 0,$15 ; 0,45[$ \\
\hline
\end{tabular}




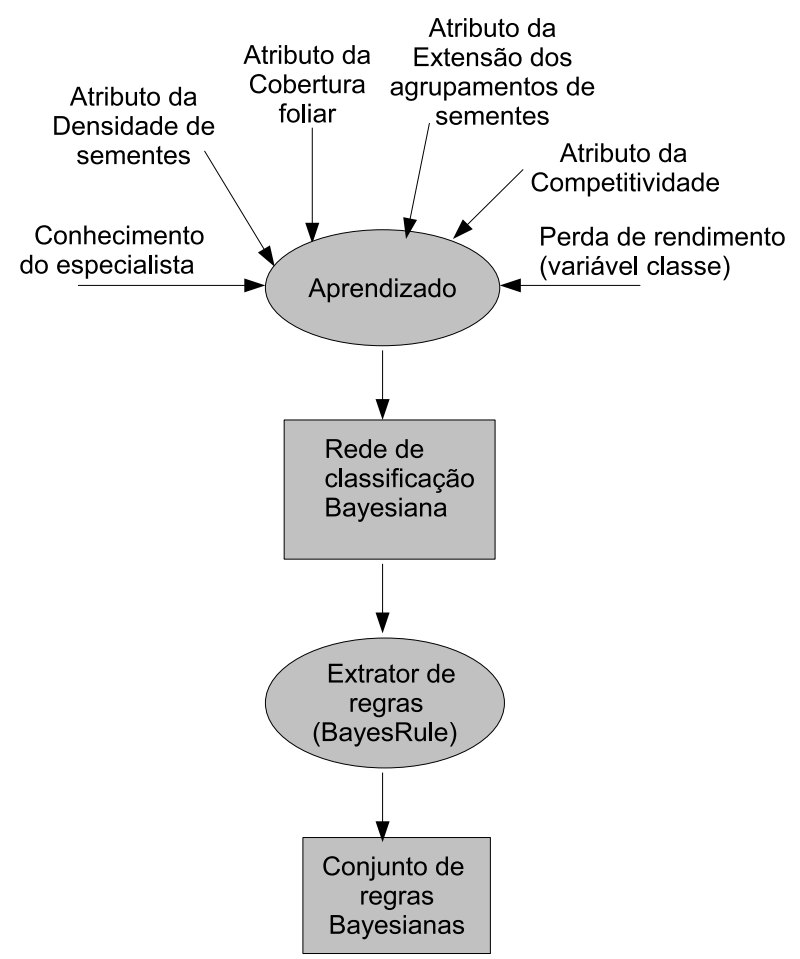

Figura 8.5: Aprendizado da rede com BayesRule para o risco de infestação.

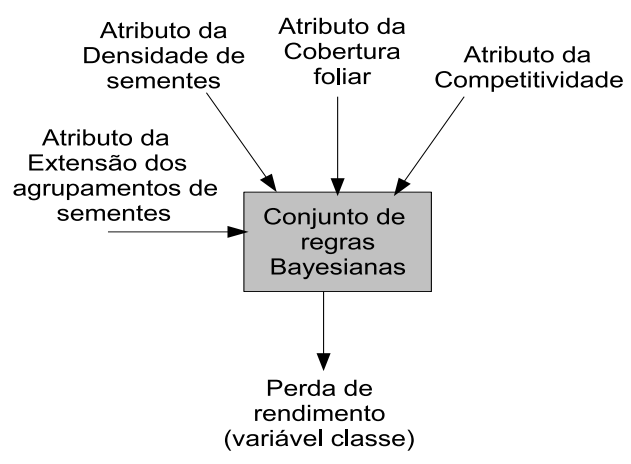

Figura 8.6: Inferência do risco de infestação. 


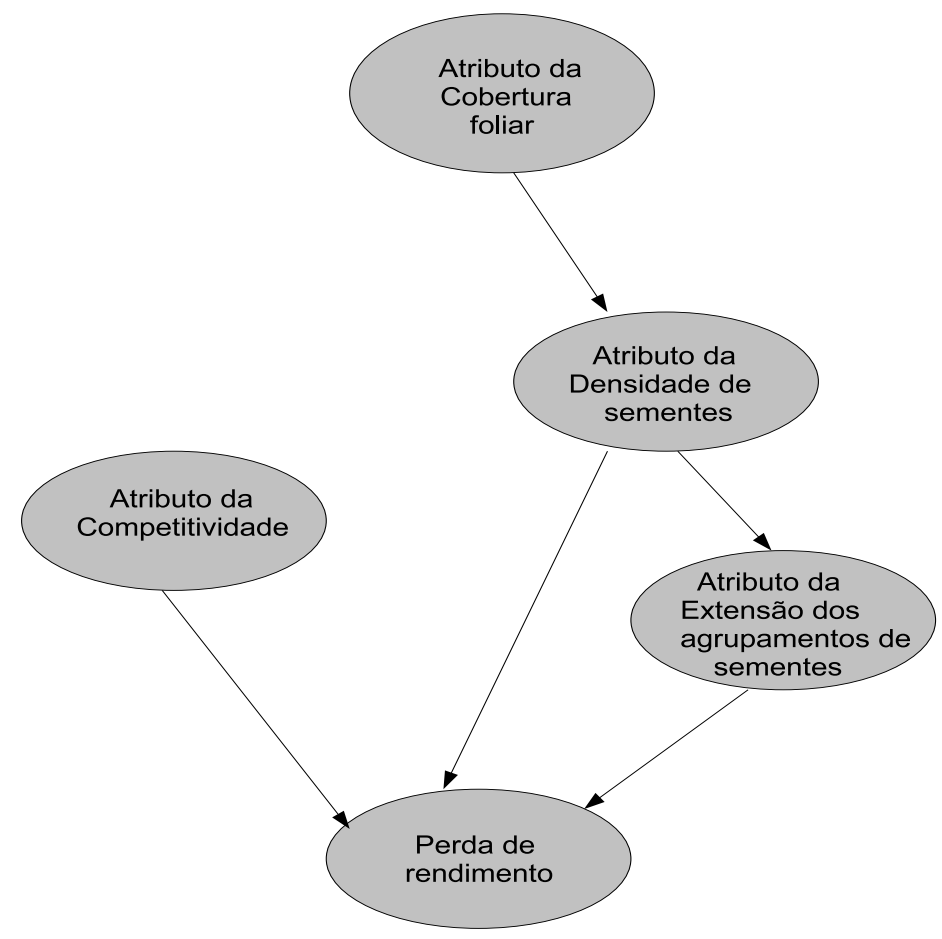

Figura 8.7: Rede de classificação Bayesiana irrestrita para o risco de infestação.

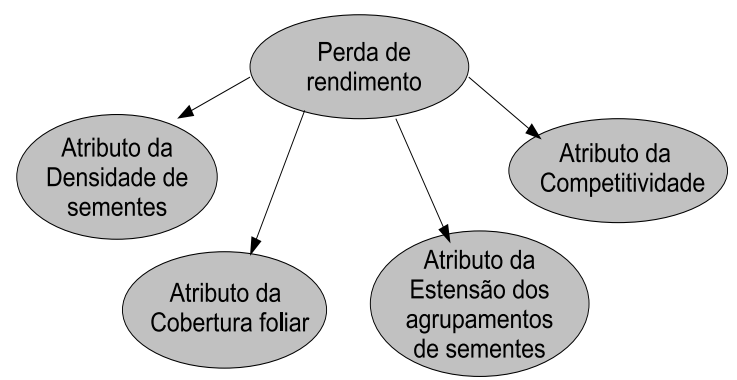

Figura 8.8: Rede de classificação naïve Bayes para o risco de infestação.

Tabela 8.19: Probabilidades condicionais do nó Competitividade na rede irrestrita.

\begin{tabular}{cc}
\multicolumn{2}{c}{ Competitividade } \\
\hline A & 0,29 \\
B & 0,40 \\
M & 0,31
\end{tabular}


Tabela 8.20: Probabilidades condicionais do nó Cobertura Foliar na rede irrestrita.

\begin{tabular}{ll}
\multicolumn{2}{c}{ Cobertura foliar } \\
\hline Ds & 0,00 \\
Ra & 0,89 \\
Mo & 0,11
\end{tabular}

Tabela 8.21: Probabilidades condicionais do nó Densidade de Sementes na rede irrestrita.

\begin{tabular}{cccc} 
Cobertura foliar & Ds & Ra & Mo \\
\hline A & 0,04 & 0,00 & 0,00 \\
B & 0,58 & 0,91 & 0,90 \\
M & 0,38 & 0,09 & 0,10
\end{tabular}

Tabela 8.22: Probabilidades condicionais do nó Extensão dos Agrupamentos de Sementes na rede irrestrita.

\begin{tabular}{cccc} 
Densidade de sementes & $\mathrm{G}$ & $\mathrm{P}$ & $\mathrm{R}$ \\
\hline $\mathrm{A}$ & 0,42 & 0,00 & 0,00 \\
$\mathrm{~B}$ & 0,35 & 1,00 & 0,75 \\
M & 0,23 & 0,00 & 0,25
\end{tabular}


Tabela 8.23: Probabilidades condicionais do nó Perda de Rendimento na rede irrestrita.

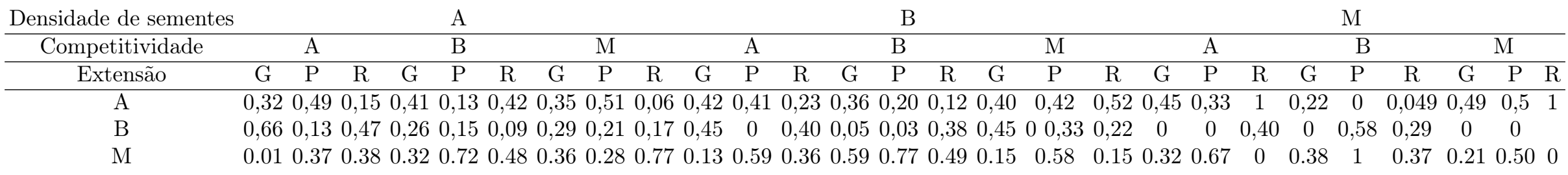

$\begin{array}{lllllllllllllllllllllllllll}0.01 & 0.37 & 0.38 & 0.32 & 0.72 & 0.48 & 0.36 & 0.28 & 0.77 & 0.13 & 0.59 & 0.36 & 0.59 & 0.77 & 0.49 & 0.15 & 0.58 & 0.15 & 0.32 & 0.67 & 0 & 0.38 & 1 & 0.37 & 0.21 & 0.50 & 0\end{array}$ 
Tabela 8.24: Probabilidades condicionais do nó Perda de Rendimento na rede naïve.

\begin{tabular}{lc}
\multicolumn{2}{c}{ Perda de rendimento } \\
\hline A & 0,34 \\
B & 0,01 \\
M & 0,65
\end{tabular}

Tabela 8.25: Probabilidades condicionais do nó Densidade de Sementes na rede naïve.

\begin{tabular}{cccc} 
Perda de rendimento & A & B & M \\
\hline A & 0,00 & 0,00 & 0,00 \\
B & 0,83 & 1,00 & 0,91 \\
M & 0,17 & 0,00 & 0,09
\end{tabular}

Tabela 8.26: Probabilidades condicionais do nó Cobertura Foliar na rede naïve.

\begin{tabular}{cccc} 
Perda de rendimento & A & B & M \\
\hline Ds & 0,00 & 0,00 & 0,00 \\
Mo & 0,80 & 1,00 & 0,96 \\
Ra & 0,20 & 0,00 & 0,04
\end{tabular}

O nó Cobertura foliar não faz parte dos nós que constituem o Markov blanket do nó classe. Por isso, é eliminado dos antecedentes das regras pelo método BayesRule (Seção 5.2.3), o qual extraiu um conjunto de 27 regras probabilísticas de cada rede de classificação Bayesiana, conforme pode ser visto na Tabela 8.29 para rede irrestrita. Neste caso, não é necessário utilizar a estratégia de poda proposta anteriormente, já que o conceito de Markov blanket é suficiente para reduzir a complexidade e o número de regras.

Considerando o conjunto de regras Bayesiano extraído da rede de classificação irrestrita, os resultados obtidos para o conjunto de teste exposto aqui são mostrados na Tabela 8.31. As regras apresentam um índice de acerto de 66,6\%, pois 6 das 9 instâncias testadas são classificadas corretamente. Para todos os 10 conjuntos de teste da validação cruzada, os resultados indicam um índice de acerto de 64,3\% desde que 63 das 98 instâncias são classificadas corretamente.

Quando considerando o conjunto de regras Bayesiano extraído da rede de classificação naïve, os resultados obtidos para um dos conjuntos de teste estão na Tabela 8.32. Os resultados revelam que as regras apresentam um índice de acerto de $88,9 \%$, pois 8 
Tabela 8.27: Probabilidades condicionais do nó Extensão dos Agrupamentos de Sementes na rede naïve.

\begin{tabular}{cccc} 
Perda de rendimento & A & B & M \\
\hline G & 0,00 & 0,00 & 0,00 \\
P & 0,90 & 1,00 & 0,98 \\
R & 0,10 & 0,00 & 0,02
\end{tabular}

Tabela 8.28: Probabilidades condicionais do nó Competitividade na rede naïve.

\begin{tabular}{cccc} 
Perda de rendimento & A & B & M \\
\hline A & 0,43 & 0,00 & 0,24 \\
B & 0,23 & 1,00 & 0,48 \\
M & 0,33 & 0,00 & 0,28
\end{tabular}

das 9 instâncias testadas são classificadas corretamente. Para todos os 10 conjuntos de teste da validação cruzada, os resultados indicam um índice de acerto de 69,4\%, desde que 68 das 98 instâncias são classificadas corretamente.

\subsection{Comparação Entre a Base de Regras Fuzzy e o Con- junto de Regras Bayesiano}

Com a finalidade de comparar os resultados obtidos para os riscos de infestação utilizando o sistema de classificação fuzzy proposto e a rede de classificação Bayesiana irrestrita, o conjunto de regras gerado pelo método BayesRule, apresentado na Tabela 8.29, é comparado com a base de regras utilizada no sistema fuzzy, exibida na Tabela 6.1. Os resultados são descritos na Tabela 8.33. Analisando a concordância dos valores linguísticos de ambas as saídas, os resultados apontam uma concordância de 81,5\%, desde que 22 das 27 regras geradas pelo método BayesRule inferem a mesma saída que a base de regras do sistema fuzzy. 
Tabela 8.29: Conjunto de regras Bayesianas da rede irrestrita para o risco de infestação.

1 Se (Dens. sementes é A) e (Competitividade é A) e (Extensão é G) então perda é A (0.664797)

2 Se (Dens. sementes é A) e (Competitividade é A) e (Extensão é P) então perda é A $(0.496122)$

3 Se (Dens. sementes é A) e (Competitividade é A) e (Extensão é R) então perda é A (0.466992)

4 Se (Dens. sementes é A) e (Competitividade é B) e (Extensão é G) então perda é A (0.412088)

5 Se (Dens. sementes é A) e (Competitividade é B) e (Extensão é P) então perda é M (0.718012)

6 Se (Dens. sementes é A) e (Competitividade é B) e (Extensão é R) então perda é M (0.480589)

7 Se (Dens. sementes é A) e (Competitividade é M) e (Extensão é G) então perda é M (0.358054)

8 Se (Dens. sementes é A) e (Competitividade é M) e (Extensão é P) então perda é M (0.510196)

9 Se (Dens. sementes é A) e (Competitividade é M) e (Extensão é R) então perda é M (0.771326)

10 Se (Dens. sementes é B) e (Competitividade é A) e (Extensão é G) então perda é A (0.664797)

11 Se (Dens. sementes é B) e (Competitividade é A) e (Extensão é P) então perda é M (0.612017)

12 Se (Dens. sementes é B) e (Competitividade é A) e (Extensão é R) então perda é A (0.928592)

13 Se (Dens. sementes é B) e (Competitividade é B) e (Extensão é G) então perda é B (0.412088)

14 Se (Dens. sementes é B) e (Competitividade é B) e (Extensão é P) então perda é M (0.844477)

15 Se (Dens. sementes é B) e (Competitividade é B) e (Extensão é R) então perda é B (0.541906)

16 Se (Dens. sementes é B) e (Competitividade é M) e (Extensão é G) então perda é M (0.358054)

17 Se (Dens. sementes é B) e (Competitividade é M) e (Extensão é P) então perda é M (0.551821)

18 Se (Dens. sementes é B) e (Competitividade é M) e (Extensão é R) então perda é M (0.920858)

19 Se (Dens. sementes é M) e (Competitividade é A) e (Extensão é G) então perda é A (0.500000)

20 Se (Dens. sementes é M) e (Competitividade é A) e (Extensão é P) então perda é M $(0.666667)$

21 Se (Dens. sementes é M) e (Competitividade é A) e (Extensão é R) então perda é A (1.000000)

22 Se (Dens. sementes é M) e (Competitividade é B) e (Extensão é G) então perda é M (0.842056)

23 Se (Dens. sementes é M) e (Competitividade é B) e (Extensão é P) então perda é M (1.000000)

24 Se (Dens. sementes é M) e (Competitividade é B) e (Extensão é R) então perda é M (0.582893)

25 Se (Dens. sementes é M) e (Competitividade é M) e (Extensão é G) então perda é M (0.625000)

26 Se (Dens. sementes é M) e (Competitividade é M) e (Extensão é P) então perda é M (0.500000)

27 Se (Dens. sementes é M) e (Competitividade é M) e (Extensão é R) então perda é A (1.000000) 
Tabela 8.30: Conjunto de regras Bayesianas da rede naïve para o risco de infestação.

1 Se (Dens.sementes é A) e (Cobertura é Ds) e (Extensão é G) e (Competitividade é A), então perda é M (0.518519)

2 Se (Dens.sementes é A) e ( Cobertura é Ds) e (Extensão é G) e (Competitividade é B), então perda é M (0.777778)

3 Se (Dens.sementes é A) e ( Cobertura é Ds) e (Extensão é G) e (Competitividade é M), então perda é M (0.615385)

4 Se (Dens.sementes é A) e ( Cobertura é Ds) e (Extensão é P) e (Competitividade é A), então perda é M (0.540431)

5 Se (Dens.sementes é A) e ( Cobertura é Ds) e (Extensão é P) e (Competitividade é B), então perda é M (0.790334)

6 Se (Dens.sementes é A) e ( Cobertura é Ds) e (Extensão é P) e (Competitividade é M), então perda é M (0.635983)

7 Se (Dens.sementes é A) e ( Cobertura é Ds) e (Extensão é R) e (Competitividade é A), então perda é A (0.843400)

8 Se (Dens.sementes é A) e ( Cobertura é Ds) e (Extensão é R) e (Competitividade é B), então perda é A (0.591837)

9 Se (Dens.sementes é A) e ( Cobertura é Ds) e (Extensão é R) e (Competitividade é M), então perda é A (0.783784)

10 Se (Dens.sementes é A) e (Cobertura é Ra) e (Extensão é G) e (Competitividade é A), então perda é M (0.565167)

11 Se (Dens.sementes é A) e (Cobertura é Ra) e (Extensão é G) e (Competitividade é B), então perda é M (0.803773)

12 Se (Dens.sementes é A) e (Cobertura é Ra) e (Extensão é G) e (Competitividade é M), então perda é M (0.658824)

13 Se (Dens.sementes é A) e (Cobertura é Ra) e (Extensão é P) e (Competitividade é A), então perda é M (0.586649)

14 Se (Dens.sementes é A) e (Cobertura é Ra) e (Extensão é P) e (Competitividade é B), então perda é M (0.814771)

15 Se (Dens.sementes é A) e (Cobertura é Ra) e (Extensão é P) e (Competitividade é M), então perda é M (0.678312)

16 Se (Dens.sementes é A) e (Cobertura é Ra) e (Extensão é R) e (Competitividade é A), então perda é A (0.816932)

17 Se (Dens.sementes é A) e (Cobertura é Ra) e (Extensão é R) e (Competitividade é B), então perda é A (0.545749)

18 Se (Dens.sementes é A) e (Cobertura é Ra) e (Extensão é R) e (Competitividade é M), então perda é A (0.750223)

19 Se (Dens.sementes é A) e (Cobertura é Mo) e (Extensão é G) e (Competitividade é A), então perda é A (0.843400)

20 Se (Dens.sementes é A) e (Cobertura é Mo) e (Extensão é G) e (Competitividade é B), então perda é A (0.591837)

21 Se (Dens.sementes é A) e (Cobertura é Mo) e (Extensão é G) e (Competitividade é M), então perda é A (0.783784)

22 Se (Dens.sementes é A) e (Cobertura é Mo) e (Extensão é P) e (Competitividade é A), então perda é A (0.831428)

23 Se (Dens.sementes é A) e (Cobertura é Mo) e (Extensão é P) e (Competitividade é B), então perda é A (0.570427)

24 Se (Dens.sementes é A) e (Cobertura é Mo) e (Extensão é P) e (Competitividade é M), então perda é A (0.768504)

25 Se (Dens.sementes é A) e (Cobertura é Mo) e (Extensão é R) e (Competitividade é A), então perda é A (0.968980) 
26 Se (Dens.sementes é A) e (Cobertura é Mo) e (Extensão é R) e (Competitividade é B), então perda é A (0.893730)

27 Se (Dens.sementes é A) e (Cobertura é Mo) e (Extensão é R) e (Competitividade é M), então perda é A (0.954597)

28 Se (Dens.sementes é B) e ( Cobertura é Ds) e (Extensão é G) e (Competitividade é A), então perda é M (0.541474)

29 Se (Dens.sementes é B) e ( Cobertura é Ds) e (Extensão é G) e (Competitividade é B), então perda é M (0.789222)

30 Se (Dens.sementes é B) e ( Cobertura é Ds) e (Extensão é G) e (Competitividade é M), então perda é M (0.636955)

31 Se (Dens.sementes é B) e ( Cobertura é Ds) e (Extensão é P) e (Competitividade é A), então perda é M $(0.563222)$

32 Se (Dens.sementes é B) e ( Cobertura é Ds) e (Extensão é P) e (Competitividade é B), então perda é M (0.800924)

33 Se (Dens.sementes é B) e ( Cobertura é Ds) e (Extensão é P) e (Competitividade é M), então perda é M $(0.657043)$

34 Se (Dens.sementes é B) e ( Cobertura é Ds) e (Extensão é R) e (Competitividade é A), então perda é A (0.830838)

35 Se (Dens.sementes é B) e ( Cobertura é Ds) e (Extensão é R) e (Competitividade é B), então perda é A (0.569397)

36 Se (Dens.sementes é B) e ( Cobertura é Ds) e (Extensão é R) e (Competitividade é M), então perda é A (0.767756)

37 Se (Dens.sementes é B) e (Cobertura é Ra) e (Extensão é G) e (Competitividade é A), então perda é M (0.587667)

38 Se (Dens.sementes é B) e (Cobertura é Ra) e (Extensão é G) e (Competitividade é B), então perda é M (0.813416)

39 Se (Dens.sementes é B) e (Cobertura é Ra) e (Extensão é G) e (Competitividade é M), então perda é M (0.679228)

40 Se (Dens.sementes é B) e (Cobertura é Ra) e (Extensão é P) e (Competitividade é A), então perda é M (0.608807)

41 Se (Dens.sementes é B) e (Cobertura é Ra) e (Extensão é P) e (Competitividade é B), então perda é M (0.823597)

42 Se (Dens.sementes é B) e (Cobertura é Ra) e (Extensão é P) e (Competitividade é M), então perda é M (0.698085)

43 Se (Dens.sementes é B) e (Cobertura é Ra) e (Extensão é R) e (Competitividade é A), então perda é A (0.802743)

44 Se (Dens.sementes é B) e (Cobertura é Ra) e (Extensão é R) e (Competitividade é B), então perda é A (0.522819)

45 Se (Dens.sementes é B) e (Cobertura é Ra) e (Extensão é R) e (Competitividade é M), então perda é A (0.732556)

46 Se (Dens.sementes é B) e (Cobertura é Mo) e (Extensão é G) e (Competitividade é A), então perda é A (0.830838)

47 Se (Dens.sementes é B) e (Cobertura é Mo) e (Extensão é G) e (Competitividade é B), então perda é A (0.569397)

48 Se (Dens.sementes é B) e (Cobertura é Mo) e (Extensão é G) e (Competitividade é M), então perda é A (0.767756)

49 Se (Dens.sementes é B) e (Cobertura é Mo) e (Extensão é P) e (Competitividade é A), então perda é A (0.818112)

50 Se (Dens.sementes é B) e (Cobertura é Mo) e (Extensão é P) e (Competitividade é B), então perda é A (0.547710) 
51 Se (Dens.sementes é B) e (Cobertura é Mo) e (Extensão é P) e (Competitividade é M), então perda é A (0.751703)

52 Se (Dens.sementes é B) e (Cobertura é Mo) e (Extensão é R) e (Competitividade é A), então perda é A (0.966086)

53 Se (Dens.sementes é B) e (Cobertura é Mo) e (Extensão é R) e (Competitividade é B), então perda é A (0.884653)

54 Se (Dens.sementes é B) e (Cobertura é Mo) e (Extensão é R) e (Competitividade é M), então perda é A (0.950431)

55 Se (Dens.sementes é M) e ( Cobertura é Ds) e (Extensão é G) e (Competitividade é A), então perda é A (0.642249)

56 Se (Dens.sementes é M) e ( Cobertura é Ds) e (Extensão é G) e (Competitividade é B), então perda é M (0.674157)

57 Se (Dens.sementes é M) e ( Cobertura é Ds) e (Extensão é G) e (Competitividade é M), então perda é A (0.547170)

58 Se (Dens.sementes é M) e ( Cobertura é Ds) e (Extensão é P) e (Competitividade é A), então perda é A (0.621794)

59 Se (Dens.sementes é M) e ( Cobertura é Ds) e (Extensão é P) e (Competitividade é B), então perda é M (0.693178)

60 Se (Dens.sementes é M) e ( Cobertura é Ds) e (Extensão é P) e (Competitividade é M), então perda é A (0.525297)

61 Se (Dens.sementes é M) e ( Cobertura é Ds) e (Extensão é R) e (Competitividade é A), então perda é A (0.912376)

62 Se (Dens.sementes é M) e ( Cobertura é Ds) e (Extensão é R) e (Competitividade é B), então perda é A (0.737073)

63 Se (Dens.sementes é M) e ( Cobertura é Ds) e (Extensão é R) e (Competitividade é M), então perda é A (0.875130)

64 Se (Dens.sementes é M) e (Cobertura é Ra) e (Extensão é G) e (Competitividade é A), então perda é A (0.597987)

65 Se (Dens.sementes é M) e (Cobertura é Ra) e (Extensão é G) e (Competitividade é B), então perda é M (0.714043)

66 Se (Dens.sementes é M) e (Cobertura é Ra) e (Extensão é G) e (Competitividade é M), então perda é A (0.500297)

67 Se (Dens.sementes é M) e (Cobertura é Ra) e (Extensão é P) e (Competitividade é A), então perda é A (0.576670)

68 Se (Dens.sementes é M) e (Cobertura é Ra) e (Extensão é P) e (Competitividade é B), então perda é M (0.731662)

69 Se (Dens.sementes é M) e (Cobertura é Ra) e (Extensão é P) e (Competitividade é M), então perda é M (0.521681)

70 Se (Dens.sementes é M) e (Cobertura é Ra) e (Extensão é R) e (Competitividade é A), então perda é A (0.896130)

71 Se (Dens.sementes é M) e (Cobertura é Ra) e (Extensão é R) e (Competitividade é B), então perda é A (0.699046)

72 Se (Dens.sementes é M) e (Cobertura é Ra) e (Extensão é R) e (Competitividade é M), então perda é A (0.853090)

73 Se (Dens.sementes é M) e (Cobertura é Mo) e (Extensão é G) e (Competitividade é A), então perda é A (0.912376)

74 Se (Dens.sementes é M) e (Cobertura é Mo) e (Extensão é G) e (Competitividade é B), então perda é A (0.737073)

75 Se (Dens.sementes é M) e (Cobertura é Mo) e (Extensão é G) e (Competitividade é M), então perda é A (0.875130) 
76 Se (Dens.sementes é M) e (Cobertura é Mo) e (Extensão é P) e (Competitividade é A), então perda é A (0.905083)

77 Se (Dens.sementes é M) e (Cobertura é Mo) e (Extensão é P) e (Competitividade é B), então perda é A (0.719673)

78 Se (Dens.sementes é M) e (Cobertura é Mo) e (Extensão é P) e (Competitividade é M), então perda é A (0.865196)

79 Se (Dens.sementes é M) e (Cobertura é Mo) e (Extensão é R) e (Competitividade é A), então perda é A (0.983711)

80 Se (Dens.sementes é M) e (Cobertura é Mo) e (Extensão é R) e (Competitividade é B), então perda é A (0.942060)

81 Se (Dens.sementes é M) e (Cobertura é Mo) e (Extensão é R) e (Competitividade é M), então perda é A (0.975989)

Tabela 8.31: Resultados do conjunto de teste da rede Bayesiana irrestrita para o risco de infestação.

Dens.sementes Extensão Competitividade Perda Regra teste Prob.regra

\begin{tabular}{lllllll}
\hline B & P & B & M & 14 & acertou & $84 \%$ \\
B & P & M & M & 17 & acertou & $55 \%$ \\
B & P & B & M & 14 & acertou & $84 \%$ \\
B & P & M & M & 17 & acertou & $55 \%$ \\
M & R & M & M & 27 & errou & $100 \%$ \\
B & P & B & M & 14 & acertou & $84 \%$ \\
B & P & A & A & 11 & errou & $61 \%$ \\
B & P & A & A & 11 & errou & $61 \%$ \\
M & R & A & A & 21 & acertou & $100 \%$
\end{tabular}

Tabela 8.32: Resultados do conjunto de teste da rede naïve Bayes para o risco de infestação.

\begin{tabular}{cccccccc}
\multicolumn{2}{c}{ Cobertura } & Dens.sementes Extensão Competitividade & Perda & Regra & teste & Prob.regra \\
\hline $\mathrm{Ra}$ & $\mathrm{B}$ & $\mathrm{B}$ & $\mathrm{P}$ & $\mathrm{M}$ & 41 & acertou & $82 \%$ \\
$\mathrm{Ra}$ & $\mathrm{B}$ & $\mathrm{B}$ & $\mathrm{P}$ & $\mathrm{M}$ & 41 & acertou & $82 \%$ \\
$\mathrm{Ra}$ & $\mathrm{B}$ & $\mathrm{B}$ & $\mathrm{G}$ & $\mathrm{M}$ & 40 & acertou & $61 \%$ \\
$\mathrm{Ra}$ & $\mathrm{B}$ & $\mathrm{B}$ & $\mathrm{R}$ & $\mathrm{M}$ & 42 & acertou & $70 \%$ \\
$\mathrm{Ra}$ & $\mathrm{B}$ & $\mathrm{B}$ & $\mathrm{R}$ & $\mathrm{M}$ & 42 & acertou & $70 \%$ \\
$\mathrm{Ra}$ & $\mathrm{B}$ & $\mathrm{B}$ & $\mathrm{P}$ & $\mathrm{M}$ & 41 & acertou & $82 \%$ \\
$\mathrm{Ra}$ & $\mathrm{B}$ & $\mathrm{B}$ & $\mathrm{R}$ & $\mathrm{A}$ & 42 & errou & $70 \%$ \\
$\mathrm{Mo}$ & $\mathrm{B}$ & $\mathrm{B}$ & $\mathrm{R}$ & $\mathrm{A}$ & 51 & acertou & $75 \%$ \\
$\mathrm{Mo}$ & $\mathrm{B}$ & $\mathrm{B}$ & $\mathrm{G}$ & $\mathrm{A}$ & 49 & acertou & $82 \%$
\end{tabular}


Tabela 8.33: Comparação entre as regras Fuzzy e BayesRule. A: alto, M: médio, B: baixo.

Número da Regra $\mid$ Resultado da $\mid$ Resultado da|Concordância BayesRule Regra BayesRule Regra Fuzzy

\begin{tabular}{|c|c|c|c|}
\hline Daycature & Hegra Daycaterte & & \\
\hline 1 & $\mathrm{~A}$ & $\mathrm{~A}$ & SIM \\
\hline 2 & $\mathrm{~A}$ & $\mathrm{~A}$ & SIM \\
\hline 3 & $\mathrm{~A}$ & $\mathrm{~A}$ & SIM \\
\hline 4 & $\mathrm{~A}$ & M & $\mathrm{NÃO}$ \\
\hline 5 & M & M & SIM \\
\hline 6 & M & M & SIM \\
\hline 7 & M & M & SIM \\
\hline 8 & M & M & SIM \\
\hline 9 & M & M & SIM \\
\hline 10 & $\mathrm{~A}$ & $\mathrm{~A}$ & SIM \\
\hline 11 & M & M & SIM \\
\hline 12 & $\mathrm{~A}$ & M & SIM \\
\hline 13 & B & B & SIM \\
\hline 14 & M & $\mathrm{B}$ & $\mathrm{NA} \mathrm{A}$ \\
\hline 15 & B & $\mathrm{B}$ & SIM \\
\hline 16 & M & M & SIM \\
\hline 17 & M & M & SIM \\
\hline 18 & M & M & SIM \\
\hline 19 & $\mathrm{~A}$ & $\mathrm{~A}$ & SIM \\
\hline 20 & M & $\mathrm{A}$ & $\mathrm{NA} \mathrm{A}$ \\
\hline 21 & $\mathrm{~A}$ & $\mathrm{~A}$ & SIM \\
\hline 22 & M & M & SIM \\
\hline 23 & M & B & $\mathrm{NA} \mathrm{A}$ \\
\hline 24 & M & M & SIM \\
\hline 25 & M & M & SIM \\
\hline 26 & M & $\mathrm{M}$ & SIM \\
\hline 27 & A & $\mathrm{M}$ & $\mathrm{N} \widetilde{A} \mathrm{O}$ \\
\hline
\end{tabular}




\section{Capítulo 9}

\section{Conclusões}

Neste trabalho, o risco de infestação por plantas daninhas em regiões de uma cultura é descrito por atributos relevantes obtidos a partir de mapas da densidade de sementes e da cobertura foliar, e amostras de densidade de plantas. Em virtude dos dados apresentarem dependência espacial, a técnica de estimação por Krigagem é utilizada para a construção dos mapas de estimativa da distribuição de densidade de sementes de plantas daninhas, bem como de cobertura foliar. Isto porque as plantas daninhas não se desenvolvem uniformemente na cultura, com tendência a se agregarem em reboleiras, e esta variabilidade espacial é passível de ser mapeada, possibilitando um manejo localizado nas áreas de ocorrência. Observando-se os resultados obtidos das análises de resíduos da estimação por Krigagem, todos apresentam média próxima a zero, variância constante e seguem distribuição normal. Desta forma, tem-se evidências de uma boa estimativa por Krigagem, e consequentemente, de uma escolha adequada do modelo variográfico adotado.

A análise de mapas gerados por meio da Krigagem é importante porque a partir dos mapas é possível obter algum conhecimento a priori, por exemplo, orientando-se pelas curvas e cores dos mapas, obtém-se informações sobre os focos de maior (cores mais claras) e menor (cores mais escuras) densidade de sementes de plantas daninhas e cobertura foliar. O aumento da densidade de sementes em função das gerações sucessivas das plantas daninhas, sugere que quanto antes a cultura for tratada por um método de controle que reduza o número de sementes que germinam, mais cedo se controla a infestação. 
Os mapas estimados por Krigagem são tratados como imagens. Sobre estas imagens é feita uma análise para extrair os objetos que as constituem, necessários para o cálculo dos atributos da da densidade de sementes, da cobertura foliar e da extensão dos agrupamentos de sementes por região. Cada objeto, por sua vez, é constituído por pixels que carregam valores de um determinado atributo. Estes pixels são agrupados de acordo com suas intensidades e os objetos são identificados com a utilização do modelo de vizinhança 4-conectado. A partir da identificação dos objetos da imagem, são obtidos, por região, os principais atributos que descrevem a infestação, que são o atributo da cobertura foliar na geração atual, o atributo da densidade de sementes de plantas daninhas na geração seguinte, o atributo da extensão dos agrupamentos de sementes na geração seguinte e o atributo da competitividade das plantas daninhas na geração atual. Este último, dada a impossibilidade de ser inferido diretamente, é obtido a partir de um sistema neurofuzzy supervisionado pela biomassa das plantas, cujas entradas são a densidade total de plantas daninhas e sua respectiva proporção em plantas do tipo folha larga e folha estreita. Os valores de cada atributo constituem as entradas de um sistema de classificação fuzzy, cuja saída infere um risco de infestação para cada região, em duas gerações distintas, correspondentes a dois plantios da cultura.

Os riscos de infestação obtidos em cada região da cultura são agrupados, pelo método k-médias, em agrupamentos com valores de risco semelhantes considerando sua localização. O algoritmo k-médias proposto na Seção 6.4.1 realiza o zoneamento automaticamente, formando agrupamentos de valores semelhantes, sem a subjetividade do usuário escolher o número de grupos. Os diferentes agrupamentos obtidos confirmam a variabilidade da infestação. Com as informações dos agrupamentos de riscos de infestação, o controle pode ser efetuado por meio de máquinas munidas de sistemas de posicionamento e de controle de pulverização que permitem variar a aplicação de acordo com o risco de infestação de cada local.

A perda de rendimento é utilizada para explicar o risco de infestação estimado na mesma geração. Desta forma, mapas estimados por Krigagem da perda de rendimento são obtidos a partir dos valores coletados nas parcelas experimentais da cultura. Os valores estimados por Krigagem da perda de rendimento são agrupados pelo método k-médias no mesmo número de agrupamentos que o risco de infestação. A análise estatística dos resíduos entre a perda ocorrida e o risco estimado indica que o risco 
de infestação reflete a perda de rendimento ocorrida na geração correspondente. A vantagem do sistema de classificação fuzzy proposto é que nenhum modelo de perda de rendimento é necessário. Os dados de perda de rendimento são empregados apenas para avaliar o sistema de classificação, o qual pode ser usado como parte de um sistema de aplicação de herbicida para proporcionar doses economicamente ótimas.

A obtenção dos riscos de infestação é feita para duas plantações da cultura de milho correspondentes às gerações $t$ e $t+2$. Desta forma, um estudo do comportamento da infestação nas gerações é realizado. As matrizes de risco de infestação agrupadas por k-médias nas duas gerações são estatisticamente comparadas. Os resultados da análise comparativa indicam que é rejeitada a hipótese destas matrizes serem distintas, apresentando média e variância estatisticamente iguais entre si. Esta indicação sugere que o risco de infestação, uma vez obtido, é válido para pelo menos uma geração seguinte da cultura.

Por motivo de comparação, redes de classificação Bayesianas são também utilizadas para a obtenção do conjunto de regras para o risco de infestação, por se tratar de um classificador que considera incertezas, por expressar os resultados em forma de regras linguísticas e por permitir a inserção do conhecimento do especialista na estrutura da rede. Dois tipos de redes Bayesianas, irrestrita e naïve, são utilizadas para obter a competitividade e o risco de infestação. As redes são estruturadas com auxílio de especialistas e os parâmetros numéricos são obtidos a partir do treinamento da rede com os dados. O método BayesRule, empregado para extrair as regras a partir do classificador Bayesiano, utiliza o conceito de Markov blanket para reduzir o número de antecedentes das regras. A estimativa da probabilidade da classe é usada como estratégia de poda para reduzir o conjunto de regras quando o Markov blanket do nó classe não proporciona a redução do conjunto de regras, ou seja, for constituído por todos os nós da rede. Os resultados utilizando esta estratégia de poda são promissores, pois mantém ou melhoram o índice de acerto da classificação e o número de regras é reduzido. Além disso, o conjunto de regras resultante traduz o conhecimento do especialista. Resultados da classificação com redes Bayesianas também indicam que a rede irrestrita proporciona um conjunto de regras mais preciso quando comparado ao conjunto de regras extraído das redes naïve, dado que os índices de acerto são maiores, como mostra a Tabela 8.17. Na classificação do risco de infestação o conceito de Markov blanket reduziu 
o conjunto de 81 regras, com todas as combinações dos atributos, para 27 regras, sem perder a qualidade da classificação. É importante ressaltar que, independentemente dos índices de acerto das regras, as redes de classificação Bayesianas reconheceram padrões que são considerados promissores pelo especialista de domínio.

Para comparar os resultados dos dois métodos de classificação utilizados, o conjunto de regras da Tabela 8.29, gerado pela rede irrestrita que infere sobre o risco de infestação, é comparado com a base de regras da Tabela 6.1, utilizada no processo de inferência do sistema fuzzy. A comparação entre as saídas das regras apresenta um índice de concordância de 81,5\%, conforme Tabela 8.33, indicando a convergência entre as regras obtidas via aprendizado a partir dos dados fornecidos (redes Bayesianas) e as regras obtidas via conhecimento do especialista (sistema fuzzy). A comparação das bases de regras mostrou-se consistente. Extrair um número real para o risco a partir do conjunto de regras Bayesiano, para comparar com a saída defuzzificada, requer uma escolha de um critério para obter a média dos intervalos de discretização das variáveis. Este critério, por sua vez, deve ser comprovadamente equivalente ao processo de defuzzificação, o qual é feito para cada região, para uma comparação justa.

O resultado diferenciado da classificação do risco de infestação de plantas daninhas por regiões permite a tomada de decisões importantes em relação ao aumento da eficiência na utilização de herbicidas. A aplicação de recomendações médias de herbicidas pode resultar em uma super ou sub aplicação de uma área, com implicações negativas no ambiente e na relação custo-benefício. O mapa da variabilidade espacial das propriedades do solo e o risco de infestação regional da cultura permitem a aplicação de herbicidas por zonas de manejo, de forma diferenciada, agindo eficientemente nos locais de maior e menor risco, favorecendo a otimização da produtividade, aumentando a eficiência do insumo, maximizando os benefícios e reduzindo custos e o impacto ambiental, tornando o ambiente agrícola melhor controlado.

\subsection{Contribuições}

As principais contribuições deste trabalho incluem:

1. A aplicação dos sistemas fuzzy e neurofuzzy, bem como de redes Bayesianas, na agricultura, para inferir sobre a competitividade entre plantas daninhas e cultura 
e sobre o risco de infestação para cada região da cultura.

2. O levantamento dos principais atributos que descrevem a infestação da cultura por plantas daninhas. Tais atributos constituem as entradas do sistema fuzzy e das redes Bayesianas para a classificação do risco de infestação de regiões da cultura.

3. A exploração da técnica de estimação por Krigagem juntamente com a análise de imagens na confeç̧ão de mapas de distribuição de densidade de sementes e de cobertura foliar.

4. A proposta de um sistema de classificação fuzzy, incluindo a base de regras, as funções de pertinência e as classes de infestação.

5. A proposição de um sistema para inferir sobre a competitividade de plantas daninhas que associa a presença de plantas classificadas em folha estreita (gramíneas) e folha larga com a biomassa da cultura.

6. A automatização do agrupamento dos riscos de infestação, incorporando um coeficiente de variação ao método k-médias. Permite determinar com mais precisão as regiões com maior e menor riscos de infestação por plantas daninhas, tirando a subjetividade do usuário escolher o número de agrupamentos.

O trabalho deu origem a diversos artigos completos em conferências (Bressan et al., 2005; Cruvinel et al., 2005; Bressan et al., 2006b; Hruschka et al., 2007; Bressan et al., 2007a; Bressan et al., 2007b), uma publicação em revista (Bressan et al., 2006a) e duas submissões a revistas (Bressan et al., 2007), sendo que uma delas está em confecção. 


\section{Capítulo 10}

\section{Perspectivas de Continuidade do Trabalho}

Para a continuidade deste trabalho, os seguintes problemas são propostos:

- Obter a cobertura foliar por captura de imagens das parcelas. A identificação das espécies de plantas daninhas encontradas a partir de imagens aéreas pode ser usada para calcular a porcentagem de ocupação das plantas emergentes nas parcelas, em vez de utilizar a inspeção visual de especialistas;

- Testar todas as combinações possíveis dos atributos da infestação para analisar a relevância de cada um na inferência do risco de infestação e sua relação com os demais;

- Inserir atributos relacionados ao clima e ao solo, que podem influenciar na emergência das plantas e na distribuição das sementes;

- Traduzir os mapas de agrupamentos dos riscos de infestação obtidos aqui para a aplicação localizada de herbicida. Esta aplicação pode ser efetuada por meio de máquinas munidas de sistemas de posicionamento, como GPS, e de controle de pulverização, permitindo variar a quantidade de herbicida de acordo com o risco de infestação de cada local, visando um controle de infestação eficiente;

- Utilizar redes Bayesianas para gerar regras de associação, buscando uma melhor interpretação do comportamento e relacionamento de cada atributo da rede. 


\section{Apêndice $A$}

\section{Pacote de Geoestatística para MATLAB: Geomatlab}

Este apêndice descreve as funções geoestatísticas presentes no pacote GEOMATLAB e os parâmetros necessários para sua execução. O arquivo de dados a ser lido deve estar com a extensão '.dat'. A primeira linha deve conter o título do arquivo de dados e segunda o número de colunas. As linhas seguintes devem conter o título de cada coluna e, por fim a matriz de dados, sendo que cada coluna representa os dados de uma variável, ou seja, a primeira coluna contém as coordenadas leste-oeste; a segunda coluna contém as coordenadas norte-sul e a terceira apresenta os valores amostrados da variável correspondente.

Para o ajuste dos variogramas, a função 'variograma1 'é utilizada, a qual apresenta a seguinte sintaxe:

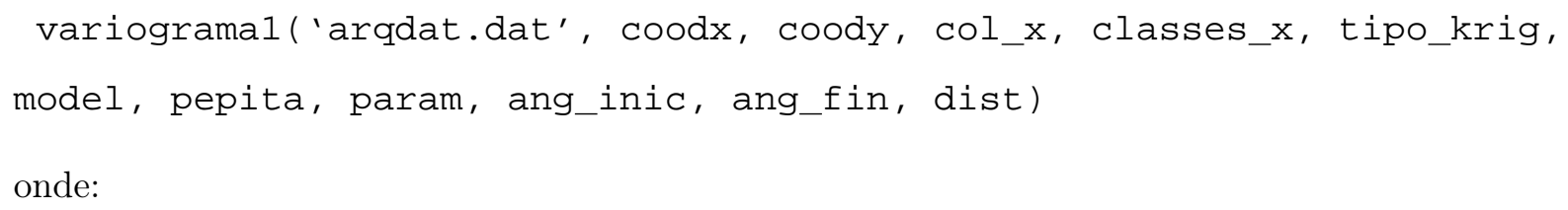

arqdat: nome do arquivo de dados;

coodx: número da coluna do vetor de coordenadas espaciais de eixo x;

coody: número da coluna do vetor de coordenadas espaciais de eixo y;

col_x: número da coluna na matriz da variável a ser analisada;

classes_x: vetor que delimita as classes ;

tipo_krig: método de Krigagem (ordinária/indicativa) 
modelo: modelo de variograma teórico: esférico, linear, exponencial, gaussiano e potencial;

pepita: valor do efeito pepita;

param: vetor $1 \times 2$ com o valor do patamar e do alcance, respectivamente;

ang_inic, ang_fin = Angulo inicial e final da analise (em graus);

dist: Tipo de distribuição (normal/lognormal)

Para a geração dos mapas através da estimação por Krigagem, a função 'krigagem1'é utilizada, a qual apresenta a seguinte sintaxe:

krigagem1(coord, col_x, min_xy, tam_lag, num_lag, tipo_krig, modelo, parametros, num_max, dis_max, arqdat, resp_plot, dist)

onde

coord $=$ colunas com os vetores das coordenadas Leste-Oeste e Norte-Sul $=[\mathrm{E}-\mathrm{W}$ N-S $]$;

min_xy: valores mínimos da abscissa e da ordenada $=\left[\operatorname{Min} \_x\right.$ Min_y $]$;

tam_lag: valores do tamanho do passo da malha $=\left[\operatorname{lag}_{E} W l a g_{N} S\right]$;

num_lag: números de lags desejado $=\left[\operatorname{num}_{E} W n u m_{N} S\right]$;

tipo_krig: método de Krigagem (Ordinária=1, Indicativa=2);

modelo: modelo para para o ajuste. Exemplo: exponentialV, gaussianV, sphericalV, linearV (entre aspas simples);

num_max: número máximo de pontos amostrados a serem considerados para a estimativa;

dis_max: distância máxima a ser considerada do ponto a ser estimado e do ponto amostrado;

dist: tipo de distribuiçao( $1=$ normal $/ 2=$ lognormal $)$.

Para avaliar a qualidade da estimação, a validação cruzada pode ser feita executandose a função 'validacao1', a qual apresenta a seguinte sintaxe:

validacaol(coord, col_x, modelo, parâmetros, num_max, dis_max, arqdat, tipo_krig)

onde

coord: colunas com os vetores das coordenadas Leste-Oeste e Norte-Sul $=[\mathrm{E}-\mathrm{W}$ N-S $]$; col_x: coluna de dados para a análise;

modelo: modelo para o ajuste. Exemplo: exponencial, gaussiano, esférico, linear (entre 
aspas simples);

parâmetros: valores do patamar e alcance respectivamente: [patamar alcance];

num_max: número máximo de pontos amostrados a serem considerados para a estimação;

dis_max: distância máxima a ser considerada do ponto a ser estimado e do ponto amostrado;

arqdat: nome do arquivo de dados entre aspas simples;

tipo_krig: método de Krigagem (ordinária/indicativa). 


\section{Apêndice B}

\section{Sistemas Fuzzy e Neurofuzzy utilizando o Toolbox do MATLAB}

No Toolbox Fuzzy Logic há cinco GUI (Grafical User Interface) para construir, editar e analisar sistemas fuzzy: Fuzzy Inference System ou FIS Editor, Membership Function Editor, Rule Editor, Rule Viewer e Surface Viewer. Na tela de comando do Matlab deve-se digitar 'fuzzy'para inicializar o Toolbox Fuzzy. A função 'anfis', referenta ao sistema neurofuzzy, usa um dado conjunto de entradas e saídas para construir um sistema de inferência fuzzy cujas funções de pertinência são ajustadas por algoritmos de treinamento, a partir dos dados.

\section{B.1 FIS Editor}

O FIS Editor mostra informações gerais sobre um sistema fuzzy. Os diagramas no topo mostram os nomes de cada variável de entrada na esquerda, e o nome das variáveis de saída na direita. Abaixo deste diagrama há o nome do sistema e o tipo de inferência usada (Mamdani no caso). Abaixo do nome do sistema, podem ser selecionados os métodos interseção (and), união (or), implicação (implication), agregação (aggregation) e defuzzificação (defuzzification). Na área "Current Variable", pode-se visualizar as características de cada uma das variáveis. Os métodos, na seqüência em que são 
executados, são descritos a seguir. A Figura B.1 exibe o ambiente do editor.

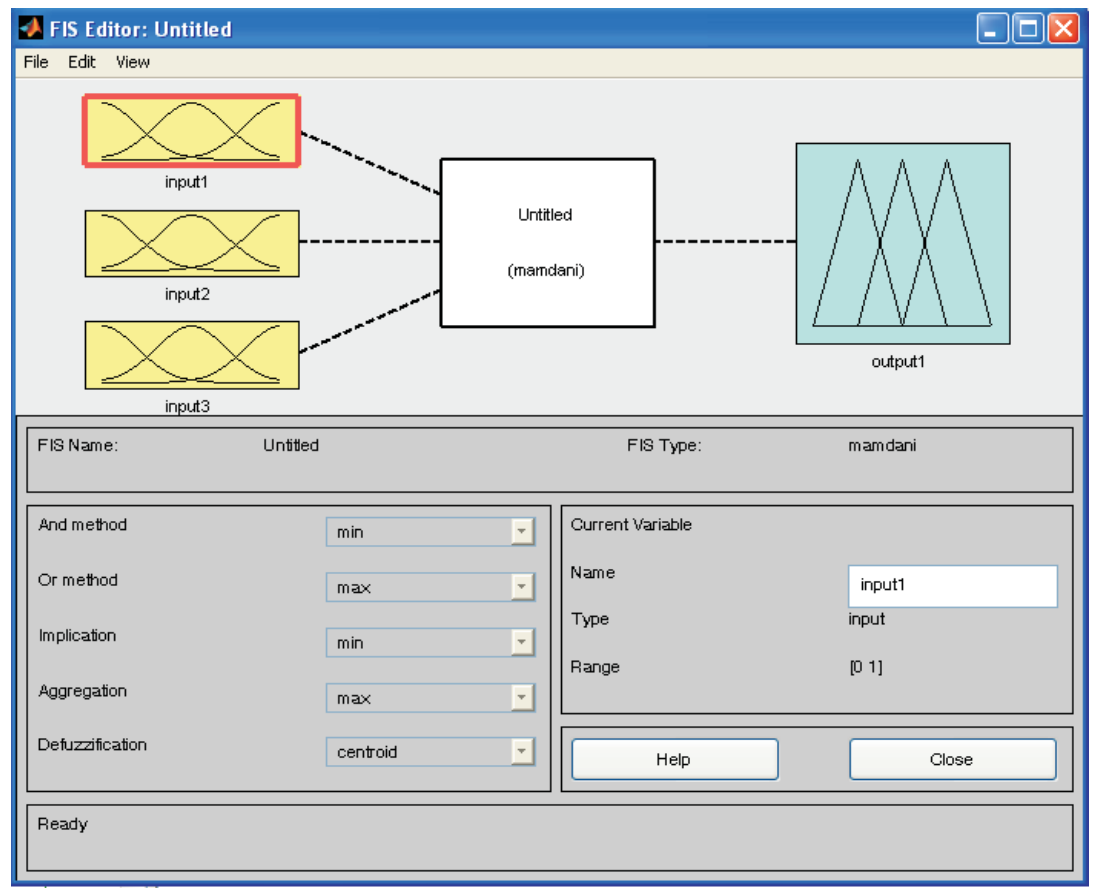

Figura B.1: Fis editor

- Métodos de interseção (E) - são empregados para funções de pertinência de universos diferentes, quando existir mais de uma premissa com conectivo 'e'.

- Métodos de união (OU) - são empregados para funções de pertinência de universos diferentes, quando existir mais de uma premissa com conectivo 'ou'.

- Métodos de implicação - são empregados na inferência fuzzy para determinar a função de pertinência da saída em função do valor assumido pela função de pertinência da variável de entrada para uma determinada entrada.

- Métodos de agregação - é o modo de combinar funções de pertinência de saída caso mais de uma condição seja atendida.

- Métodos de defuzzificação - é o modo como uma variável do domínio fuzzy é transformada para uma variável do domínio real. 


\section{B.2 Editor de Funções de Pertinência}

Através desta interface, são adicionadas e editadas as funções de pertinência relacionadas a cada uma das entradas e saídas do sistema. Para adicionar funções de pertinência relacionadas a uma determinada entrada ou saída, selecione uma destas na região "FIS Variables", no item Edit do menu selecione Add MFs.... Uma nova janela aparecerá, onde poderão ser selecionados o tipo e número de funções de pertinência que se deseja adicionar. Na área "Current Membership Functions", pode-se alterar o nome, tipo e parâmetros (forma), da função de pertinência previamente selecionada na área "Membership Functions Plots". Na área "Current Variable", estão descritos o nome e o tipo (saída/entrada) da variável selecionada. No capo "Range"pode-se definir o universo de discurso da variável em questão. A Figura B.2 exibe o ambiente para inserir as funções de pertinência para cada uma das variáveis do sistema.

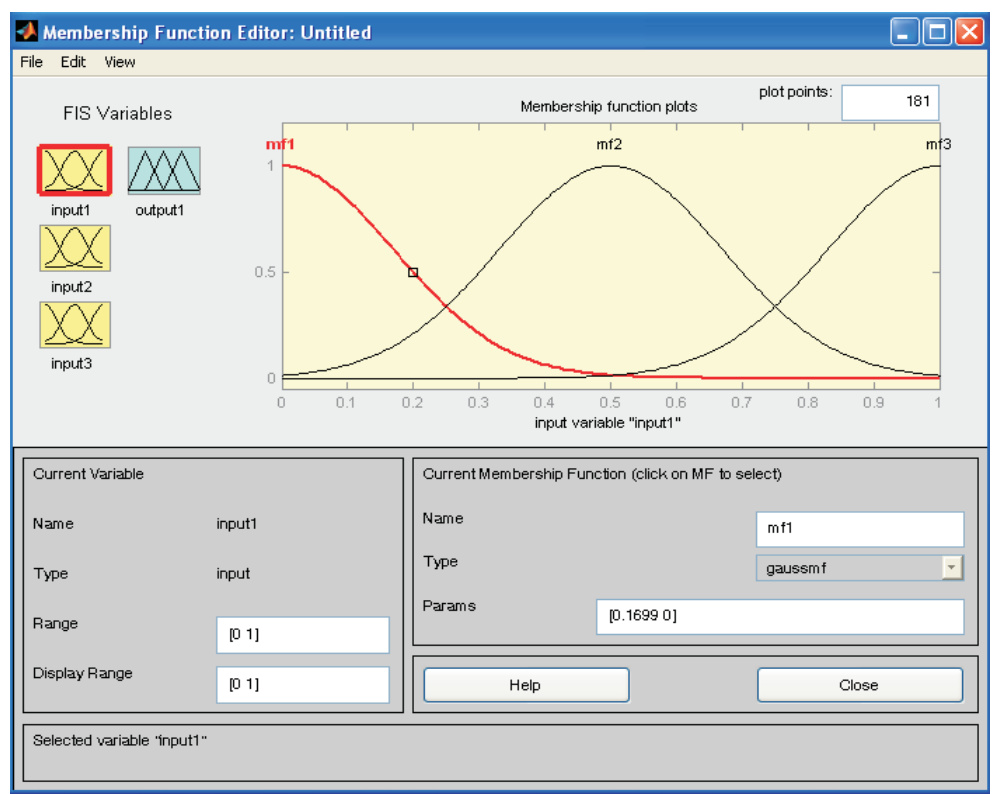

Figura B.2: Editor de funções de pertinência

\section{B.3 Editor de Regras}

Uma vez definida a estrutura de entrada e saída do sistema de inferência, a base de regras é construída utilizando-se o editor de regras. Para adicionar uma regra, deve-se selecionar os itens de entrada, um item no campo da saída e um tipo de conectivo. O número entre parênteses representa o peso de cada regra. 


\section{B.3.1 Visualizador de Regras e Visualizador de Superfície}

Ambas as estruturas não permitem a edição do sistema de inferência, ou seja, são apenas para visualização e análise. No visualizador de regras, exibido na Figura B.3, pode-se simular uma determinada configuração para os valores das entradas, e então, verificar o resultado dos processos de fuzzificação, implicação, agregação e defuzzificação.

O visualizador de superfície ilustra a superfície gerada pela saída do sistema, em função de todos os valores contidos no universo de discurso das variáveis de entrada.

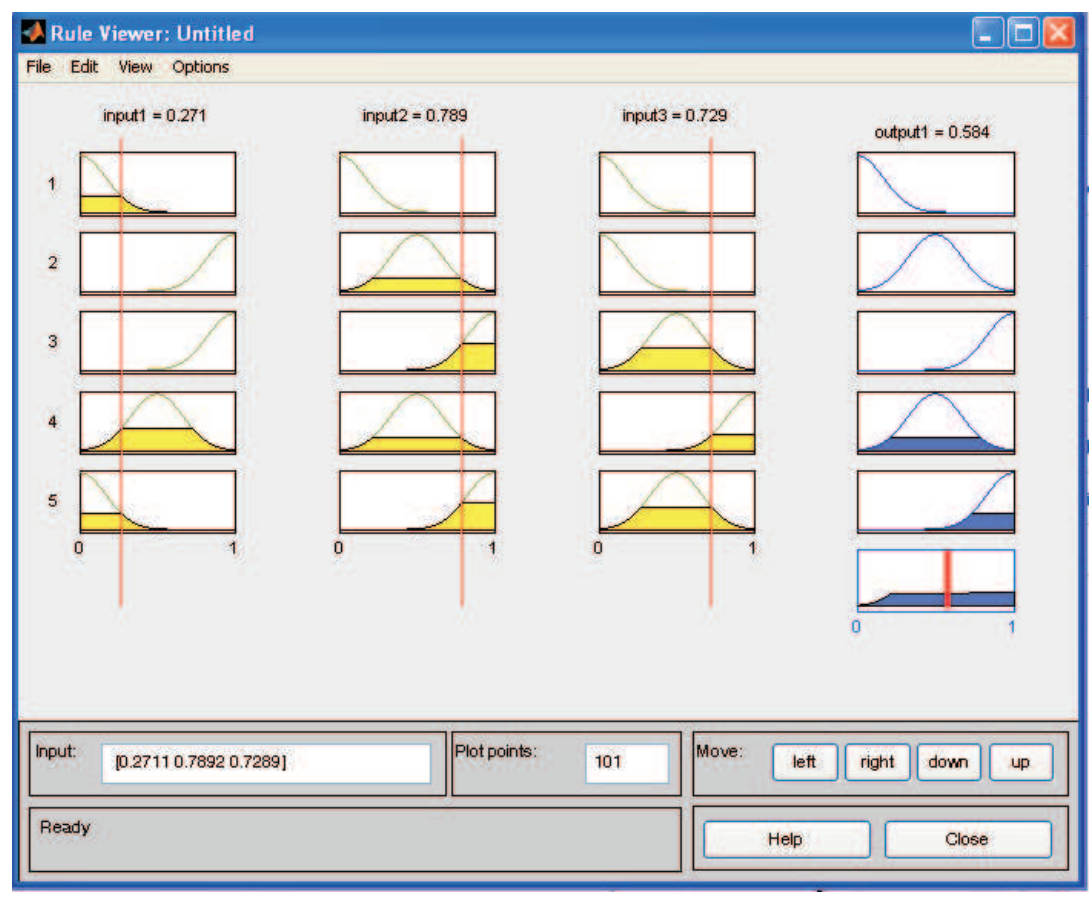

Figura B.3: Visualizador das regras e simulador do sistema

\section{B.4 Sistemas de Inferência Fuzzy - Mamdani}

Inferência fuzzy é o processo de formular o mapeamento de uma dada entrada para uma saída usando lógica fuzzy. O mapeamento então interpreta os valores no vetor entrada e, baseado em algum conjunto de regras, designa valores para o vetor saída.

O método de inferência fuzzy de Mamdani é a metodologia mais vista, pois é um dos primeiros sistemas de controle construídos usando a teoria de conjuntos fuzzy. Foi proposto em 1975 por Ebrahim Mamdani como uma tentativa de controlar uma máquina a vapor sintetizando um conjunto de regras de controle linguísticas obtidas por operadores 
humanos.

No Toolbox Fuzzy do MATLAB, há cinco partes do processo de inferência fuzzy, as quais são definidas a seguir.

\section{B.4.1 Fuzzificação das Entradas}

O primeiro passo é tomar as entradas e determinar o seu grau de pertinência em cada um dos conjuntos fuzzy via funções de pertinência. No Toolbox Fuzzy do MATLAB, a entrada é sempre um valor numérico limitado ao universo de discurso da variável entrada (intervalo entre 0 e 10) e a saída é um grau fuzzy de pertinência no conjunto linguístico (intervalo entre 0 e 1 ).

Antes das regras serem avaliadas, as entradas devem ser fuzzificadas de acordo com cada um desses conjuntos linguísticos.

\section{B.4.2 Aplicação do Operador Fuzzy}

Uma vez as entradas fuzzificadas, é conhecido o grau do antecedente de cada regra. Se o antecedente de uma dada regra tem mais que uma parte, o operador fuzzy é aplicado para obter um número que representa o resultado do antecedente para aquela regra. Este número será aplicado para a função saída. Duas funções constituem o operador E: min (mínimo) e prod (produto), e para o operador OU, o max (máximo).

\section{B.4.3 Aplicação do Método de Implicação}

Toda regra possui um peso, que é aplicado ao número dado pelo antecedente. Geralmente este peso é 1, não tendo efeito no processo de implicação. Uma vez proposta esta ponderação, o método da implicação é implementado para cada regra.

A entrada para o processo de implicação é um número dado pelo antecedente, e a saída é um conjunto fuzzy. Duas funções são utilizadas: min (mínimo), que trunca o conjunto fuzzy saída e prod (produto), que escala o conjunto fuzzy saída. 


\section{B.4.4 Agregação das Saídas}

A agregação é o processo pelo qual os conjuntos fuzzy que representam as saídas de cada regra são combinados em um só conjunto fuzzy. A entrada é a lista de funções truncadas do passo anterior, e a saída é um conjunto fuzzy para cada variável saída. O resultado da agregação é a combinação gráfica de todas as implicações.

\section{B.4.5 Defuzzificação}

A entrada para o processo de defuzzificação é um conjunto fuzzy e a saída é um número simples. Como a fuzzificação auxilia a avaliação das regras durante os passos intermediários, a saída desejada para cada variável é geralmente um número simples.

Talvez o mais conhecido método de defuzzificação é o cálculo do centróide, que retorna o centro de área sob a curva. Há 5 métodos conhecidos de defuzzificação:

- Centróide: centro de massa das áreas delimitadas pelas funções de pertinência, é o mais utilizado e não produz descontinuidades, mas exige grande esforço computacional para o cálculo da integral.

- Bisector: determina o ponto que divide a área delimitada pelas funções de pertinência em duas partes iguais, não é muito utilizado em controle porque apresenta fortes descontinuidades.

- média do máximo: é a média dos valores de saída referentes aos picos das funções de pertinência.

- maior dos máximos: é o maior dos valores de saída em módulo referentes aos picos das funções de pertinência, também apresenta fortes descontinuidades.

- menor dos máximos: é o menor dos valores de saída em módulo referentes aos picos das funções de transferência, também apresenta fortes descontinuidades.

\section{B.5 Inferência Fuzzy do Tipo Sugeno}

O método de inferência fuzzy Takagi-Sugeno-Kang foi introduzido em 1985. A principal diferença entre este e Mamdani é que, no tipo Sugeno, as funções de pertinência de saída 
são lineares ou constantes. Os processos de fuzzificação das entradas e de aplicação dos operadores fuzzy são exatamente os mesmos. Uma típica regra fuzzy de ordem zero no modelo Sugeno tem a forma:

$$
\text { Se } x \text { é } A \text { e } y \text { é } B \text { então } z=k
$$

onde $A$ e $B$ são conjuntos fuzzy no antecedente, e $k$ é uma constante no consequente. Quando a saída de cada regra é uma constante como esta, a similaridade com o método de Mamdani é notável. As únicas distinções são que todas as funções de pertinência de saída são um único retângulo em pé, e os métodos de implicação e agregação são fixos e podem não ser editados. O método de implicação é uma simples multiplicação, e a agregação apenas inclui todos os retângulos. A regra fuzzy de primeira ordem no modelo Sugeno tem a forma:

$$
\text { Se } x \text { é } A \text { e } y \text { é } B \text { então } z=p * x+q * y+r
$$

onde $p, q, r$ são constantes. Os modelos fuzzy de Sugeno cujas funções de pertinência de saída são maiores que a primeira ordem não são tratadas no Toolbox.

\section{B.6 Editor Anfis}

A função do toolbox que realiza o ajuste das funções de pertinência e da base de regras automaticamente, a partir do treinamento de dados de entrada e saída, é chamada ANFIS. Para abrir o editor ANFIS, basta digitar no prompt a palavra anfisedit e as seguintes seções são apresentadas:

- Load data: carrega os dados desejados, podendo treiná-los, testá-los e verificá-los, pela seleção dos ícones apropriados na seção load data e depois selecionando a opção load data.

- Generate FIS: gera um sistema de inferência fuzzy (FIS) or carrega um FIS já existente. Traz um menu onde pode-se escolher o número e o tipo de funções de pertinência. São apenas duas opções para função de pertinência da saída: constante ou linear, devido à restrição de operar apenas com sistemas do tipo Sugeno. 
- Structure: exibe a estrutura do modelo FIS uma vez que este tem sido gerado ou carregado. As funções de pertinência ou as regras podem ser vistas abrindo os editores no ícone view.

- Train FIS: treina a partir do algorirmo "backpropagation "ou de uma mistura entre "backpropagation "e mínimos quadrados (método híbrido). Seleciona-se o número de épocas de treinamento e a tolerância do erro de treinamento, usada para criar um critério de parada do treinamento. O modelo FIS é treinado selecionando-se o botão train, o qual ajusta os parâmetros da função de pertinência.

- Test FIS: exibe a saída do modelo FIS versus o treinamento, verificação ou teste selecionando o botão test now.

O ambiente ANFIS e as seções descritas acima podem ser visualizados na Figura B.4. O ANFIS não é aplicável a todos os sistemas de inferência fuzzy, suportando apenas os sistemas do tipo Sugeno, os quais devem atribuir peso unitário para cada regra e possuir uma única saída, obtida a partir da defuzzificação por média ponderada. As saídas são lineares ou constantes, não apresentando funções de pertinência. O conjunto de dados deve ser uma matriz com dados de entrada arranjados em colunas. Os dados de saída devem estar na última coluna.

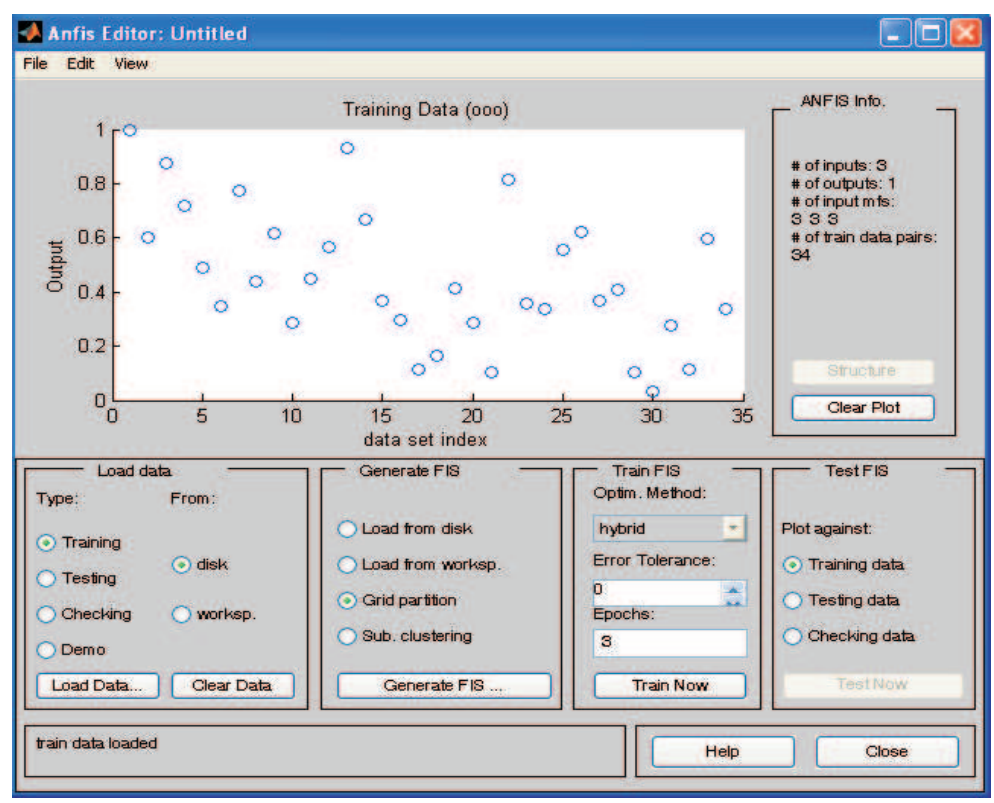

Figura B.4: Ambiente anfis. 


\title{
Apêndice C
}

\section{Alguns Conceitos Estatísticos}

\begin{abstract}
Alguns conceitos e testes estatísticos foram eficientemente empregados nos cálculos e testes de hipóteses ao longo do texto. Para facilitar a consulta e o entendimento dos métodos utilizados, os principais testes estatísticos são descritos de forma sintetizada neste apêndice.
\end{abstract}

\section{C.1 Teste de Hipóteses}

Uma hipótese estatística é uma formulação dos parâmetros de uma distribuição.

$$
\begin{gathered}
H_{0} \text { : hipótese nula }\left(\mu_{1}=\mu_{2}\right) \\
H_{1}: \text { hipótese alternativa }\left(\mu_{1} \neq \mu_{2}\right)
\end{gathered}
$$

Utiliza-se o teste de hipóteses para especificar o conjunto de valores e através desse conjunto rejeita-se ou não $H_{0}$. Tal conjunto de valores é chamado de região crítica para o teste. Quando o teste é usado podem ser gerados dois erros. Se $H_{0}$ é rejeitada quando $\mu_{1}=\mu_{2}$ é obtido o erro do tipo I. Se $H_{0}$ não é rejeitada quando $\mu_{1} \neq \mu_{2}$ é obtido o erro do tipo II. As probabilidades desses dois erros são dadas por:

$$
\begin{gathered}
\alpha=\mathrm{P}(\text { erro do tipo } \mathrm{I})=\mathrm{P}\left(\text { rejeitar } H_{0} / H_{0} \text { é verdadeiro }\right) \\
\beta=(\text { erro do tipo } \mathrm{II})=\mathrm{P}\left(\text { não rejeitar } H_{0} / H_{0} \text { é falso }\right)
\end{gathered}
$$

O poder do teste é dado pela função

$$
1-\beta=\mathrm{P}\left(\text { rejeitar } H_{0} / H_{0} \text { é verdadeiro }\right)
$$




\section{C.1.1 P-valor}

O P-valor é o menor nível de significância $\alpha$ que conduz à rejeição da hipótese nula $H_{0}$. Pode-se utilizar o p-valor no teste de hipóteses, que conduz à decisão da rejeição ou não da hipótese nula com um nível $\alpha$ de significância.

Para concluir a rejeição da hipótese ou não, pode-se encontrar a região crítica ou utilizar o p-valor. O uso do p-valor pode ser vantajoso e desvantajoso. A vantagem de se utilizar o p-valor é que às vezes a conclusão é feita (rejeitando ou não a hipótese nula) sem saber ao certo se a distância do valor encontrado da região crítica é significativa. Com o p-valor pode-se concluir para qualquer nível de significância $\alpha$. O cálculo do p-valor não é elementar e pode ser obtido mais precisamente com o uso de pacotes estatísticos.

\section{C.2 Experimento de Comparação Simples}

O experimento de comparação simples é um teste de média utilizado quando se tem um ou dois conjuntos de dados (Montgomery, 1997).

O teste de médias é empregado para uma amostra quando pretende-se comparar a média amostral com um valor de $\mu$ especificado. No caso de existir duas amostras, o teste de médias é utilizado para comparar as duas média amostrais.

Para iniciar o teste de comparação de médias através do teste de hipóteses deve-se inicialmente verificar se as variâncias são conhecidas ou não. Se as variâncias forem conhecidas é utilizado o teste estatístico que se baseia nos dados da distribuição normal e, se as variâncias forem desconhecidas, o teste estatístico que se baseia na distribuição t-student. Tais testes levam em consideração a igualdade ou não das variâncias. Quando as variâncias são conhecidas pode-se trivialmente verificar a igualdade ou desigualdade entre estas. Porém, quando não conhecida, o teste de hipóteses pode ser utilizado.

\section{C.2.1 Teste de igualdade das variâncias: Teste F}

As hipóteses do teste são definidas como segue.

$$
H_{0}: \sigma_{1}^{2}=\sigma_{2}^{2}
$$




$$
H_{1}: \sigma_{1}^{2} \neq \sigma_{2}^{2}
$$

A estatística do teste é definida por

$$
F_{0}=\frac{s_{1}^{2}}{s_{2}^{2}} \sim F_{n_{1}-1, n_{2}-1}
$$

Dado o nível de significância $\alpha$ são encontrados os valores $F_{1}$ e $F_{2}$ na tabela da distribuição de Fisher, chamada distribuição-F.

$$
\begin{gathered}
\text { Se } F_{0}<F_{1} \text { ou } F_{0}>F_{2} \text {, rejeita-se } H_{0} \\
\text { Se } F_{1} \leq F_{0} \leq F_{2} \text {, não rejeita-se } H_{0} \\
\text { p-valor }=2 \min P\left[F_{n_{1}-1, n_{2}-1}>F_{0}\right] ; P\left[F_{n_{1}-1, n_{2}-1}<F_{0}\right]
\end{gathered}
$$

onde o p-valor é o menor nível de significância $\alpha$ para o qual rejeita-se a hipótese $H_{0}$.

\section{C.2.2 Teste de Levene}

O teste de Levene é usado para testar se $k$ dados têm igual variâncias quando não se tem evidências de que os dados seguem distribuição normal.

As hipóteses do teste são definidas como segue

$$
\begin{gathered}
H_{0}: \sigma_{1}=\sigma_{2}=\ldots=\sigma_{k} \\
H_{1}: \sigma_{i} \neq \sigma_{j} \text { para pelo menos um } \operatorname{par}(i, j)
\end{gathered}
$$

Dada uma variável $Y$ com conjunto de dados de tamanho $N$ dividido em $k$ subgrupos, onde $N_{i}$ é o tamanho do conjunto do i-ésimo subgrupo, a estatística do teste de Levene é definido como

$$
W=\frac{(N-k) \sum_{i=1}^{k} N_{i}\left(\bar{Z}_{i .}-\bar{Z}_{. .}\right)^{2}}{(k-1) \sum_{i=1}^{k} \sum_{j=1}^{k} N_{i}\left(\bar{Z}_{i j}-\bar{Z}_{i .}\right)^{2}}
$$

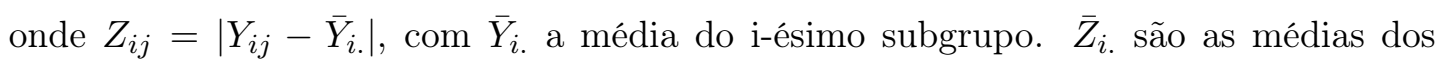
grupos de $Z_{i j}$ e $\bar{Z}$.. é a média global de $Z_{i j}$.

O teste de Levene rejeita a hipótese de que as variâncias são iguais se $W>F_{(\alpha, k-1, N-k)}$, 
onde $F_{(\alpha, k-1, N-k)}$ é o valor crítico da distribuição-F com $k-1$ e $N-k$ graus de liberdade em um nível de significância $\alpha$.

\section{C.2.3 Teste de média com variância conhecida}

\section{Caso 1: um conjunto de dados}

As hipóteses definidas para o teste de média de um conjunto de dados são as seguintes.

$$
\begin{aligned}
& H_{0}: \mu=\mu_{0} \\
& H_{1}: \mu \neq \mu_{0}
\end{aligned}
$$

onde $\mu_{1}$ é uma média amostral e $\mu_{0}$ é uma média especificada.

A estatística do teste é definida por

$$
z_{0}=\frac{\bar{y}-\mu_{0}}{\frac{\sigma}{\sqrt{n}}}
$$

$$
\text { Se }\left\|z_{0}\right\|>z_{\frac{\alpha}{2}} \text {, rejeita-se } H_{0}
$$

Se $\left\|z_{0}\right\| \leq z_{\frac{\alpha}{2}}$, não se rejeita $H_{0}$

O intervalo de confiança com $100(1-\alpha) \%$ de confiança é definido por

$$
\bar{y}-z \frac{\alpha}{2} \frac{\sigma}{\sqrt{n}} \leq \mu \leq \bar{y}+z \frac{\alpha}{2} \frac{\sigma}{\sqrt{n}}
$$

\section{Caso 2: dois conjuntos de dados}

As hipóteses definidas para o teste de média de um conjunto de dados são as seguintes.

$$
\begin{aligned}
& H_{0}: \mu_{1}=\mu_{2} \\
& H_{1}: \mu_{1} \neq \mu_{2}
\end{aligned}
$$

A estatística do teste é definida por

$$
z_{0}=\frac{\overline{y_{1}}-\overline{y_{2}}}{\sqrt{\frac{\sigma_{1}^{2}}{n_{1}}+\frac{\sigma_{2}^{2}}{n_{2}}}}
$$




$$
\text { Se }\left\|z_{0}\right\|>z_{\frac{\alpha}{2}}, \text { rejeita-se } H_{0}
$$

Se $\left\|z_{0}\right\| \leq z_{\frac{\alpha}{2}}$, não se rejeita $H_{0}$

O intervalo de confiança com 100(1- $\alpha) \%$ de confiança é definido por

$$
\overline{y_{1}}-\overline{y_{2}}-z_{\frac{\alpha}{2}} \sqrt{\frac{\sigma_{1}^{2}}{n_{1}}+\frac{\sigma_{2}^{2}}{n_{2}}} \leq \mu_{1}-\mu_{2} \leq \overline{y_{1}}-\overline{y_{2}}+z_{\frac{\alpha}{2}} \sqrt{\frac{\sigma_{1}^{2}}{n_{1}}+\frac{\sigma_{2}^{2}}{n_{2}}}
$$

\section{C.2.4 Teste de média com variância desconhecida: Teste t}

O teste t é empregado quando duas média são comparadas (ou média amostra com média amostral ou média amostral com um $\mu$ especificado). Através dessa comparação, rejeita-se ou não a hipótese de igualdade das médias. Para utilizar o teste t assume-se que o processo é estável e que os dados amostrais assumem uma distribuição normal.

\section{Teste t para variâncias iguais $\left(\sigma_{1}^{\overline{ }} \sigma_{2}^{2}\right)$}

O teste t para variâncias iguais é definido pelas seguintes hipóteses

$$
\begin{aligned}
& H_{0}: \mu_{1}=\mu_{2} \\
& H_{1}: \mu_{1} \neq \mu_{2}
\end{aligned}
$$

onde $\mu_{1}$ e $\mu_{2}$ são médias amostrais.

A estatística do teste é definida como segue.

$$
t_{0}=\frac{\overline{y_{1}}-\overline{y_{2}}}{S_{p} \sqrt{\frac{1}{n_{1}}+\frac{1}{n_{2}}}}
$$

que segue distribuição t com $n_{1}+n_{2}-2$ graus de liberdade, onde $\overline{y_{1}}$ e $\overline{y_{1}}$ são médias amostrais, $n_{1}$ e $n_{2}$ são os tamanhos da amostra e $S_{p}^{2}$ é uma estimativa da variância $\sigma_{1}^{2}=\sigma_{2}^{2}=\sigma^{2}$ que pode ser calculada como

$$
S_{p}^{2}=\frac{\left(n_{1}-1\right) s_{1}^{2}+\left(n_{2}-2\right) s_{2}^{2}}{n_{1}+n_{2}-2}
$$

onde $s_{1}^{2}$ e $s_{2}^{2}$ são duas estimativas de variâncias amostrais.

$$
\text { Se }\left\|t_{0}\right\|>t_{\frac{\alpha}{2}}, n_{1}+n_{2}-2 \text {, rejeita-se } H_{0}
$$


Se $\left\|t_{0}\right\| \leq t_{\frac{\alpha}{2}}, n_{1}+n_{2}-2$, não se rejeita $H_{0}$

O intervalo de confiança com 100(1- $\alpha) \%$ de confiança é definidor por

$$
\overline{y_{1}}-\overline{y_{2}}-t_{\frac{\alpha}{2}, n_{1}+n_{2}-2} S p \sqrt{\frac{1}{n_{1}}+\frac{1}{n_{2}}} \leq y_{1}-y_{2} \leq \overline{y_{1}}-\overline{y_{2}}+t_{\frac{\alpha}{2}, n_{1}+n_{2}-2} S p \sqrt{\frac{1}{n_{1}}+\frac{1}{n_{2}}}
$$

Teste t para variâncias diferentes $\left(\sigma_{1}^{2} \neq \sigma_{2}^{2}\right)$

\section{Caso 1: um conjunto de dados}

O teste t para variâncias diferentes de um conjunto de dados é definido pelas seguintes hipóteses.

$$
\begin{aligned}
& H_{0}: \mu=\mu_{0} \\
& H_{1}: \mu \neq \mu_{0}
\end{aligned}
$$

A estatística do teste é definida como segue.

$$
t_{0}=\frac{\bar{y}-\mu_{0}}{\frac{s}{\sqrt{n}}}
$$

onde $\bar{y}=$ média amostral, $s=$ variância estimada e $n$ é o tamanho do conjunto de dados.

$$
\begin{gathered}
\left\|t_{0}\right\|>t \frac{\alpha}{2}, \text { rejeita-se } H_{0} \\
\left\|t_{0}\right\| \leq t \frac{\alpha}{2}, \text { não se rejeita } H_{0}
\end{gathered}
$$

o intervalo de confiança com 100(1 - $\alpha) \%$ de confiança é definido por

$$
\bar{y}-t_{\frac{\alpha}{2}, n-1} \sigma \sqrt{n} \leq \mu \leq \bar{y}-t_{\frac{\alpha}{2}, n-1} \sigma \sqrt{n}
$$

\section{Caso 2: dois conjuntos de dados}

O teste t para variâncias diferentes de dois conjuntos de dados é definido pelas seguintes hipóteses.

$$
\begin{aligned}
& H_{0}: \mu_{1}=\mu_{2} \\
& H_{1}: \mu_{1} \neq \mu_{2}
\end{aligned}
$$


A estatística do teste é definida como segue.

$$
t_{0}=\frac{\overline{y_{1}}-\overline{y_{2}}}{\sqrt{\frac{s_{1}^{2}}{n_{1}}+\frac{s_{2}^{2}}{n_{2}}}}
$$

que segue distribuição t com v graus de liberdade dado por

$$
v=\frac{\left(\frac{s_{1}^{2}}{n_{1}}+\frac{s_{2}^{2}}{n_{2}}\right)^{2}}{\frac{\left(\frac{s_{1}^{2}}{n_{1}}\right)^{2}}{n_{1}-1}+\frac{\left(\frac{s_{2}^{2}}{n_{2}}\right)^{2}}{n_{2}-1}}
$$

Se $\left\|t_{0}\right\|>t_{\frac{\alpha}{2}}, v$, rejeita-se $H_{0}$

\section{C.3 Teste de Correlação de Pearson}

Dado um conjunto de pares de valores $\left(x_{i}, y_{i}\right), i=1,2, \ldots, n$, o coeficiente de correlação, denotado $r$, é uma medida de associação linear entre os valores de $x$ e de $y$, dado por

$$
r=\frac{\sum_{i=1}^{n}\left(x_{i}-\mu_{x}\right) \sum_{i=1}^{n}\left(y_{i}-\mu_{y}\right)}{\sqrt{\sum_{i=1}^{n}\left(x_{i}-\mu_{x}\right)^{2} \sum_{i=1}^{n}\left(y_{i}-\mu_{y}\right)^{2}}}
$$

com $-1 \leq r \leq 1$, sendo que a proximidade de zero indica a falta de associação entre os valores e a proximidade de $|1|$ indica forte associação entre os valores. A correlação positiva indica que os valores de $x$ e $y$ crescem ou decrescem juntos. A correlação negativa indica que os valores de $x$ crescem enquanto os valores de $y$ decrescem e viceversa.

As hipóteses adotadas para verificar se há correlação entre os dados amostrais são

$$
\begin{aligned}
& H_{0}: r=0, \\
& H_{1}: r \neq 1 .
\end{aligned}
$$

Para a aceitação de uma das hipóteses, deve ser feita a verificação do p-valor. Para um nível de significância $\alpha=5 \%$, se p-valor $>0,05$, a hipótese nula $H_{0}$ é aceita, ou seja, não há associação entre os valores amostrais e, se p-valor $<0,05$, a hipótese nula é rejeitada e a hipótese alternativa $H_{1}$ é aceita, o que indica que existe associação entre os valores amostrais. 


\section{C.4 Teste de Anderson-Darling}

O teste de Anderson-Darling é usado para testar se uma amostra de dados segue uma distribuição específica. É uma modificação do teste de Kolmogorov-Smirnov com peso maior nas caldas da função. O teste de Anderson-Darling faz uso da distribuição específica para calcular os valores críticos. As tabelas dos valores críticos são disponíveis para as seguintes distribuições: normal, lognormal, exponencial, Weibull e logística e podem ser consultadas em Stephens (1974), Stephens (1976), Stephens (1977) e Stephens (1979).

O teste de Anderson-Darling é definido pelas hipóteses

$H_{0}$ : Os dados seguem a distribuição especificada (neste caso, normal)

$H_{1}$ : Os dados não seguem a distribuição especificada (neste caso, normal)

A estatística do teste é definida como $A^{2}=-N-S$, onde

$$
S=\sum_{i=1}^{N} \frac{2 i-1}{N}\left[\ln F\left(y_{i}\right)+\ln \left(1-F\left(y_{N+1-i}\right)\right)\right]
$$

$F$ é a função de distribuição acumulada da distribuição especificada e $y_{i}$ são os dados ordenados. A hipótese nula é rejeitada se a estatística do teste, $A$, é maior que o valor crítico. 


\section{Apêndice D}

\section{Tabelas de Dados Coletados em Campo}

Neste apêndice estão dispostas todas as tabelas de dados coletados em campo, na área experimental da Embrapa Milho e Sorgo situada no município de Sete Lagoas, MG.

o número de espécies por metro quadrado em cada parcela, obtido somando-se as espécies encontradas nos 4 quadros em cada parcela, foram classificadas em plantas do tipo folha larga e folha estreita. A densidade de plantas daninhas por metro quadrado do tipo folha larga e folha estreita é mostrada na Tabela D.1, para a geração $t-1$. Esta tabela, juntamente com a densidade total de plantas por parcela, obtida somando-se as densidades de folha larga e estreita, é entrada do sistema neurofuzzy cuja saída infere o índice de competitividade para cada parcela. A última coluna desta tabela exibe a biomassa obtida em cada parcela. Os valores de densidade de plantas e biomassa são normalizados entre 0 e 1. A Tabela D.3 exibe as densidades de sementes de plantas daninhas total de cada parcela, em metros quadrados, na geração $t$. A segunda coluna desta tabela exibe a porcentagem de cobertura foliar total de cada parcela, na geração $t-1$. Da mesma forma, para a geração $t+1$, a Tabela D.2 exibe a porcentagem da densidade total de plantas daninhas, sua respectiva proporção em plantas do tipo folha larga e folha estreita e a biomassa das plantas. A Tabela D.4 exibe a densidade total de sementes por metro quadrado nas parcelas, associada à produção de sementes, na geração $t+2$ e a porcentagem total de cobertura foliar na geração $t+1$. 
Tabela D.1: Densidade de plantas daninhas total de cada parcela, a correspondente proporção em folha larga e folha estreita e biomassa na geração $t-1$.

\begin{tabular}{|c|c|c|c|}
\hline Densidade de plantas \% & Folha Larga \% & Folha Estreita \% & Biomassa \% \\
\hline 0,58 & 0,21 & 0,79 & 1,00 \\
\hline 0,61 & 0,17 & 0,83 & 0,60 \\
\hline 0,47 & 0,30 & 0,70 & 0,87 \\
\hline 0,50 & 0,80 & 0,20 & 0,72 \\
\hline 0,38 & 0,59 & 0,41 & 0,49 \\
\hline 0,36 & 0,17 & 0,83 & 0,35 \\
\hline 0,44 & 0,14 & 0,86 & 0,78 \\
\hline 0,81 & 0,70 & 0,30 & 0,44 \\
\hline 1,00 & 0,78 & 0,22 & 0,62 \\
\hline 0,67 & 0,82 & 0,18 & 0,29 \\
\hline 0,30 & 0,17 & 0,83 & 0,45 \\
\hline 0,27 & 0,92 & 0,08 & 0,57 \\
\hline 0,27 & 0,04 & 0,96 & 0,93 \\
\hline 0,52 & 0,33 & 0,67 & 0,67 \\
\hline 0,49 & 0,10 & 0,90 & 0,37 \\
\hline 0,29 & 0,11 & 0,89 & 0,30 \\
\hline 0,30 & 1,00 & 0,00 & 0,12 \\
\hline 0,60 & 0,10 & 0,90 & 0,16 \\
\hline 0,27 & 0,35 & 0,65 & 0,41 \\
\hline 0,42 & 0,51 & 0,49 & 0,29 \\
\hline 0,47 & 0,48 & 0,52 & 0,10 \\
\hline 0,27 & 0,08 & 0,92 & 0,82 \\
\hline 0,28 & 0,00 & 1,00 & 0,36 \\
\hline 0,15 & 0,00 & 1,00 & 0,34 \\
\hline 0,36 & 0,29 & 0,71 & 0,56 \\
\hline 0,26 & 0,08 & 0,92 & 0,62 \\
\hline 0,19 & 0,00 & 1,00 & 0,37 \\
\hline 0,16 & 0,00 & 1,00 & 0,41 \\
\hline 0,30 & 0,52 & 0,48 & 0,11 \\
\hline 0,46 & 1,00 & 0,00 & 0,03 \\
\hline 0,81 & 0,00 & 1,00 & 0,28 \\
\hline 0,19 & 0,58 & 0,42 & 0,12 \\
\hline 0,39 & 0,26 & 0,74 & 0,59 \\
\hline 0,43 & 0,52 & 0,48 & 0,34 \\
\hline 0,27 & 0,92 & 0,08 & 0,07 \\
\hline 0,35 & 0,41 & 0,59 & 0,63 \\
\hline 0,19 & 0,74 & 0,26 & 0,18 \\
\hline 0,36 & 0,51 & 0,49 & 0,27 \\
\hline 0,29 & 0,79 & 0,21 & 0,15 \\
\hline 0,22 & 0,41 & 0,59 & 0,28 \\
\hline 0,38 & 0,73 & 0,27 & 0,45 \\
\hline
\end{tabular}


Tabela D.2: Densidade de plantas daninhas total de cada parcela, a correspondente proporção em folha larga e folha estreita e biomassa na geração $t+1$.

\begin{tabular}{|c|c|c|c|}
\hline Densidade de plantas \% & Folha larga \% & Folha estreita \% & Biomassa \% \\
\hline 0,48 & 0,03 & 0,97 & 0,46 \\
\hline 0,8 & 0,29 & 0,71 & 0,01 \\
\hline 1 & 0,74 & 0,26 & 0,75 \\
\hline 0,64 & 0,82 & 0,18 & 0,57 \\
\hline 0,36 & 1 & 0 & 0,37 \\
\hline 0,57 & 0,9 & 0,1 & 0,18 \\
\hline 0,01 & 0 & 1 & 0,01 \\
\hline 0 & 0 & 0 & 0 \\
\hline 0,23 & 0,13 & 0,88 & 0,29 \\
\hline 0,12 & 0,5 & 0,5 & 0,12 \\
\hline 0,29 & 1 & 0 & 0,01 \\
\hline 0,17 & 0,08 & 0,92 & 0,22 \\
\hline 0,16 & 1 & 0 & 0,21 \\
\hline 0,17 & 0,83 & 0,17 & 0,03 \\
\hline 0,25 & 1 & 0 & 0,46 \\
\hline 0,32 & 0,41 & 0,59 & 0,32 \\
\hline 0,42 & 1 & 0 & 0,55 \\
\hline 0,38 & 0,58 & 0,42 & 0,69 \\
\hline 0,48 & 0,82 & 0,18 & 0,4 \\
\hline 0,33 & 0,78 & 0,22 & 0,47 \\
\hline 0,22 & 0,93 & 0,07 & 0,22 \\
\hline 0,26 & 1 & 0 & 0,31 \\
\hline 0,16 & 0,18 & 0,82 & 0,31 \\
\hline 0,2 & 0,36 & 0,64 & 0,75 \\
\hline 0,29 & 0,55 & 0,45 & 0,62 \\
\hline 0,43 & 0,8 & 0,2 & 0,62 \\
\hline 0,32 & 0,5 & 0,5 & 0,56 \\
\hline 0,25 & 0,71 & 0,29 & 0,31 \\
\hline 0,13 & 0,33 & 0,67 & 0,65 \\
\hline 0,67 & 0,89 & 0,11 & 0,35 \\
\hline 0,28 & 0,68 & 0,32 & 1 \\
\hline 0,19 & 0,69 & 0,31 & 0,17 \\
\hline 0,17 & 0,42 & 0,58 & 0,17 \\
\hline 0,22 & 0,33 & 0,67 & 0,84 \\
\hline 0,19 & 0,69 & 0,31 & 0,31 \\
\hline 0,17 & 0,33 & 0,67 & 0,2 \\
\hline 0,48 & 0,61 & 0,39 & 0,55 \\
\hline 0,16 & 0,45 & 0,55 & 0,16 \\
\hline 0,19 & 0,08 & 0,92 & 0,27 \\
\hline 0,26 & 0,39 & 0,61 & 0,4 \\
\hline 0,32 & 0,09 & 0,91 & 0,17 \\
\hline
\end{tabular}


Tabela D.3: Densidade de sementes por metro quadrado na geração $t$ e proporção de cobertura foliar na geração $t-1$.

\begin{tabular}{|c|c|}
\hline Densidade de sementes & Cobertura foliar \% \\
\hline 2567 & 0,70 \\
\hline 543 & 0,60 \\
\hline 1793 & 0,50 \\
\hline 1369 & 0,50 \\
\hline 2392 & 0,55 \\
\hline 4817 & 0,75 \\
\hline 8540 & 0,35 \\
\hline 836 & 0,20 \\
\hline 1203 & 0,20 \\
\hline 312 & 0,60 \\
\hline 291 & 0,35 \\
\hline 191 & 0,35 \\
\hline 439 & 0,65 \\
\hline 105 & 0,20 \\
\hline 158 & 0,50 \\
\hline 678 & 0,60 \\
\hline 7699 & 0,20 \\
\hline 4304 & 0,25 \\
\hline 894 & 0,20 \\
\hline 2690 & 0,55 \\
\hline 1583 & 0,30 \\
\hline 5112 & 0,15 \\
\hline 1783 & 0,15 \\
\hline 1073 & 0,35 \\
\hline 7189 & 0,30 \\
\hline 3040 & 0,60 \\
\hline 7238 & 0,55 \\
\hline 7761 & 0,20 \\
\hline 1295 & 0,50 \\
\hline 1266 & 0,15 \\
\hline 1424 & 0,25 \\
\hline 1171 & 0,18 \\
\hline 2382 & 0,50 \\
\hline
\end{tabular}


Tabela D.4: Densidade de sementes por metro quadrado na geração $t+2$ e proporção de cobertura foliar na geração $t+1$.

\begin{tabular}{c|c}
\hline Densidade de sementes & Cobertura foliar \% \\
\hline 1260 & 0,19 \\
48 & 0,01 \\
2945,5 & 0,45 \\
3513 & 0,54 \\
1408,5 & 0,22 \\
3624 & 0,56 \\
632,5 & 0,1 \\
0 & 0 \\
2112,5 & 0,33 \\
1387 & 0,21 \\
277 & 0,04 \\
3168 & 0,49 \\
3265,5 & 0,5 \\
882,5 & 0,14 \\
727,5 & 0,11 \\
747,5 & 0,12 \\
1254,5 & 0,19 \\
24 & 0 \\
2032 & 0,31 \\
2997,5 & 0,46 \\
2182,5 & 0,34 \\
1391 & 0,21 \\
1628 & 0,25 \\
4994 & 0,77 \\
1800 & 0,28 \\
1920 & 0,3 \\
1015 & 0,16 \\
1130 & 0,17 \\
1221 & 0,19 \\
6500 & 1 \\
23,5 & 0 \\
1869 & 0,29 \\
5693 & 0,88 \\
3384 & 0,52 \\
442 & 0,07 \\
3582 & 0,55 \\
0 & 0 \\
&
\end{tabular}




\section{Bibliografia}

Adati, C. R. (2006). Análise e Ajuste de Modelos Matemáticos para Perdas de Rendimento Causadas por Plantas Daninhas na Cultura do Milho, Dissertação de Mestrado - EESC/USP, São Carlos, SP.

Aguirre, L. A. (2004). Introdução à Identificação de Sistemas - Técnicas Lineares e Não Lineares Aplicadas a Sistemas Reais, 2a edição, Editora UFMG, Belo Horizonte, MG.

Baio, F. H. R. e Balastreire, L. A. (2001). Aplicação Localizada de Defensivos Baseada na Variabilidade Espacial das Plantas Daninhas, Dissertação de Mestrado - ESALQ/USP Piracicaba, SP.

Balastreire, L. A. e Baio, F. H. R. (2001). Avaliação de uma metodologia prática para o mapeamento de plantas daninhas, Revista Brasileira de Engenharia Agrícola e Ambiental 5(2): 349-352.

Bezdek, J. C. (1999). Fuzzy models and algorithms for pattern recognition and image processing, Kluwer Academic Public, Boston.

Bicudo, C. E. M., Menezes, M., Cordeiro, I., Menezes, N. A., Sendacz, S. e Vuono, Y. S. (1998). Identificação, monitoramento, avaliação e minimização de impactos Negativos, Fundação André Tosello, http://www.bdt.org.br/publicaçoes/política/gtt/gtt1.

Bressan, G. M., Koenigkan, L. V., Oliveira, V. A., Cruvinel, P. E. e Karam, D. (2006a). Sistema de classificação fuzzy para o risco de infestação de plantas daninhas considerando a sua variabilidade espacial, Planta Daninha 24(2): 229-238. 
Bressan, G. M., Koenigkan, L. V., Oliveira, V. A., Cruvinel, P. E. e Karam, D. (2007). Risk classification system for weed infestation using fuzzy logic and image analysis, Weed Research . (submetido).

Bressan, G. M., Koenigkan, L. V., Oliveira, V. A. e Cruvinel, P. E. (2005). Classificação de risco de infestação de regiões por plantas daninhas, IV Congresso Temático de Dinâmica, Controle e Aplicações pp. 345-352. UNESP, Bauru, SP.

Bressan, G. M., Koenigkan, L. V., Oliveira, V. A. e Karam, D. (2006b). Classificação nebulosa do risco de infestação de regiões por plantas daninhas, XVI Congresso Brasileiro de Automática, pp. 833-838.

Bressan, G. M., Oliveira, V. A., Hruschka, E. R. J. e Nicoletti, M. C. (2007a). Biomass based weed-crop competitiveness classification using Bayesian networks, 7th International Conference on Intelligent Systems Design and Applications. (aceito).

Bressan, G. M., Oliveira, V. A., Hruschka, E. R. J. e Nicoletti, M. C. (2007b). A probability estimation based strategy to optimize the classification rule set extracted from Bayesian network classifiers, VIII Simpósio Brasileiro de Automação Inteligente. (aceito).

Brooker, P. I. (1979). Kriging, EeMJ - Engineering and Mining Journal 180(9): 148153.

Bussab, W. e Morettin, P. (2005). Estatística Básica, 5a edição, Saraiva.

Carvalho, J. R. P. e Vieira, S. R. (2001). Avaliação e comparação de estimadores de krigagem para variáveis agronômicas - uma proposta, Embrapa Informática Agropecuária pp. 1-20. Documento 3.

Cheng, J., Greiner, R., Kelly, J., Bell, D. e Liu, W. (2002). Learning Bayesian networks from data: an information-theory based approach, Artificial Intelligence 137(1): 43-90.

Chiang, J. e Hsu, J. (2002). Fuzzy classification trees for data analysis, Fuzzy Sets and Systems 130(1): 87-99.

Christakos, G., Bogaert, P. e Serre, M. L. (2002). Temporal Geographical Information Systems: Advanced Functions for Field-Based Applications, Springer-Verlag. 
Clemente, A. L. e Muniz, J. A. (2002). Avaliação do coeficiente de variação em experimentos com gramíneas forrageiras, Ciência e Agrotecnologia 26(1): 197-203.

Committee, A. C. Y. (1997). Precision Agriculture in the 21th Century: geospatial and information technologies in crop management, National Academy Press, Washington, US.

Cousens, R. (1985). A simple model relating yield loss to weed density, Annals of Applied Biology 107(2): 239-252.

Cousens, R. e Mortimer, M. (1995). Dynamics of Weed Populations, Cambridge University Press, Cambridge, UK.

Cruvinel, P. E., Oliveira, V. A., Koenigkan, L. V., Bressan, G. M., Parisi, F. e Mantovani, E. C. (2005). Metodologia para o mapeamento georeferenciado da aplicação de chuva artificial em Área de plantio com base no uso de visão computacional, III Simpósio Internacional de Agricultura de Precisão, pp. 1-8.

Doyle, C. J. (1997). A review of the use of models of weed control in integrated crop protection, Elsevier Science B. V. - Agriculture, Ecosystems and Environment 64(2): 165-172.

Esquerdo, J. C. D. M. (2002). Adaptação de um Pulverizador Convencional para a Aplicação Localizada de Defensivos Agrícolas, Dissertação de Mestrado - ESALQ/USP, Piracicaba, SP.

Exposito, A. J., Granados, F. L., Andujar, J. L. G. e Torres, L. G. (2004). Spatial and temporal analysis of convolvulus arvensis l. populations over four growing seasons, European Journal of Agronomy 21(3): 287-296.

Faechner, T., Norrena, K., Thomas, A. G. e Deutsch, C. V. (2002). A risk-qualified approach to calculate locally varyiang herbicide application rates, European Weed Research Society Weed Research 42(6): 476-485.

Firbank, L. G. e Watkinson, A. R. (1985). A model of interference within plant monocultures, Journal of Theoretical Biology 116(2): 291-311.

Gazziero, D. L. P., Brighenti, A. M., Voll, E. e Maciel, C. D. G. (1998). Convivência da planta daninha amendoim bravo (euphorbia heterophylla) com a cultura da soja no 
estado do paraná, XX Reunião de Pesquisa em Soja na Região Central do Brasil, p. 378.

Gerhards, R. e Oebel, H. (2006). Practical experiences with a system for site-specific weed control in arable crops using real-time image analysis and GPS-controlled patch spraying, Weed Research 46(3): 185-193.

Gonzalez-Andujar, J. L. (1996). High control measures cannot produce extinction in weed populations, Ecological Modelling 91(1-3): 293-294.

Gonzalez, R. C. e Woods, R. E. (2000). Processamento de Imagens Digitais, Editora Edgard Blücher, São Paulo.

Granitto, P. M., Navone, H. D., Verdes, P. F. e Ceccatto, H. A. (2002). Weed seeds identification by machine vision, Computers and Electronics in Agriculture 33(2): 91103.

Granitto, P. M., Verdes, P. F. e Ceccatto, H. A. (2005). Large-scale investigation of weed seed identification by machine vision, Computers and Electronics in Agriculture 47(1): 15-24.

Hartigan, J. A. e Wong, M. A. (1979). A k-means clustering algorithm, Applied Statistics 28(1): 100-108

Haykin, S. (1999). Neural Networks: a comprehensive foundation, Prentice Hall, Upper Saddle River, NJ.

Henrion, M. e Druzdzel, M. J. (1990). Qualitative propagation and scenario-based approaches to explanation of probabilistic reasoning, Proc. of the Sixth Conference on Uncertainty in Artificial Intelligence, Cambridge, MA,. pp. 17- 32.

Hruschka, E. R. J., Nicoletti, M. C., Oliveira, V. A. e Bressan, G. M. (2007). Markovblanket based strategy for translating a Bayesian classifier into a reduced set of classification rules, 7th International Conference on Hybrid Intelligent Systems. (aceito).

Hu, B., Gosine, R. G., Cao, L. X. e Silva, C. W. (1998). Application of a fuzzy classification technique in computer grading of fish products, IEEE Transactions on Fuzzy Systems 6(1): 144-152. 
Imai, N., Vicente, J., Lima, D., Tachibana, V., Silva, E. A., Voll, E. e Oliveira, H. (2003). Análise Comparativa da Interpolação por Krigagem Ordinária e krigagem por Indicação no Caso de Ervas Daninhas em Cultura de Soja. www.cartografia.org.br.

Isaaks, E. H. e Srivastana, R. M. (1989). An Introduction to Applied Geostatistics, Oxford University Press, New York.

Ishibuchi, H. e Nakashima, T. (2001). Effect of rule weights in fuzzy rule - based classification systems, IEEE Transactions on Fuzzy Systems 9(4): 506-515.

Iwashita, F. e Landim, P. B. (2003). GEOMATLAB: Análise Geoestatística usando MATLAB, Instituto de Geologia e Ciências Exatas - UNESP, Rio Claro, SP. pp. 1-17, Texto Didático 12.

Jang, J. R. (1993). Anfis: Adaptive - network - based fuzzy inference system, IEEE Transactions on Systems, Man, and Cybernetics 23(3): 665-685.

Kavdir, I. e Guyer, D. E. (2003). Apple grading using fuzzy logic, Turkish Journal Agriculture and Forestry 27(6): 375-382.

Kropff, M. J. e Spitters, C. J. T. (1991). A simple model of crop loss by weed competition from early observations on relative leaf area of the weeds, Weed Research 31(2): 97105.

Lacerda, A. L. S. (2003). Fluxos de emergência e banco de sementes de plantas daninhas em sistemas de semeadura direta e convencional e curvas dose-resposta ao Glyphosate, Tese de Doutorado - ESALQ/USP, Piracicaba, SP.

Landim, P. B. e Sturaro, J. R. (2002). Krigagem Indicativa Aplicada à Elaboração de Mapas Probabilísticos de Riscos, Instituto de Geologia e Ciências Exatas - UNESP, Rio Claro, SP. pp. 1-19, Texto Didático 6.

Landim, P. M. B. (2003). Geoeas: Exemplo de aplicação em análise geoestatística. pp. 1-10, Texto Didático 11.

Lauritzen, S. e Spiegelhalter, D. (1988). Local computations with probabilities on graphical structures and their application to expert systems, Journal of the Royal Statistical Society B 50(2): 157-224. 
Levene, H. (1960). Robust Tests for Equality of Variance. In Contributions to Probability and Statistics, Stanford University Press. pp.278-292.

Lorenzi, H. (2000). Plantas Daninhas do Brasil: Terrestres, Aquáticas, Parasitas e Tóxicas, 3a edição, Instituto Plantarum de Estudos da Flora.

Lotz, L. A. P., Christensen, S., Cloutier, D., Quintanilla, C. F., Lègère, A., Lemieux, C., Lutman, P. J. W., Iglesias, A. P., Salonen, J., Sattin, M., Stigliani, L. e Tei, F. (1996). Prediction of the competitive effects ef weeds on crop yields based on the relative leaf area of weeds, Weed Research 36(1): 93-101.

Marchant, J. A. e Onyango, C. M. (2003). Comparison of a bayesian classifier with a multilayer feed-forward neural network using the example of plant/weed/soil discrimination, Computers and Electronics in Agriculture 39(1): 3-22.

Montgomery, D. C. (1997). Design and Analysis of Experiments, 4a. edição, John Wiley and Sons.

Nordmeyer, H., Hausler, A. e Niemann, P. (1997). Patchy weed control as an approach in precision farming, In: Precision Agriculture, 2 1: 307-314.

Nurnberger, A., Klose, A. e Kruse, R. (2001). Effects of Antecedent Pruning in Fuzzy Classification Systems, University of Magdeburg, Germany.

Odom, D. I. S., Cacho, O. J., Sinden, J. A. e Griffith, G. R. (2003). Policies for the management of weeds in natural ecosystems: the case of scoth broom (cytisus scopariusl.) in an australian national park, Ecological Economics 44(1): 119-135.

Park, S. E., Benjamin, L. R. e Watkinson, A. R. (2003). The theory and application of plant competition models: an agronomic perspective, Annals of Botany 92(6): 741748.

Pearl, J. (1988). Probabilistic Reasoning in Intelligent Systems: Networks of Plausible Inference, Morgan Kaufmann, San Mateo, CA.

Pedrycz, W. e Gomide, F. (1998). An Introduction to Fuzzy Sets, MIT Press.

Peixoto, M. S., Barros, L. C. e Bassanezi, R. C. (2004). Um modelo fuzzy presa-predador em citros: pulgões e joaninhas, Biomatemática 14: 29-38. 
Puente, J., de la Fuente, D., Priore, R. e Pino, R. (2002). Abc classification with uncertain data. a fuzzy model vs a probabilistic model, Applied Artifical Intelligence 16(6): 443-456.

Queiroz, G. A. F., Tozzi, C. L. e Langone, F. (1997). Avaliação morfológica e morfométrica de axônios mielínicos utilizando classificador fuzzy, X Simpósio Brasileiro de Computação Gráfica e Processamento de Imagens pp. 1-8.

Rizzardi, M. A. e Fleck, N. G. (2004). Métodos de quantificação da cobertura foliar da infestação de plantas daninhas e da cultura da soja, Ciência Rural 34(1): 13-18.

Rizzardi, M. A., Fleck, N. G., Riboldi, J. e Agostinetto, D. (2003). Ajuste de modelo para quantificar o efeito de plantas daninhas e Época de semeadura no rendimento da soja, Pesquisa Agropecuária Brasileira 38(1): 35-43.

Sakai, K. (2001). Nonlinear Dynamics and Chaos in Agricultural Systems, Developments in Agricultural Systems, Elsevier, Amsterdan, Netherlands.

Shaw, I. S. e Simões, M. G. (1999). Controle e Modelagem Fuzzy, 1a. edição, Edgard Blücher, São Paulo, SP.

Shiratsuchi, L. S. e Christoffoleti, P. J. (2001). Mapeamento da Variabilidade Espacial das Plantas Daninhas com a Utilização de Ferramentas da Agricultura de Precisão, Dissertação de Mestrado - ESALQ/USP, Piracicaba, SP.

Shiratsuchi, L. S., Molin, J. P. e Christoffoleti, P. J. (2004). Mapeamento da distribuição espacial da infestação de panicum maximum durante a colheita da cultura de milho, Planta Daninha 22(2): 269-274.

Shiratsuchi, L. S., Nicolai, M., Cortucci, M., Suguisawa, J. M. e Christoffoleti, P. J. (2002). Aplicação localizada de herbicida em soja utilizando mapas de banco de sementes e ferramentas da agricultura de precisão, II Simpósio Internacional de Tecnologia de Aplicação de Agrotóxicos: Eficiência, Economia e Preservação da Saúde Humana e do Ambiente pp. 1-5.

Stephens, M. A. (1974). Edf statistics for goodness of fit and some comparisons, Journal of the American Statistical Association 69(347): 730-737. 
Stephens, M. A. (1976). Asymptotic results for goodness-of-fit statistics with unknown parameters, Annals of Statistics 4(2): 357-369.

Stephens, M. A. (1977). Goodness of fit for the extreme value distribution, Biometrika 64(3): 583-588.

Stephens, M. A. (1979). Tests of fit for the logistic distribution based on the empirical distribution function, Biometrika 66(3): 591-595.

Tieppo, R. C., Souza, E. G., Opazo, M. A., Gabriel, A. e Johann, J. (2001). Avaliação de diferentes interpoladores na geração de mapas temáticos da produtividade de soja e agricultura de precisão, XXX Congresso Brasileiro de Engenharia Agrícola .

Tversky, A. e Kahneman, D. (1974). Judgment under uncertainlty: heuristics and biases, Science 185(4157): 1124-1131.

Vieira, S. R. (1995). Uso da Geoestatística em Estudos de Variabilidade Espacial, Curso de Atualização em Conservação do Solo, pp. 1-61, Campinas, IAC.

Vieira, S. R. (2000). Geoestatística em estudos de variabilidade espacial do solo, In: Novais, R.F., Alvarez, V.V.H., Schaefer, C.E.G.R. Tópicos em Ciência do Solo, Sociedade Brasileira de Ciência do Solo, Viçosa, pp. 1-54.

Vieira, S. R., Neto, F. L. e Burrows, I. T. (1981). Mapeamento da chuva máxima provável para o Estado de São Paulo, Revista Brasileira de Ciência do Solo 15(1): 93-98.

Vismara, L. S., Oliveira, V. A. e Karam, D. (2005). Revisão de modelos matemáticos da dinâmica do banco de sementes de plantas daninhas em agroecossistemas, $I V$ Congresso Temático de Dinâmica, Controle e Aplicações pp. 380-389. UNESP, Bauru, SP.

Wallinga, J., Groeneveld, R. M. W. e Lotz, L. A. P. (1998). Measures that describe weed spatial patterns at different levels of resolution and their applications for patch spraying of weeds, Weed Research 38(5): 351-359.

Yang, C. C., Prasher, S. O., Landry, J. A. e Ramaswamy, H. S. (2003). Development of a herbicide application map using artificial neural networks and fuzzy logic, Agricultural Systems 76(2): 561-574. 
Yang, C. C., Prasher, S. O., Landry, J. A., Perret, J. e Ramaswamy, H. S. (2000). Recognition of weeds with image processing and their use with fuzzy logic for precision farming, Canadian Agricultural Engineering 14(4): 195-200.

Zadeh, L. A. (1965). Fuzzy sets, Information and Control 8(3): 338-353. 